Florida International University

FIU Digital Commons

$11-6-2019$

\title{
Development of Local and Global Corrosion Sensing Technique to Monitor Structural Behavior of Prestressed Concrete Structures
}

Dewan Z. Hossain

Florida International University, dhoss001@fiu.edu

Follow this and additional works at: https://digitalcommons.fiu.edu/etd

Part of the Structural Engineering Commons

\section{Recommended Citation}

Hossain, Dewan Z., "Development of Local and Global Corrosion Sensing Technique to Monitor Structural Behavior of Prestressed Concrete Structures" (2019). FIU Electronic Theses and Dissertations. 4294.

https://digitalcommons.fiu.edu/etd/4294

This work is brought to you for free and open access by the University Graduate School at FIU Digital Commons. It has been accepted for inclusion in FIU Electronic Theses and Dissertations by an authorized administrator of FIU Digital Commons. For more information, please contact dcc@fiu.edu. 


\section{FLORIDA INTERNATIONAL UNIVERSITY}

Miami, Florida

DEVELOPMENT OF LOCAL AND GLOBAL CORROSION SENSING TECHNIQUE TO MONITOR STRUCTURAL BEHAVIOR OF PRESTRESSED CONCRETE STRUCTURES

A dissertation submitted in partial fulfillment of the requirements for the degree of DOCTOR OF PHILOSOPHY

in

CIVIL ENGINEERING

by

Dewan Hossain 
To: Dean John L. Volakis

College of Engineering and Computing

This dissertation, written by Dewan Hossain, and entitled Development of Local and Global Corrosion Sensing Technique to Monitor Structural Behavior of Prestressed Concrete Structures, having been approved in respect to style and intellectual content, is referred to you for judgment.

We have read this dissertation and recommend that it be approved.

Norman Munroe

Ioannis Zisis

Seung Jae Lee

Kingsley Lau, Co-Major Professor

David Garber, Co-Major Professor

Date of Defense: November 6, 2019

The dissertation of Dewan Hossain is approved.

Dean John L. Volakis

College of Engineering and Computing

Andrés G. Gil

Vice President for Research and Economic Development and Dean of the University Graduate School

Florida International University, 2019 
(C) Copyright 2019 by Dewan Hossain

All rights reserved. 


\section{DEDICATION}

To my parents, siblings and my supervisor for their continuous support and motivation 


\section{ACKNOWLEDGMENTS}

First of all, I would like to thank the Almighty for His blessings to successfully complete my research work. Special thanks to my parents for backing me in this difficult journey and motivating me like fighting an uphill battle.

I greatly acknowledge the financial support from the Florida Department of Transportation to conduct this research. Particularly, the contributions of the project manager Ivan Lasa and others at the State Materials Office are greatly appreciated.

My supervisor, teacher and coach Dr. David Garber, Assistance Professor, Department of Civil and Environmental Engineering, Florida International University, has been supportive to this work from its inception. His constructive research related discussion, and feedback, throughout my course work, and research challenges has added new dimensions to my intellectual perception. In fact, the organization skill and efficient execution to all the research deliverables came true because of his consistent availability.

I am highly honored and would like to express my gratitude to my co-major Professor Dr. Kingsley Lau for his thought-provoking support and engineering knowledge from time to time, he shared with me to make critical calls and accurate decisions while approaching to an engineering problem. I sincerely express my gratitude to all my committee members, Dr. Norman Munroe, Dr. Ioannis Zisis and Dr. Seung Jae Lee for their valuable inputs and sharing helpful experiences in this journey.

Last but not the least, I would like to thank the staff of Coreslab for their unconditional assistance, the staff at the department of civil and environmental engineering and the staff at the dean's office of college of engineering and computing who were always there to assist me during my stay at the university. 


\author{
ABSTRACT OF THE DISSERTATION \\ DEVELOPMENT OF LOCAL AND GLOBAL CORROSION SENSING \\ TECHNIQUE TO MONITOR STRUCTURAL BEHAVIOR OF PRESTRESSED \\ CONCRETE STRUCTURES \\ by \\ Dewan Hossain
}

Florida International University, 2019

Miami, Florida

Professor David Garber, Co-Major Professor

Professor Kingsley Lau, Co-Major Professor

Corrosion of steel rebar in reinforced concrete structures is a concern for highway bridge owners. According to 2002 study by the Federal Highway Administration, 15\% of the highway bridges in the US are structurally deficient due to corrosion and have an estimated annual direct cost of $\$ 8.3$ billion. Generally, in post-tensioned bridges, ducts filled with poor or incomplete grouting can allow the tendons to come into contact with water, leading to corrosion and fracture. Although new and improved procedures of grouting have been developed to reduce the instances of poor grouting, the problem of how to reliably inspect tendons on existing structures remains. This research aimed to evaluate the feasibility of using currently available local and global corrosion sensing techniques to monitor the performance of concrete structures. This dissertation explores the use of three local corrosion sensors (resistivity sensors, relative humidity sensors, and resistor- 
inductor-capacity [RLC] sensors). In this research, local sensors (i.e. RH sensors and fourpoint resistivity sensors) placed at an interval of every three foot were able to detect corrosion conducive environment in PT ducts by measuring the electrical properties and moisture contents of the grout. However, the measured RH was consistently lower in the low point of the specimens compared to the high points for all the specimens. The fourpoint resistivity sensors were able to detect a clear difference between the grouted ducts with good grout compared to ducts with chloride-rich grout with voids and layered-chloride rich grout without voids. To evaluate destructive testing and monitor the global response, two full-scale prestressed concrete inverted-tee (IT) beams were constructed and instrumented with vibrating wire strain gauges (VWSGs) located in multiple planes along the length. The VWSGs were able to clearly detect the initiation of corrosion in the first prestressing strand in each beam. The local corrosion damage in the first strand resulted in a change in the behavior of the beam, which was detected by the VWSGs (through a change in slope of curvature versus time). 
CHAPTER

PAGE

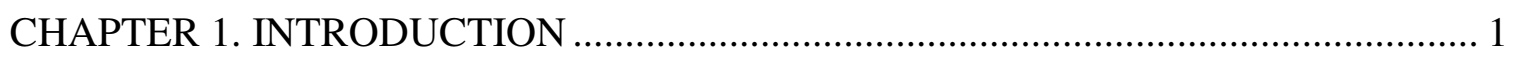

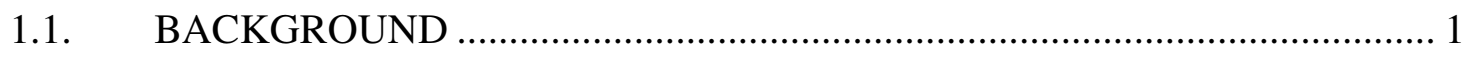

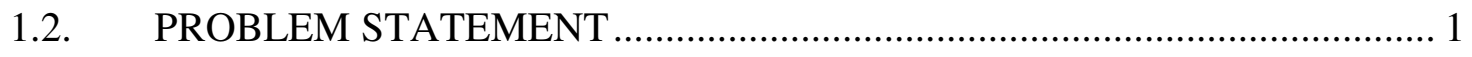

1.3. RESEARCH OBJECTIVES ………………......................................... 3

1.4. DISSERTATION FRAMEWORK ……………...................................... 3

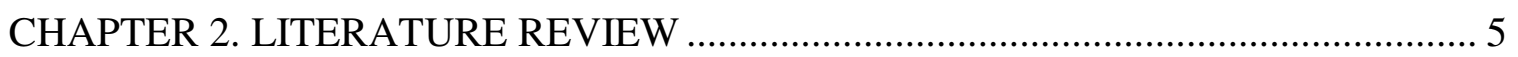

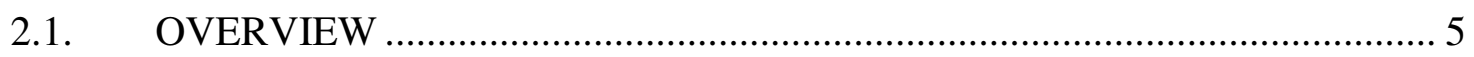

2.2. COMPLETE BRIDGE MONITORING SYSTEM ………….................... 5

2.3. LOCAL AND GLOBAL STRAIN-BASED CORROSION MONITORING . 7

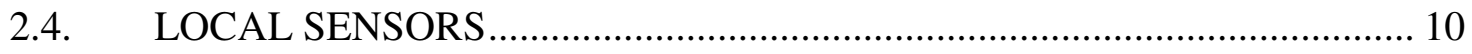

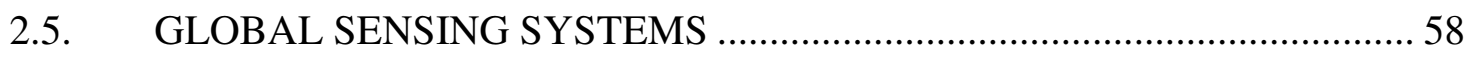

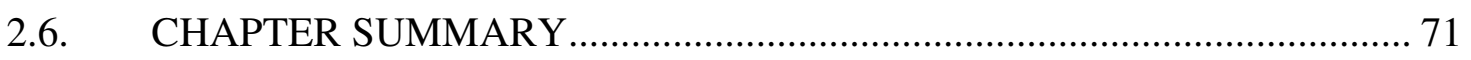

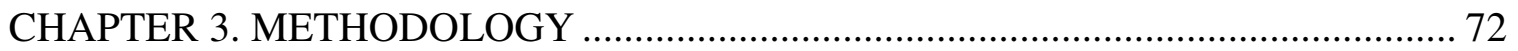

3.1. OVERVIEW OF RESEARCH OBJECTIVES AND HYPOTHESES .......... 72

3.2. ENVISIONED SENSING SYSTEM........................................................... 73

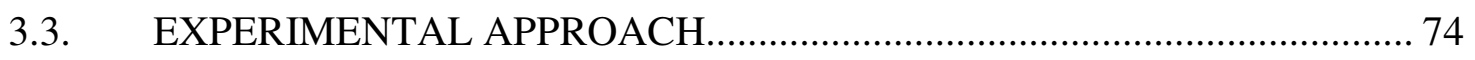

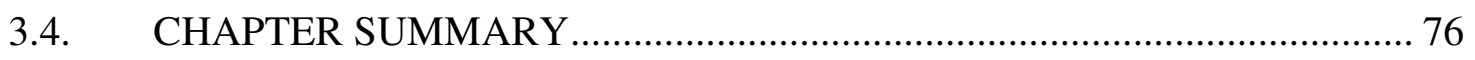

CHAPTER 4. EXPERIMENTAL CORROSION EVALUATION OF LOCAL

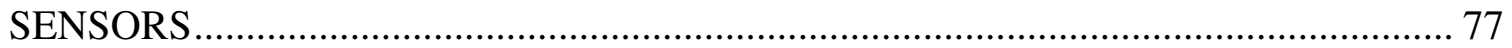

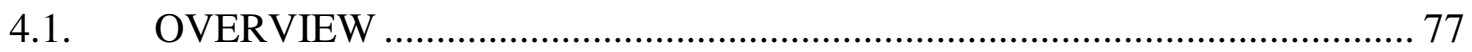

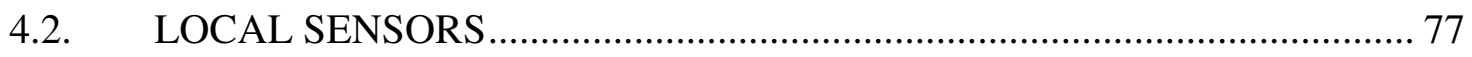

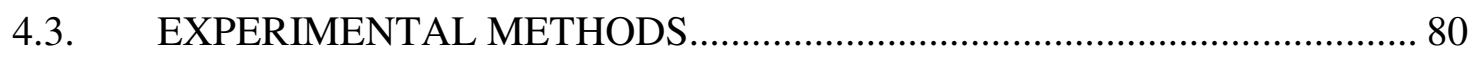

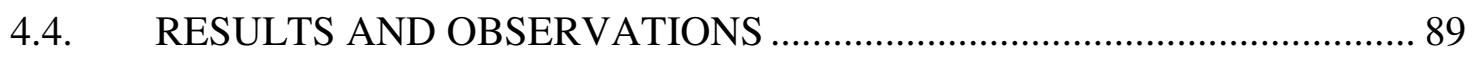

4.5. RESONANT SENSOR DEVELOPMENT …….................................... 95

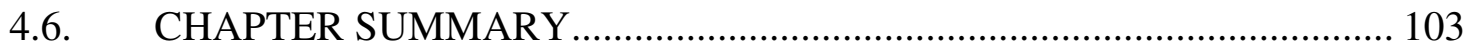


CHAPTER 5. EXPERIMENTAL CORROSION EVALUATION OF GLOBAL

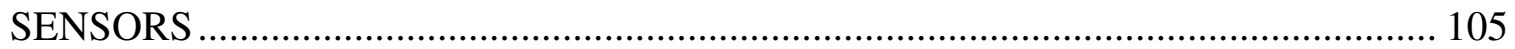

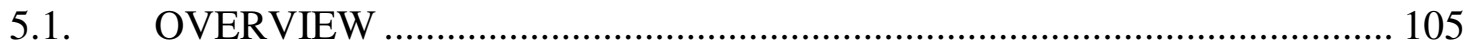

5.2. BEAM DESIGN AND CONSTRUCTION ………………...................... 105

5.3. DEFECT DESIGN AND CONSTRUCTION ............................................ 107

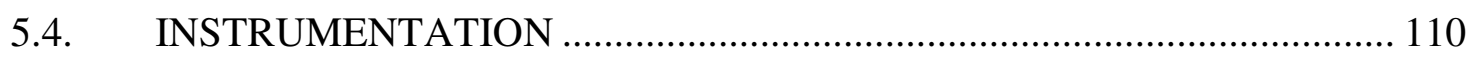

5.5. DATA ACQUISITION SYSTEM......................................................... 116

5.6. STABILIZATION OF LONG-TERM BEHAVIOR ……………………...... 117

5.7. CORROSION INITIATION OF STRANDS …………………………....... 121

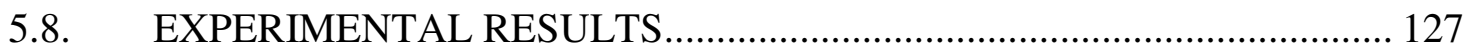

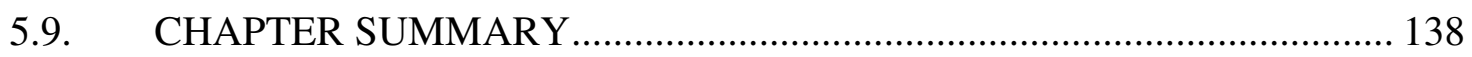

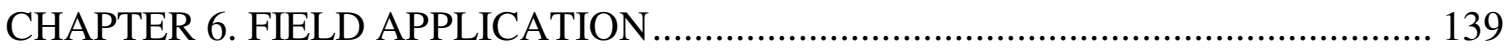

6.1. OVERVIEW ……………….......................................................... 139

6.2. APPLICABILITY TO POST-TENSIONED STRUCTURES ..................... 139

6.3. SENSOR AND GAUGE SELECTION ....................................................... 141

6.4. OVERVIEW OF INSTRUMENTATION STRATEGIES …....................... 143

6.5. RECOMMENDED INSTRUMENTATION SCHEDULE ........................... 143

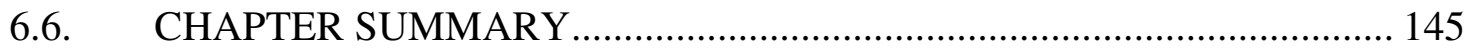

CHAPTER 7. CONCLUSION AND RECOMMENDATIONS .................................... 146

7.1. SUMMARY AND CONCLUSIONS ………........................................ 146

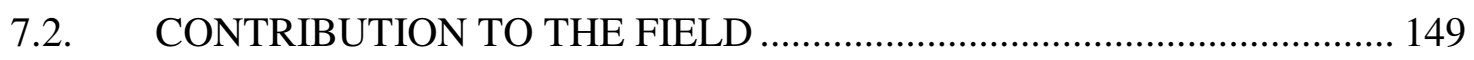

7.3. RECOMMENDATIONS FOR FUTURE RESEARCH.............................. 150

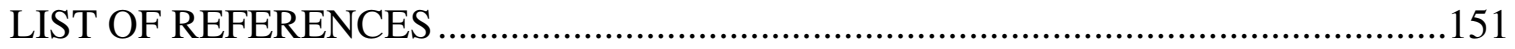

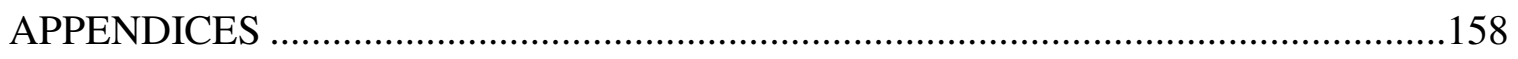

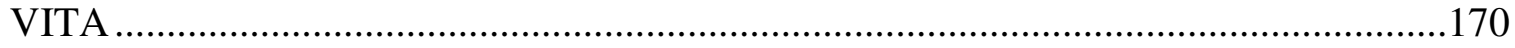




\section{LIST OF TABLES}

TABLE

PAGE

Table 2-1: Brief overview of resonant corrosion sensor.

Table 2-2: Brief overview of electrical conductivity-based sensor 16

Table 2-3: Brief overview of embedded corrosion instrument sensor 24

Table 2-4: Brief overview of Nagel-System sensor

Table 2-5: Brief overview of micro-linear polarization resistance Corrosion Sensor ...... 37

Table 2-6: Brief overview of passive embeddable wireless sensors

Table 2-7: Brief overview of smart aggregate (SA) sensors. 47

Table 2-8: Brief overview of corrosion probes 53

Table 2-9: Brief overview of vibrating wire strain gage.

Table 2-10: Brief overview of RFID-based wireless strain gage 66

Table 4-1: Initial test matrix for evaluation of local sensors 81

Table 4-2: Mix designs for grout used in small-scale testing 86

Table 4-3: Average compressive strength for grout 87

Table 4-4: Dates of important events for small-scale test specimens 88

Table 4-5: Impedance element of RLC Circuit 96

Table 4-6: Exposure test using RLC meter for different components of RLC circuit.... 100

Table 5.1: Geokon Model 4200 VWSGs Specification [61] 111 
Table 5.2: Important events for both beams

Table 5.3: Timing for accelerated corrosion cycles

Table 5.4: Relevant slopes for strain readings loss for FIU-1 (all units $\mu \varepsilon /$ day) ............ 129

Table 5.5: Relevant slopes for strain readings loss for FIU-2 (all units $\mu \varepsilon /$ day) ............ 130

Table 5.6: Relevant slopes for prestress loss for FIU -1 ........................................... 134

Table 5.7: Relevant slopes for prestress loss for FIU-2 ....................................... 134

Table 5.8: Relevant slopes for curvature for FIU-1 .............................................. 137

Table 5.9: Relevant slopes for curvature for FIU-2 .............................................. 137 


\section{LIST OF FIGURES}

FIGURE

PAGE

Figure 1-1: Impact of corrosion :(a) Lowes 80-ft pedestrian bridge section collapse [5], (b) San Francisco Bay bridge bolts failure [6] ....................................... 3

Figure 2-1: Schematic diagram of structural health monitoring system [7] ................... 6

Figure 2-2: Local corrosion mechanism [10]....................................................... 8

Figure 2-3: Corrosion damage detection using strain-based monitoring technique [11].... 9

Figure 2-4: Two different resonant corrosion sensor configurations [13]. 12

Figure 2-5: RLC circuit diagram and phase response: (a) resonant sensor magnetically coupled to external reader coil, and (b) phase of impedance measured across terminals of external reader coil [13]............. 14

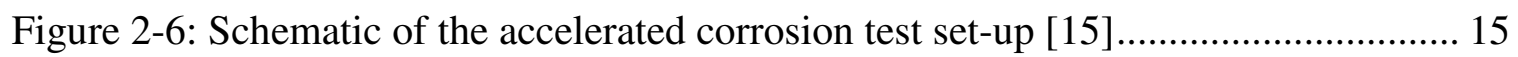

Figure 2-7: Crack maps of prism specimen (prism SW and prism TW) ....................... 15

Figure 2-8: Schematic illustration of electrical conductivity-based sensor [16] .............. 18

Figure 2-9: Flowchart of operation for the compact field point sensor system [19] ....... 20

Figure 2-10: Setup for the measurement of the conductivity of cement paste [20]......... 21

Figure 2-11: Schematic diagram of relative humidity (RH) sensor [19] ........................ 22

Figure 2-12: Schematic diagram of solution conductivity sensor [19] ......................... 22

Figure 2-13: Sensors positioned inside plastic molds before the placement of cement paste; (a) relative humidity sensor (b) pore solution

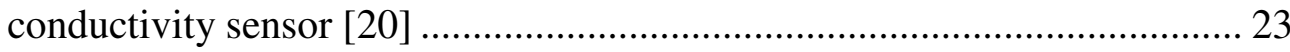

Figure 2-14: Model of ECi-2 Embedded Corrosion Instrument [22] ............................ 25

Figure 2-15: Local area network plan of embedded corrosion instrument (ECi) [22] ..... 26 
Figure 2-16: Mortar mix inside ECi device [23]

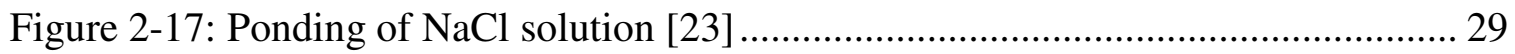

Figure 2-18: Placement of ECI-1 units prior to concrete placement [23]...................... 30

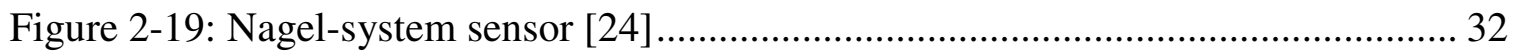

Figure 2-20: Wired ERE-probe with embeddable Nagel-system corrosion probe [25] ... 32

Figure 2-21: Data logging system to measure corrosion current [26] ........................... 33

Figure 2-22: Measuring advancement of the depassivation front using NagelSystem sensor [25] ....................................................................... 34

Figure 2-23: Equivalent circuit for corrosion in closed circuit condition [24] ................ 35

Figure 2-24: Øresund Tunnel instrumented with Nagel-System sensor [26] .................. 36

Figure 2-25:Four micro linear polarization resistance ( $\mu$ LPR) sensor with one node (left) and the close-up image of $\mu$ LPR sensor (right) [27] ........................ 37

Figure 2-26: Close-up view of good LPR sensors after dissection [27] ........................ 40

Figure 2-27: Close-up view of damaged LPR section after cable dissection (a)

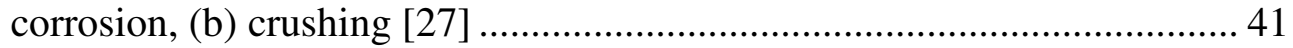

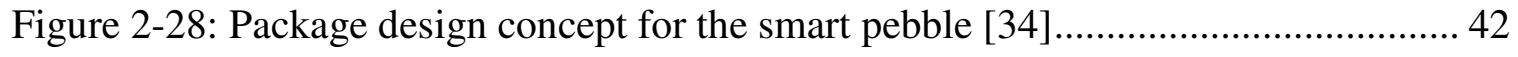

Figure 2-29: Electrochemical cell geometry for smart pebble [34] .............................. 43

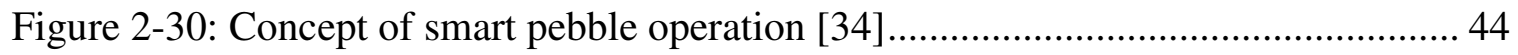

Figure 2-31: Detailed smart pebble block diagram.................................................. 45

Figure 2-32: Frame for mounting smart pebble to rebar [34] .................................... 46

Figure 2-33: Schematic concept of smart aggregate (SA) system [35] .......................... 49 
Figure 2-34: Redesigned wireless embedded sensor platform (WESP) assembly [35].... 50

Figure 2-35: Bridge installation of smart aggregate in holders [35]

Figure 2-36: Second filed installation: (a) deck pouring and (b) post deck pour

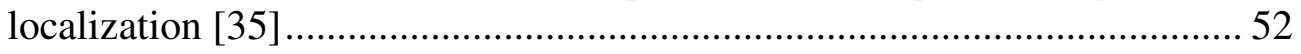

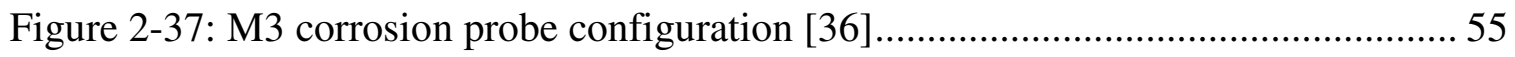

Figure 2-38: M4 corrosion probe configuration [36].............................................. 56

Figure 2-39: Installed M3 probe prior to placement of concrete [36] ............................ 57

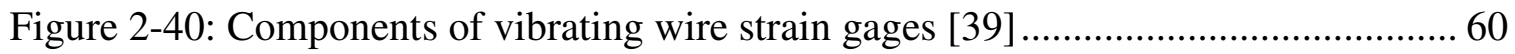

Figure 2-41: Vibrating wire gages attached to a test specimen; (A) before straining, (B) after straining [37]

Figure 2-42: Load steps at different phases of the construction (strain data

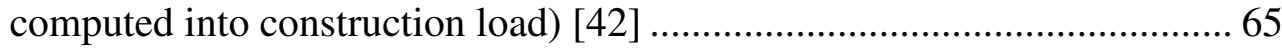

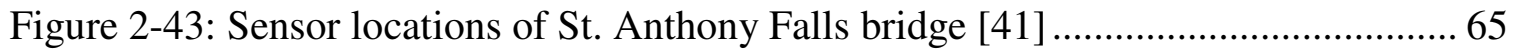

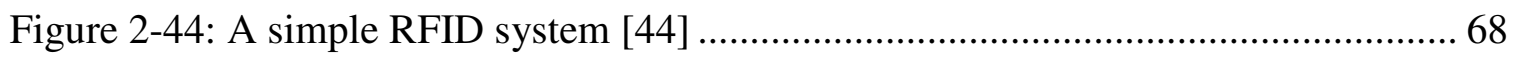

Figure 2-45: Phase IV's RFID (a) strain sensors attached with steel rods and (b) backpack with RFID reader and antenna [47] .......................................... 69

Figure 2-46: Embedded RFID strain sensor in tunnel reinforcement ring [47].............. 70

Figure 3-1: Schematic of proposed monitoring system with local corrosion sensors and strain sensors for structural behavior monitoring .............................. 74

Figure 3-2: Overview of experimental program .................................................... 75

Figure 4-1: Schematic diagram of the Wenner four-point resistivity ............................ 78

Figure 4-2: (a) Schematic of 4-point resistivity sensor and (b) installed sensor

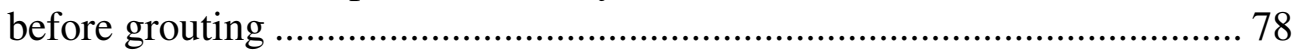

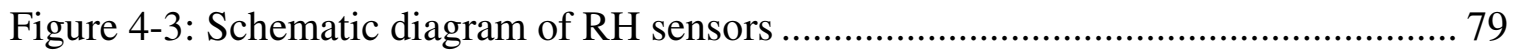


Figure 4-4: Installation of RH sensors (a) clearing dust, (b) inserting sensor and (c) putting cap 80

Figure 4-5: Key components of test setup (a) schematic and (b) test setup after grouting first 30-degree specimen

Figure 4-6: Two strand profiles used for grouted pipe specimens (a) 30 degrees and (b) 5 degrees 82

Figure 4-7: Location of resistivity and RH sensors 82

Figure 4-8: Schematic 30-degree specimen with (a) good grout condition, (b) chloride-rich grout, (c) Section A-A with good consolidation, (d) Section B-B with small random Styrofoam voids, and (e) Section C-C with large concentrated Styrofoam void 83

Figure 4-9: Schematic 30-degree specimen with dissimilar grout (a) elevation and (b) Section A-A 84

Figure 4-10: Specimens with (a) 30-degree strand profile and (b) 5-degree strand profile

Figure 4-11: (a) Surface dust removal of strands before putting in plastic duct and (b) use of acetone to remove dust from the bar surface 85

Figure 4-12: Grouting process for all specimens 87

Figure 4-13: Constant potential difference created to induce strand corrosion 88

Figure 4-14: Good grout resistivity for (a) 30-degree strand profile and (b) 5-degree strand profile 90

Figure 4-15: Chloride-rich grout resistivity for (a) 30-degree strand profile and (b) 5-degree strand profile.

Figure 4-16: Layered grout resistivity for (a) 30-degree strand profile and (b) 5degree strand profile

Figure 4-17: Minimum and maximum daily ambient humidity and average daily temperature during time of testing 92

Figure 4-18: Relative humidity of good grout for (a) 30-degree strand profile and (b) 5-degree strand profile. 
Figure 4-19: Relative humidity of chloride-rich grout for (a) 30-degree strand profile and (b) 5-degree strand profile

Figure 4-20: Relative humidity of layered grout for (a) 30-degree strand profile and (b) 5-degree strand profile.

Figure 4-21: Graphical representation of RLC circuit impedance versus frequency [59] 96

Figure 4-22: Construction of the series RLC circuit using CircuitLab software starting at $10 \mathrm{~m} \Omega$ resistance

Figure 4-23: Magnitude of the series RLC circuit at $10 \mathrm{~m} \Omega, 100 \mathrm{~m} \Omega, 1 \Omega, 10 \Omega, 100 \Omega$ and $10 \mathrm{k} \Omega$ resistance

Figure 4-24: Phase angle of the series RLC circuit at $10 \mathrm{~m} \Omega, 100 \mathrm{~m} \Omega, 1 \Omega, 10 \Omega$, $100 \Omega$ and $10 \mathrm{k} \Omega$ resistance

Figure 4-25: Exposure test using RLC meter for different components of the RLC circuit at (a) control environment, (b) mild corrosive environment and (c) severe corrosive environment 100

Figure 4-26: Development of RLC circuit (Prototype I) [60]. 101

Figure 4-27: Development of RLC circuit (Prototype II) [60] 102

Figure 5-1: Cross section dimensions and strand location and prestress force. 106

Figure 5-2: Typical construction procedure, including delivery to FIU 107

Figure 5-3: Schematic of formwork used for mockup defect 108

Figure 5-4: Schematic of mixed metal oxide mesh and other components in defect mockup 108

Figure 5-5: Corrosion damage of mockup after 4 days of applying voltage to one of top strands. 109

Figure 5-6: Procedure for creating defect in full-scale beams 110

Figure 5-7: Concrete Embedment 4200 strain gauges (based on [61]) 111

Figure 5-8: Installation of the vibrating wire gauges (VWSGs) (a) measuring the location, (b) fastening with rebar 
Figure 5-9: Location of VWSGs in cross section for (a) FIU-1 (offset defect) and (b) FIU-2 (mid-span defect).

Figure 5-10: Location of VWSGs and defect along length of (a) FIU-1 (offset defect) and (b) FIU-2 (midspan defect)...

Figure 5-11: Installed VWSGs in full-scale beams

Figure 5-12: Method for determining strain in prestressing strands from VWSG strain measurements

Figure 5-13: A typical DAQ system for collecting VWSGs data.

Figure 5-14: Prestress losses measured at three sections in FIU-1 (with mid-span defect)..... 118

Figure 5-15: Prestress losses measured at two sections in FIU-2 (with offset defect) ... 119

Figure 5-16: Strain readings in all VWSGs in FIU-1 120

Figure 5-17: Strain readings in all VWSGs in FIU-2

Figure 5-18: Schematic of mixed metal oxide mesh and other components for accelerated and controlled corrosion

Figure 5-19: (a) Strand labeling and (b) categorization of risk of corrosion initiation... 123

Figure 5-20: Mass loss versus time for strand A9 after start of accelerated corrosion in (a) FIU-1 and (b) FIU-2.

Figure 5-21: Visual corrosion product after accelerated corrosion of A1 on FIU-1 on (a) side of beam and (b) bottom of beam

Figure 5-22: Strain measurements from VWSGs in FIU-1 for (a) Section 1, (b) Section 2, and (c) Section 3 .....

Figure 5-23: Strain measurements from VWSGs in FIU-2 for (a) Section 1 and (b) Section 2

Figure 5-24: Average prestress loss versus time for (a) FIU-1 (with offset defect) and (b) FIU-2 (with midspan defect).

Figure 5-25: Prestress loss at different sections in FIU-1 
Figure 5-26: Prestress loss at different sections in FIU-2.

Figure 5-27: Measured prestress loss in FIU-1 at Section 1 with linear regressions for voltage applications on strands A1, A10, and A9............................ 133

Figure 5-28: Average measured curvature for (a) FIU-1 and (b) FIU-2 ....................... 135

Figure 5-29: Curvature at different sections in FIU-1 ............................................ 136

Figure 5-30: Curvature at different sections in FIU-2 …...................................... 136

Figure 6-1: Strain response in prestressing strands for (a) pretensioned and (b) bonded post-tensioned beams 140

Figure 6-2: Strain response in prestressing strands for unbonded PT structures

Figure 6-3: Schematic of current flow in four-point resistivity sensors with (a) smaller and (b) larger amounts of prestressing strands

Figure 6-4: Recommended VWSG placement in (a) single web and (b) multi-web sections

Figure 6-5: Schematic of recommended instrumentation schedule 145 


\section{CHAPTER 1. INTRODUCTION}

\subsection{BACKGROUND}

Corrosion of steel rebar in reinforced concrete structures is a major concern for highway bridge owners. There are $\sim 350,000$ reinforced concrete and prestressed concrete bridges in the US. Many prestressed concrete bridges were constructed from the 1950s onward and the oldest of these are now nearing the end of their design lives [1]. Reinforced concrete in severe environments with exposure to chloride ions and carbon dioxide for example can result in corrosion deterioration with subsequent consequences in serviceability of the structure and increased maintenance costs. The Federal Highway Administration found in a 2002 study that about $15 \%$ of the highway bridges in the US are structurally deficient due to corrosion with an estimated annual direct cost of $\$ 8.3$ billion [2]. On an individual basis, failure of a prestressed concrete component may have a significant impact on the structural integrity of a bridge. Because prestressed concrete members rely on the tensile strength of the tendons to sustain load, the loss of even a few tendons may lead to the catastrophic failure of a bridge component.

\subsection{PROBLEM STATEMENT}

Post-tensioned structures rely on the strength of field installed tendons to maintain the integrity of the structure. There have been recent instances of these post-tensioned strands being poorly installed and incompletely grouted, which has led to corrosion of the strands [3]. Generally, in post-tensioned bridges, ducts filled with poor or incomplete grouting can allow the tendons to come into contact with water, leading to corrosion and fracture. The problem is aggravated by the presence of salts from road treatments, which 
can accelerate the corrosion process [4]. In addition to causing pitting of the prestressed strands, corrosion reactions lead to the evolution of atomic hydrogen, which is subsequently absorbed into the steel, leading to hydrogen embrittlement of the steel strands and causing the strands to fail at lower than designed bridge loads. The tendons are critical to the strength of the structure, and failure can lead to a transfer of load to other tendons, leading to a chain reaction of failures that will eventually cause the structure to collapse. In 2000, an 80-foot section of the 320-foot concrete and steel walkway fell onto U.S. Highway 29 due to corrosion of 11 cables as shown in Figure 1-1(a). Similarly, in 2008, one of the largest public work projects in the United States suffered from 32 steel bolt failure due to corrosion as shown in Figure 1-1 (b).

Although new and improved procedures of grouting have been developed to reduce the instances of poor grouting, the problem of how to reliably inspect tendons on existing structures remains. There are many inspection techniques available to bridge engineers, but the embedded nature of the tendons, combined with the fact that the tendons are located in ducts, makes the inspection of individual tendons extremely difficult. Current available standards, such as radiography, are capable of locating ducts and detecting voids in the grout, but the resolution is not sufficient to determine tendon condition [4]. 


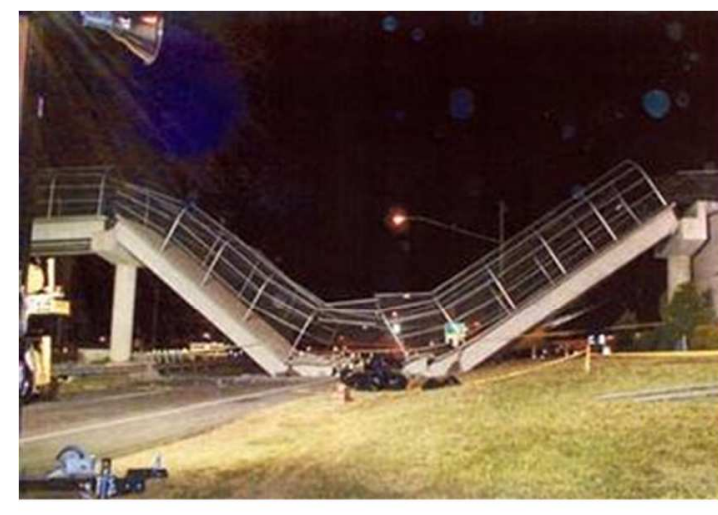

(a)

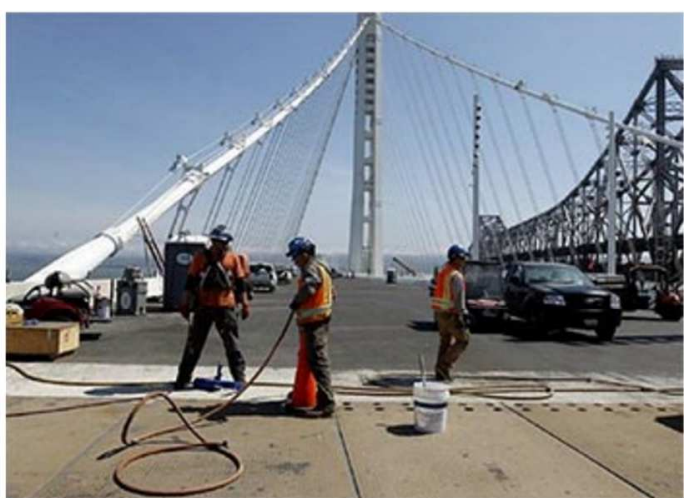

(b)

Figure 1-1: Impact of corrosion :(a) Lowes 80-ft pedestrian bridge section collapse [5], (b) San Francisco Bay bridge bolts failure [6]

\subsection{RESEARCH OBJECTIVES}

The primary goal of this research was to facilitate the investigation of sensors for corrosion detection of embedded steel components in cementitious materials in applications of prestress concrete structures. The specific objectives of this study were:

- To evaluate the feasibility of using currently available local and global corrosion sensing techniques to monitor the performance of concrete structures,

- To develop a protocol for the evaluation of local and global sensors to facilitate the validation of new technologies as they become available, and

- To develop recommended sensor placement layouts to give professional engineers guidance to when and where sensors should be used.

\subsection{DISSERTATION FRAMEWORK}

This research is focused on the development of local and global corrosion sensing technique to monitor structural behavior of prestressed concrete structures. Therefore, 
localized corrosion, local and global sensors and structural response of prestressed concrete structures are studied in this dissertation.

Chapter 2 summarizes a comprehensive literature review of the currently available methods and technologies for passive corrosion and active structural integrity monitoring. Chapter 3 introduces the methodologies adopted to answer the proposed research questions and confirm the research hypotheses. Chapter 4 describes the experimental corrosion evaluation of local sensors. Chapter 5 describes the experimental corrosion evaluation of global sensors with detail data collection, preparation and analysis effort. Chapter 6 discusses how the research findings can be extended to post-tensioned structures for field applications. Chapter 7 concludes this dissertation by summarizing all the findings and presents conclusions for future research. 


\section{CHAPTER 2. LITERATURE REVIEW}

\subsection{OVERVIEW}

Due to the limitations of currently available inspection techniques, the use of internally embedded or externally attached sensors as part of monitoring systems are being explored to see their potential for identifying problems at an early age. These systems are limited by: (a) the capability of available sensors, (b) the effort required to read the sensors, (c) the expense of fully instrumenting and monitoring a structure, and (d) the amount of data that needs to be processed in such a system. The focus of this chapter is to give an indepth overview of available sensors and systems with these limitations in mind.

\subsection{COMPLETE BRIDGE MONITORING SYSTEM}

The goal of an effective bridge monitoring system is to: (i) diagnose the structural condition of the bridge, (ii) quantify any localized damage for evaluating critical sections, and (iii) provide information for a sustainable and targeted maintenance plan.

Complete bridge monitoring systems typically include the following components:

- Sensors: Sensing modules attached or embedded on the structure that consist of various types of sensors to collect data to identify the damage nature of the structure

- Data acquisition system: Data communication systems to transfer the collected data from bridge sensors

Data collected from the bridge monitoring system must then be analyzed to provide an evaluation of the condition of the structure based on application area. 
The objective of this collective monitoring system is to provide necessary information of the structural condition and possible causes of damage to identify strategic and operational goals. Therefore, the selection of a comprehensive monitoring technology is to identify the onset of corrosion, the extent of corrosion and provide safe warning of potential failure. A typical structural health monitoring system will monitor the following key things in a structure: (i) detecting the damage, (ii) type of damage, (iii) location of damage and (iv) severity of damage [7]. Researchers [7] have developed a schematic diagram of structural health monitoring system as shown in Figure 2-1.

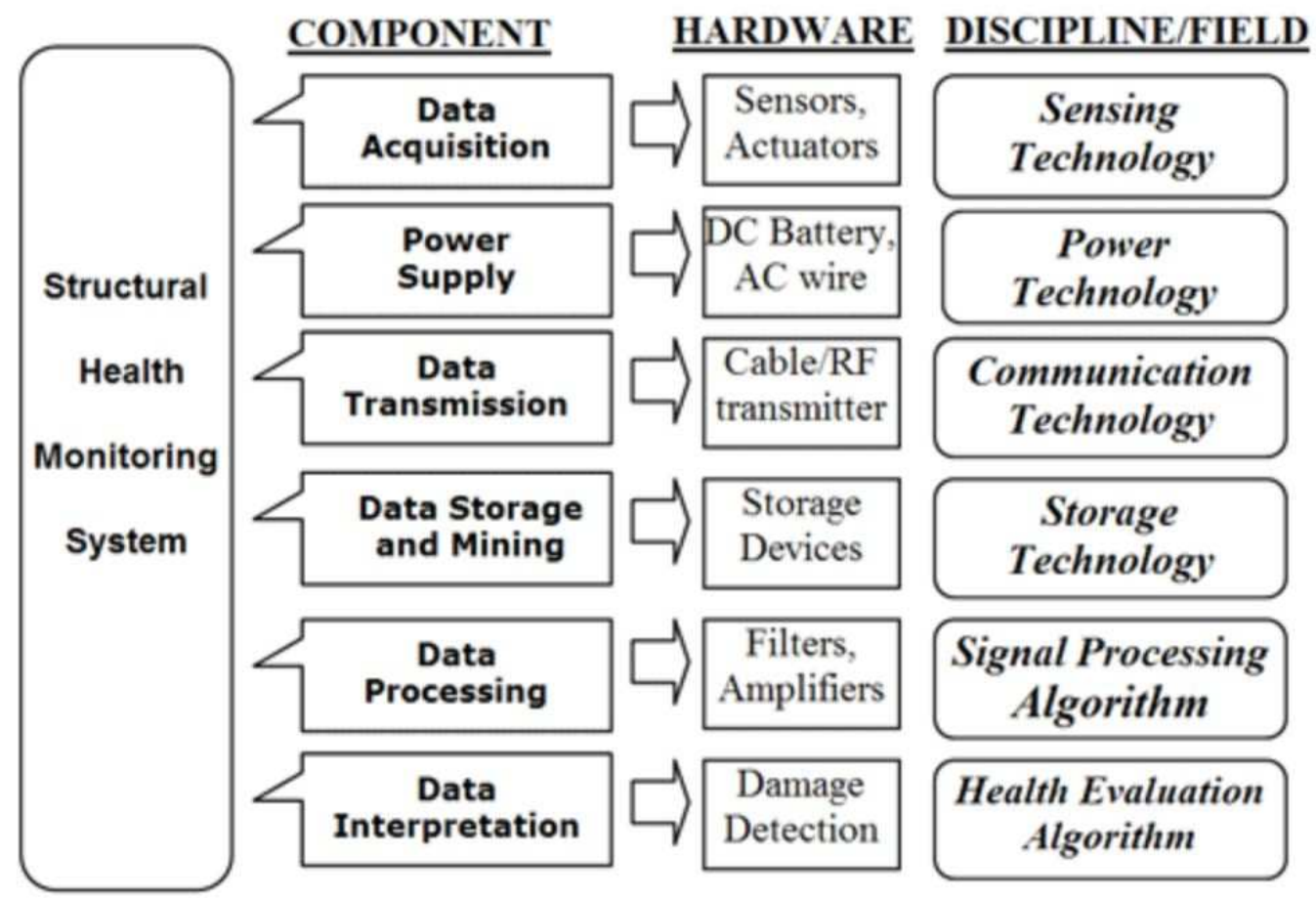

Figure 2-1: Schematic diagram of structural health monitoring system [7]

To develop a comprehensive local and global strain-based corrosion detection methodology, selection of the optimal sensor configuration in the structure needs to be addressed. So, adequate sensor placement to detect local and global scale corrosion plays 
a key role for characterizing the overall performance of the structure and establishing a sensor layout plan for monitoring the onset of corrosion, locate the corrosion spots and quantify the severity [8]. Study results show that the issue of optimally locating a given number of sensors in a large structure mainly depends on the considerations of [9]:

- Minimizing the cost of instrumentation, data processing and data handling efforts,

- Obtaining more accurate estimations of model parameters (less noise in measurements)

- Improving structural control with the use of superior structural models,

- Efficiently determining structural properties and their changes, and

- Improving early fault-detection capabilities.

\subsection{LOCAL AND GLOBAL STRAIN-BASED CORROSION MONITORING}

The corrosion process starts locally, and its progression can be subdivided into four steps, as shown in Figure 2-2. 
1-Corrosion initiation: Diffusion equation will control corrosion initiation time. The process is probabilistic, due to uncertainty in material parameters

2-Crack initiation: Due to volume increases, cracks will eventually occur in concrete

3-Crack propagation: concrete cracking will propagate as the corrosion process continues

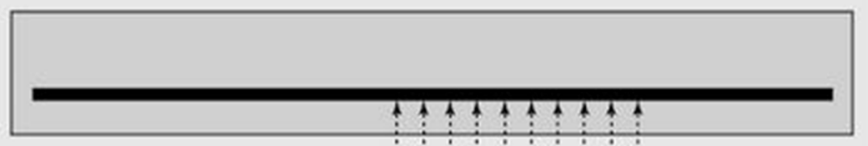

4-Concrete spalling: Larger chunks of concrete will spall, as the cracks spread further
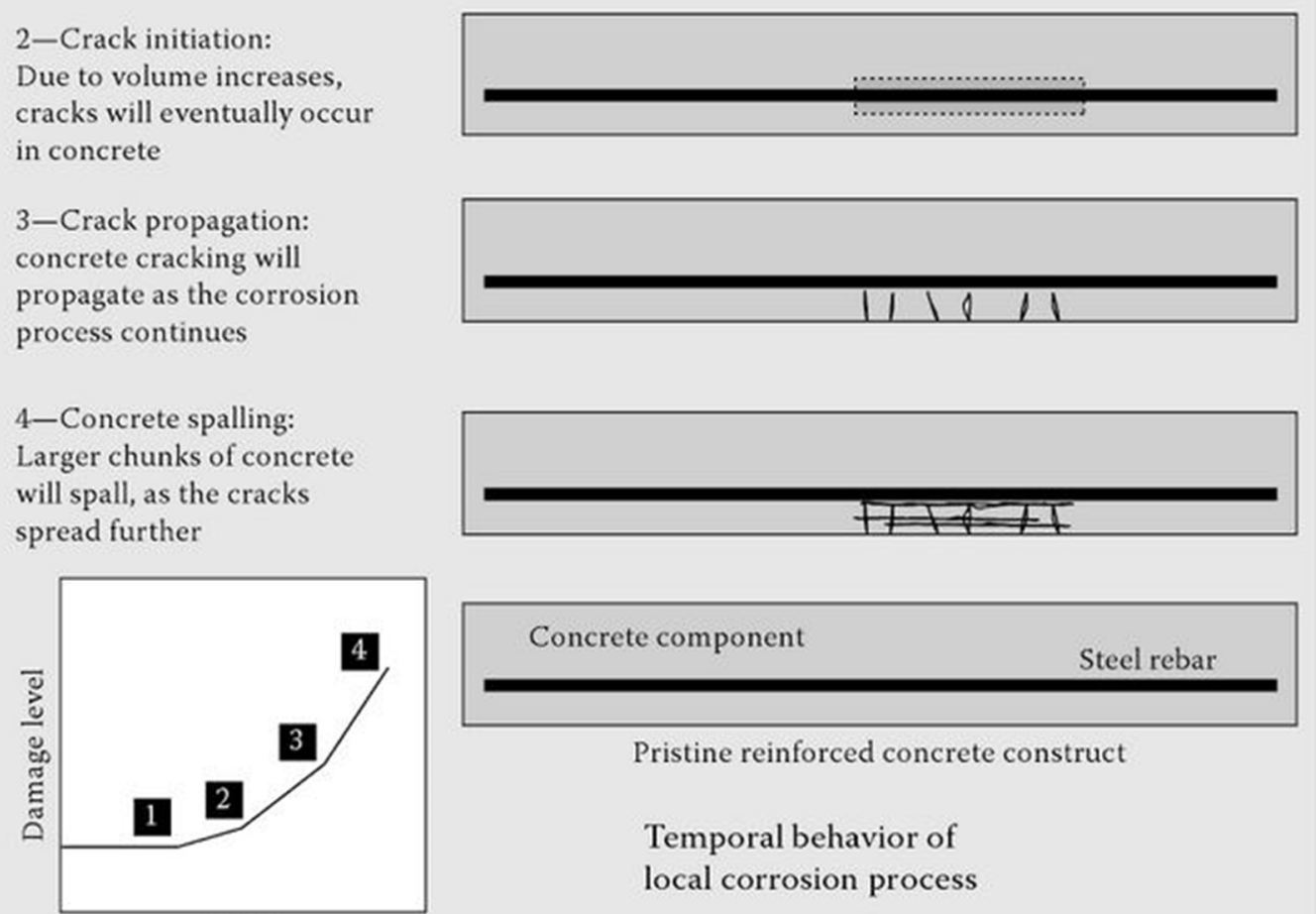

Time

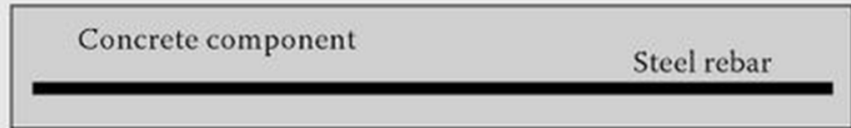

Pristine reinforced concrete construct

Temporal behavior of

local corrosion process

Figure 2-2: Local corrosion mechanism [10]

This localized corrosion damage will generate a local strain change at the damageinduced position. When the localized corrosion damage is large enough, the localized strain change will impact the average strain over the length of the bridge, as shown in Figure 2-3 [11]. This change in the average strain behavior would allow for strain sensors at locations away from the damaged region to detect the damage. Similarly, corrosion would cause a localized change in curvature that would impact the average curvature behavior over the length of the bridge. 


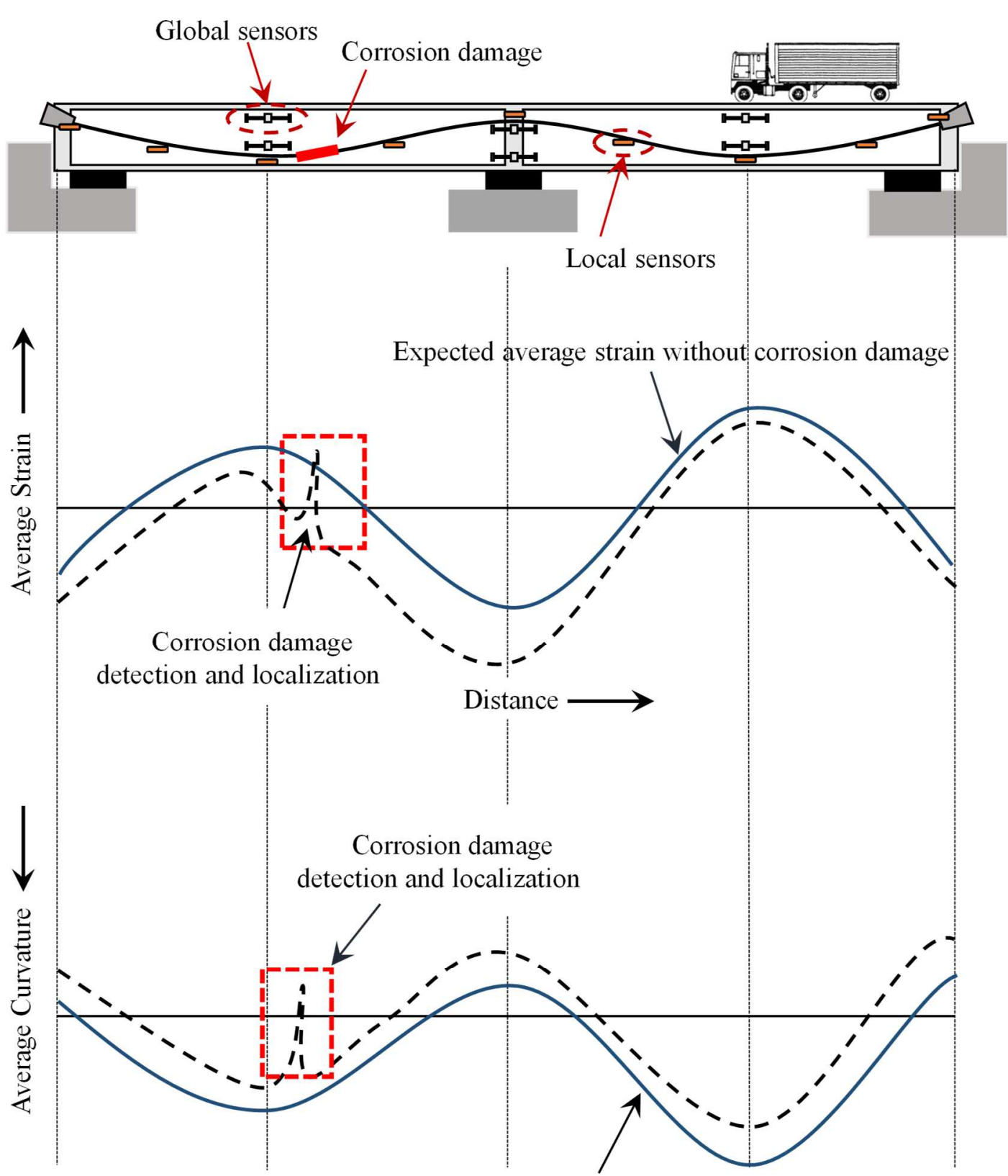

Expected average curvature without corrosion damage

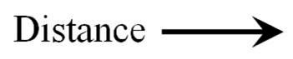

Figure 2-3: Corrosion damage detection using strain-based monitoring technique [11] 
The objective of the overall bridge monitoring system is then to monitor the impact of corrosion on the bridge performance and detect the location of corrosion damage (or regions with conditions conducive to corrosion) using the local sensor.

\subsection{LOCAL SENSORS}

The primary two methods that local corrosion sensors detect corrosion is by either: (i) monitoring the concrete environment and determine when the environment is conducive for corrosion or (ii) monitoring the corrosion damage of a sacrificial element made up of similar material to the reinforcement or prestressing. There are many different local corrosion sensors that fall into these areas. A summary of these sensors is provided in this section and includes the following:

- Overview of sensor (with overview table for each)

- Background of theory / mechanism applied in sensor technology

- Summary of previous research studies performed

- Discussion on commercial availability

The sensors have also been categorized using the following classifications:

- Corrosion Monitoring Type: local, global

- Gage Position: embeddable, non-embeddable (note that only embeddable gauges were selected in this review)

- Communication and Power Source: wired, wireless (battery), wireless (batteryfree)

- Required Communication System: datalogger, specialized reader 
- Commercial Availability: commercially available; not commercially available

- Corrosion Detection Method: sacrificial element, environment monitoring

These categories are included as the first row in the summary tables.

\subsubsection{Product 1: Resonant Corrosion Sensor}

\subsubsection{Overview}

Resonant corrosion sensors are passive wireless sensors made of resistor-inductorcapacitor (RLC) circuits that exhibit unique resonance properties. The frequency response of the resonant circuits embedded in resonant sensors is measured by the impedance, which is an external reader coil within a range of swept frequencies. A hermetically sealed resonant circuit comprising an inductor, a resistor and a capacitor and for the RLC circuit, the resonant frequency depends solely on its inductance and capacitance [12]. A brief overview of resonant corrosion sensor is shown in Table 2-1.

Table 2-1: Brief overview of resonant corrosion sensor

\begin{tabular}{|c|c|c|}
\hline \multicolumn{2}{|c|}{ Resonant Corrosion Sensor } \\
\hline \hline Categories & $\begin{array}{l}\text { Local, passive, embeddable, wireless and reader based, sacrificial } \\
\text { corrosion sensor }\end{array}$ \\
\hline \multirow{4}{*}{ Pros } & $\begin{array}{l}\text { - } \\
\text { - }\end{array}$ & Sireless \\
& Sensor is relatively inexpensive to fabricate \\
& $\begin{array}{l}\text { Durable: includes a protective cementitious housing } \\
\text { surrounding the resonant circuit }\end{array}$ \\
& $\begin{array}{l}\text { Selection of the geometry of the reader coil could be optimized } \\
\text { based on the embedment depth of the sensor }\end{array}$ \\
\hline Cons & $\begin{array}{l}\text { Optimum coupling between the sensor system component is } \\
\text { achieved only when the radius of reader coil is equal to read } \\
\text { distance }\end{array}$ \\
& $\begin{array}{l}\text { Capable of providing information for immediate sensor } \\
\text { location only } \\
\text { A higher number of sensors needed to be installed to } \\
\text { approximate the extent of corrosion damage }\end{array}$ \\
\hline
\end{tabular}




\begin{tabular}{|c|c|}
\hline \multicolumn{2}{|r|}{ Resonant Corrosion Sensor } \\
\hline & $\begin{array}{l}\text { Upon interrogation, likelihood of corrosion detection at the } \\
\text { location of the sensor is low when two resonant frequencies } \\
\text { are present }\end{array}$ \\
\hline Other Details & $\begin{array}{l}\text { - Comprises of sacrificial transducer coupled to resonant circuit } \\
\text { which is exposed to an environment outside sensor to monitor } \\
\text { corrosion } \\
\text { - Structural epoxy seal and reinforced fiber mortar seal ensure } \\
\text { resonant circuit signal reliability } \\
\text { - The response of the sensor is expected to remain mainly at } \\
\text { either the initial uncorroded state or the final fully corroded } \\
\text { state }\end{array}$ \\
\hline Manufacturer & Not commercially available \\
\hline References & $\begin{array}{l}\text { Abu-Yosef, et al. [13] } \\
\text { Pasupathy, P. [14] } \\
\text { Abu-Yosef, A. [15] }\end{array}$ \\
\hline
\end{tabular}

The sensor was envisioned to serve the objectives of low-cost, long-time serviceability and reliable output. The sensor platform was developed at the University of Texas at Austin and is shown in Figure 2-4 [13]. Two different sensor configurations were developed by researchers: one determining when a sensing coil is corroded and no longer causes a phase dip when read; the other measuring the change in phase dip as a steel washer or steel spiral corrodes. These will be discussed in more depth in the following section.

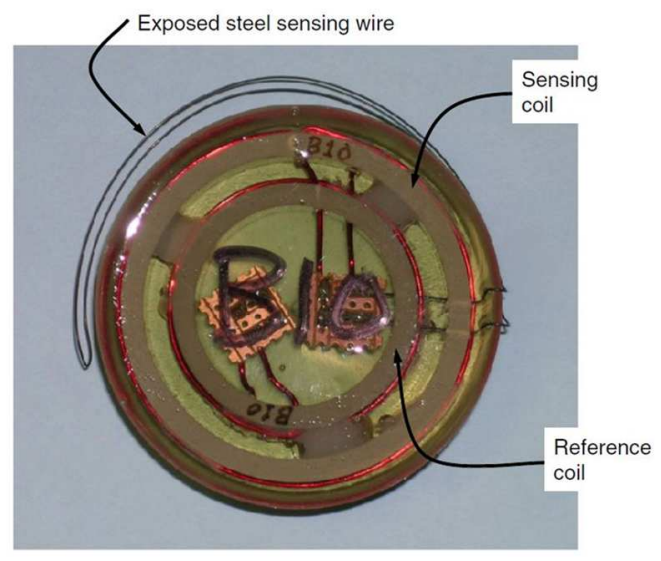

(a)

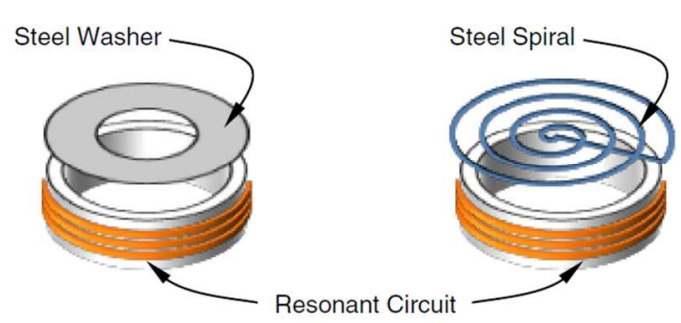

(b)

Figure 2-4: Two different resonant corrosion sensor configurations [13] 


\subsubsection{Theory/Mechanism}

The resonant corrosion sensor works on the measurement of resonant characteristics of resistance, inductance and capacitance (RLC) circuit. The RLC circuit is designed in such a way that the frequency response of the circuit can be determined by measuring the impedance across the terminals of the reader coil [13]. Theoretically, the activity of the power amplifier produces an alternative current through the RLC circuit. The amplitude of the current which is a function of frequency depends on the impedance in the circuit. The current reaches a maximum at the resonant frequency and becomes less than maximum for greater or lesser frequencies. These currents can be determined from the ratio of the resistor voltage to the resistance. The voltage drop (a.k.a., potential difference) is measured across the resistor in the circuit as shown in Figure 2-5. The value

of the resonant frequency depends on the values of the inductance, $\mathrm{L}_{2}$, and capacitance, $\mathrm{C}_{2}$, of the resonant circuit as in Equation 2-1.

$$
f=\frac{1}{2 \pi} \sqrt{\frac{1}{L_{2} \cdot C_{2}}}
$$

Equation 2-1 


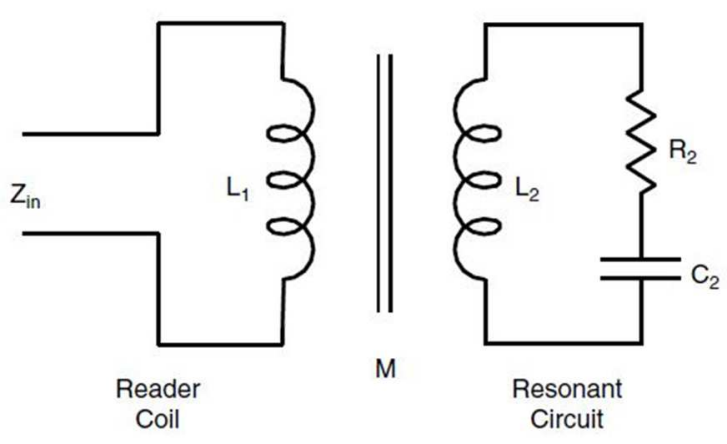

(a)

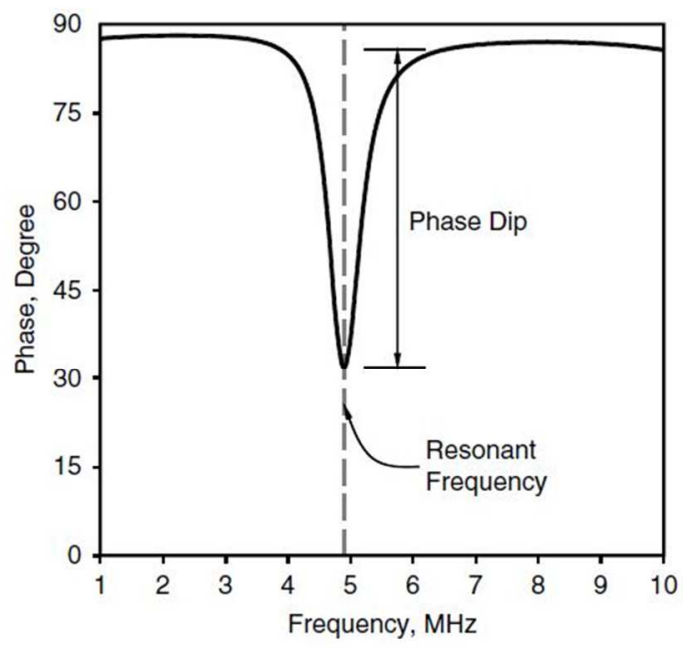

(b)

Figure 2-5: RLC circuit diagram and phase response: (a) resonant sensor magnetically coupled to external reader coil, and $(b)$ phase of impedance measured across terminals of external reader coil [13]

The researchers developed two different sensors based on this concept. The first measures a reference and sensing phase dips and determines when the sensing phase dip no longer exists (after corrosion occurs). When the steel wire gets corroded and fractured, then only the resonant frequency of the reference circuit can be detected upon interrogation because the frequency of the sensing circuit disappears [13]. The other sensor configuration involves using a steel washer or steel spiral as a corroding element disrupting the resistance between the reader and resonant circuit.

\subsubsection{Previous Studies}

A preliminary study was conducted at the University of Texas at Austin [15]. In this preliminary evaluation, sensor response was evaluated at different levels of chloride exposure under cyclic corrosion. Two reinforced concrete prisms were tested in this experimental process. One prism (Prism SW) was exposed to salt water solution $(3.5 \%$ $\mathrm{NaCl}$ by weight) while the other (Prism TW) was exposed to tap water [15]. Salt water was 
dripped onto the top surface of Prism SW to mimic the environment of the splash zone on the surface of the test prism and was expected to corrode faster than Prism TW, as shown in Figure 2-6.

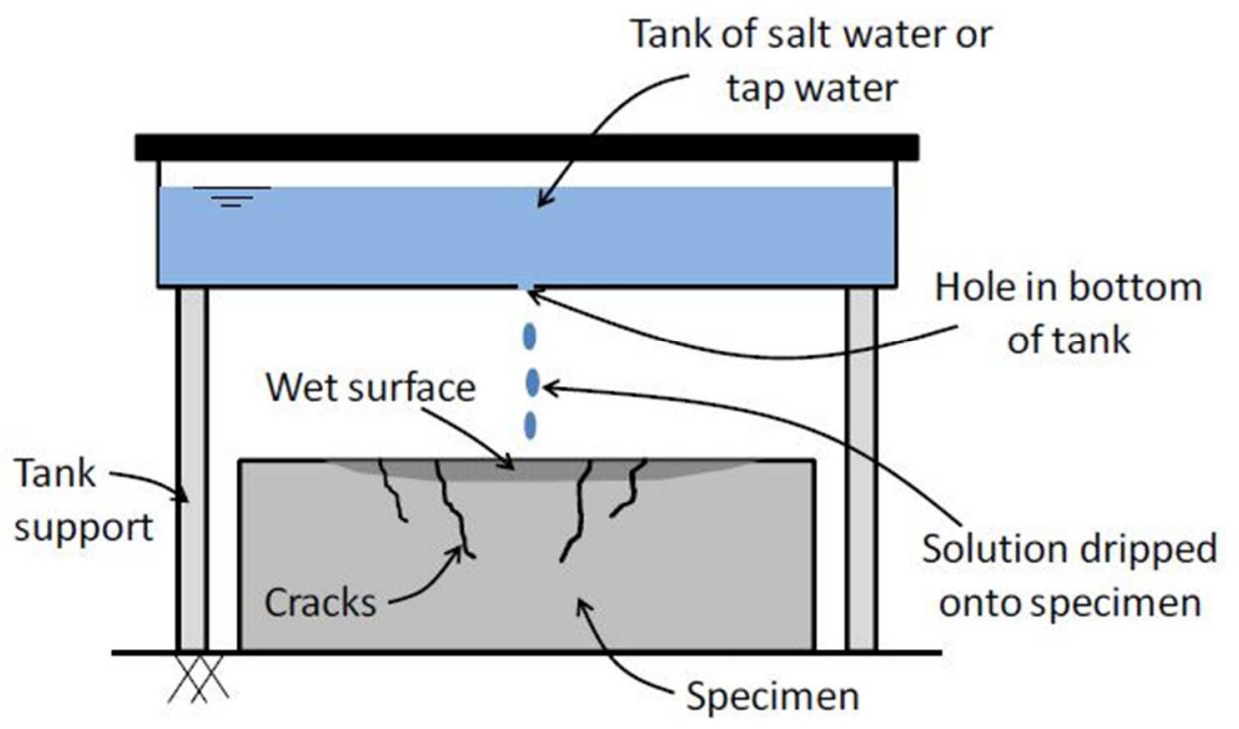

Figure 2-6: Schematic of the accelerated corrosion test set-up [15]

Prior to the exposure test, both prism samples were cracked under flexure loading to reach a crack width of 0.03 inches. It was observed that cracks were concentrated over the embedded sensors and extended across the width of the top surface of both prisms as shown in Figure 2-7 [15].

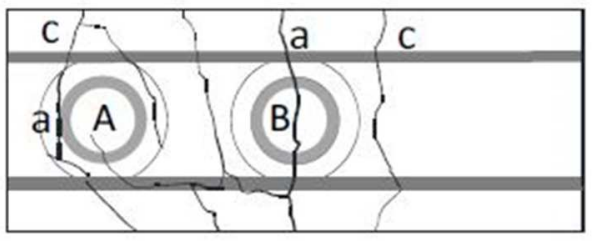

Specimen SW

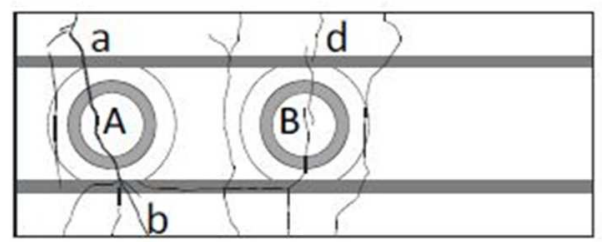

a : 0.03 in.

$\mathrm{b}: 0.02$ in.

c: 0.01 in.

$\mathrm{d}: 0.008 \mathrm{in}$.

Figure 2-7: Crack maps of prism specimen (prism SW and prism TW) 
To determine the frequency response of embedded resonant sensors, impedance data were used to determine the state of sensors. Phase dip, changes in the measurement of resonant frequency and bandwidth data were used as an indicative parameter of corrosion activity in the sacrificial washer. Finally, mass loss measurements were conducted using the reinforcing bars removed from the prism to monitor the exposure period of the accelerated corrosion test [15]. At the end of the exposure test, concrete cover was removed from all slabs to determine the extent of corrosion. Longitudinal reinforcement in the region of moisture fluctuation experienced corrosion in all the four specimens [13].

\subsubsection{Commercial Products}

The resonant corrosion sensor technology developed at UT Austin is patented, and it is not commercially available.

\subsubsection{Product 2: Electrical Conductivity-Based (Resistivity) Sensor}

\subsubsection{Overview}

The electrical conductivity sensing systems was developed to monitor: (i) internal chemistry of the system due to ion penetration, (ii) setting and hardening of concrete and measure microstructural and transport properties of the material and (iii) moisture transport and shrinkage of the material [16]. A brief overview of electrical conductivity-based sensors is shown in Table 2-2 and Figure 2-8.

\section{Table 2-2: Brief overview of electrical conductivity-based sensor}

\section{Electrical Conductivity-based Sensor}

Categories Local, embeddable, wired, datalogger based, environmental monitoring communication system 


\begin{tabular}{|c|c|}
\hline \multicolumn{2}{|r|}{ Electrical Conductivity-based Sensor } \\
\hline Pros & $\begin{array}{l}\text { - Capable of in-situ measurement of several concrete material } \\
\text { properties (e.g., permeability, diffusion coefficient) and internal } \\
\text { state parameters (e.g., ion concentration, moisture content, } \\
\text { corrosion damage or micro cracking) } \\
\text { - Simultaneous analysis of concrete conductivity, pore solution } \\
\text { conductivity, relative humidity and temperature resolves } \\
\text { concurrent influences of pore solution, moisture content and } \\
\text { temperature variation } \\
\text { - Final outputs enable measurement of the microstructural } \\
\text { properties as well as monitor moisture and ion transport inside } \\
\text { concrete }\end{array}$ \\
\hline Cons & $\begin{array}{l}\text { - Conductivity property is influenced by hydration and } \\
\text { microstructural variation, moisture variation, changes in pore } \\
\text { solution composition, and temperature variation } \\
\text { - Simultaneous influence of temperature, moisture, pore solution } \\
\text { and hydration influence a single measurement of concrete } \\
\text { conductivity } \\
\text { - Wired gages }\end{array}$ \\
\hline Other Details & $\begin{array}{l}\text { - Electrical conductivity sensors include a concrete conductivity } \\
\text { sensor, a pore solution conductivity sensor, and a conductivity- } \\
\text { based relative humidity (RH) sensor and a temperature sensor } \\
\text { - Sensing system provide sufficient warning before significant } \\
\text { structural failure by providing three types of electrical } \\
\text { conductivity measurements inside the structural material }\end{array}$ \\
\hline Manufacturer & Not commercially available \\
\hline References & $\begin{array}{l}\text { Rajabipour, et al. [16] } \\
\text { Christensen, et al. [17] } \\
\text { Garboczi, E. J. [18] } \\
\text { Jayant, D.M. [19] } \\
\text { Rajabipour, F. [20] }\end{array}$ \\
\hline
\end{tabular}




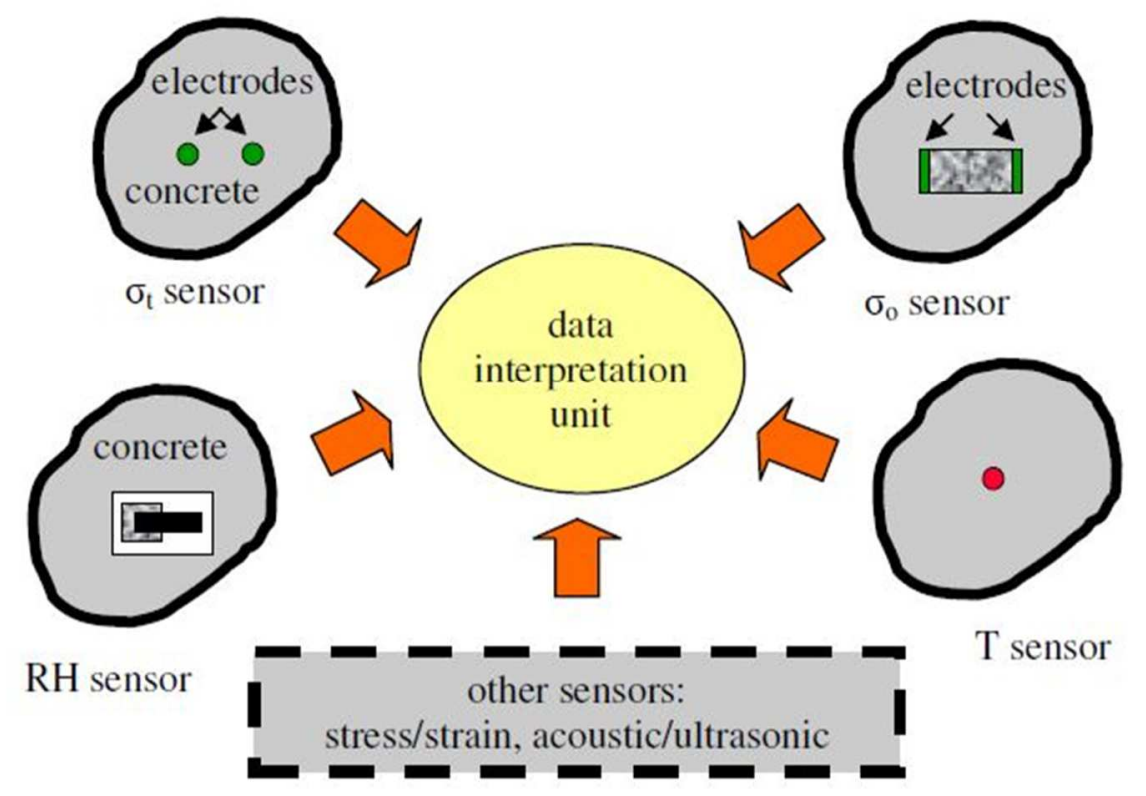

Figure 2-8: Schematic illustration of electrical conductivity-based sensor [16]

\subsubsection{Theory/Mechanism}

Electrical conductivity of concrete is an inside material property of concrete which is obtained by measuring the electrical resistance between two points (i.e., electrodes) inside concrete. The measured distance to account the effect of specimen and electrode geometry is expressed by Equation 2-2 [21].

$$
\sigma_{t}=\frac{K}{R_{b}}
$$

Equation 2-2

Where,

$$
\begin{aligned}
& \sigma_{\mathrm{t}}=\text { conductivity of concrete } \\
& \mathrm{R}_{\mathrm{b}}=\text { measured resistance } \\
& \mathrm{k}=\text { geometry factor }
\end{aligned}
$$


The electrical conductivity of concrete is related to the microstructural properties like porosity and pore connectivity of concrete and is expressed using modified parallel law equation as shown in Equation 2-3 [17].

$$
\sigma_{t}=\sigma_{0} \phi \beta
$$

Equation 2-3

Where,

$$
\begin{aligned}
& \varphi \beta=\text { product of porosity and connectivity } \\
& \sigma_{0}=\text { pore solution conductivity }
\end{aligned}
$$

To measure the ionic diffusion (i.e., a transport mechanism of random walk between charged species), the electrical conduction is driven by the presence of electrical potential between two points inside the material. On the other hand, diffusion is driven by the chemical potential (i.e., concentration gradient). Like the modified parallel law equation, ionic diffusion inside concrete is described by Equation 2-4 [18].

$$
D=D_{0} \phi \beta
$$

Equation 2-4

Where,

$$
\begin{aligned}
& \mathrm{D}_{0}=\text { diffusion coefficient of the substance through pore fluid } \\
& \mathrm{D}=\text { effective diffusion coefficient of specific substance (e.g. sodium }
\end{aligned}
$$
chloride)

With the use of single or multi-frequency alternating current (AC), and with the assistance of commercially available instruments impedance analyzer, the electrical response of the material can be assessed by applying a small magnitude of current/voltage 
and observing its response [19]. The four-point measurement is applied when a certain minimum distance is required to maintain within two oppositely charged electrodes. To complete one cycle of data acquisition, a logical flow diagram of the process needs to be followed as shown in Figure 2-9. This data acquisition system is arranged by user specified time period [19].

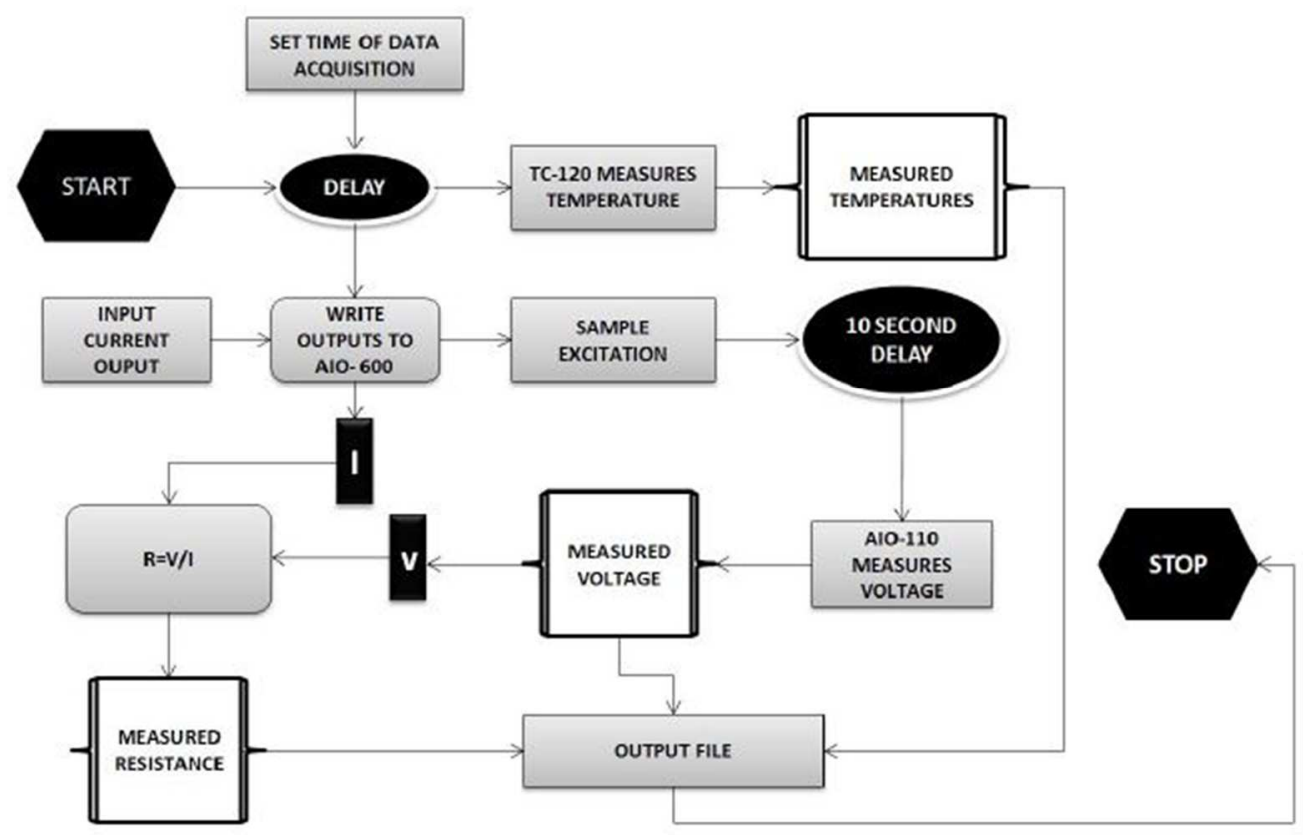

Figure 2-9: Flowchart of operation for the compact field point sensor system [19]

\subsubsection{Previous Studies}

The design and manufacturing of the sensors for experimental evaluation were conducted in laboratory environment. To measure the conductivity of the cement paste as a function of age using conductivity $\left(\sigma_{t}\right)$ sensor embedded inside cylindrical specimens (22 $\mathrm{mm}$ diameter and $50 \mathrm{~mm}$ height), stainless steel electrodes were embedded longitudinally inside cylindrical plastic mold. The insertion was made before the casting of the cement paste as shown in Figure 2-10. 


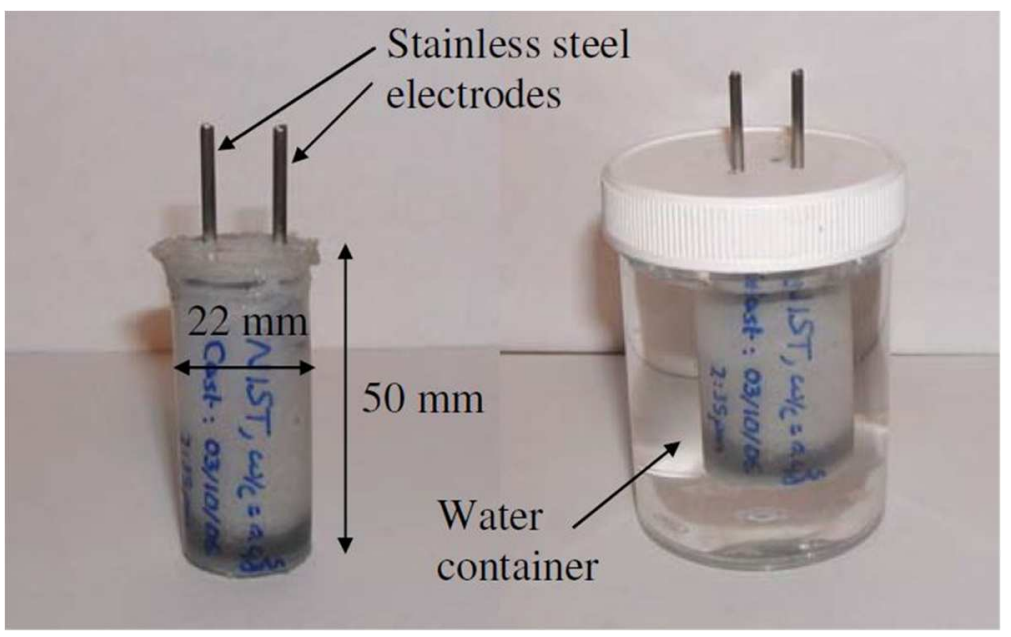

Figure 2-10: Setup for the measurement of the conductivity of cement paste [20]

Solarton 1260 Impedance Gain-Phase analyzer was used to measure the bulk resistance. An AC stimulus was applied to the specimen over the frequency range of 10 MHz to $1 \mathrm{~Hz}$ with 10 steps/frequency decade. The conductivity $\left(\sigma_{t}\right)$ was obtained from the measurement of bulk resistance $\left(\mathrm{R}_{\mathrm{b}}\right)$ and geometry factor $(\mathrm{k})$ [20]. The relative humidity (RH) sensor was composed of a siltstone specimen. This specimen was actually cut to an $8 \times 5 \times 2 \mathrm{~mm}$ prism using an Isomet low speed saw. Then, a pair of stainless steel terminals were attached to each prism (on the opposing $5 \times 2 \mathrm{~mm}$ faces) using conductive silver epoxy [20]. The conductivity of the silver epoxy was maintained $3.3 \times 105 \mathrm{~S} / \mathrm{m}$ which was commercially manufactured by Resin Technology Group. Finally, the terminals were further covered with a waterproof marine epoxy. Stranded tinned-copper wires (20 AWG) were used to complete the connections [20]. A schematic diagram of the relative humidity sensor is shown in Figure 2-11. 


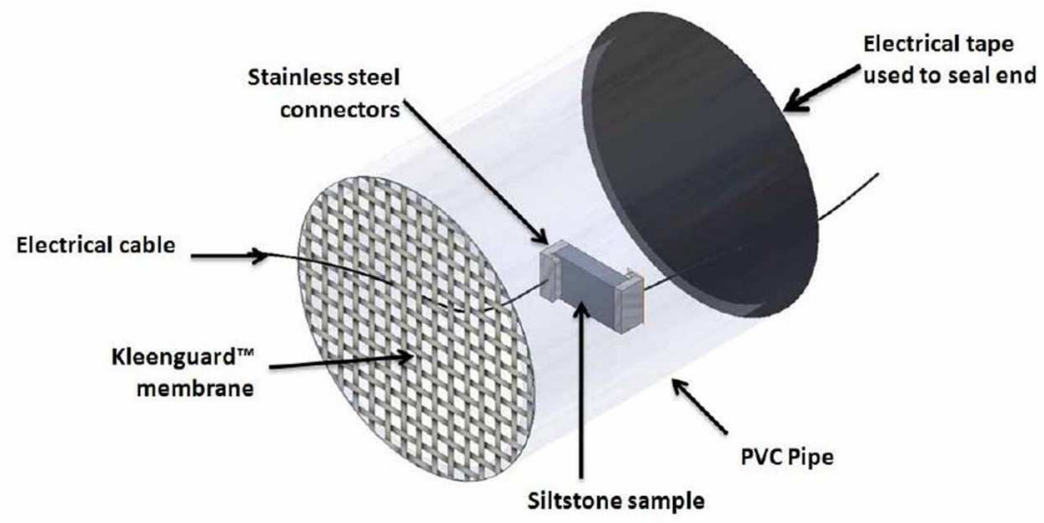

Figure 2-11: Schematic diagram of relative humidity $(R H)$ sensor [19]

In preparing the conductivity sensor, siltstone was cut to $8 \times 8 \times 2 \mathrm{~mm}$ prisms. Then, a pair of steel electrodes were glued to the centers of the opposing $8 \times 8 \mathrm{~mm}$ faces using the conductive silver epoxy and all the wires for connection were attached to the electrodes by using silver epoxy. Waterproof marine epoxy was used as connections coating to prevent rusting and to make the sensor impermeable against the flow of electricity through the surrounding concrete [20]. A schematic diagram of solution conductivity sensor is shown in Figure 2-12.

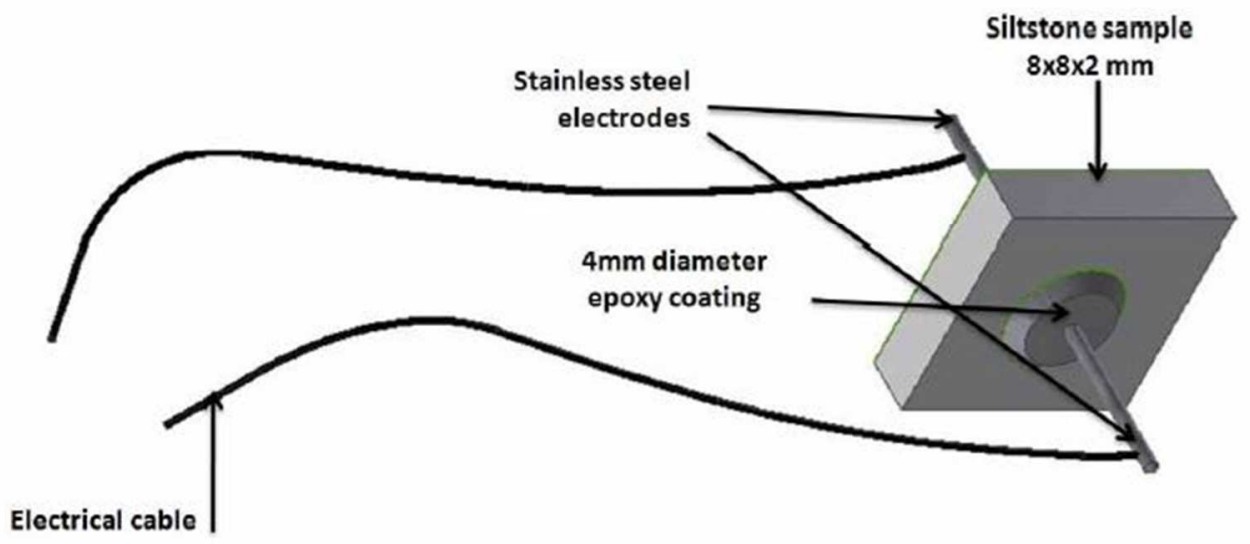

Figure 2-12: Schematic diagram of solution conductivity sensor [19] 
Both the resistivity and the conductivity sensors were embedded in cement paste specimen in laboratory environment to evaluate their performance. With a water/cement ratio of 0.3 and in accordance with ASTM C305, prism paste specimen (50x50x20 mm) were prepared using plastic molds and each sensor was positioned inside approximately at the center of the plastic mold [20]. Cement paste were poured around the sensors and after pouring plastic molds sealed immediately to prevent any drying of initial 48 hours of hydration as shown in Figure 2-13.

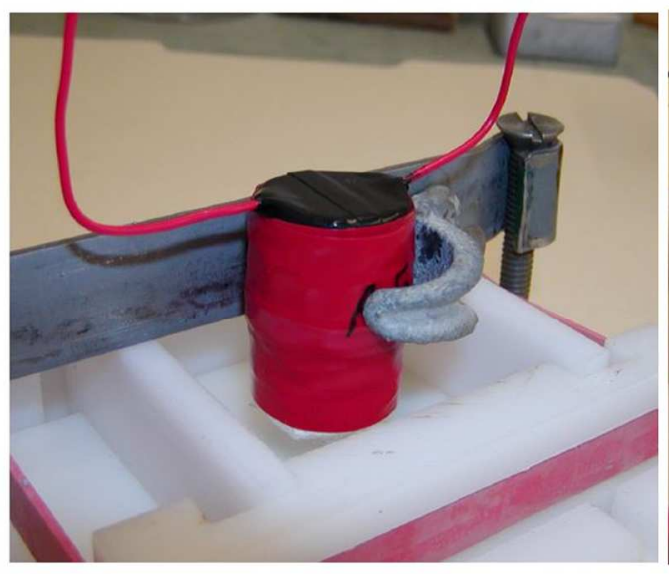

(a)

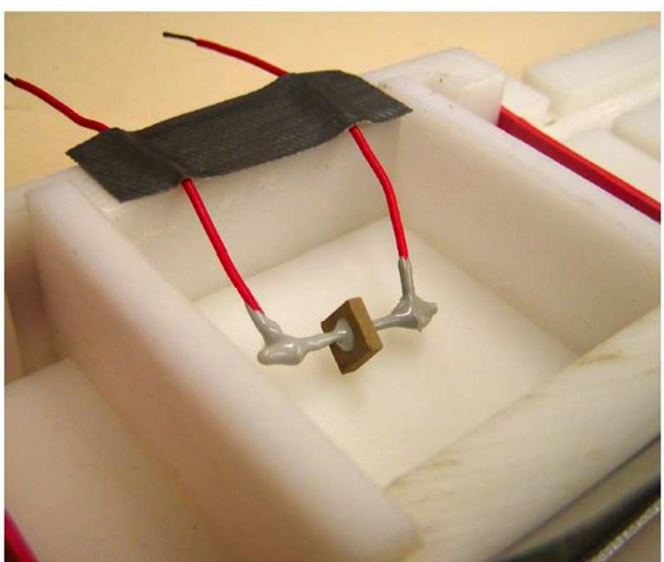

(b)

Figure 2-13: Sensors positioned inside plastic molds before the placement of cement paste; (a) relative humidity sensor (b) pore solution conductivity sensor [20]

\subsubsection{Commercial Products}

This sensing system is not commercially available although there are few concrete resistivity meter products commercially available.

\subsubsection{Product 3: Embedded Corrosion Instrument Sensor}

\subsubsection{Overview}

The Embeddable Corrosion Instrument (ECi) sensor is a commercially available corrosion sensor produced by Virginia Technologies Inc. Each sensor contains a chloride 
threshold indicator, a temperature sensor, conductivity and resistivity sensor, a polarization resistance sensor, and an open-circuit potential sensor. ECi sensors transmit their readings to a datalogger via digital signals, rather than analog wave-forms, which facilitates the coverage of a far larger area by each datalogger which minimizes the cost of supporting electronics and can be downloaded remotely, and integrable into computerized management systems. A model and brief overview of the typical ECi device is shown in Figure 2-14 and Table 2-3, respectively.

Table 2-3: Brief overview of embedded corrosion instrument sensor

\begin{tabular}{|c|c|}
\hline \multicolumn{2}{|r|}{ Embedded Corrosion Instrument Sensor } \\
\hline Categories & $\begin{array}{l}\text { Local, embeddable, wireless(battery-based), datalogger based, } \\
\text { sacrificial corrosion sensor }\end{array}$ \\
\hline Pros & $\begin{array}{l}\text { - Wireless } \\
\text { - } \text { Puard data against electro-magnetic interference } \\
\text { instrumentosure gives moisture and chemical protection to the } \\
\text { - Measures several different corrosion-related parameters } \\
\text { including: chloride threshold indicator, a temperature sensor, } \\
\text { conductivity and resistivity sensor, a polarization resistance } \\
\text { sensor, and an open-circuit potential sensor }\end{array}$ \\
\hline Cons & $\begin{array}{l}\text { - The datalogger is powered either by local electrical power lines } \\
\text { or optionally a battery that is recharged by a solar collector } \\
\text { - To mimic same environmental and corrosion condition of the } \\
\text { steel reinforcement, device orientation needs to be placing the } \\
\text { electrodes facing the bridge at the level of the top reinforcement } \\
\text { steel }\end{array}$ \\
\hline Other Details & $\begin{array}{l}\text { Typical use is to monitor the corrosion of reinforcement steel in } \\
\text { concrete bridge deck } \\
\text { - Can monitor moisture content and temperature of the structure } \\
\text { during the curing process (ensure maximum strength of the } \\
\text { concrete). Once the data and instrument locations have been } \\
\text { collected it can be processed to form a "corrosion map" of the } \\
\text { structure }\end{array}$ \\
\hline Manufacturer & Virginia Technologies, Inc. \\
\hline References & $\begin{array}{l}\text { Virginia Technologies, Inc. website [22] } \\
\text { Reis \& Gallaher [23] }\end{array}$ \\
\hline
\end{tabular}




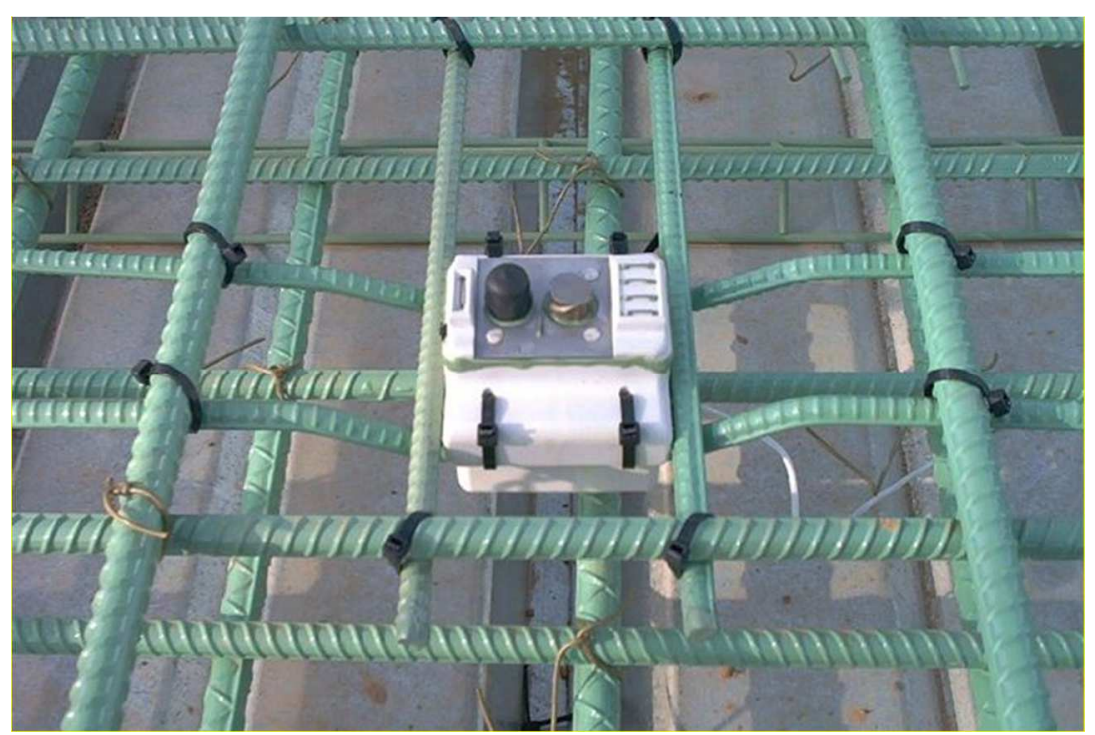

Figure 2-14: Model of ECi-2 Embedded Corrosion Instrument [22]

\subsubsection{Theory/Mechanism}

ECi-2 device measures linear polarization resistance by using a steel working electrode, stainless steel as counter electrode, and manganese dioxide as reference electrode. The working electrode which is made of black steel corrodes at the same rate as the ASTM 615/A-compliant steel. Defective areas in protective coatings over structural steel, which in such case is an epoxy or stainless-steel cladding, are expected to mimic the corrosion characteristics. To measure the open circuit potential (OCP) between the working and reference electrodes in the potentiostat circuit, ECi-2 applies the appropriate potentiostat drive potential between the counter and working electrodes. A zero-resistance ammeter in the potentiostat circuit measures the cell current, and the device scans cell current and drive potential over a range about the OCP to calculate polarization resistance. When LPR is high and OCP remains small in magnitude, the reinforcement steel in any structure is considered as passive represents suffering a low rate of corrosion. As the depassivation of steel initiates due to an increased concentration of chloride ion or other 
corrosive environmental conditions, LPR value will decrease and OCP value will become increasingly negative. To monitor corrosion in concrete, a galvanostat circuit is used, which drives current through the outer pair of electrodes, and compare the potential measurements between the inner pair at each step. This comparison provides information of the relative amount of moisture in concrete. The ECi-2 device uses a silver $(\mathrm{Ag}) /$ silver-chloride $(\mathrm{AgCl})$ ion specific electrode in combination with its reference electrode to measure chloride ion concentration. With time, a potential difference develops between $\mathrm{Ag} / \mathrm{AgCl}$ electrode and a reference electrode, and the magnitude of this potential is related to the chloride ion concentration that surrounds the instrument. Once the data of linear polarization resistance (LPR), open circuit potential (OCP), resistivity, chloride ion concentration, and temperature are known along with instrument locations, it can be processed to generate a "corrosion map" of the structure as shown in Figure 2-15.
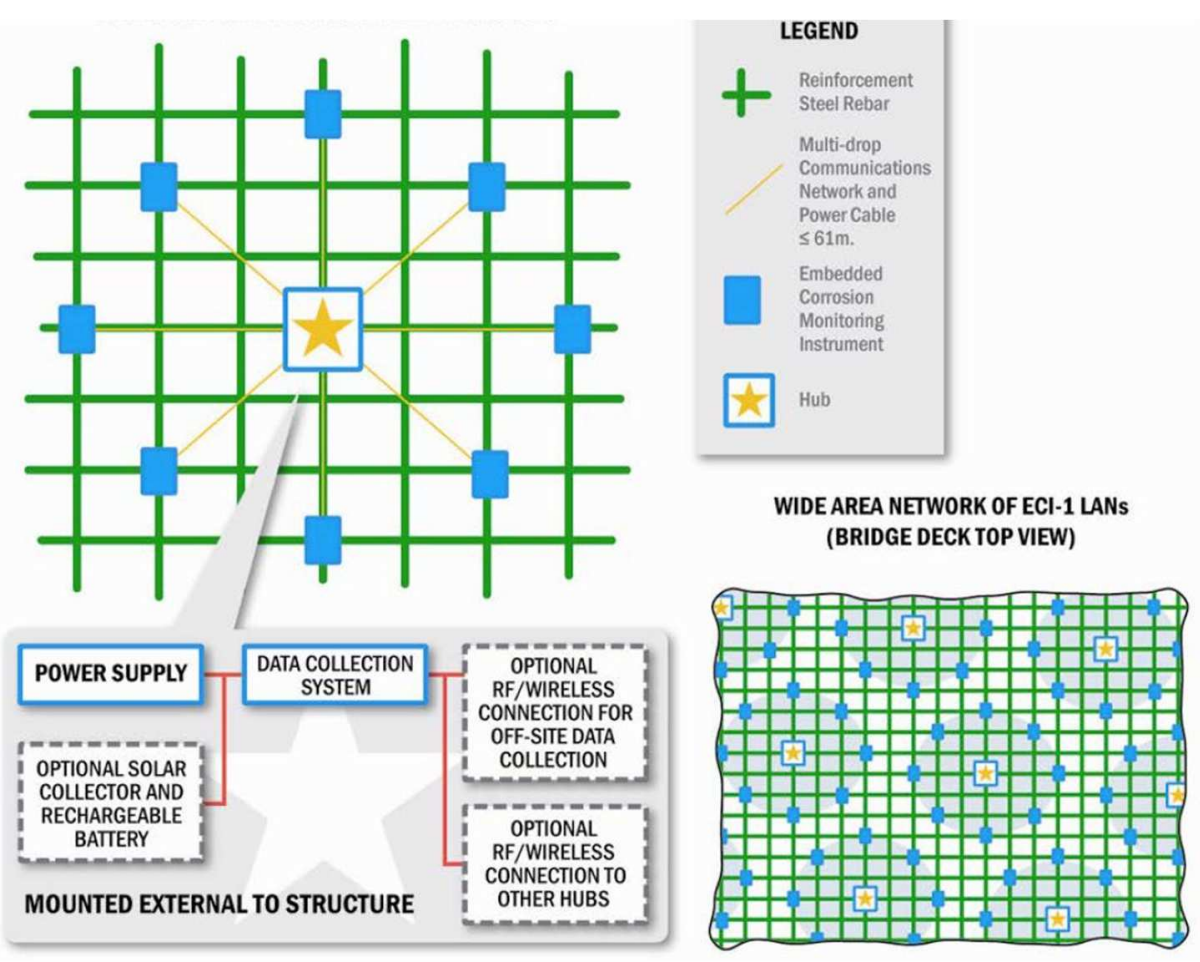

Figure 2-15: Local area network plan of embedded corrosion instrument (ECi) [22] 


\subsubsection{Previous Studies}

California Department of Transportation (Caltrans) used embedded corrosion instrument devices in a bridge deck located in Northern California in addition to laboratory study. The bridge deck was subjected to deicing salt applications during winter snow periods and ECI-1 devices were used to evaluate the long-term ( 10 to 12-years) performance [23]. The objective of this research was to monitor the device in a cementbased matrix to evaluate the effectiveness of the ECI-1 device to measure the corrosion activity in terms of sensor parameters such as chloride sensing, concrete resistivity measurement, and linear polarization measurement capability and also evaluate the performance of the device into a bridge deck during a deck reconstruction project.

For laboratory testing, four ECI-1 devices were evaluated in the laboratory. All the devices were cast into mortar using forms fabricated and then these forms were used to construct and provided stable platforms with additional electrodes for the evaluation. PVC forms were mainly used prior to placing of workable mortar mix so that the mortar mix could be placed into the molds and consolidated with minimal vibration using a vibration table and three lifts of mortar. All four ECI devices were placed into the molds to provide a mortar cover of approximately $25 \mathrm{~mm}$ over the working electrode as shown in Figure $2-16$. 


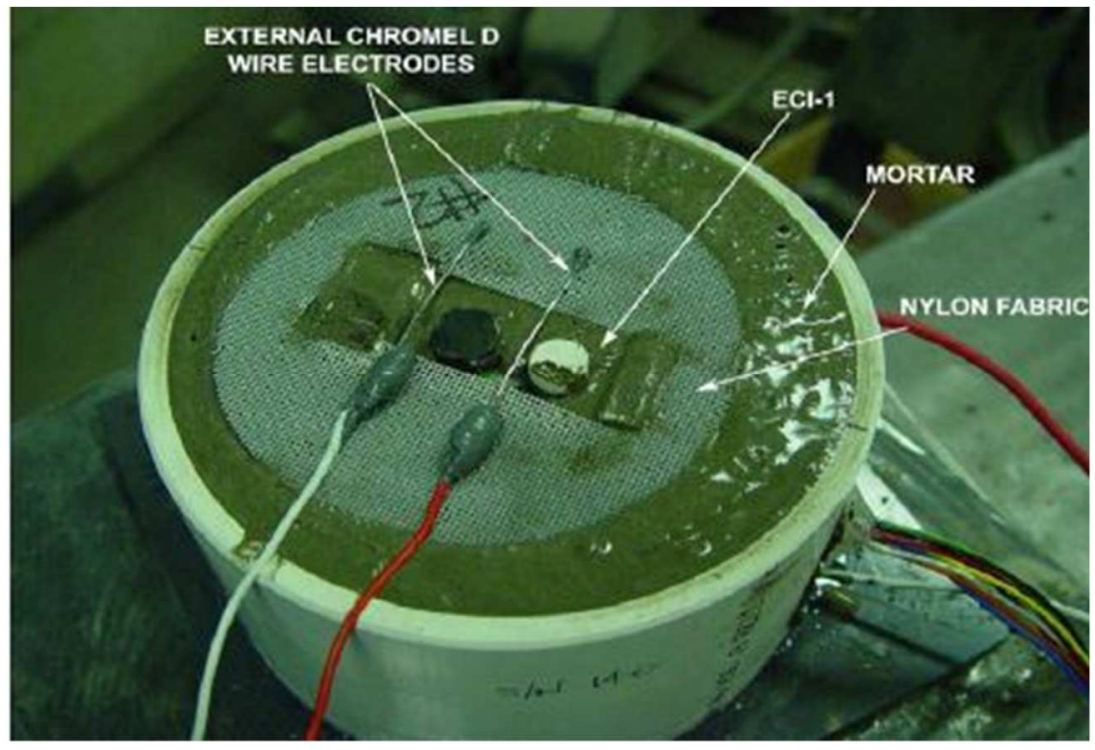

Figure 2-16: Mortar mix inside ECi device [23]

To evaluate the ability of the ECI-1 devices, chlorides were artificially drawn into the mortar matrix using the external power supply. This test used to detect changes in the mortar as chloride concentrations increased over time as shown in Figure 2-17. Chloride ions added into the mortar mix from a $3.5 \%$ by mass sodium chloride solution held in the reservoir at the top of the sample mold. The power supply potential was set at 20 Volts, and applied for an initial 12-hour cycle. Electrochemical corrosion measurements were obtained after a rest period of a minimum of 48-hours. This sequence was repeated once, and then with a continued 48-hour minimum rest periods between electrochemical measurements the power cycle increments were decreased to 6-hours. The 6-hour power cycles were continued with 48- hour minimum rest cycles prior to performing electrochemical tests. This was continued until the corrosion current density of each sample approached $10 \mu \mathrm{A} / \mathrm{cm} 2$ which was based on specification provided by the manufacturer with a surface area of $6.967 \mathrm{~cm}^{2}$ [23]. 


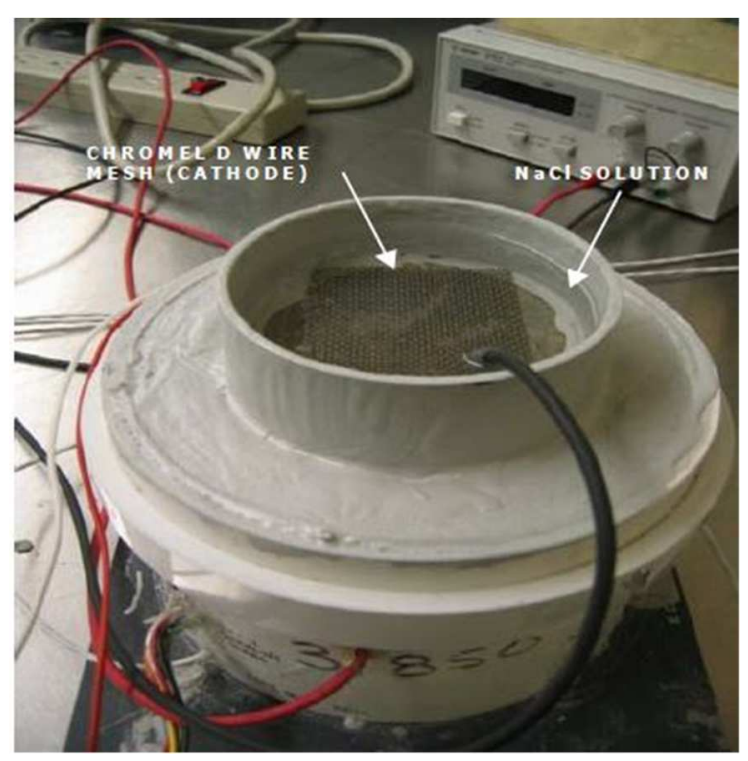

Figure 2-17: Ponding of $\mathrm{NaCl}$ solution [23]

When a corrosion current approached $10 \mu \mathrm{A} / \mathrm{cm}^{2}$ in a sample, testing was terminated, and the sample was sectioned to observe and document the condition of the working electrode, and to information regarding the chloride concentration of the mortar adjacent to the working electrode.

To evaluate the long-term ( 10-years) performance of the ECI devices in actual concrete, four ECI-1 devices were installed in a replacement bridge deck on The Sacramento River Bridge as shown in Figure 2-18. The selection of this bridge was important because the deck was subjected to deicing salt applications during winter snow periods and the entire bridge was scheduled for replacement within 10 to 12 years as it was severely deteriorated due to corrosion (spalling) and cracking. For long-term installations, ECI-1 devices were collecting data no more than once every 2 weeks to minimize damage to the working electrode that could occur due to repeated LPR measurements. For the Antlers bridge deck installation, three of the ECI-1 devices were installed to collect data 
twice a month because only the resistivity and temperature measurements were necessary [23].

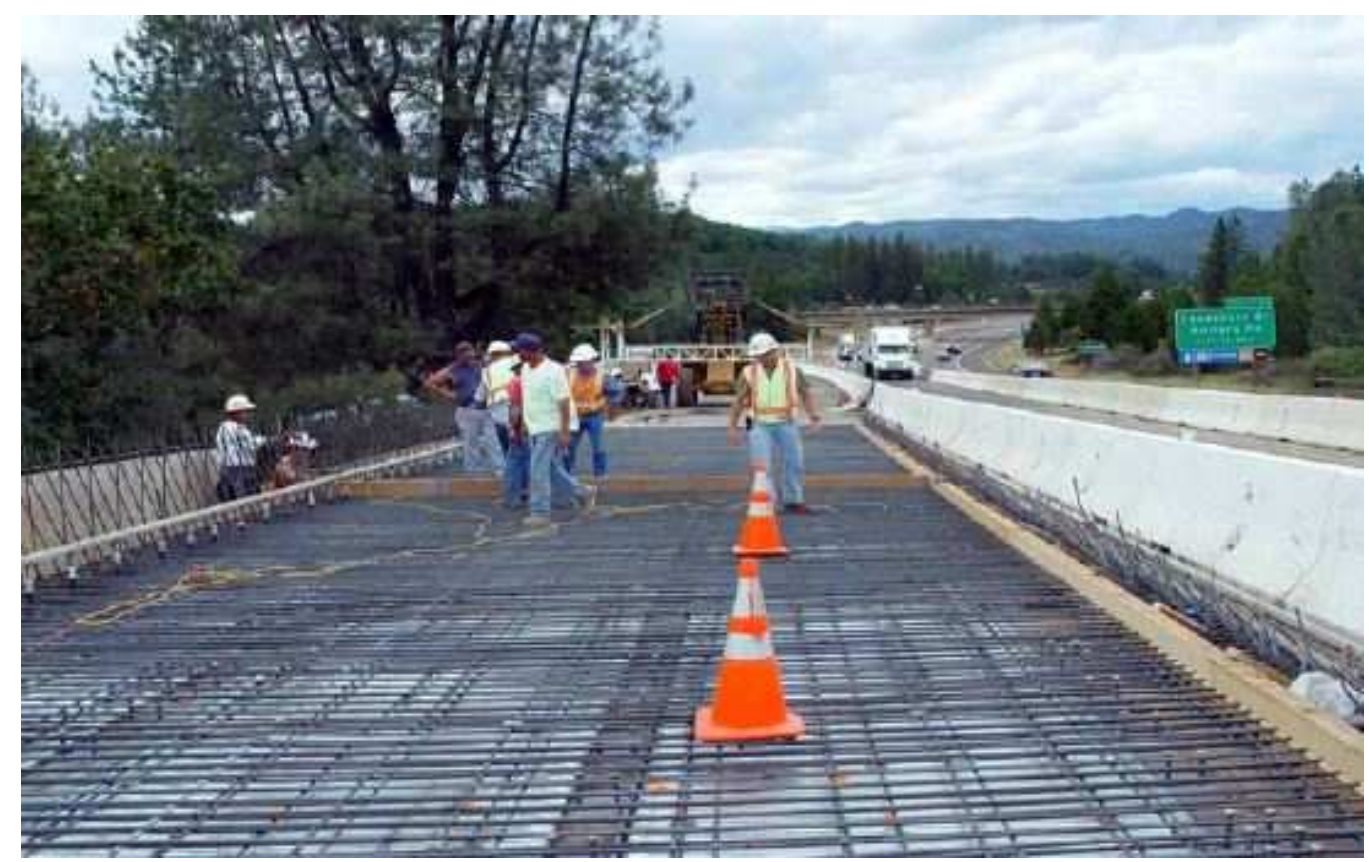

Figure 2-18: Placement of ECI-1 units prior to concrete placement [23]

\subsubsection{Commercial Products}

The Embedded Corrosion Instrument is a product line from Virginia Technologies, Inc. The instrument consists of the ECi-2 corrosion monitor and NetCon-10 interface module.

\subsubsection{Product 4: Nagel-System Senor (Embedded Corrosion Front Probes) \\ 2.4.4.1. Overview}

The Nagel-System sensor is an embeddable, wired sensor that measures several basic corrosion parameters. The sensor is consisted of four black steel anodes, one noble metal cathode, one reinforcement connection and an internal temperature sensor. A brief overview of embeddable corrosion front probe in described in Table 2-4. 
Table 2-4: Brief overview of Nagel-System sensor

\begin{tabular}{|c|c|}
\hline \multicolumn{2}{|r|}{ Nagel-System Sensor (Embedded Corrosion Front Probes) } \\
\hline Categories & Local, embeddable, wired, datalogger based communication system \\
\hline Pros & $\begin{array}{l}\text { - Monitor chloride ingress in marine concrete structures } \\
\text { - Provide possible prediction of reinforcement corrosion by } \\
\text { measuring depth wise reading of concrete structures } \\
\text { - The height of anode is flexible and can be adjusted according to } \\
\text { concrete cover thickness } \\
\text { - Datalogger system can be made automatic }\end{array}$ \\
\hline Cons & $\begin{array}{l}\text { - Erroneous reading may be obtained under drying or saturated } \\
\text { conditions of concrete (concrete resistance taking control in } \\
\text { macrocell corrosion) } \\
\text { - Installation position is only recommended between the concrete } \\
\text { surface and the outer reinforcement layer } \\
\text { - Sensor functionality may get interrupted if mounting position of } \\
\text { the probe changes during casting } \\
\text { - Wired gages } \\
\text { - Stable base, no metal contact with anodes and cathodes and no } \\
\text { cable damage during concrete cast are highly recommended for } \\
\text { reliable reading }\end{array}$ \\
\hline Other Details & $\begin{array}{l}\text { - Use both options of measuring corrosion current and } \\
\text { electrochemical potentials against a stable reference electrode } \\
\text { - Other potential applications are tunnels, pillars in sea water, } \\
\text { desalination plants and seaport }\end{array}$ \\
\hline Manufacturer & Germann Instruments \\
\hline References & $\begin{array}{l}\text { Xu, et al. [24] } \\
\text { Germann instruments website [25] } \\
\text { Papworths Construction testing equipment website [26] }\end{array}$ \\
\hline
\end{tabular}

The anodes are placed in a varying joint ring with flexible height to adjust the distance from the exposed concrete surface according to the specification of concrete cover thickness. The cathode is placed in the ring's periphery as shown in Figure 2-19. 


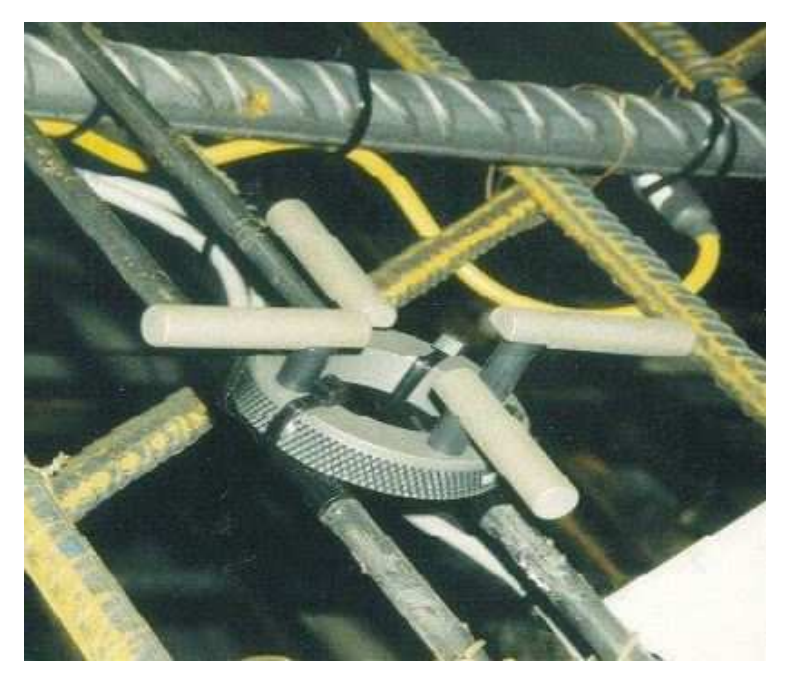

Figure 2-19: Nagel-system sensor [24]

To ensure the data accuracy of the probe sensor, it needs to be installed between concrete cover surface and the outer reinforcement layer. Also, great care needs to be taken so that the position of the probe does not change during casting period. The sensor probe measures the corrosion current either with a volt-meter or with a specially designed data logger. Additionally, an ERE-probe which acts as a reference-electrode is joined and conducted to the concrete surface for monitoring the potentials of the four black steel anodes, as shown in Figure 2-20.

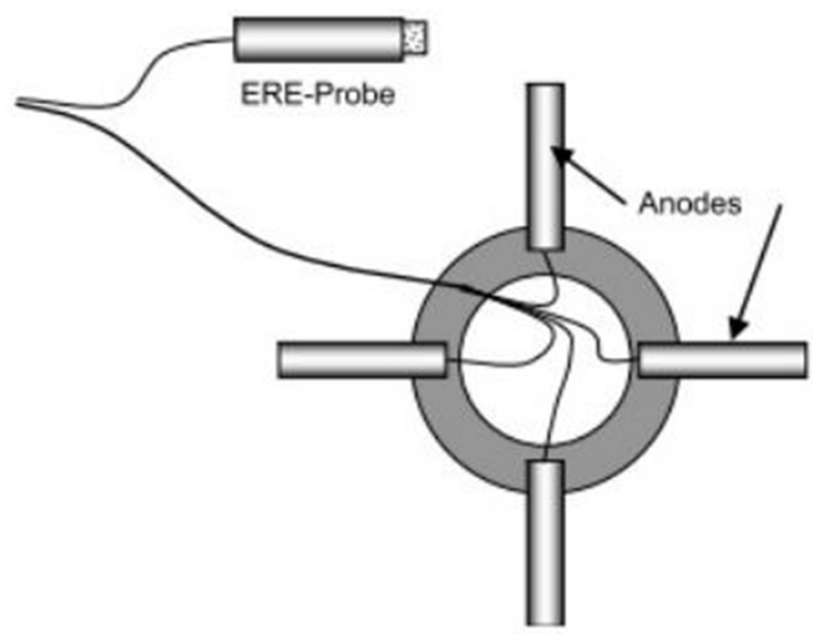

Figure 2-20: Wired ERE-probe with embeddable Nagel-system corrosion probe [25] 


\subsubsection{Theory/Mechanism}

The Nagel-System sensor acts as a macrocell to measure the corrosion activity between the anodic and cathodic metal surface. By measuring the corrosion current and electrochemical potential, this probe sensor can take measurements in different sensor depths in the concrete. From the measurements, it can predict the time to reach the corrosion to the reinforcement and allow to take necessary measures before considerable damage occurs [26]. To predict the reinforcement corrosion this probe sensor takes the electrochemical potential measurements against stable reference electrode. The current could be measured either with a volt-meter or designed data-logger as shown in Figure $2-21$.

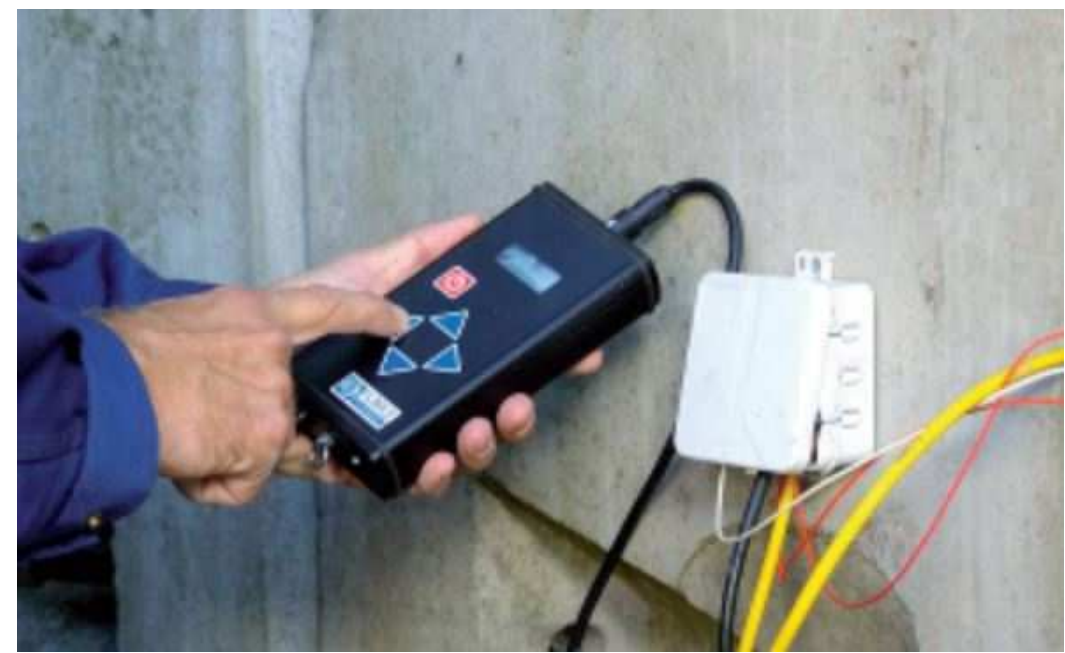

Figure 2-21: Data logging system to measure corrosion current [26]

As the corrosion starts, the current starts to increase significantly [26]. The mechanism works with the use of zero resistance ammeter technique. In the beginning, corrosion occurs on the anode as the measured corrosion current is significantly small but when the passive layer is broken due to corrosion, the measured corrosion current increases 
very rapidly. In terms of measuring the ingress of the depassivation front, the probe sensor takes measurements as shown in Figure 2-22.

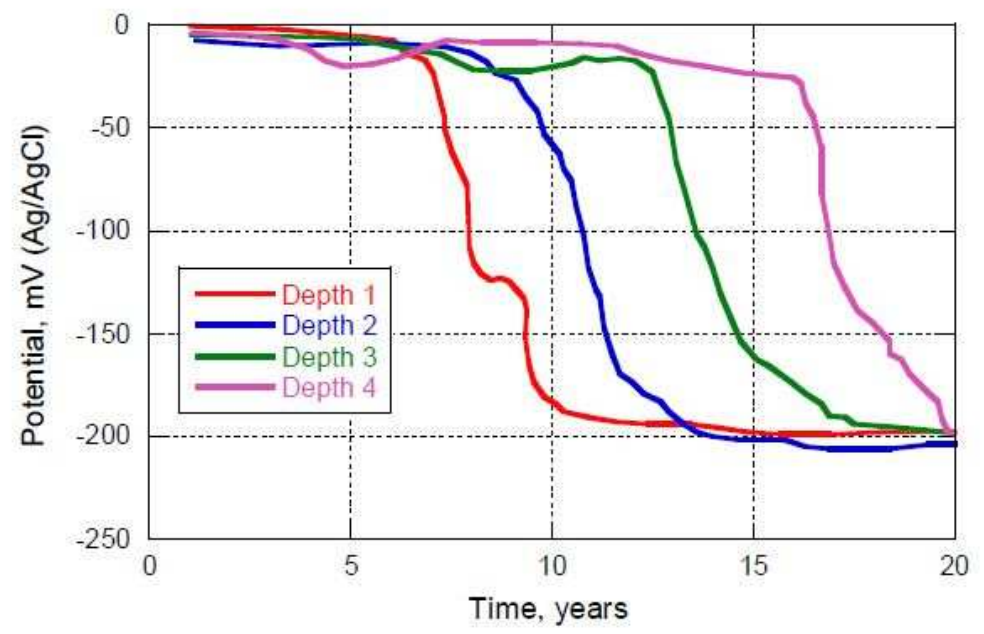

Figure 2-22: Measuring advancement of the depassivation front using Nagel-System sensor [25]

The data logging system is designed with chloride monitoring probe systems and measures half-cell potential, corrosion current and temperature. The unit can be used manually or automated. It is important to note that, depassivation of anodes at different depths is measured according to macrocell corrosion principle in electrochemistry. The macrocell corrosion appears into existence when the distance between passivation area and active area is relatively large during the corrosion of anodes [24]. Theoretically, if the resistance of the reinforcement body in the passivation area (cathode) is $R_{t}$, the resistance of reinforcement in the active area (anode) is $R_{s}$, as shown in Figure 2-23. 

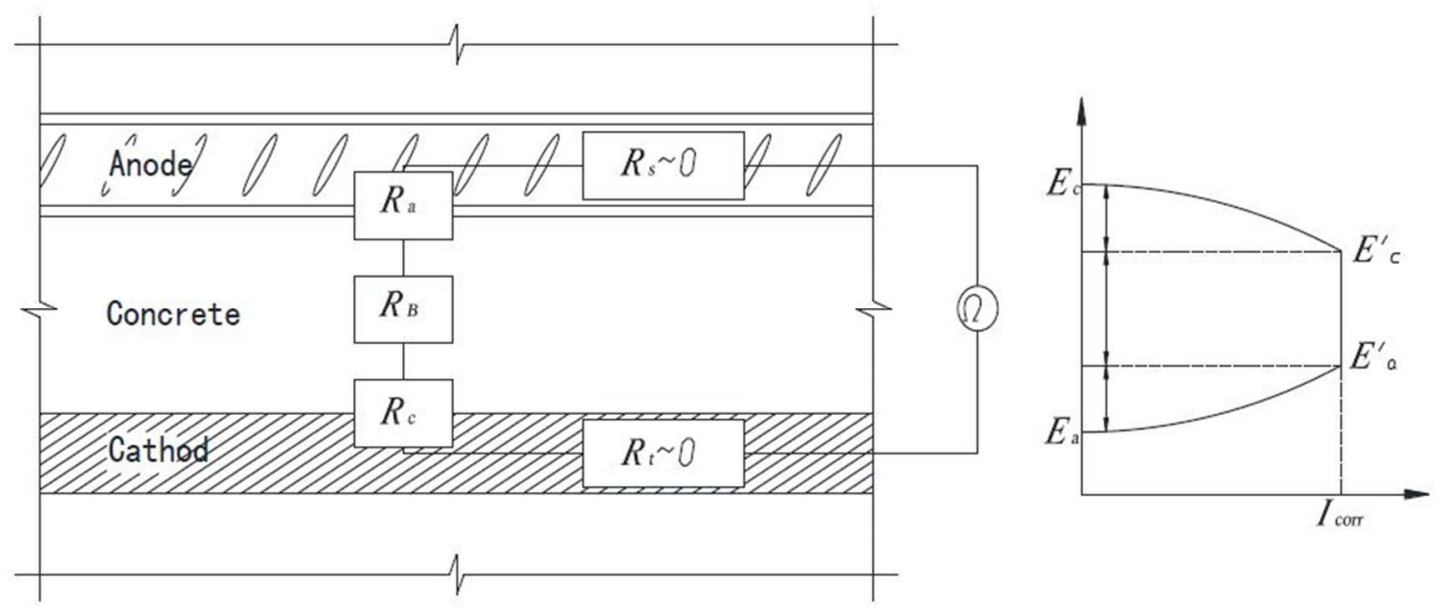

Figure 2-23: Equivalent circuit for corrosion in closed circuit condition [24]

\subsubsection{Previous Studies}

To date, the major application of this probe sensor took place in Øresund Tunnel where 189 sensors were installed in nine tunnel elements to detect corrosion in concrete covers and a warning system on the early onset of reinforcement corrosion as shown in Figure 2-24. Additionally, several medium size highway bridges in Denmark used this probe sensors. In Finland, this probe system was installed in the TVO nuclear power plant to monitor the corrosion in the cooling water channels. 


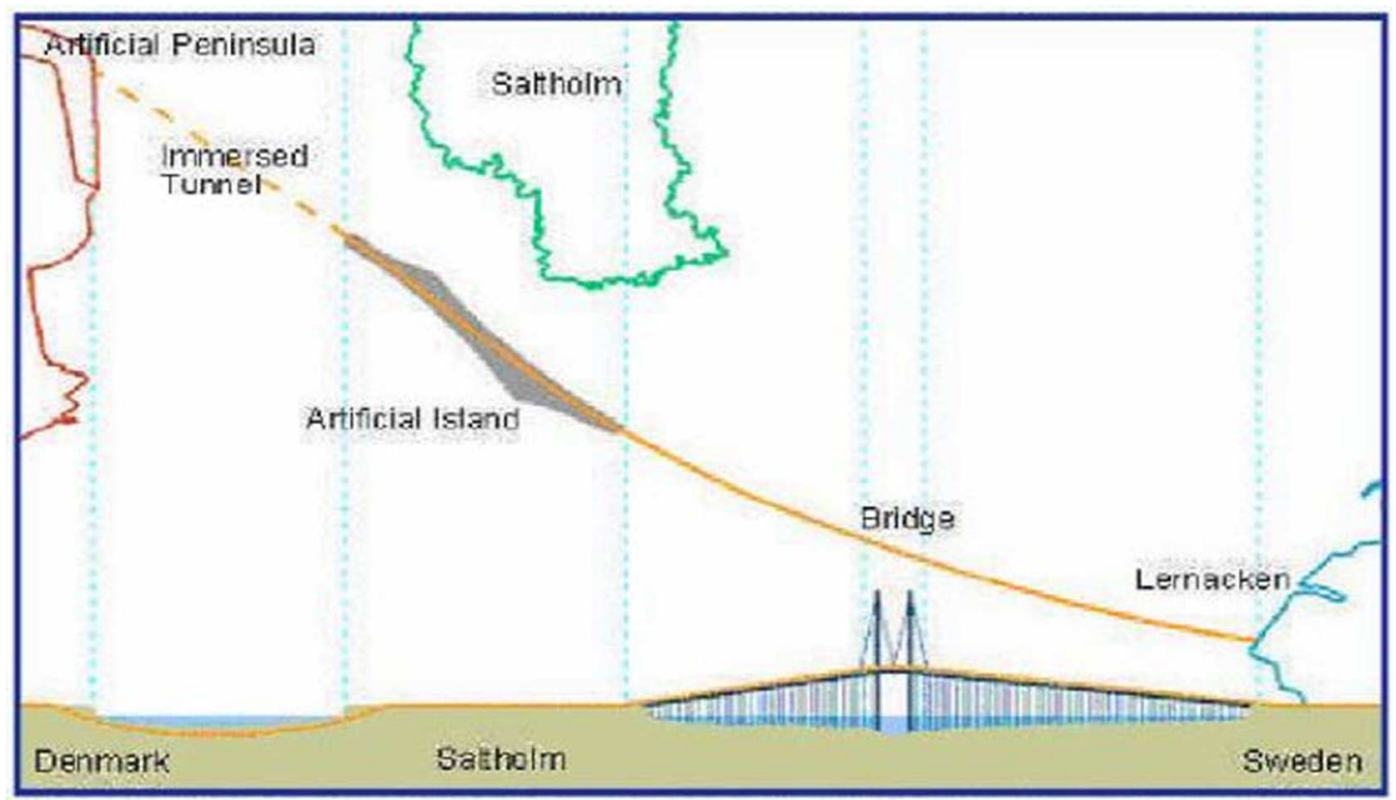

Figure 2-24: Øresund Tunnel instrumented with Nagel-System sensor [26]

\subsubsection{Commercial Products}

CorroWatch is the currently available commercial product developed by Germann Instruments. The three product lines are - (i) CorroWatch with 3-meter cables (CW-3), (ii) CorroWatch with 5-meter cables (CW-5), and (iii) CorroWatch with 10-meter cables (CW10).

\subsubsection{Product 5: Micro-Linear Polarization Resistance Corrosion Sensors}

\subsubsection{Overview}

Micro-linear polarization resistance corrosion sensors can provide direct real-time measurements of electrochemical activity in bridges, buildings, pipelines, ships, ground vehicles and aircraft. These sensors utilize linear polarization resistance (LPR) technology and show output of identical corrosion rate for metallic structures on which they are placed. Each micro linear polarization resistance sensor network consists of data acquisition (DAQ) nodes which can support a combination of up to 8 sensors that provide 
measurements of corrosion, time-of-wetness (TOW), and salinity measurements as well as temperature, and humidity as shown in Figure 2-25:Four micro linear polarization resistance ( $\mu \mathrm{LPR})$ sensor with one node (left) and the close-up image of $\mu \mathrm{LPR}$ sensor (right)Figure 2-25 and Table 2-5.
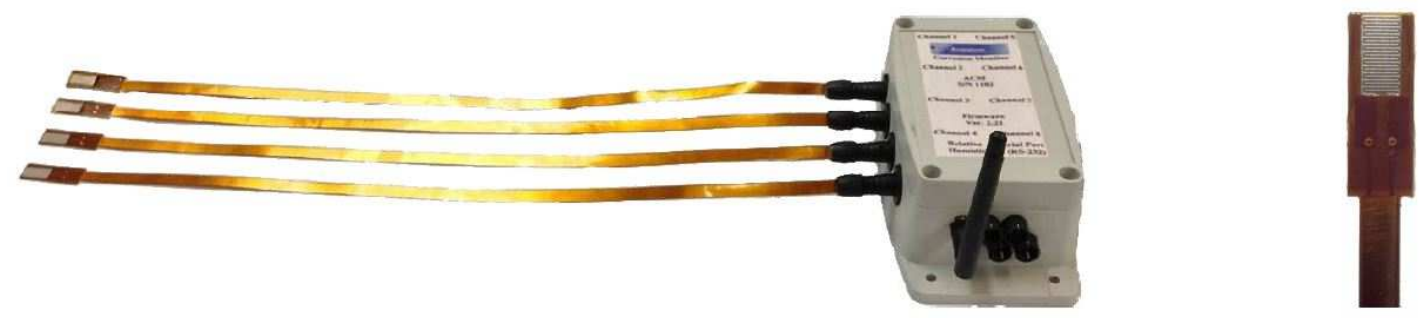

Figure 2-25:Four micro linear polarization resistance ( $\mu L P R)$ sensor with one node (left) and the close-up image of $\mu L P R$ sensor (right) [27]

Table 2-5: Brief overview of micro-linear polarization resistance Corrosion Sensor

\begin{tabular}{|c|c|}
\hline \multicolumn{2}{|r|}{ Micro-linear polarization resistance Corrosion Sensor } \\
\hline Categories & $\begin{array}{l}\text { Local, non-embeddable, wired, nodal monitoring unit based } \\
\text { communication system }\end{array}$ \\
\hline Pros & $\begin{array}{l}\text { - Direct corrosion measurement and fast measurement response } \\
\text { time } \\
\text { - Use established linear polarization resistance (LPR) technology } \\
\text { - Sensors output can detect corrosion rate for the metallic } \\
\text { structure on which they are placed DAQ unit can support any } \\
\text { combination of up to } 8 \text { sensors } \\
\text { - Provides simultaneous measurement of corrosion, time-of- } \\
\text { wetness (TOW), salinity measurements, temperature and } \\
\text { humidity }\end{array}$ \\
\hline Cons & $\begin{array}{ll}\text { - } & \text { Battery or external power source required } \\
\text { - } & \text { Battery life approximately } 7 \text { years } \\
\text { - } & \text { Extensive corrosion damages sensor functionality } \\
\text { - } & \text { Wired sensor } \\
& \text { Non-embeddable } \\
\end{array}$ \\
\hline Other Details & $\begin{array}{l}\text { - Open circuit potential of these sensor uses two operational } \\
\text { amplifiers. The voltage input (ranges from } 0 \text { to } 1.5 \mathrm{~V} \text { ) to the } \\
\text { sensor circuit is provided by the analog-to-digital converter of } \\
\text { the micro-controller and the output voltage is proportional to } \\
\text { the current through the sensor. } \\
\text { - The slope of the input voltage versus output voltage curve is } \\
\text { proportional to the polarization resistance and the polarization }\end{array}$ \\
\hline
\end{tabular}




\begin{tabular}{|c|l|}
\hline \multicolumn{2}{|c|}{ Micro-linear polarization resistance Corrosion Sensor } \\
\hline \hline \multirow{5}{*}{ Manufacturer } & \multicolumn{1}{|c|}{$\begin{array}{c}\text { data collected from the sensor are converted into corrosion rate } \\
\text { values. }\end{array}$} \\
\hline & Analatom, Inc. \\
\hline & $\begin{array}{l}\text { Analatom, Inc. website [27] } \\
\text { Jones, D. [28] }\end{array}$ \\
Feliu, et al. [29] \\
Broomfield, et al. [30] \\
Broomfield, J. [31] \\
Betti, et al. [32]
\end{tabular}

\subsubsection{Theory/Mechanism}

According to ACI 222R-2010, linear polarization resistance (LPR) for reinforcement steel is considered most reliable method for estimating corrosion rate [33]. Theoretically, corrosion rate represents the amount of steel dissolving in the anode [28]. The measurement of electric current at the anode which is basically the rate of electron production helps to calculate the mass loss using Faraday's law of metal loss. Stern and Geary LPR technique is used to determine instantaneous corrosion rate in situations of galvanic corrosion.

The instrumentational arrangement of LPR is sophisticated as it consists of reference electrode, auxiliary electrode and a low voltage Dc current supply. The potential change is measured using the reference electrode and the current increment can be measured monotonically until the corrosion potential changes by $\pm 25 \mathrm{mV}$ [28]. The timeof-wetness (TOW) and salinity is measured by using the resistance (or conductivity) measured between the two interdigitated LPR electrodes. Technically, the TOW is defined as the amount of time elapsed when the relative humidity is at least $80 \%$. The data is collected using a calibrated environmental temperature / humidity chamber and time of 
wetness (TOW) is determined by setting a threshold value for the resistance corresponding to the point at which the relative humidity is at least $80 \%$. Once data is received, the time of wetness is computed as the amount of time the resistance was recorded below the threshold. Based on temperature threshold and calibration data, the threshold value varies between 7MW to 9MW [27]. For field applications, the relative humidity will approach $100 \%$, or saturation, when water is present between the electrodes of the device [27]. To measure the salinity, the average resistance measured between the interdigitated electrodes is computed along with the standard deviation and plotted in a log plot as resistance vs. salinity.

\subsubsection{Previous Studies}

In 2014, Columbia University performed a research project on "Corrosion Monitoring Research for City of New York Bridges" to develop an integrated methodology that used a smart sensor system integrated with NDE technologies, including the Analatom LPR sensor. A series of sensing technologies measuring different parameters were used to indirectly quantify the corrosion rate. These technologies included Precon HW2000V temperature and relative humidity sensors, coupled multi-electrode corrosion sensors, and Analatom LPR sensor. Previous studies had shown the LPR sensor to become damaged with prolonged exposure in harsh conditions, so the purpose of this experiment was to evaluate the functionality the sensors and determine the reason for their malfunctioning [32]. For the data analysis, eight LPR sensors were placed in the cable cross section. The study results showed that two LPR sensors out of eight were able to provide consistent data beyond noise level threshold. The protective casing of these LPR sensors were remained 
intact and the sensor probe did not appear to be damaged or corroded as shown in Figure $2-26$.

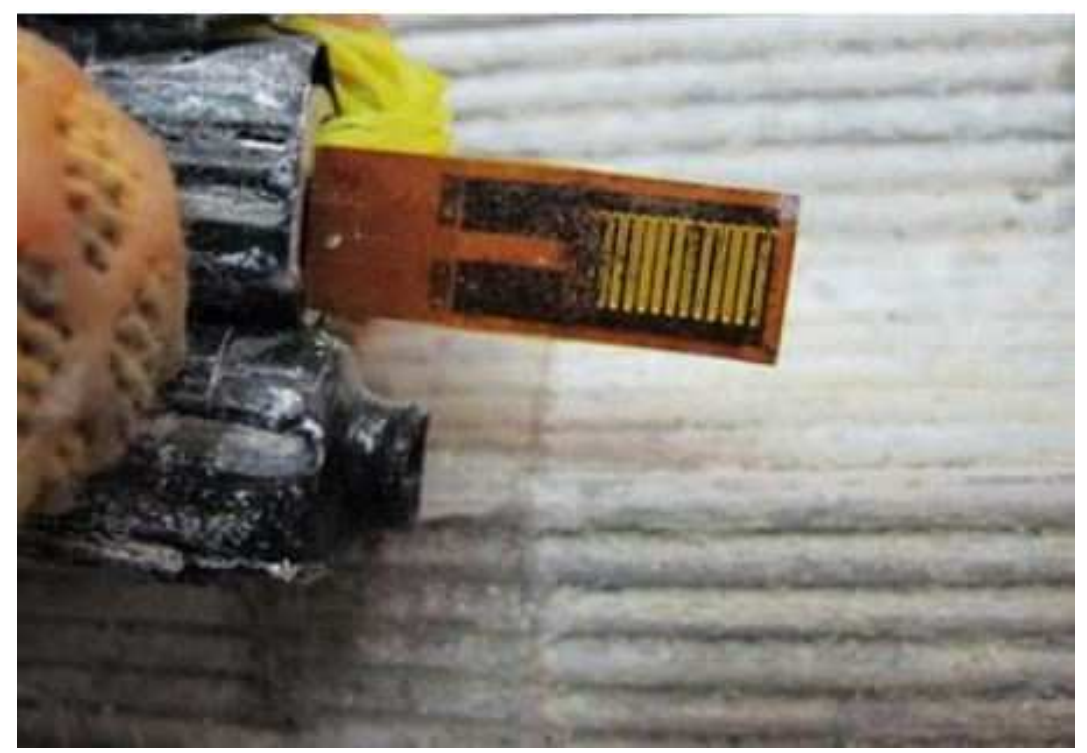

Figure 2-26: Close-up view of good LPR sensors after dissection [27]

Few LPR sensors suffered from extensive corrosion damage, comprising their functionality and recorded fluctuations beyond noise threshold. The erratic data recording behavior of these LPR sensors occurred due to sever corrosion. This kind of behavior were found in areas of heavy salt deposits which were subjected to aggressive corrosive environment in these sensors. Also, sensors that were installed closer to the surface of cable cross section were more likely to fail due to crushing as shown in Figure 2-27. The LPR sensors that were not damaged during installation and survived the prolonged aggressive environment provided reliable reading of the corrosion rate [34]. Better protection methods should be provided during LPR sensor installation if the sensors are to be used. 


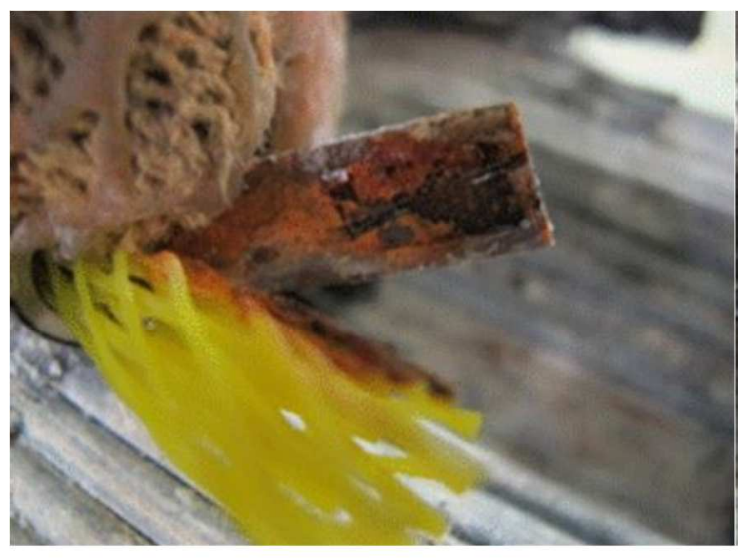

(a)

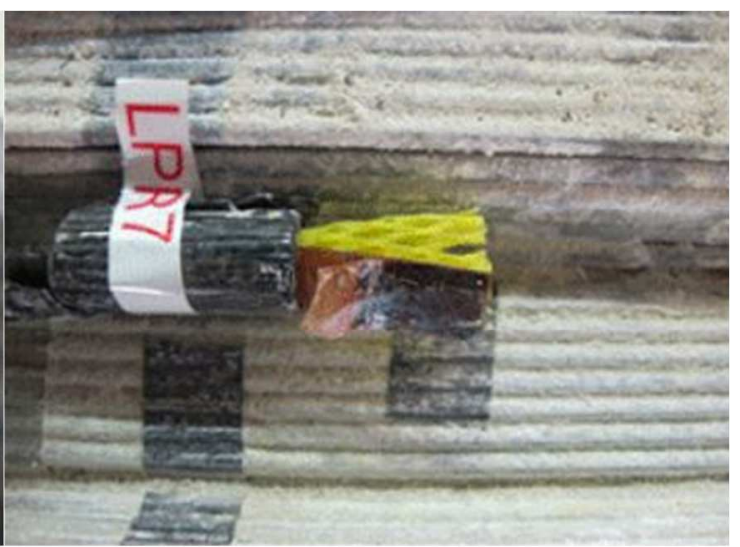

(b)

Figure 2-27: Close-up view of damaged LPR section after cable dissection (a) corrosion, (b) crushing [27]

\subsubsection{Commercial Products}

Analatom's AN110-C with DAQ node and micro linear polarization (uLPR) is the available commercial product that uses this sensor technology.

\subsubsection{Product 6: Passive Embeddable Wireless Sensors (SMART PEBBLES) \\ 2.4.6.1. Overview}

The concept of passive embeddable wireless sensor (a.k.a., smart pebbles) were envisioned as being inserted in a back-filled core for chloride ingress evaluation [34]. The components of smart pebble was designed by FushionDesign where the components were enclosed by polyurethane rubber that hold the reference and ion-selective electrodes and their electrolytes. A brief overview of smart pebbles is described in Table 2-6 and Figure $2-28$. 
Table 2-6: Brief overview of passive embeddable wireless sensors

\begin{tabular}{|c|c|}
\hline \multicolumn{2}{|r|}{ Passive Embeddable Wireless Sensors (Smart Pebbles) } \\
\hline Categories & $\begin{array}{l}\text { Local, embeddable, wireless, reader-based (radio frequency } \\
\text { powered), environmental monitoring system }\end{array}$ \\
\hline Pros & $\begin{array}{l}\text { - Wireless } \\
\text { - } \quad \text { Size and weight are roughly of a typical piece of rock } \\
\text { identification (RFID) chip interrogation } \\
\text { - Powered remotely }\end{array}$ \\
\hline Cons & $\begin{array}{l}\text { - Electrochemical cell in the pebble device has limited stability } \\
\text { over the intended design life } \\
\text { - Drying of water-based electrolyte may cause drift of the } \\
\text { electrode potential } \\
\text { - Drying also affects calibration and design value of the } \\
\text { components in the potential-conditioning circuit } \\
\text { - Can measure only chloride concertation threshold }\end{array}$ \\
\hline Other Details & $\begin{array}{l}\text { - For new bridges, smart pebbles could be inserted when pouring } \\
\text { concrete and for existing bridges, back-filled core is doable } \\
\text { - Designed for monitoring the level of chloride ingress into } \\
\text { concrete bridge decks }\end{array}$ \\
\hline Manufacturer & Not commercially available \\
\hline References & Watters, et al. [34] \\
\hline
\end{tabular}

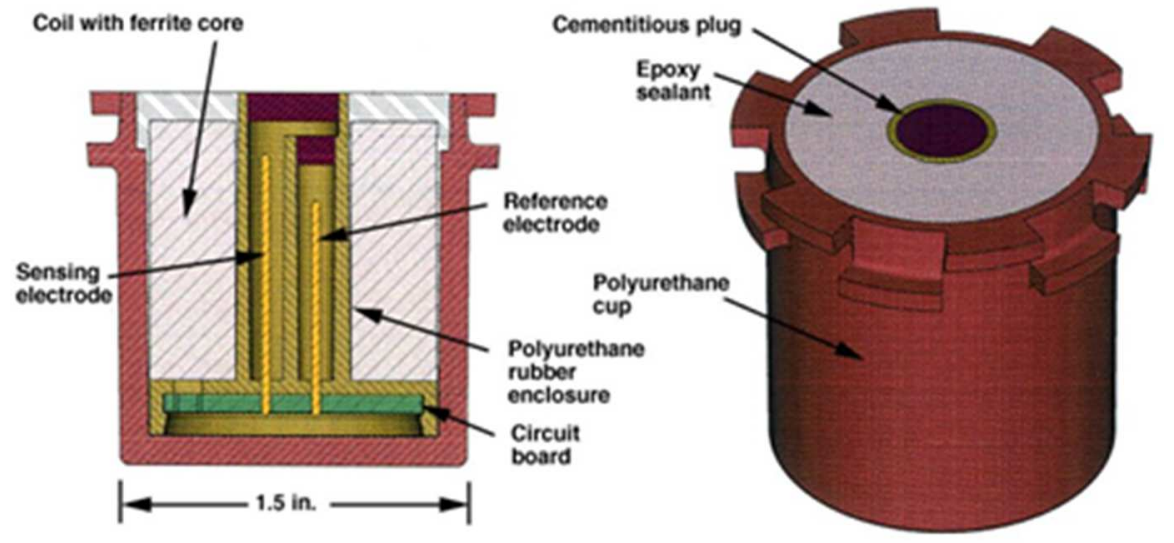

Figure 2-28: Package design concept for the smart pebble [34] 


\subsubsection{Theory/Mechanism}

The polyurethane rubber of smart pebble not only enclosed the electrodes but also protected the circuit board, and the rigid cup protected the whole unit including the coil. A prime sensor candidate were selected for this application as an electrochemical sensor which generated an electric potential depends on the concentration of chloride ions [34]. The circuit of this sensor included an RFID chip which not only indicated a threshold level when exceeded by inverting the ID-code bit stream but also be able to power external electronics. The electrochemical sensor cell were designed of two electrodes: a chlorideselective electrode and a reference electrode so that the potential of the reference electrode remain consistent over the service life. This electrochemical cell was enclosed in an interior compartment with a cementitious (grout) acting as the salt bridge that separated the two half-cell [34]. The external cementitious plug was opened to the bridge deck environment to enable the electrochemical cell to reach equilibrium with chloride concentration as shown in Figure 2-29.

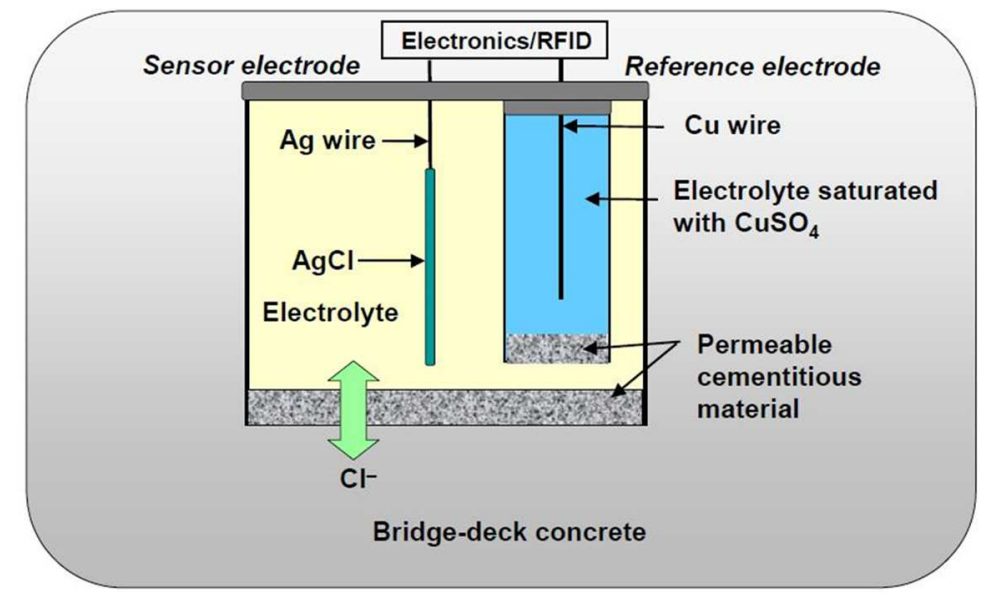

Figure 2-29: Electrochemical cell geometry for smart pebble [34]

The reader of smart pebble was designed to convert ID-code bit stream into a unique ID-code so that reader could indicate the under and over-threshold chloride 
concentration condition with a green or red light respectively [34]. The overall concept of smart pebble operation is shown in Figure 2-30.

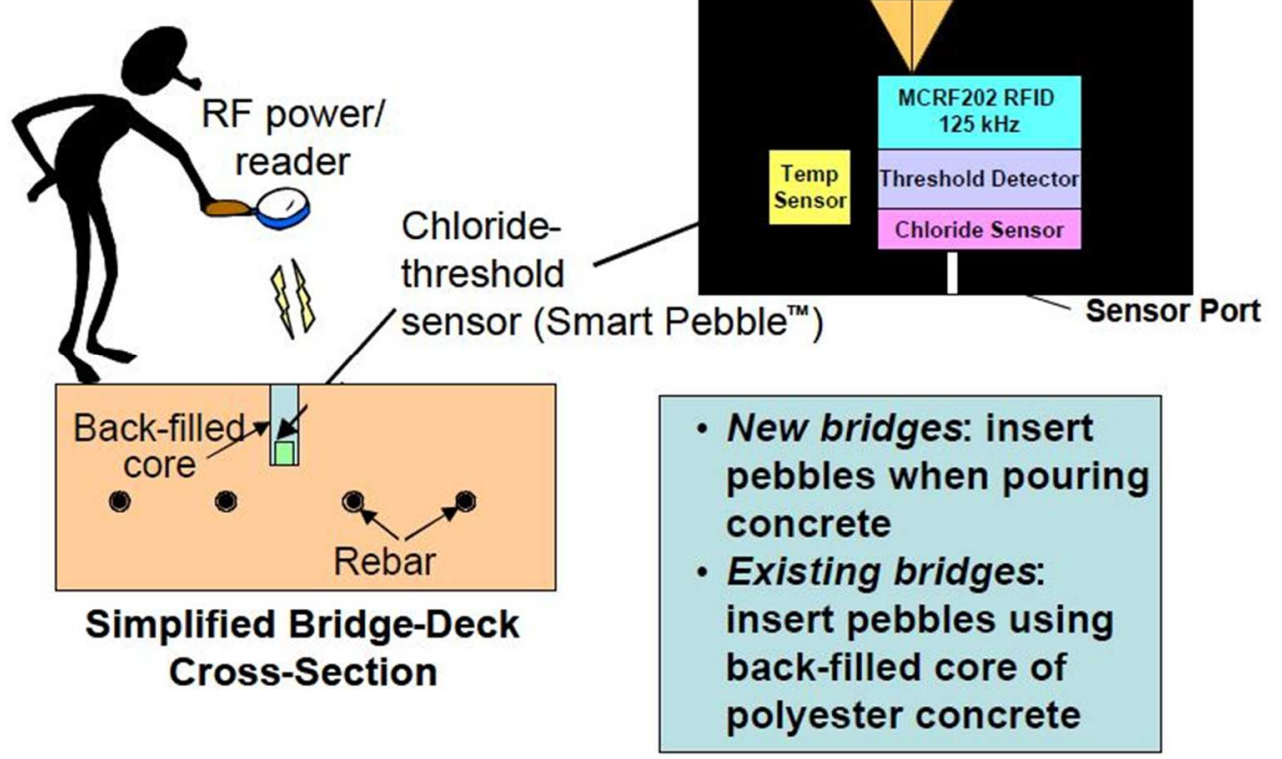

Figure 2-30: Concept of smart pebble operation [34]

Detailed block diagram of the Smart Pebble showing the resonant antenna, the RFID chip, the sensor-interface circuitry, and the reference and ion-selective electrodes that are part of the electrochemical cell is shown in Figure 2-31. The RFID chip can provide power up to 10 microwatts to power the sensor electronics, and the electro chemical cell that produces a voltage proportional to the log of the chloride concentration. The task of operational amplifier is to amplify this signal by approximately a factor of ten and compensate the temperature. When the signal exceeds $1.2-\mathrm{V}$ threshold of the comparator (comparator output changes from high to low), and thus changes switch port on RFID. The electrochemical cell is opened to deck environment, but the RFID and sensor electronics are sealed within the pebble. 


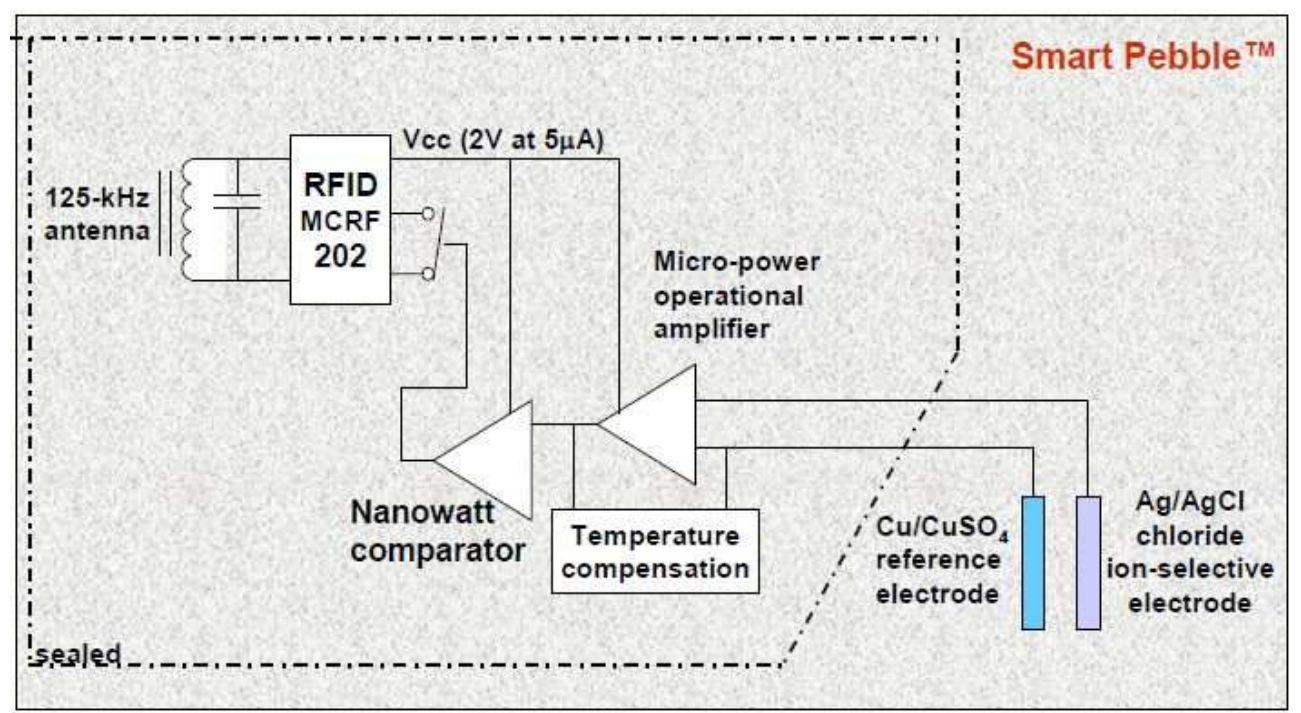

Figure 2-31: Detailed smart pebble block diagram

\subsubsection{Previous Studies}

One of the approaches to the measurement of chloride concentration in old bridges considered for smart pebble installation and testing was to make a core sample extracted from the bridge deck. In this design approach, one kind of operation was to drill the core from the top surface of the bridge, insert the pebble, and then refill the core with polyester concrete which is moisture impermeable [34]. The only concern that was raised in this technique was to ensure that moisture does not flow along the boundary between backfilled core and the bridge deck material. For large scale testing, this method was considered more convenient. Another design approach was to drill the core from the bottom of the bridge. In this method, the top of the bridge deck was unaltered but required access to the bridge deck from the underside [34]. On the contrary, for new bridges smart pebbles could be included during concrete pour but random distribution did not provide reliable data for bridge health. In fact, smart pebbles that were located too close to the top surface might not provide useful chloride ingress data, and if pebbles were placed beneath the rebar, the data might get altered or the rebar query would become difficult [34]. Therefore, the 
preferred approach considered was to tie smart pebbles to the rebar matrix prior to concrete pouring. For field application, Caltrans fabricated a frame to hold the pebble at the desired depth attached to the top mat of rebar as shown in Figure 2-32.
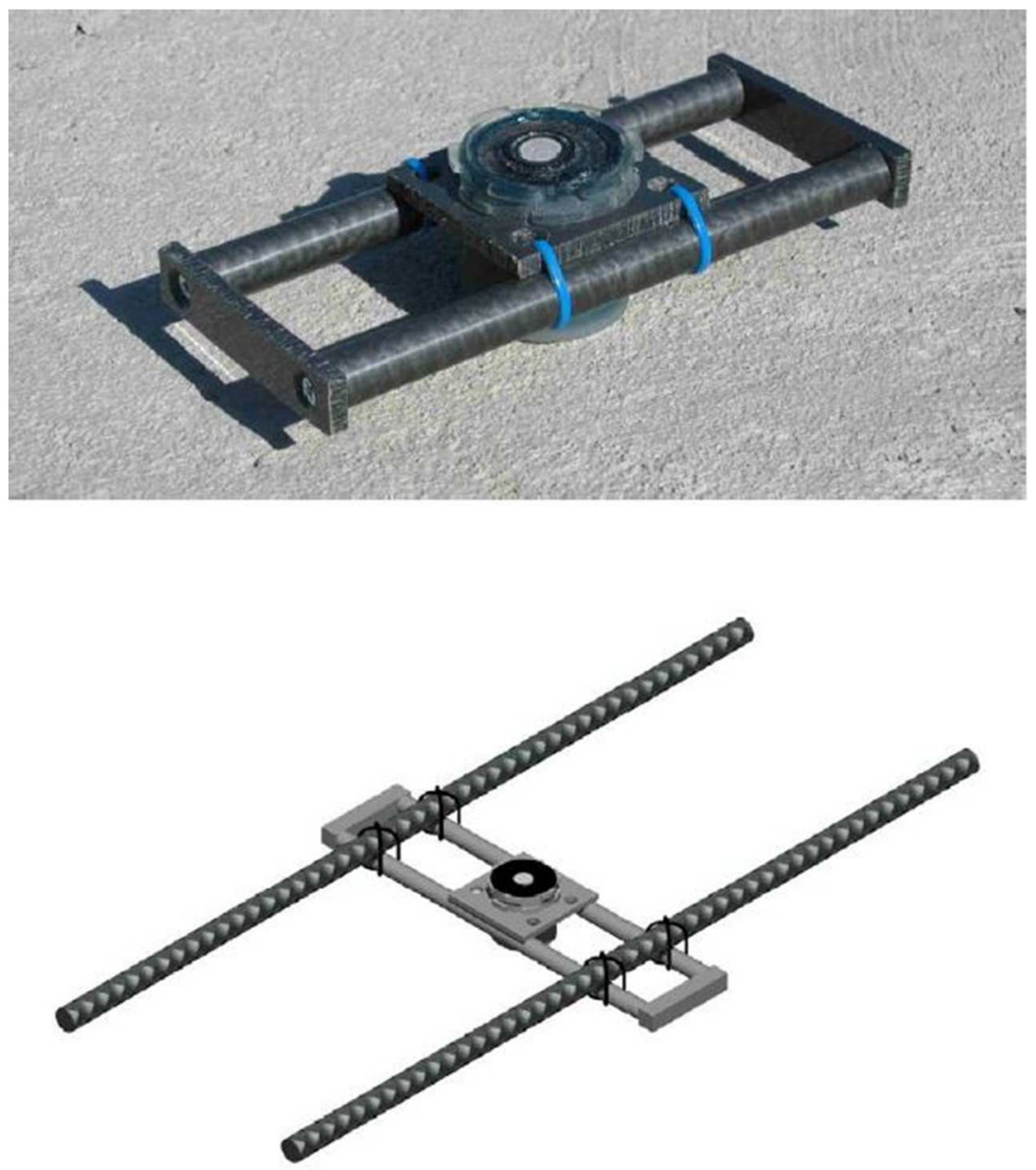

Figure 2-32: Frame for mounting smart pebble to rebar [34]

\subsubsection{Commercial Products}

SRI International developed the technology of passive embeddable wireless sensor for monitoring the level of chloride ingress, but it is no longer commercially available. 


\subsubsection{Product 7: Smart Aggregate (SA) Sensors}

\subsubsection{Overview}

Smart Aggregate (SA) sensor was developed in such a way that conductivity of concrete could be measured not only as the indicator of the corrosivity environment in concrete but also to measure resistance of concrete which can be converted to resistivity reading (inverse of conductivity). The complete smart aggregate (SA) sensor system was consisted of sensors, sensor signal processing electronics, communications electronics and power conditioning. A brief overview of smart aggregate is described in Table 2-7.

Table 2-7: Brief overview of smart aggregate (SA) sensors

\begin{tabular}{|c|c|}
\hline \multicolumn{2}{|r|}{ Smart Aggregate Sensors } \\
\hline Categories & $\begin{array}{l}\text { Local, embeddable, wireless, readerbased (power transmitter), } \\
\text { environmental monitoring sensing system }\end{array}$ \\
\hline Pros & $\begin{array}{l}\text { - Wireless } \\
\text { - Sensor is relatively inexpensive } \\
\text { - Durable sensor, since its projected life is over } 50 \text { years } \\
\text { - Reader head has remote powering and data collection system }\end{array}$ \\
\hline Cons & $\begin{array}{l}\text { - Has limitation of measuring open circuit voltage (OCV) across } \\
\text { the electrodes } \\
\text { - Sensor design has limitation on the number of the current } \\
\text { microprocessor outputs } \\
\text { - Sensor package integrity is considered to be the lifetime } \\
\text { limiting facet of smart aggregate }\end{array}$ \\
\hline Other Details & $\begin{array}{l}\text { To measure corrosion activity smart aggregate sensor includes } \\
\text { conductivity and temperature measurements with external } \\
\text { reader for signal processing, power and communication } \\
\text { electronics }\end{array}$ \\
\hline Manufacturer & Not commercially available \\
\hline References & Cain, et al. [35] \\
\hline
\end{tabular}




\subsubsection{Theory/Mechanism}

The main objective of smart aggregate (SA) sensor was to provide an inexpensive, reliable sensing capability to measure corrosive environment in steel reinforced concrete [35]. Generally, measurement of temperature, conductivity, chloride ion concentration, oxygen and $\mathrm{pH}$ represents an adequate study of corrosive environment in concrete. In the first prototype developed for SA, Temperature and conductivity were the two sensing capabilities that were incorporated [35]. Previous experimental studied showed that concrete with chloride ion present in the mix was found value of low conductivity (high resistivity) and corroded at a very low rate and as the conductivity increased, so the increased rate of corrosion. Electronically the Smart Aggregate (SA) was designed to measure the second voltage measurement once the circuit gets open. The conductivity measurements was depending on the open-circuit voltage, and this open-circuit-voltage of the conductivity cell changed as the cell ages inside concrete. The circuit was designed in such a way that it was shunted with the electrodes while the SA was un-powered and was put in short with the electrodes just before the measurement in order to minimize the open-circuitvoltage [35]. To validate the design and calibrate the measurement, measurements of known conductivity solutions made with the Smart Aggregate circuit with measurements from a laboratory grade instrument. A conceptual schematic of smart aggregate system is shown in Figure 2-33. 


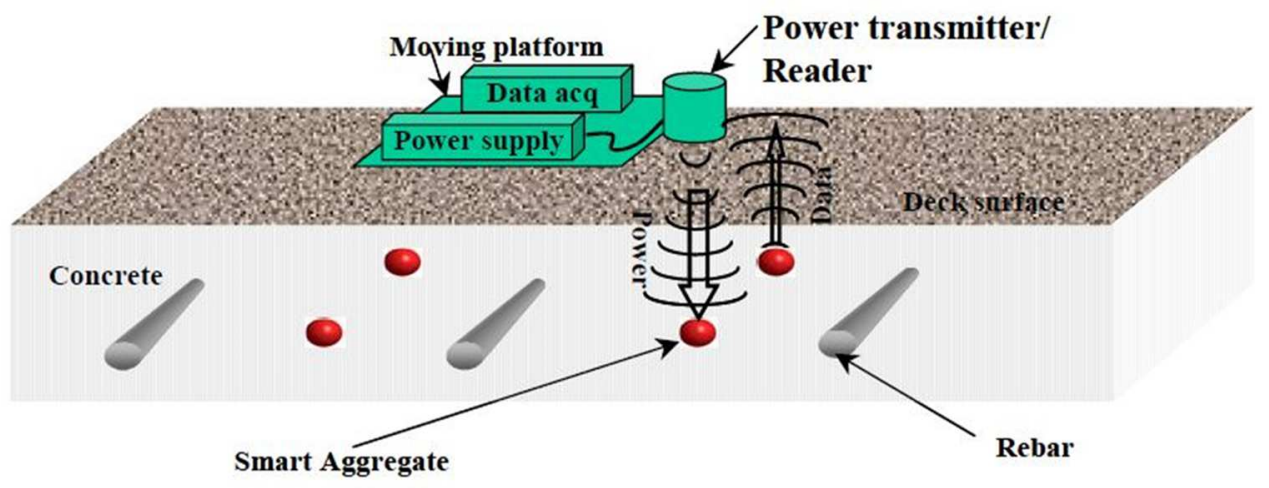

Figure 2-33: Schematic concept of smart aggregate (SA) system [35]

\subsubsection{Previous Studies}

In preparation of first field test, APL conducted several visits to the US Rt. 29 and at Johns Hopkins road bridge construction site (located near APL campus). The main focus of the first filed installation was to develop approach for sensor localization measurement, plan to determine the location of sensors and conduct serviceability test with prototype sensor holders [35]. The purpose of these prototype holder installation was to test their serviceability during concrete pouring, vibrator installation and construction crew walking [35]. As the initial design failed to withstand crew load of 300 pounds, a modified design was proposed. Upon failure of initial load carrying capacity of crew walking, APl redesigned the initial prototype with WESP (wireless embedded sensor platform) to accomplish design objectives of low cost manufacturing, minimizing the possibility of cavities underneath the holder (after concrete pouring) and increase the load bearing capacity of the holder as shown in Figure 2-34. 


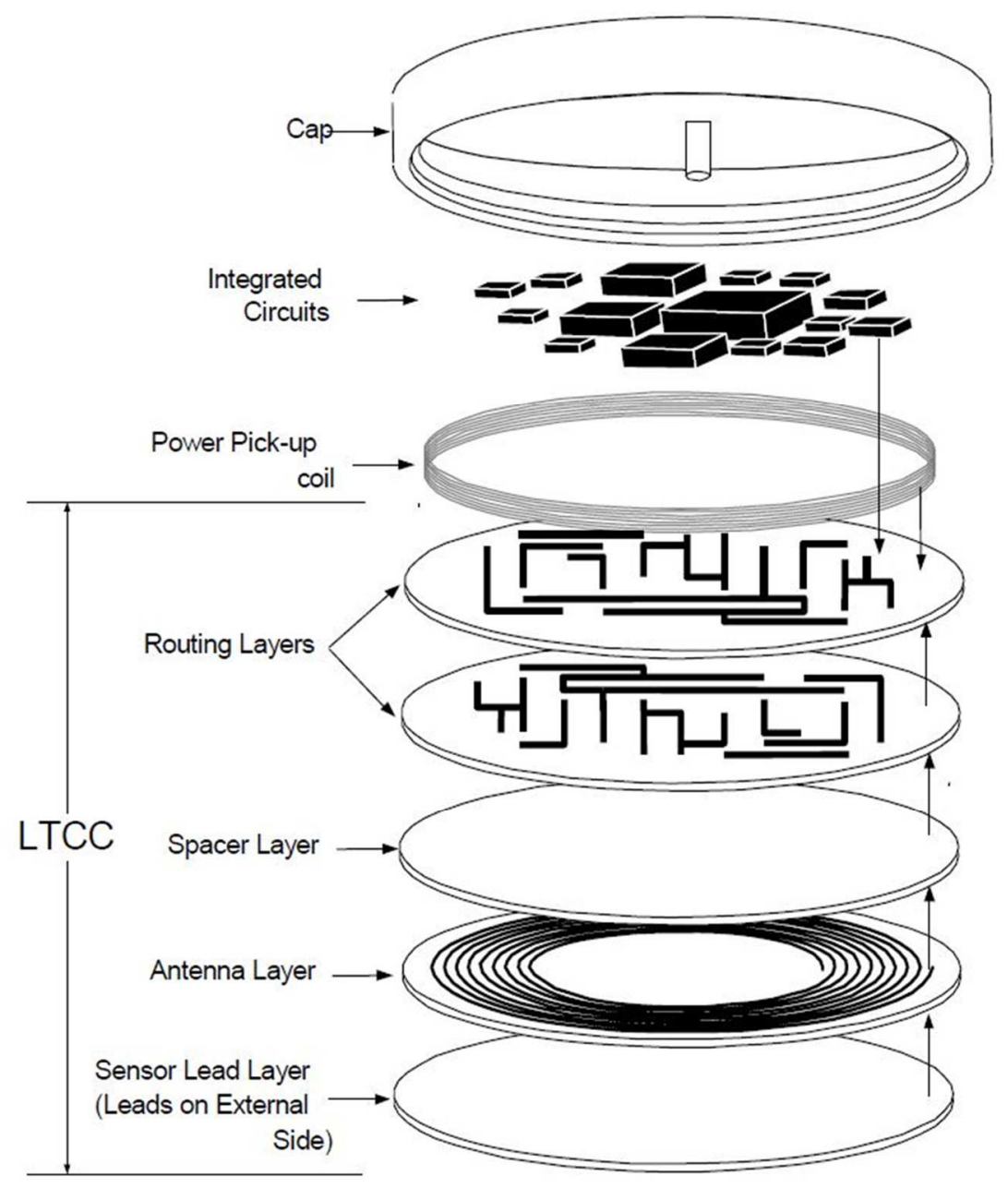

Figure 2-34: Redesigned wireless embedded sensor platform (WESP) assembly [35]

APL altogether manufactured 11 WESP packages for the first field test. Four of these sensors were used in a simulated bridge test conducted in the laboratory, and five packages were reserved for the bridge test [35]. In addition, five dummy packages (no electronics) were installed for the bridge deck pour test. After installation, APL investigated two techniques to localize the WESP package with magnetic field and ultrasound [35]. The WESP package could be readily located in concrete with $1 / 4$ inch accuracy with a small magnet inserted in the package. The sensor system was a low-cost, portable magnetometer that produces an aberration in the uniform earth's magnetic field to 
effectively locate the WESP package. APL also investigated ultrasound measurements to indicate that this technique would not work with the available ultrasound head because of excessive reflections from the aggregate and concrete surfaces [35]. Finally, after completion of simulated bridge test, APL installed 10 WESP units in the south lane of the bridge at the intersection of Johns Hopkins Road and US Route 29 as shown in Figure 2-35. After curing period of approximately 48 hours, APL tested the bridge sensors using a magnetometer based procedure similar to that demonstrated in the laboratory but were able to verify operability of the five WESP units only. The investigation of malfunctioning of these five WESP units with electronics showed that excess water, failed WESP units, inconsistent grounding of the rebar distorting the magnetic field and WESP units being deeper than the 2" penetration range of the reader head could be the possible causes for this malfunctioning [35].

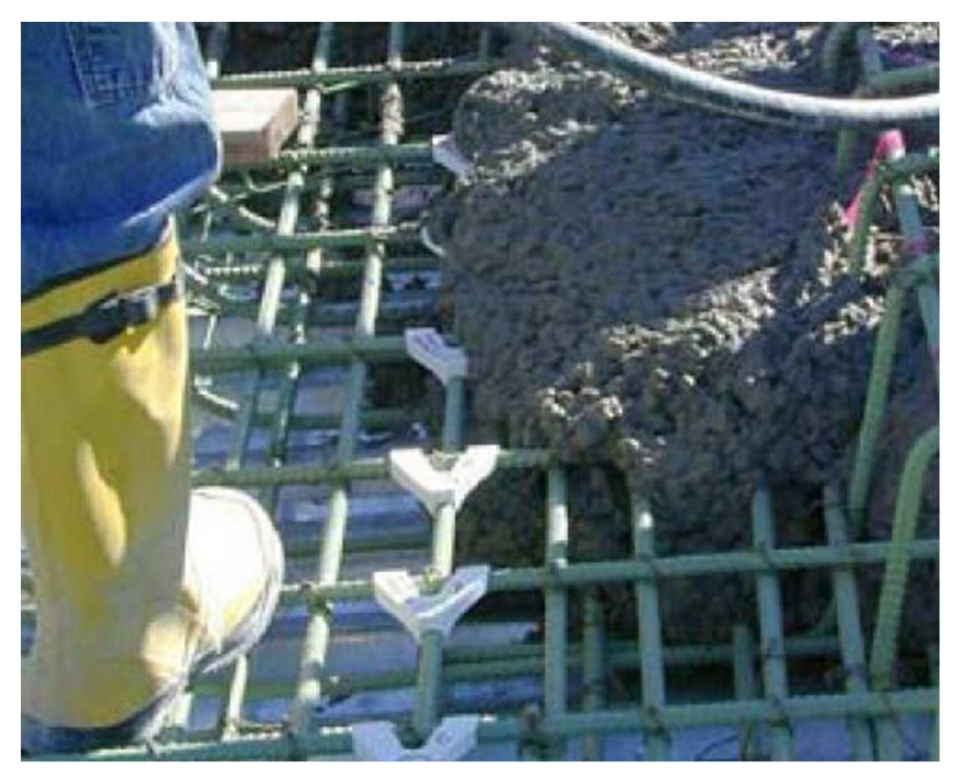

Figure 2-35: Bridge installation of smart aggregate in holders [35]

In a second attempt of the smart aggregate (SA) sensor field test, APL investigated the use of ultrasound to image the SA holders embedded in the concrete. Transducer with $500 \mathrm{KHz}$ were used in these operation in a pitch-catch configuration through 5 inches of 
concrete. However, these measurements were very sensitive to the placement (coupling) of the transducer to the concrete as shown in Figure 2-36. The obstacles faced in this technique was that ultrasonic energy might get scattered by the concrete aggregates. Also, if lower frequency transducer was used to lessen aggregate scattering then spatial resolution would get compromised [35].

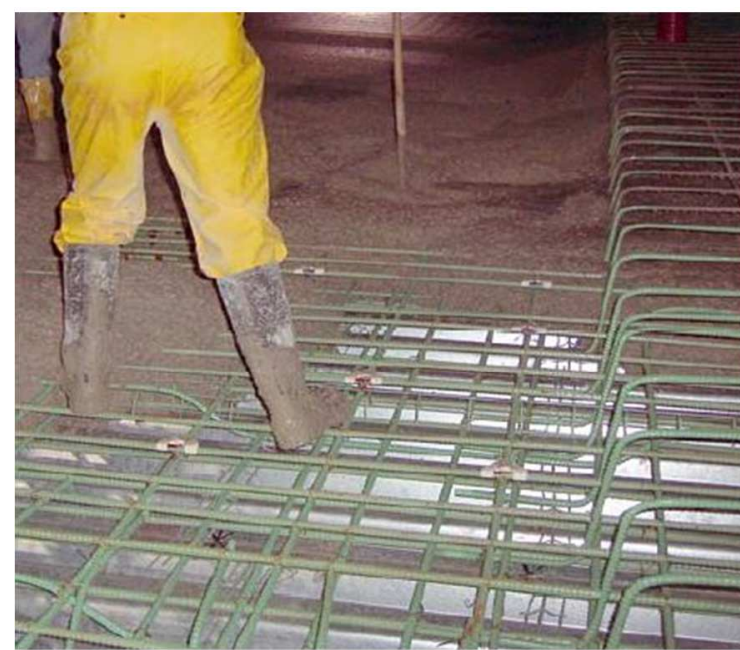

(a)

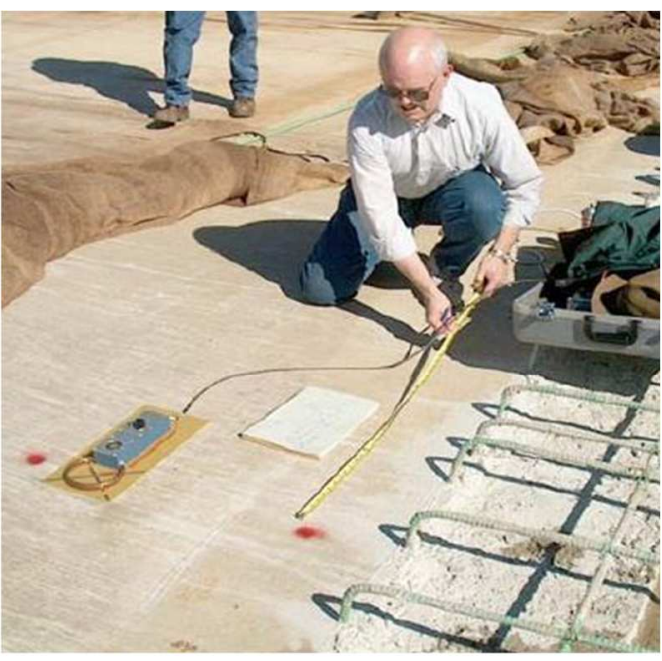

(b)

Figure 2-36: Second filed installation: (a) deck pouring and (b) post deck pour localization [35]

\subsubsection{Commercial Products}

The John Hopkins University/ Applied Physics Laboratory (APL) was funded by the Maryland State Highway Administration (SHA) to develop smart aggregate (SA) sensor, and it is no longer commercially available. 


\subsubsection{Product 8: Corrosion Probes (Wired)}

\subsubsection{Overview}

Another category of local sensor is wired corrosion probes. These sensors are wired sensors that typically measure corrosion potential, environmental conditions, or corrosion rate. The corrosion probes that are described in this section are the M3 and M4 multielement sensors from Intertek. The M3 probe can measure the corrosion potential ( $\left.\mathrm{E}_{\mathrm{corr}}\right)$ of the working electrode and the main reinforcement with respect to the reference electrode. The M3 probe also measures concrete resistivity and temperature. To measure the corrosion rate $\left(\mathrm{I}_{\text {corr }}\right)$ of the working electrode and the main reinforcement, the linear polarization method is used. The M4 probe provides early indication of corrosion events to detect degradation of structural integrity before it affects the reinforcement of the structure. The M4 probe measures the rate of corrosion at four different depths. Placing the M4 probe next to steel reinforcement within the concrete, the corrosion ingress from the concrete surface (through the concrete cover to the rebar depth) can be determined. A brief overview of corrosion probe is shown in Table 2-8.

Table 2-8: Brief overview of corrosion probes

\begin{tabular}{|c|c|}
\hline \multicolumn{2}{|r|}{ Corrosion Probes } \\
\hline Categories & $\begin{array}{l}\text { Local, embeddable, wired, readerbased (power transmitter), } \\
\text { environmental monitoring sensing system }\end{array}$ \\
\hline Pros & $\begin{array}{l}\text { - Ideal for determining the corrosion risk inducing medium } \\
\text { entering the structure } \\
\text { - Durable sensor, minimum service life of } 25 \text { years to an } \\
\text { extendable service life of } 120 \text { years } \\
\text { - Can be installed during construction phase or retrofitted into } \\
\text { existing structure } \\
\text { - Compact design minimizing the impact on the structural } \\
\text { integrity of the concrete } \\
\text { - Can operate from remote locations }\left(-40^{\circ} \mathrm{C}\right) \text { to indoor locations } \\
\left(+80^{\circ} \mathrm{C}\right) \text { in railway tunnels and buildings }\end{array}$ \\
\hline
\end{tabular}




\begin{tabular}{|c|c|}
\hline \multicolumn{2}{|r|}{ Corrosion Probes } \\
\hline Cons & $\begin{array}{l}\text { - Wired } \\
\text { - Only potential and temperature can be measured using standard } \\
\text { data acquisition systems (other features require Intertek DAQ } \\
\text { systems) } \\
\text { - Suitable to detect corrosion in chloride rich and carbonated } \\
\text { environment only }\end{array}$ \\
\hline Other Details & $\begin{array}{l}\text { Measures corrosion potentials, temperature, galvanic current, } \\
\text { resistivity and linear polarization resistance (LPR) } \\
\text { Macro-cell measurements of coupling current are possible } \\
\text { between the working electrode and the main reinforcement }\end{array}$ \\
\hline Manufacturer & Intertek CONCERTO ${ }^{\mathrm{TM}} \mathrm{SHM}$ M3, M4 corrosion probe \\
\hline References & Lyon and Gooderham [36] \\
\hline
\end{tabular}

\subsubsection{Theory/Mechanism}

A standard M3 corrosion probe comprises of the following elements: i) carbon steel as working electrode, ii) silver/silver chloride/potassium chloride $(\mathrm{Ag} / \mathrm{AgCl} / \mathrm{KCl})$ as reference electrode, iii) UNS S31600 stainless steel as auxiliary electrode, iv) flying lead connection to main reinforcing steel with integral connection and v) thermistor temperature sensor as shown in Figure 2-37. In an alternative configuration, manganese dioxide $\left(\mathrm{MnO}_{2} / \mathrm{NaOH}\right)$ could be used as true reference electrode and lead pseudo as an inert reference electrode [36]. When connected with instrumentation, the probe provides a standard set of measurements: corrosion potential $\left(\mathrm{E}_{\mathrm{corr}}\right)$ of the working electrode and the main reinforcement with respect to the reference electrode, concrete resistivity, temperature and corrosion rate ( $\left.\mathrm{I}_{\text {corr }}\right)$ of the working electrode and the main reinforcement using linear polarization method. 


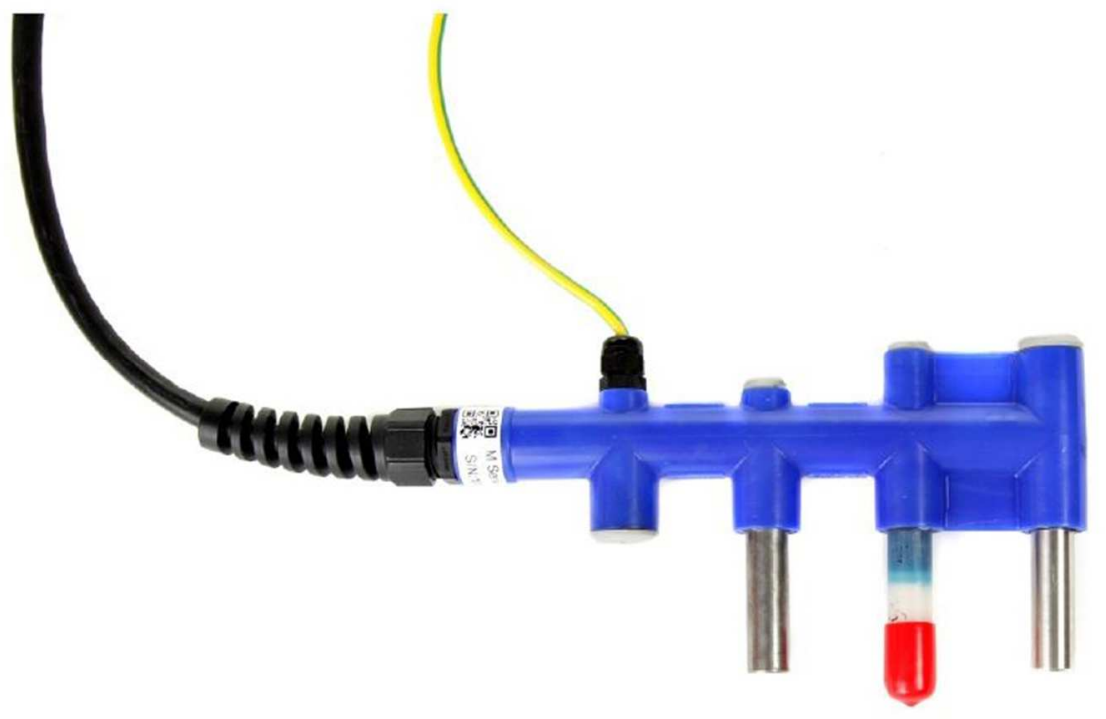

Figure 2-37: M3 corrosion probe configuration [36]

The M4 probe is a ladder type sensor that provides early indication of carrion events to detect the degradation of the structural integrity of the structure resulted from chloride penetration and carbonation. The purpose of this multi-layer system is to detect the corrosion before it affects the reinforcement of the structure. M4 corrosion probes consist of a four-element ladder assembly of $15 \mathrm{~mm}$ diameter with $34 \mathrm{~mm}$ exposed section with a surface area of $1780 \mathrm{~mm}^{2}$ per element. The reference element is made of $\mathrm{MnO}_{2} / \mathrm{NaOH}$ which is suitable in carbonated and chloride-rich environment. PT 1000 is the temperature sensor in M4 corrosion probe [36]. M4 probe is designed to use in concrete elements with up to $10 \mathrm{~m}$ head of wet concrete and constant submersion in up to $30 \mathrm{~m}$ water. The corrosion condition is measured by observing the corrosion conditions at 4 different depths: i) by placing it next to the steel reinforcement within concrete, ii) through the concrete cover, iii) corrosion ingress from the concrete surface and iv) to the rebar depth as shown in Figure 2-38. 


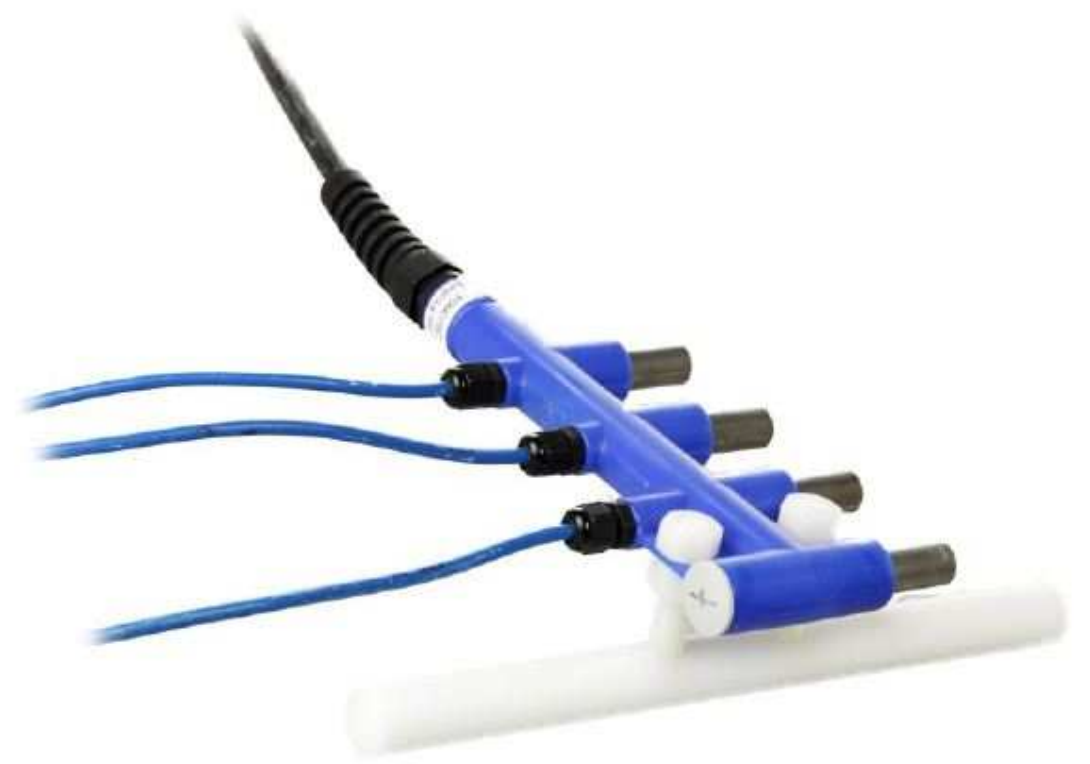

Figure 2-38: M4 corrosion probe configuration [36]

\subsubsection{Previous Studies}

For cost effective structural monitoring, careful choice and application of corrosion sensors and monitoring systems are necessary and the example of these application involves application of corrosion monitoring systems at critical concrete structures in petrochemical recycling extension in Jubilee Line Extension Tunnel, Ruwais, London [36]. The number and locations of measurement probes and data loggers are important to provide adequate information of the corrosion integrity of the monitored structure and corrective actions. In this project, to develop a monitoring system of reliable information on the overall structure performance, the number of probes were made related to a minimum of $5 \%$ to $10 \%$ of the overall structure area. Considering parameters like variation in constructions, exposure conditions- a minimum of two probes per critical structure was considered optimum [36]. Also, the location of individual probes within the structure were 
selected to provide both uniform distribution of probes around the structure, and also identifies the key positions that are most at risk of attack. Probes are connected to data loggers and the locations were selected to minimize the total probe cable length where wireless connections are impractical. The corrosion monitoring system used standard M3 probe and RCC instrumentation to provide a single-box system to automatically measure and store probe parameter at user-configured interval. M3 probes were installed at a range of different cover thickness to the reinforcement in locations considered to be at highest risk of chloride ingress and corrosion of the reinforcing steel [36]. Figure 2-39 showed the installed M3 probe (modified) before casting of reinforced concrete structure. Degradation due to corrosion was considered to be expected to occurs at locations that are south facing and exposed to highest temperature cycle, highest risk of saline water rise due to evaporation and column adjacent to the areas where increased risk of saturation from roof water run-off [36].

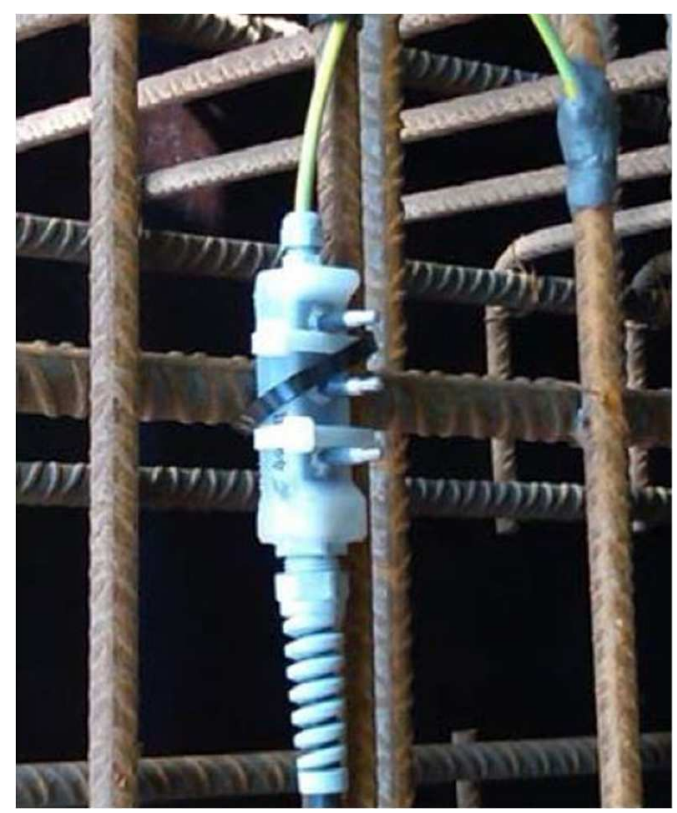

Figure 2-39: Installed M3 probe prior to placement of concrete [36] 


\subsubsection{Commercial Products}

The M3 and M4 corrosion probes are developed and commercially distributed by Intertek.

\subsection{GLOBAL SENSING SYSTEMS}

\subsubsection{Introduction}

Global sensing systems are used to detect changes in the overall behavior of a structure caused by localized damage. Researchers have related local damage to changes in strains and curvatures (as discussed above), vibrations and natural frequencies of structures, displacements, and member stresses, among others. For post-tensioned structures, the most promising is the change in strains and curvatures observed when local damage occurs. This section will give an overview of several available strain sensors that could be used as part of a global sensing system.

\subsubsection{Product 1: Vibrating Wire Strain Gage}

\subsubsection{Overview}

Vibrating wire strain gages (VWSGs) are a versatile, wired strain gage that are capable of measuring strain with an accuracy of better than $5 \mu \epsilon$ and are durable enough to remain stable in concrete for decades [37]. VWSGs measure the frequency of a small tensioned wire to determine the strain change; this vibration is immune to electrical noise and capable of signal transmission of several miles without significant loss of signal. Data acquisition equipment is now available to measure both static and dynamic responses. A brief overview of vibrating wire gauges is shown in Table 2-9. 
Table 2-9: Brief overview of vibrating wire strain gage

\begin{tabular}{|c|c|}
\hline \multicolumn{2}{|r|}{ Vibrating Wire Strain Gage } \\
\hline Categories & Global, embeddable, wired, datalogger based \\
\hline Pros & 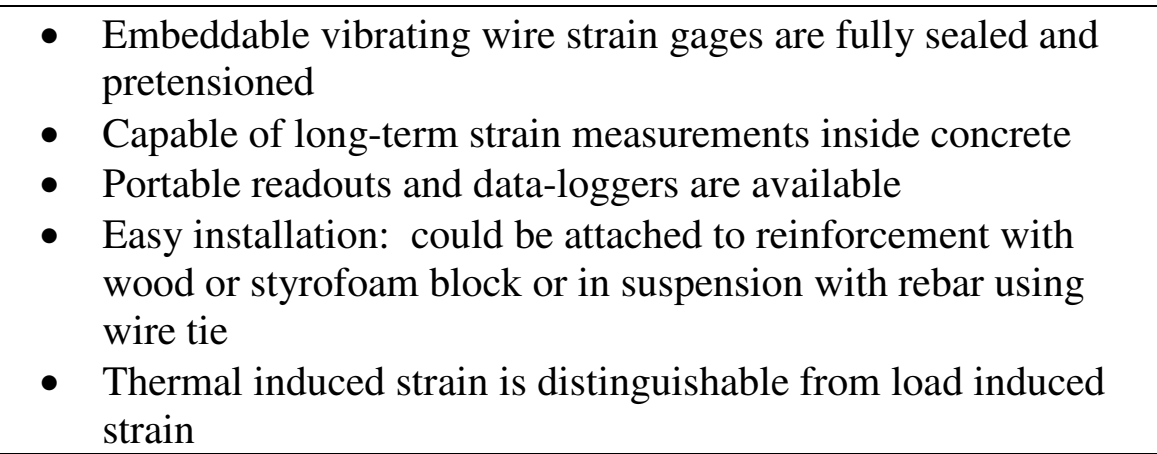 \\
\hline Cons & $\begin{array}{l}\text { - } \\
\text { - } \\
\text { - } \\
\text { - Improt suitable for high speed dynamic measurements } \\
\text { reliability of strain measurement }\end{array}$ \\
\hline Other Details & $\begin{array}{l}\text { - Strain are measured based on the measured frequency of a } \\
\text { tensioned wire } \\
\text { Deformation of concrete mass will cause the end blocks to } \\
\text { move relative to one another and thus altering the tension in } \\
\text { steel wire }\end{array}$ \\
\hline Manufacturer & Geokon Inc. \\
\hline References & $\begin{array}{l}\text { Neild, et al. [37] } \\
\text { Geokon Inc. website [38] } \\
\text { Geokon Manual (Model 4200 Series) [39] } \\
\text { DiBiagio, E. [40] } \\
\text { Hedegaard, et al. [41] }\end{array}$ \\
\hline
\end{tabular}

\subsubsection{Theory/Mechanism}

VWSGs consist of a tensioned steel wire anchored at both ends into flanges [39].

The wire is enclosed in a stainless-steel tube. Electromagnetic coils are also located within the body close to the axis of wire, as shown in Figure 2-40. A voltage or frequency excitation is applied to the coils creating a magnetic field that causes the wire to oscillate at its resonant frequency. Generally, single-coil vibrating wire gages require two seconds 
to excite statically, but with dynamic reading equipment, gages can be read up to 20 times per second $(\mathrm{Hz})$ or up to $100 \mathrm{~Hz}$ when double-coil vibrating wire gages are used [39].

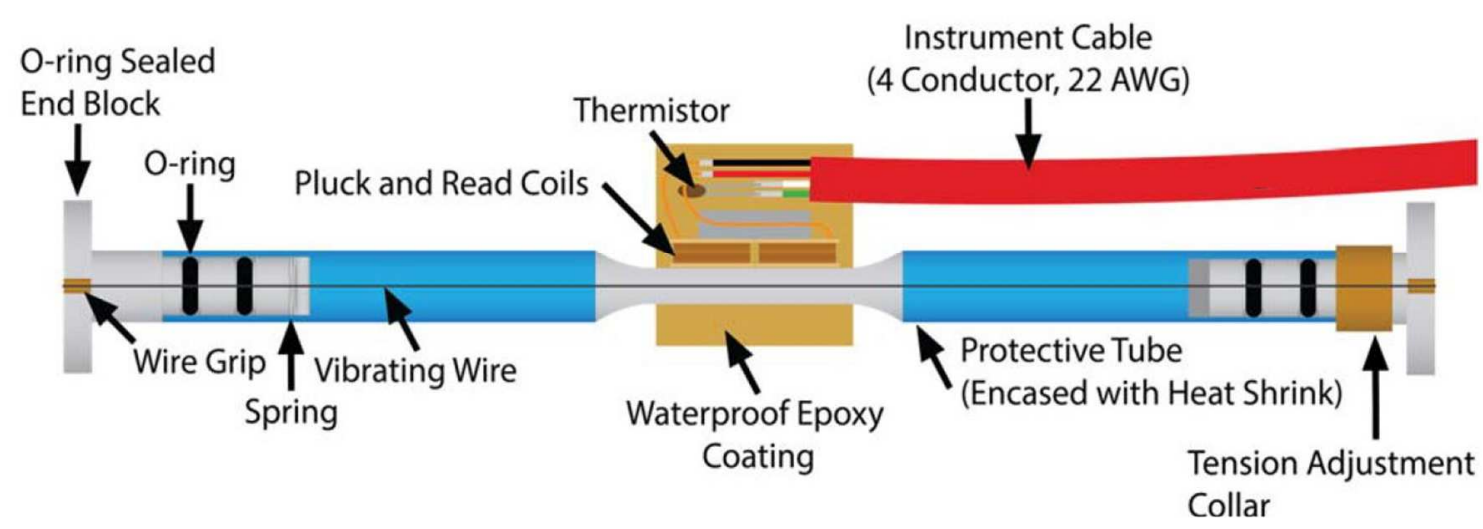

Figure 2-40: Components of vibrating wire strain gages [39]

This kind of oscillation continues through the field of permanent magnet, and thus generate alternating current (sinusoidal) output. Vibrating wire readout unit or data logger processes the frequency of the current output and converts it into engineering units of strain. A gage factor is introduced for the strain gage calibration and is necessary to convert the output of the gage reading into micro strain reading [39].

The principle of vibrating wire strain gages is based on the fundamental natural frequency of a tensioned wire, which is related to its stress, as shown in Equation 2-5.

$$
f=\frac{1}{2 l} \sqrt{\frac{\sigma}{\rho}}
$$

Where,

$$
\begin{aligned}
& \sigma=\text { stress induced in tensioned wire, } \\
& \rho=\text { density of wire, and }
\end{aligned}
$$




$$
1=\text { length of wire. }
$$

The gage measures specimen extensions between the anchor centerline because the wire itself extends between the inner faces of the anchors as shown in Figure 2-41.
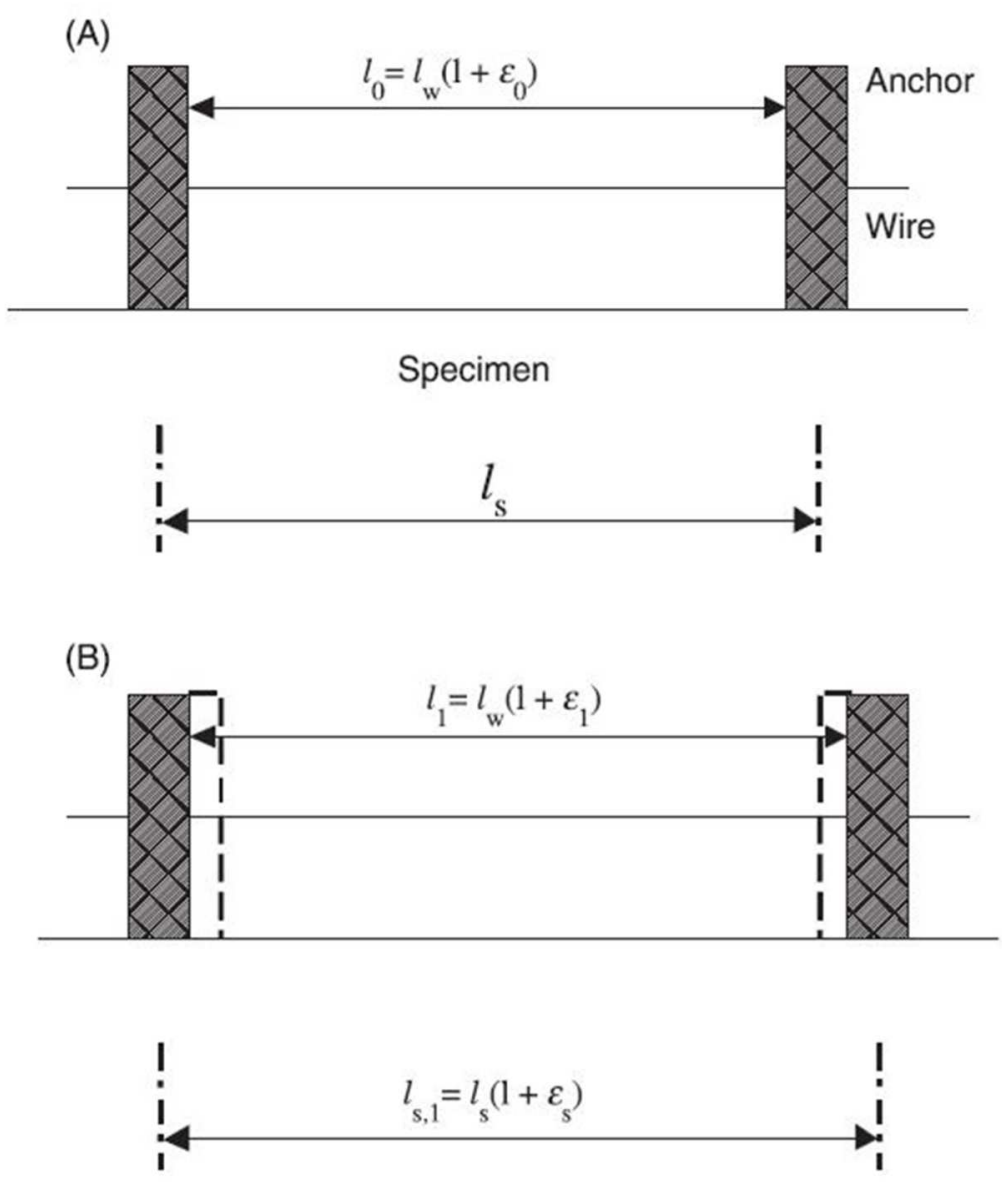

Figure 2-41: Vibrating wire gages attached to a test specimen; (A) before straining, (B) after straining [37]

A setup of initial unstrained length $\left(l_{w}\right)$, which is pretensioned to a length $\left(l_{o}\right)$, and the corresponding strain and natural frequency is shown by Equation 2-6 and Equation 2-7 [37]. 


$$
\begin{gathered}
\epsilon_{0}=\frac{l_{0}-l_{w}}{l_{w}} \\
f_{0}=\frac{1}{2 l_{0}} \sqrt{\frac{E \epsilon_{0}}{\rho}}
\end{gathered}
$$

Where,

$$
\begin{aligned}
& E=\text { Young's modulus of the wire, } \\
& l_{w}=\text { initial unstrained length of wire } \\
& l_{0}=\text { pretensioned length of wire } \\
& f_{0}=\text { natural frequency of wire } \\
& \varepsilon_{0}=\text { initial corresponding strain of wire }
\end{aligned}
$$

When the specimen is loaded, it causes an extension to a length $l_{s 1}$, and the wire gets extended to a new length $l_{1}$. The new wire strain and new specimen strain then becomes [37],

$$
\begin{gathered}
\epsilon_{1}=\frac{l_{1}-l_{w}}{l_{w}} \\
\epsilon_{s}=\frac{l_{s 1}-l_{s}}{l_{s}}
\end{gathered}
$$

Where,

$$
1_{s}=\text { distance between anchor centerline }
$$

and the corresponding natural frequency is [37], 


$$
f_{1}=\frac{1}{2 l_{1}} \sqrt{\frac{E \epsilon_{1}}{\rho}}
$$

Equation 2-10

The gage factor $\mathrm{G}$ can be expressed in terms of initial lengths and wire material properties as below [37]:

$$
G=\frac{l_{w} \epsilon_{0}}{l_{s} f_{0}^{2}}=\frac{4 l_{w} l_{0}^{2} \rho}{l_{s} E}
$$

Equation 2-11

This gage factor is given with each VWSG for the user to convert the vibration reading to strain.

Temperature variation is common in reinforced concrete structures and will affect the strain in the concrete differently that the strain in the steel wire. For this reason, a temperature related correction factor is required to eliminate this effect [39]. The correction for load related strain in concrete which consider both external load and temperature effect is given by Equation 2-12.

$$
\mu_{\text {load }}=\left(R_{1}-R_{0}\right) B+\left(T_{1}-T_{o}\right)\left(C_{1}-C_{0}\right)
$$

One of the significant advantages of vibrating wire gages is that the frequency output is immune to electrical noise, able to tolerate wet wiring, and capable of signal transmission of several miles without significant loss of signal. Static measurements of strain to measure long-term effect of temperature change can be adequately evaluated using readings at required interval. Norwegian Geotechnical Institute (NGI) conducted a study regarding reading stability of vibrating wire gages (VWSGs) in 2003, which reported that 
VWSGs can monitor data continuously for more than 27 years with no failures either of gages or excitation electronics [40].

\subsubsection{Previous Studies}

On August $1^{\text {st }}, 2007$, the I-35W Bridge over the Mississippi River in Minneapolis, Minnesota collapsed, which killed 13 people and made an urgent need to provide insight into bridge performance and long-term health [41]. To understand the long-term performance and behavior, Minnesota Department of Transportation (MnDOT), FHWA, the USF Geotechnical Research Group and Foundation \& Geotechnical Engineering (FGE), LLC collaborated to monitor the newly rebuilt I-35W bridge sub-structural members and collect real-time information [41]. The objective of the study was to monitor: (a) real-time monitoring of mass concrete effect in foundation elements, (b) real-time monitoring of construction loads and (c) long-term health monitoring of the bridge. VWSGs were installed to monitor the strain and temperature in the structure. Installation of VWSGs was done on the surface of the bridge substructure and embedded in concrete [41]. Phase I involved internal monitoring of concrete temperature, where the embedded internal thermistors of the VWSGs provided means of assurance to monitor the acceptable ranges of concrete temperature. Phase II monitored increasing load and their distribution along the length of the foundation shaft as construction progressed. The profile of VWSGs were able to identify all the load steps along the construction phases, as shown in Figure $2-42$. 


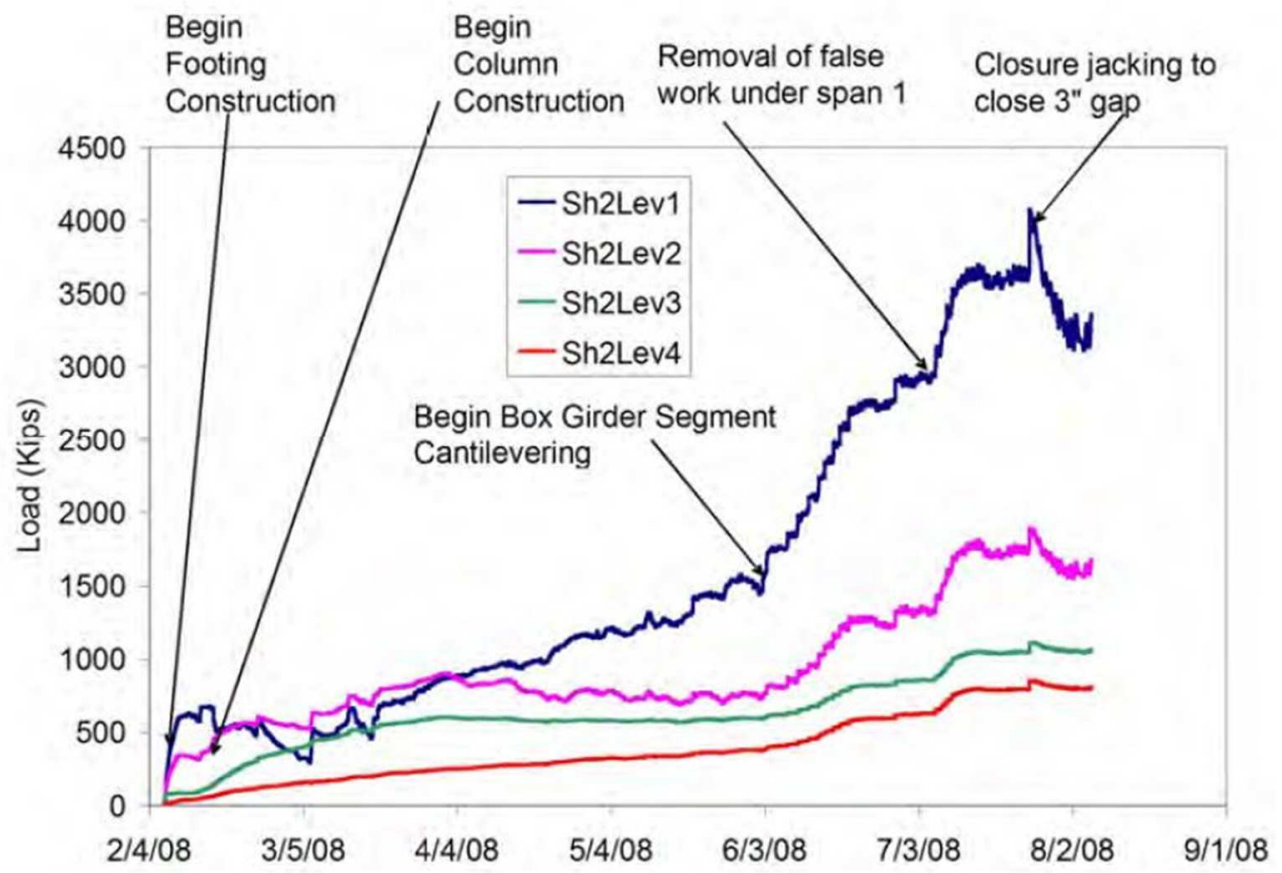

Figure 2-42: Load steps at different phases of the construction (strain data computed into construction load) [42]

Phase III identified the calibration and correlation of data from Phase II to monitor the long-term health of the bridge. The data acquisition system was self-powered with solar panels and deep cycle batteries and each system uploaded data to a remote host server via cellular modem [41]. Strain data from longitudinal VWSGs located at Sections 3, 5, 7 and 9, shown in Figure 2-43, were collected from the southbound bridge and compared with the finite element analysis results.

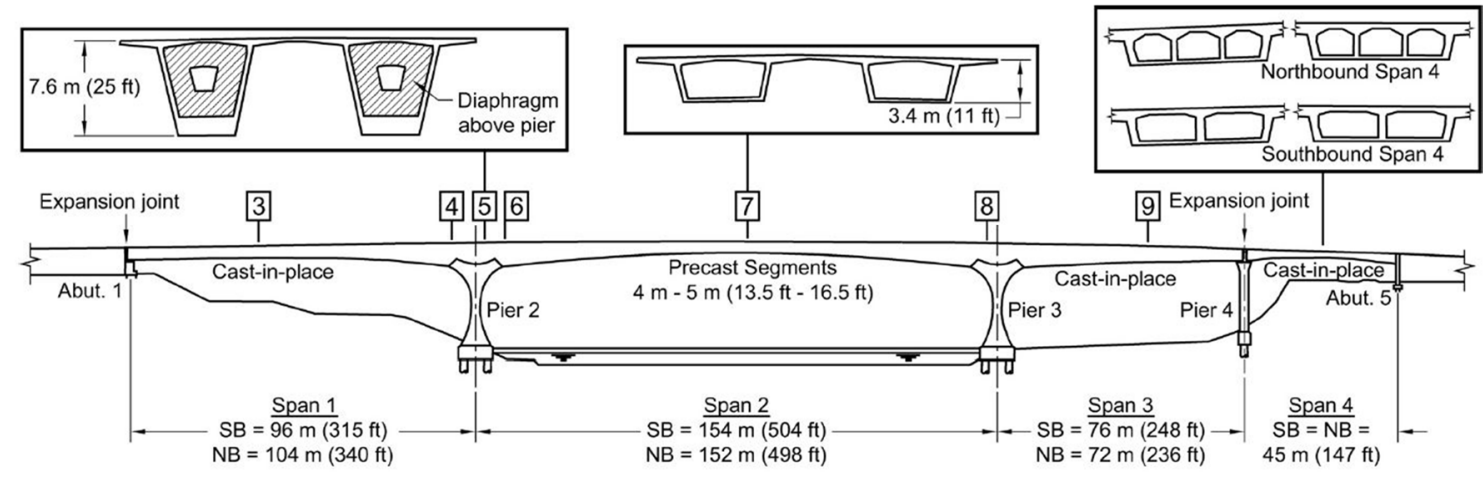

Figure 2-43: Sensor locations of St. Anthony Falls bridge [41] 


\subsubsection{Commercial Products}

Geokon Inc. supplies concrete embedment vibrating wire gages of different active lengths. Model $4200(153 \mathrm{~mm})$, model $4202(51 \mathrm{~mm})$, model $4204(102 \mathrm{~mm})$ and model $4210(250 \mathrm{~mm})$ are the current commercial products available.

\subsubsection{Product 2: RFID-Based Wireless Strain Gauges}

\subsubsection{Overview}

Radio frequency identification (RFID) based strain gages are fast and easy to install strain sensing devices. RFID sensors could be embedded in prefabricated concrete sections to verify the integrity of structures, or sensors could be installed and calibrated on-site. A brief overview of RFID-based wireless strain sensors is shown in Table 2-10.

Table 2-10: Brief overview of RFID-based wireless strain gage

\begin{tabular}{|c|c|}
\hline \multicolumn{2}{|r|}{ Passive RFID Wireless Strain Gage } \\
\hline Categories & Global, embeddable, wireless (battery-free), specialized reader \\
\hline Pros & $\begin{array}{l}\text { - No wires or batteries required to read strain } \\
\text { - Each sensor has a unique ID\# so that many sensors can be read } \\
\text { by one reader at the same time } \\
\text { - Use on-board temperature sensor for strain gauge temperature } \\
\text { compensation } \\
\text { - Can use off-the-shelf ultra-high frequency RFID electronic } \\
\text { product code based reader to read sensors } \\
\text { - Installation procedure is fast and easy to follow } \\
\text { - Sensors can be calibrated on-site }\end{array}$ \\
\hline Cons & $\begin{array}{l}\text { - Battery currently required for battery-assisted passive (BAP) } \\
\text { SensTag version } \\
\text { - Currently uses conventional steel resistance gages to measure } \\
\text { strains, which have been shown to deteriorate over time } \\
\text { - Reader range is limited to one foot maximum, and RFID needs } \\
\text { to be within a few inches of concrete surface } \\
\text { - Possibilities of sensor damage during the installation process }\end{array}$ \\
\hline Other Details & $\begin{array}{l}\text { - Battery-based data logging capabilities are available to collect } \\
\text { strain data during the first } 10+\text { years of gage's life }\end{array}$ \\
\hline
\end{tabular}




\begin{tabular}{|c|l|}
\hline \multicolumn{1}{|c|}{ Passive RFID Wireless Strain Gage } \\
\hline Manufacturer & $\begin{array}{l}\text { During field installation, to locate and read each embedded tag, } \\
\text { painting marker above each tag is required }\end{array}$ \\
\hline \multirow{5}{*}{ References } & $\begin{array}{l}\text { Phase IV IV ENGINEERING [43] } \\
\text { Ruan, et al. [44] } \\
\text { Roberts, C.M. [45] } \\
\text { Cook, et al. [46] } \\
\text { Swedberg, C. [47] }\end{array}$ \\
\hline
\end{tabular}

\subsubsection{Theory/Mechanism}

RFID is considered a wireless identification technology where radio waves are used to identify an object (tag), acquire data, or write data to the tag [44]. Theoretically, RFID is a non-contact automatic identification technology where space coupling (inductive or electromagnetic coupling) of the radio frequency signal or the reflective transmission characteristics is used to achieve automatic identification of objects (tags) and the information output. In general, RFID systems are composed of an RFID tag and a reader. For passive RFID systems no battery is required as the power comes from an external signal received and converted by an antenna [48]. The major components of a simple RFID system are shown in Figure 2-44. However, passive RFID sensor systems generally operate within a shorter read range $(<5 \mathrm{~m})$, and performance could adversely be affected by electromagnetically "noisy" environments [45]. 


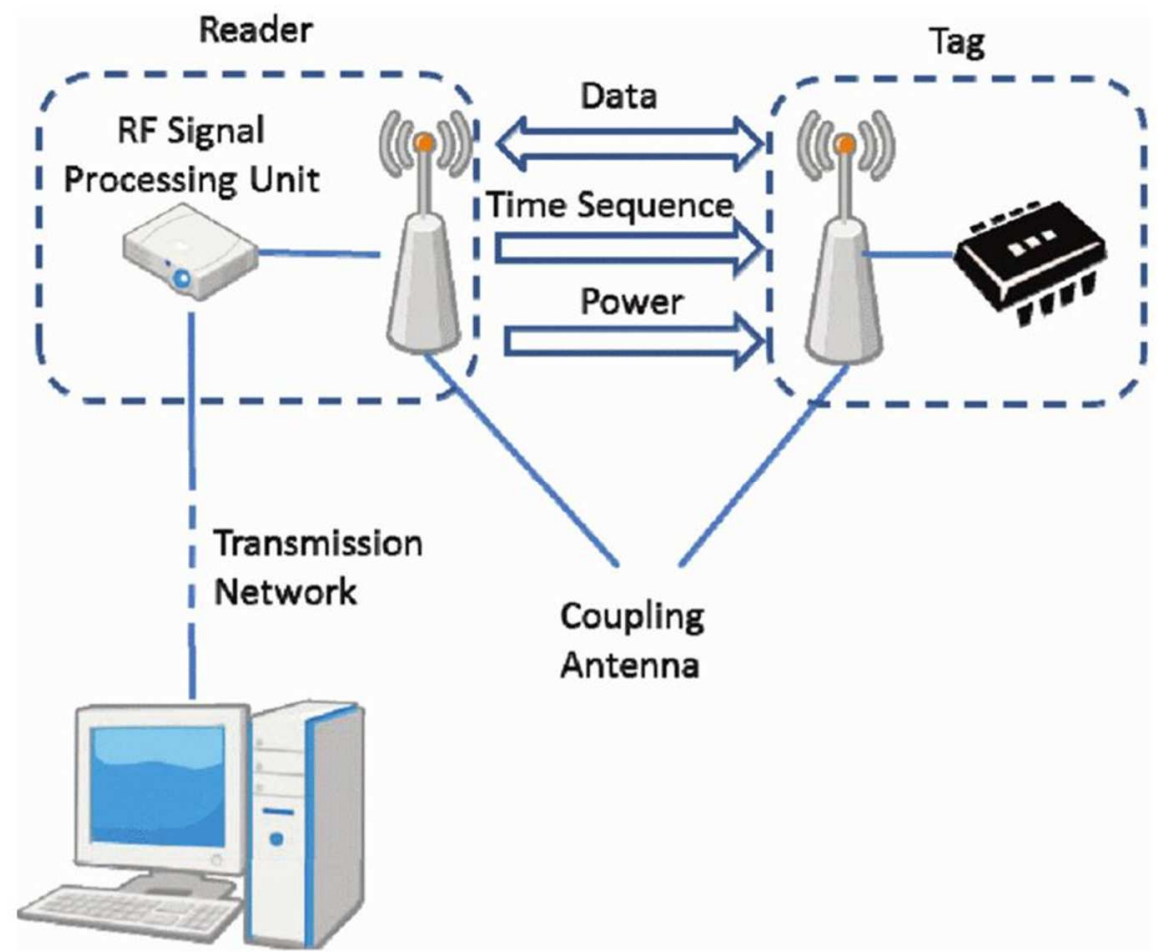

Figure 2-44: A simple RFID system [44]

The tag of RFID systems is the data carrier which consists of an antenna and a chip. Commonly used different kinds of RFID tags are classified by [44]:

- Power supply modes: active tags, passive tags and semi-passive tags,

- Working frequencies: low frequency tags $(30 \mathrm{kHz} \sim 300 \mathrm{kHz})$, high frequency tags $(3 \mathrm{MHz} \sim 30 \mathrm{MHz})$, ultra-high frequency tags $(300 \mathrm{MHz} \sim 3 \mathrm{GHz})$ and microwave frequency tags $(>3 \mathrm{GHz})$, and

- Encapsulations: credit card tags, line tags, paper-like tags, special-purpose tags, etc.

\subsubsection{Previous Studies}

RFID sensors were built into some concrete liners to detect strain and monitor the integrity of the liner during construction and in the future in the North Gate Link Extension 
light-rail tunnel in Seattle. The concrete liner was installed in a parallel pair of 3.5-milelong tunnels to accommodate Sound Transit's rail service between the University of Washington, in Seattle, and Northgate located north of the city. Preliminary studies found that wired sensors would prove bulky and difficult to install in the concrete liner, and therefore the need of wireless sensors was investigated by Phase IV Engineering [47]. Phase IV developed a battery-assisted passive (BAP) SensTag RFID strain sensor for the Northgate Link project, along with a mobile reader consisting of a telescoping antenna to interrogate the tags embedded in the liners as shown in Figure 2-45. The tags were designed in such a way that it could operate whether the battery is working or not even after the expiration of battery [47].

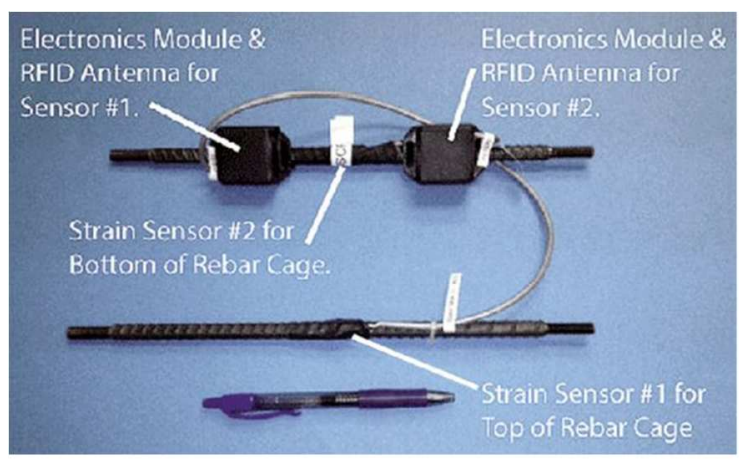

(a)

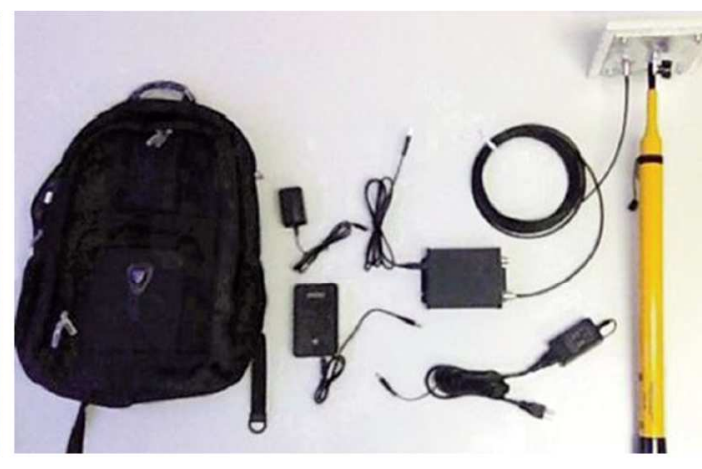

(b)

Figure 2-45: Phase IV's RFID (a) strain sensors attached with steel rods and (b) backpack with RFID reader and antenna [47]

A backpack RFID reader was designed and has the capability to reach tags in locations that are difficult to access (such as the top of the tunnel ceiling). Marks were also painted at the RFID locations to help users locate the tags during data collection. All the strain measurements were recorded, interpreted and stored using Phase IV provided software. RFID sensors were not installed into every section of the concrete liner; only 38 
segment rings where the passages are being cut were instrumented. Two sensors were embedded in three of the six sections within each of those rings giving a total number of about 200 sensors. Installation of six sensors in each ring provided some redundancy and served to check the sensors' accuracy in case of sensor malfunction or construction damage. A typical RFID sensor in the ring is shown in Figure 2-46.

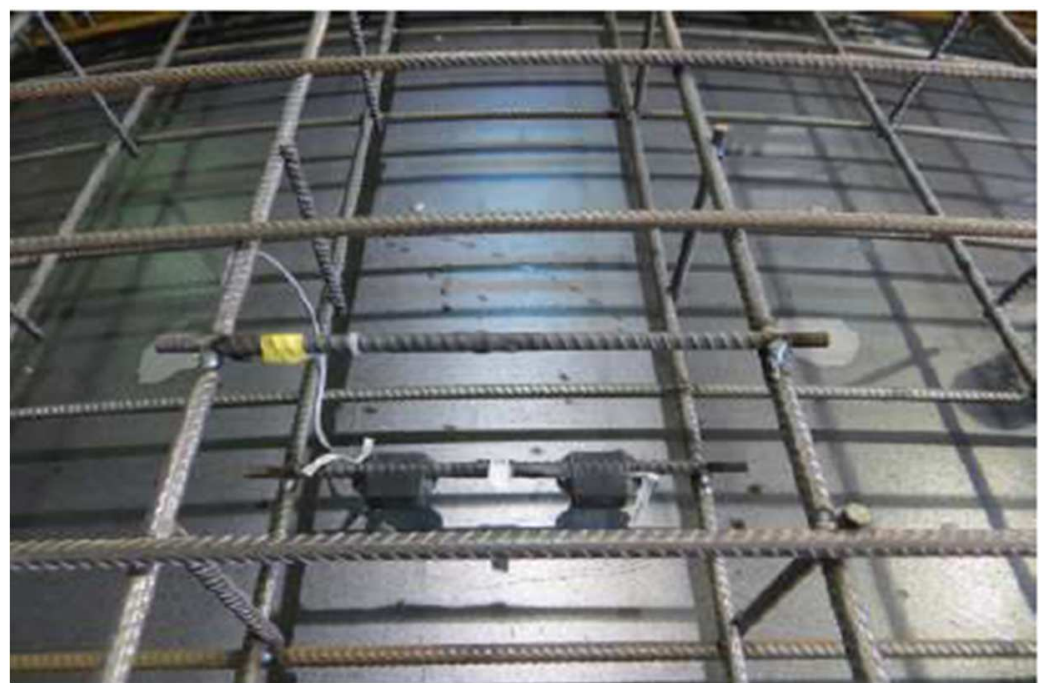

Figure 2-46: Embedded RFID strain sensor in tunnel reinforcement ring [47]

This is a recent study, so no results are yet available. The researchers did report that several the sensors were no longer responding. They hypothesized that these sensors were damaged during the casting of the concrete.

\subsubsection{Commercial Products}

Currently Phase IV's unique battery-free RFID wireless strain sensor is considered a RFID based wireless strain sensor that could be embedded in the concrete. For field use it comes with a RFID Reader Backpack. 


\subsection{CHAPTER SUMMARY}

Two types of local corrosion sensors were chosen for further investigation: (i) resonant sensors as a sacrificial element sensor and (ii) corrosion probes. A preliminary feasibility study was conducted on a resonant sensor developed by the researchers. Corrosion probes were constructed by the researchers including concrete resistivity and relative humidity sensors. Vibrating wire strain gauges (VWSGs) were used to measure strain changes in the members and verify the global monitoring technique.

Many of the problems associated with corrosion sensors occur because of the gauge or sensor being damaged during installation or casting or not being placed in the correct location or orientation. Care was made throughout the research to install gages and sensors correctly and tips for field installation were compiled. 


\section{CHAPTER 3. METHODOLOGY}

\subsection{OVERVIEW OF RESEARCH OBJECTIVES AND HYPOTHESES}

As previously introduced, the objectives of this research were:

- To evaluate the feasibility of using currently available local and global corrosion sensing techniques to monitor the performance of concrete structures,

- To develop a protocol for the evaluation of local and global sensors to facilitate the validation of new technologies as they become available, and

- To develop recommended sensor placement layouts to give professional engineers guidance to when and where sensors should be used.

The research aimed to answer two primary questions:

1. Question \#1: Will the proposed method accurately determine the localized strand corrosion and the impact of the corrosion on global behavior?

2. Question \#2: Will the proposed method help selection of sensors and sensor placement scheme (location of the sensors within these structures) for implementation of the results into industry practice?

The hypotheses based on these questions that were verified through this research were:

1. Hypothesis \#1: Local sensors can be used to detect localized corrosion by either monitoring the concrete environment to see when conditions are conducive to corrosion propagation or by monitoring the corrosion damage of a sacrificial element made of similar materials to the prestressing strands. 
Localized corrosion will impact the overall behavior of a member, which can be detected using vibrating wire gauges.

2. Hypothesis \#2: A global instrumentation scheme for bridge monitoring can be implemented to effectively and efficiently monitor the corrosion propagation for pre and post-tensioned structures.

This chapter discusses the methods in detail that were adopted to achieve the research objectives and solve the problem statement mentioned in Chapter 1.

\subsection{ENVISIONED SENSING SYSTEM}

The initially envisioned sensing system would consist of both local corrosion sensors and sensors monitoring the overall behavior of the structure. For post-tensioned (PT) structures, this would include corrosion sensors embedded in the PT ducts and strain sensors embedded in the precast element, as shown in Figure 3-1. The local corrosion would be used to detect when the environment in the PT duct would be conducive for corrosion initiation and propagation. The strain sensors would be used to determine when the localized corrosion damage was impacting the overall structural performance of the bridge. A proposed layout for these sensors along the length of the bridge will be determined through this research. 


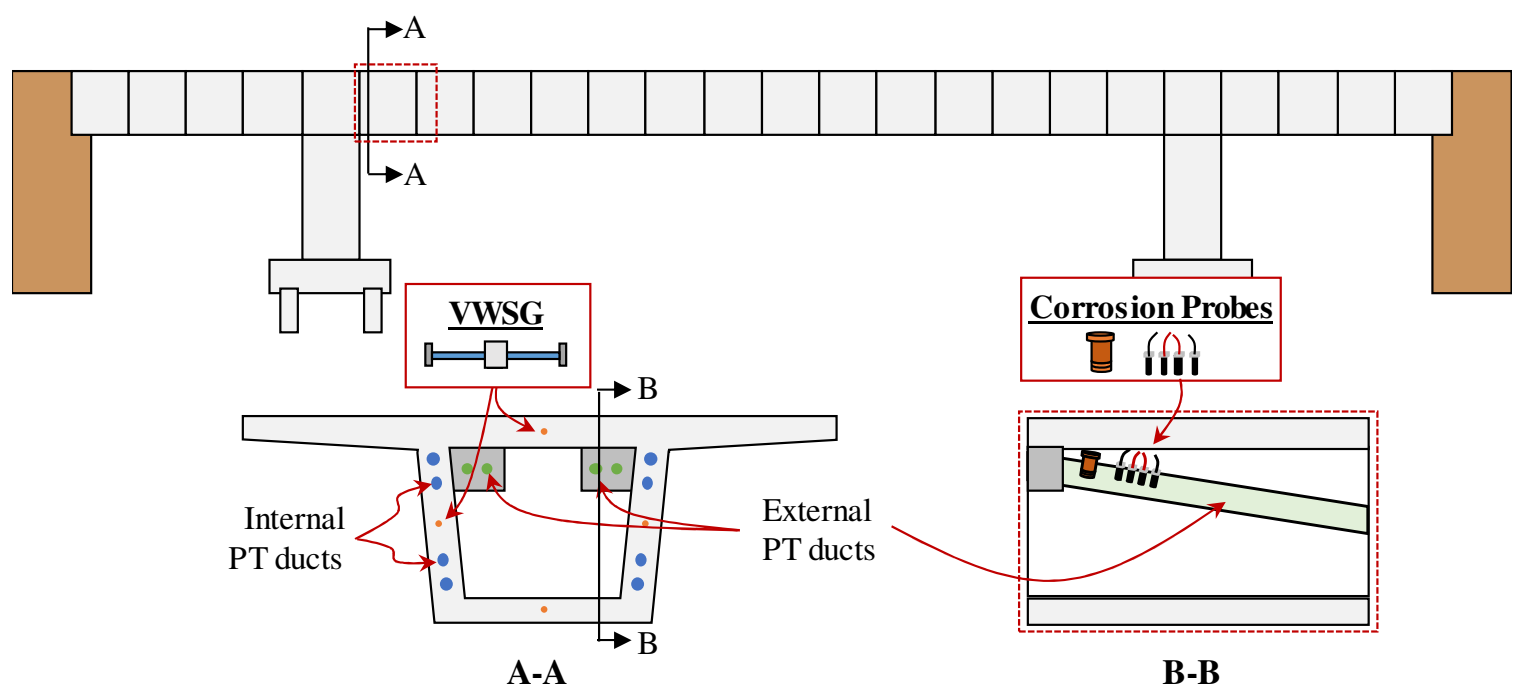

Figure 3-1: Schematic of proposed monitoring system with local corrosion sensors and strain sensors for structural behavior monitoring

\subsection{EXPERIMENTAL APPROACH}

These two monitoring systems were independently investigated through the research program, as shown in Figure 3-2. The local corrosion monitoring system was investigated through testing of grouted duct specimens. The ability of strain sensors to detect localized corrosion damage was assessed through testing of full-scale pretensioned beams. 


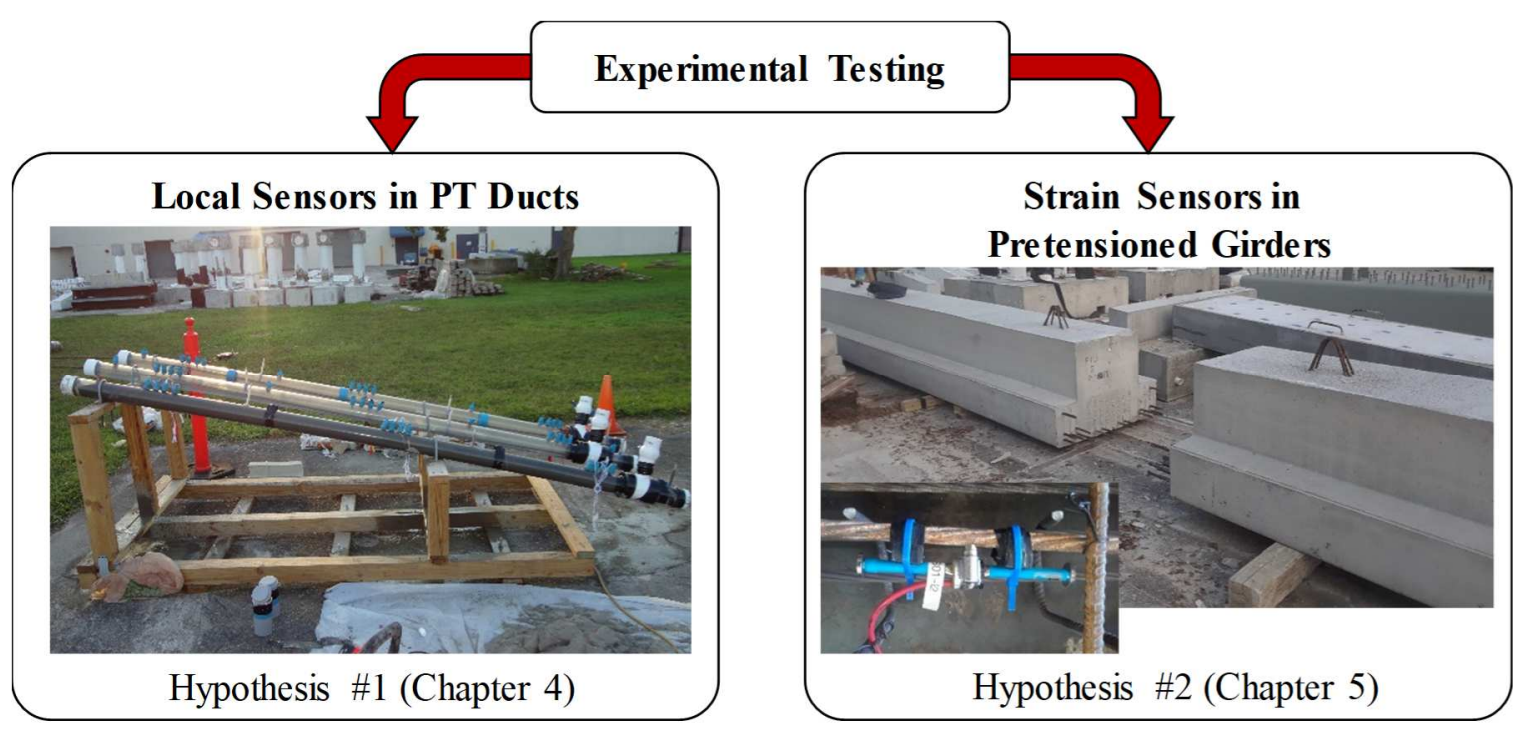

Figure 3-2: Overview of experimental program

\subsubsection{Local Corrosion Sensor Testing}

Previous researchers have shown that some of the factors that influence corrosion in grout are electrical resistance (resistivity), soluble ion content, $\mathrm{pH}$, and moisture content. Generally, lower resistivity indicates higher corrosive nature of grout, though other factors such as salinity, water content, presence of voids and direction of water flow also influence the grout resistivity properties. A four-point electrical resistivity sensor was used to monitor the grout performance by measuring the electrical properties of the grout in different locations. Relative humidity sensors were used to determine locations with high moisture contents, which can lead to increased corrosion activity.

\subsubsection{Global Performance Measurement using Strain Sensors}

Two full-scale, pretensioned inverted tee beams were instrumented with vibrating wire strain gauges (VWSGs) to measure strains and curvature in each beam at several different locations. The purpose of this instrumentation scheme is to effectively monitor the impact of localized corrosion on the global performance of structure. The collected data was compared with the non-corroded condition to determine the extent that localized 
corrosion damage influenced the global behavior of the structure. The data collection effort also included the effective design of a data acquisition system along. Results from this testing was used to recommend an efficient and effective instrumentation scheme.

\subsection{CHAPTER SUMMARY}

This chapter introduced the methodologies adopted to confirm the proposed hypotheses. These efforts are separated into a small-scale experimental program to investigate the efficacy of local corrosion sensors (Chapter 4) and destructive testing of full-scale pretensioned beams to determine the ability of strain sensors to detect corrosion initiation and propagation (Chapter 5). 


\section{CHAPTER 4. EXPERIMENTAL CORROSION EVALUATION OF LOCAL SENSORS}

\subsection{OVERVIEW}

There are two primary methods for determining corrosion of prestressing strands using local sensors: (i) monitoring the environment to determine when it is conducive for corrosion or (ii) monitoring the corrosion damage of a similar sacrificial material. In this study, two types of local sensors were used to monitor the grout environment: (1) resistivity sensors and (2) relative humidity sensors. The grout electrical resistivity would give indication of moisture content and other grout physical anomalies that can allow for accelerated corrosion. Monitoring the relative humidity of the grout would likewise provide indication of higher moisture levels and may identify physical grout anomalies that would allow accumulation of water. A preliminary study was also conducted on a sacrificial type of resistor-inductor-capacitor (RLC) wireless sensor, where corrosion to a sacrificial element shifts the resonant frequency.

\subsection{LOCAL SENSORS}

\subsubsection{4-Point Resistivity Sensors}

Previous studies have shown that electrical resistance (resistivity) of concrete and grout is a factor that influences corrosion; decreased resistivity corresponds to increased corrosion rates $[49,50]$. A Wenner four-point electrical resistivity sensor was developed to monitor the resistivity of the grout in small-scale grouted tendon specimens. Each resistivity sensor was comprised of four metal electrodes embedded in the grouted duct 1.5 
inches apart along a straight line, as shown in Figure 4-1. The voltage drop between the center pair of electrodes was measured with current flowing between the outside electrodes.

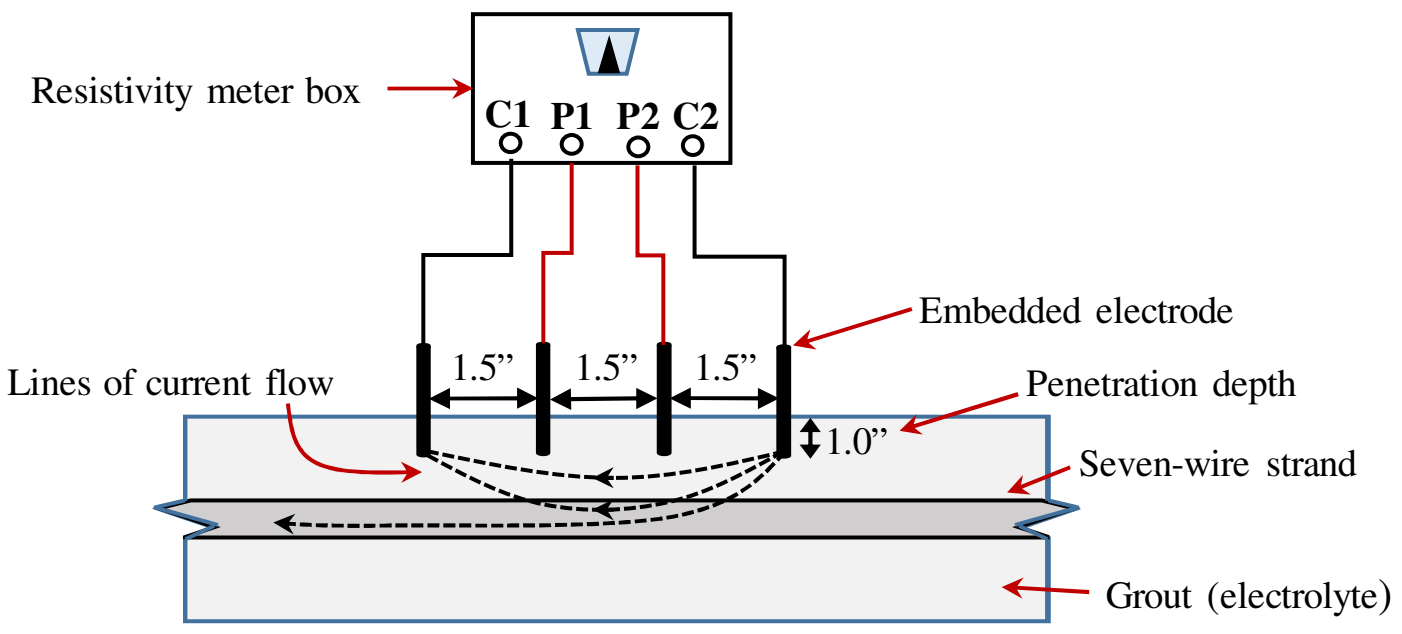

Figure 4-1: Schematic diagram of the Wenner four-point resistivity

Each embedded electrode consisted of a 0.25 -inch diameter mixed metal oxide counter electrode attached to copper wire, shown in Figure 4-2 (a). A picture of the installed sensor prior to grouting is shown in Figure 4-2 (b). Each embedded electrode extended approximately 1 inch into the grout. The embedded electrodes were placed so they did not touch the prestressing strand.

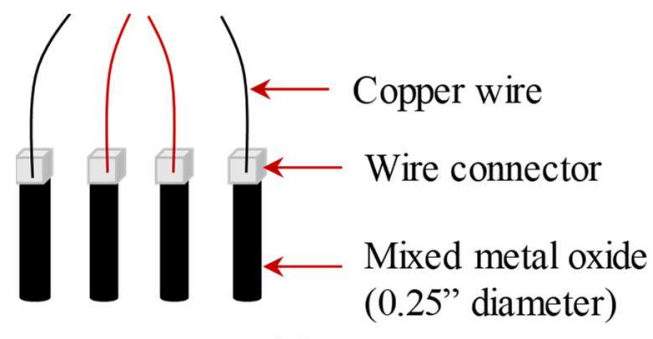

(a)

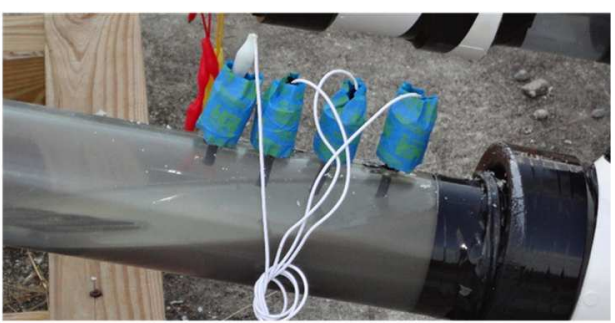

(b)

Figure 4-2: (a) Schematic of 4-point resistivity sensor and (b) installed sensor before grouting

\subsubsection{Relative Humidity Sensors}

Moisture in grouted ducts can be caused by excessive bleed water resulting from the vibration operation during grout pumping $[51,52]$ or from leaking through grout vents 
or at joints. As moisture is required for the corrosion process, high relative humidity (RH) in concrete and grout is a sign of an environment conducive for corrosion [53]. Commercially available Rapid RH 4.0 sensors were used to obtain the relative humidity reading inside the grouted duct. These sensors were designed to measure the $\mathrm{RH}$ in concrete slabs. The sensors consist of a smart touch sensor, solid side walls creating a void and a protective cap, as shown in Figure 4-3 (a). A view of the sensor from the top without the protective cap is shown in Figure 4-3 (b).

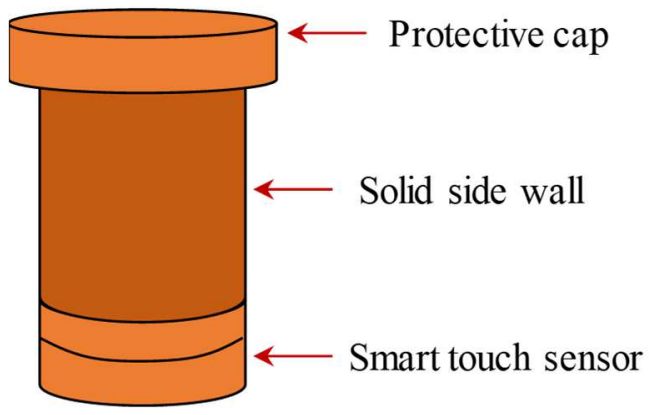

(a)

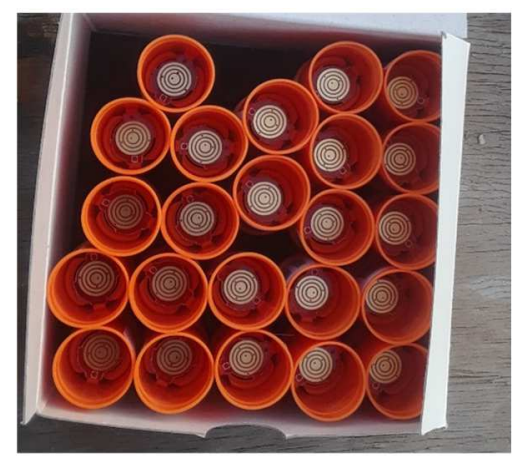

(b)

Figure 4-3: Schematic diagram of RH sensors

The process of installation of these RH sensors is shown in Figure 4-4; these sensors were installed after casting of the grout. A hole was drilled into the grouted duct, taking care to avoid any strands in the duct, and then cleaned, as shown in Figure 4-4 (a). The sensor was then installed into the drilled hole extending approximately 1 inch into the grout using an insertion tool that was provided with the sensors, Figure 4-4 (b). The protective cap was then placed on the sensor, Figure $4-4$ (c). RH was measured by removing the protective cap and inserting a specialized handheld reading device. 


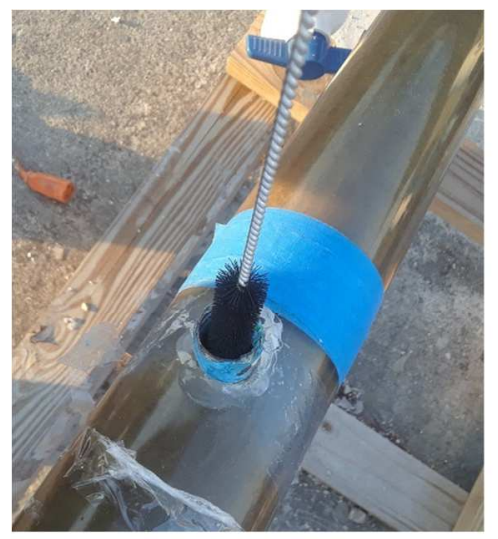

(a)

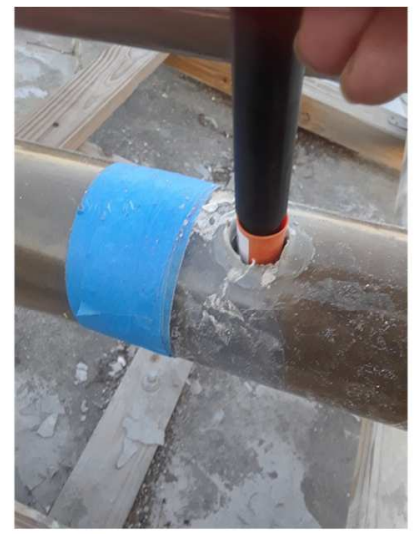

(b)

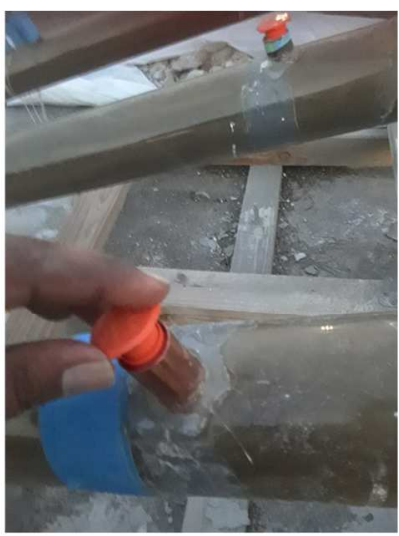

(c)

Figure 4-4: Installation of RH sensors (a) clearing dust, (b) inserting sensor and (c) putting cap

\subsection{EXPERIMENTAL METHODS}

\subsubsection{Test Setup}

Two pressure treated wooden platform anchored in a concrete slab were constructed to hold the clear PVC pipes (3-inch nominal diameter and 10 feet long). The pipes were supported by the wood frame and held in place using steel U-bolts that looped over the PVC pipe, as shown in Figure 4-5 (a). A single 0.6-inch diameter seven wire strand was placed in the pipe attached to the center of the lower cap and extending out of the center of the upper cap. The strand was held at the center of the pipe at the top and the bottom of the pipe but not restrained along the length. The strand sagged slightly at the mid-length of the pipes during casting of the grout. 


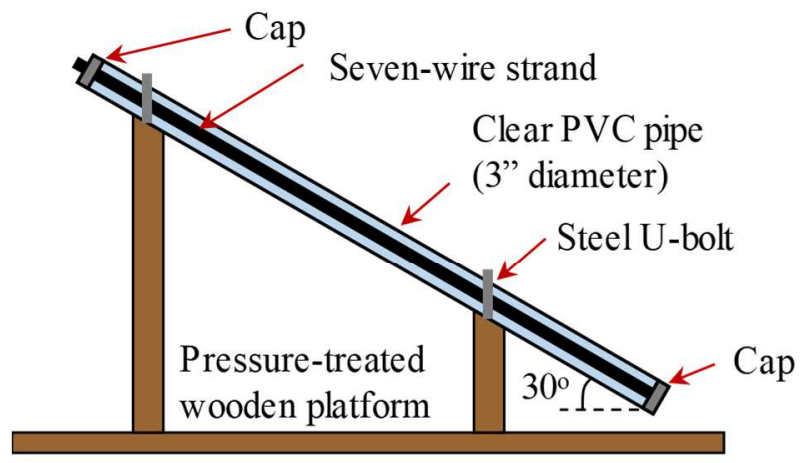

(a)

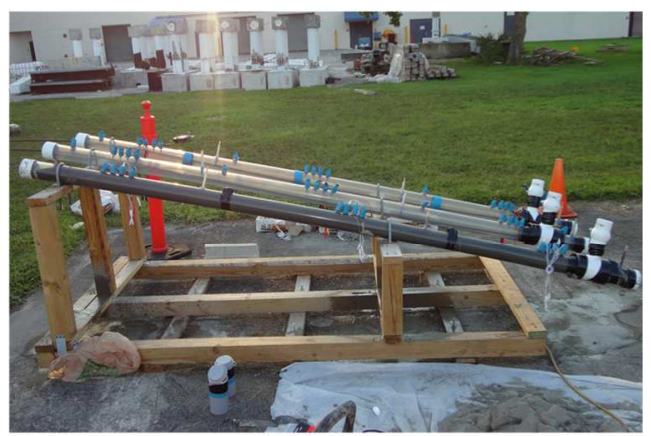

(b)

Figure 4-5: Key components of test setup (a) schematic and (b) test setup after grouting first 30-degree specimen

\subsubsection{Test Matrix}

Six 10-foot long grouted ducts (3-inch diameter) with a single prestressing strand were used to evaluate the performance of the local sensors; details for these six specimens are provided in Table $4-1$.

Table 4-1: Initial test matrix for evaluation of local sensors

\begin{tabular}{|c|c|c|c|c|c|c|}
\hline \multirow[b]{2}{*}{$\begin{array}{c}\text { Specimen } \\
\#\end{array}$} & \multirow[b]{2}{*}{$\begin{array}{l}\text { Strand } \\
\text { Profile }\end{array}$} & \multicolumn{2}{|c|}{ Number of Sensors } & \multirow[b]{2}{*}{$\begin{array}{c}\text { Chloride } \\
\text { Contamination }\end{array}$} & \multirow[b]{2}{*}{$\begin{array}{c}\text { Water } \\
\text { Recharge }\end{array}$} & \multirow[b]{2}{*}{$\begin{array}{l}\text { Grout } \\
\text { Type }\end{array}$} \\
\hline & & $\begin{array}{c}\text { Relative } \\
\text { Humidity } \\
\text { Sensors }\end{array}$ & $\begin{array}{c}\text { Electrical } \\
\text { Resistivity } \\
\text { Sensors }\end{array}$ & & & \\
\hline 1 & $30^{\circ}$ & 3 & 3 & & & Good \\
\hline 2 & $30^{\circ}$ & 3 & 3 & $5.0 \%$ & $\mathrm{x}$ & $\begin{array}{l}\text { Chloride } \\
\text { rich }\end{array}$ \\
\hline 3 & $30^{\circ}$ & 3 & 3 & $5.0 \%$ & $\mathrm{x}$ & Dissimilar \\
\hline 4 & $5^{\circ}$ & 3 & 3 & & & Good \\
\hline 5 & $5^{\circ}$ & 3 & 3 & $5.0 \%$ & $\mathrm{x}$ & $\begin{array}{c}\text { Chloride } \\
\text { rich }\end{array}$ \\
\hline 6 & $5^{\circ}$ & 3 & 3 & $5.0 \%$ & $\mathrm{x}$ & Dissimilar \\
\hline
\end{tabular}

Two different inclined strand profiles were used (5 and 30 degrees) to investigate near flat conditions and a reasonable upper limit for inclines found in the field, as shown in Figure 4-6. 


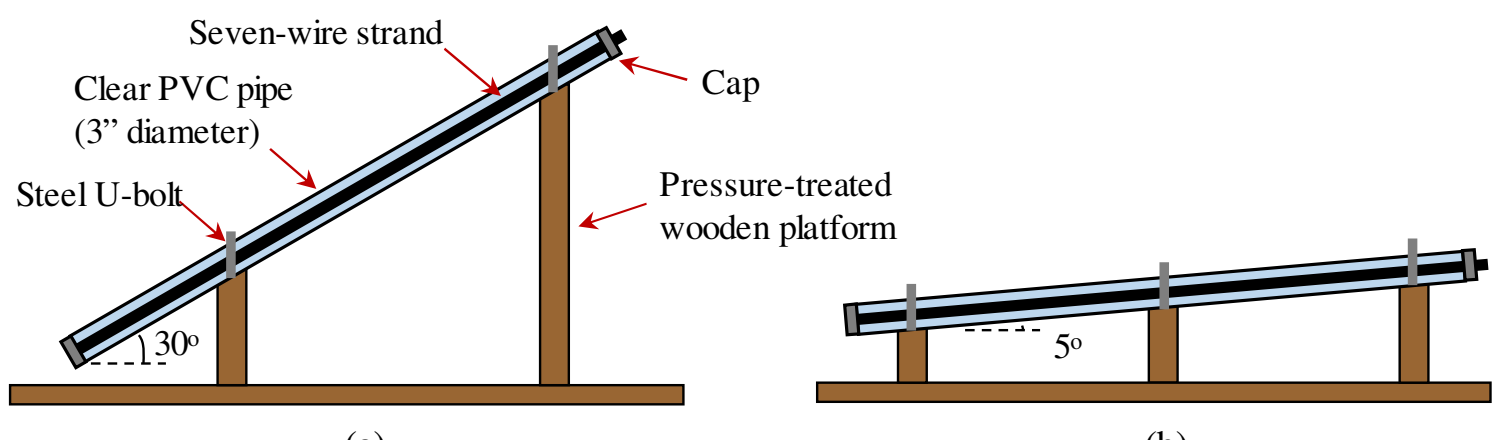

(a)

(b)

Figure 4-6: Two strand profiles used for grouted pipe specimens (a) 30 degrees and (b) 5 degrees

The same number of sensors were used in all specimens (three RH sensors and three resistivity sensors), with a sensor toward the lower end of the duct, at mid-length, and toward the upper end of the duct, as shown in Figure 4-7. The spacing of the resistivity sensors was kept equal and specified such that one sensor was located in each layer of grout in the layered grout specimens (discussed below). As described above, the resistivity sensors consisted of four 0.25 -inch diameter mixed metal oxide counter electrodes that were installed prior to casting of the grout. The RH sensors were installed after the grout had hardened.

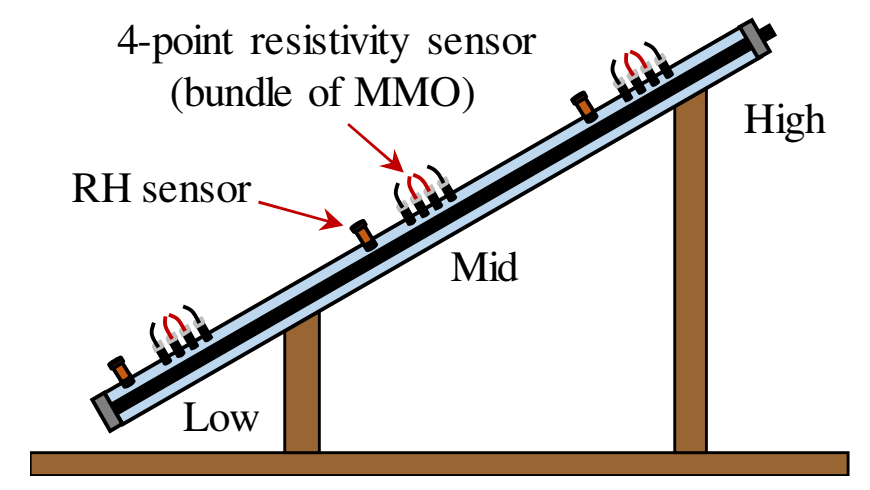

Figure 4-7: Location of resistivity and RH sensors

One control specimen was constructed for both the 5-degree and 30-degree strand profiles. The control specimen had good grout with no internal voids and no water recharge 
points, shown in Figure 4-8 (a) and (c). One specimen for both the 5-degree and 30-degree strand profiles was cast with chloride rich grout with internal voids and three water recharge points, shown in Figure 4-8 (b) and (d). Holes were drilled approximately 1.5 inches into the grout from the outside to create the water recharge points. A total chloride content of 5 percent by weight of cement was used for all chloride-rich grout as this is well above the concentration required to cause active corrosion $[54,55]$. Styrofoam was broken down and mixed in with the deficient grout to create internal voids. Small voids (Styrofoam pieces $<0.5$ in.) typically formed toward the top of section along the length, but a large void (Styrofoam pieces $>0.5$ in.) was visually observed close to the mid-length of most of the specimens, as shown in Figure 4-8 (d).

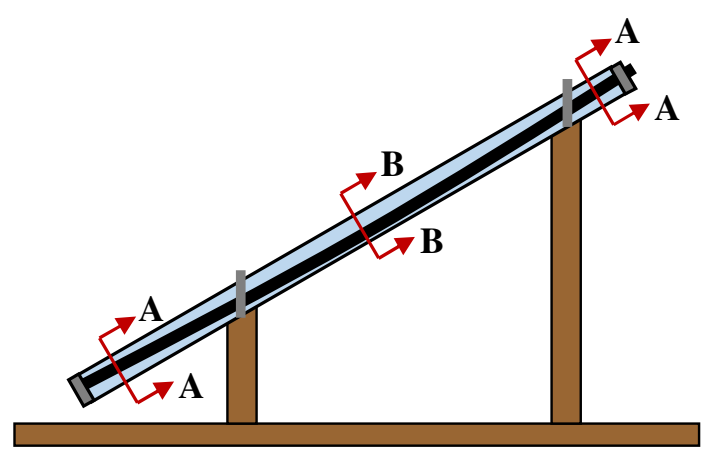

(a)

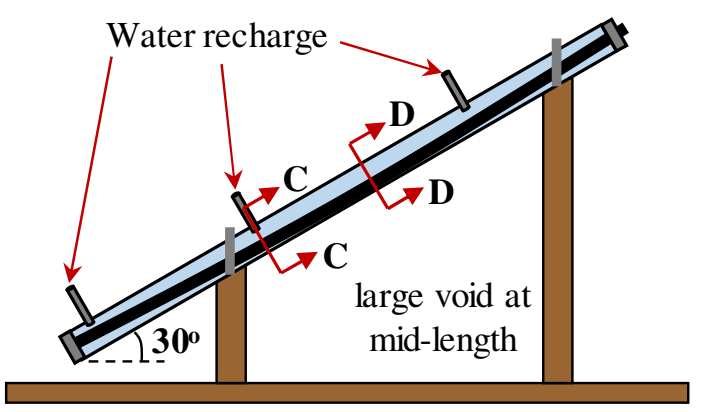

(b)

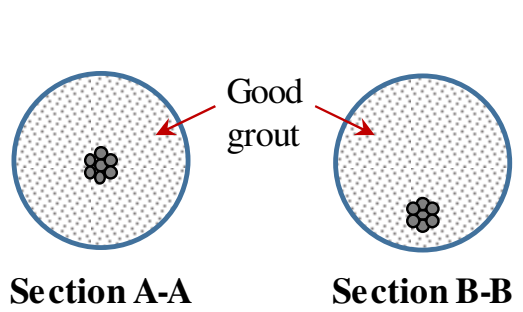

(c)

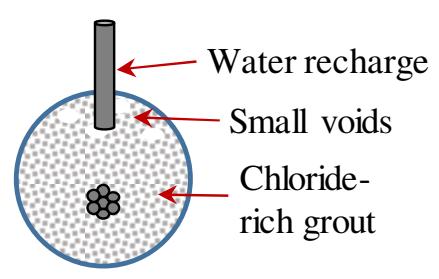

Section C-C

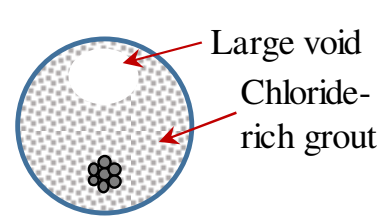

Section D-D

(d)

Figure 4-8: Schematic 30-degree specimen with (a) good grout condition, (b) chloride-rich grout, (c) Section A-A with good consolidation, (d) Section B-B with small random Styrofoam voids, and (e) Section $C$ - $C$ with large concentrated Styrofoam void 
One specimen for both the 5-degree and 30-degree strand profiles was cast with layered or dissimilar grout, shown in Figure 4-9. The grout was well consolidated along the entire length of these specimens, Figure 4-9 (b); i.e. there were no internal voids. Three layers were cast for these specimens: approximately 3 feet of good grout followed by approximately 4 feet of chloride-rich grout followed by good grout for the remainder of the specimen, as shown in Figure 4-9 (a). Each layer of grout was cast while the previous layer of grout was still wet, so no cold joints would form between the layers but crosscontamination between layers was possible.

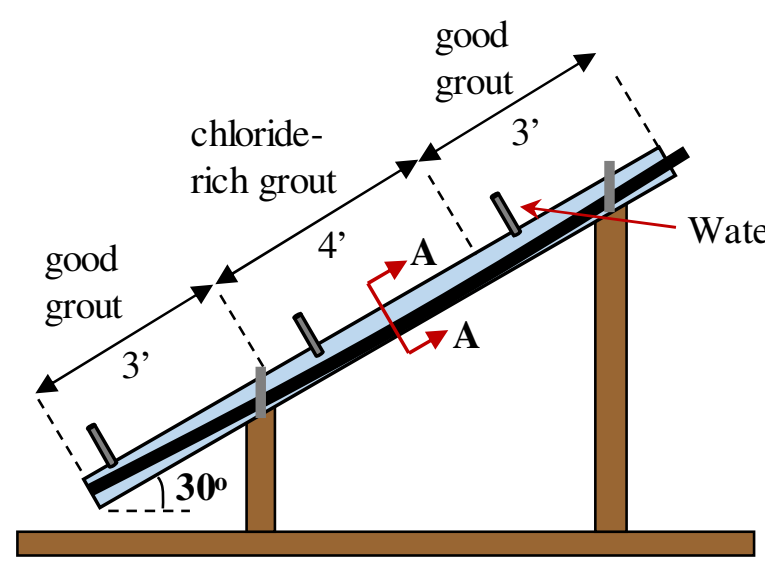

(a)

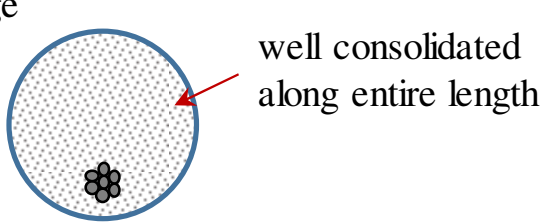

Section A-A

(b)

Figure 4-9: Schematic 30-degree specimen with dissimilar grout (a) elevation and (b) Section A-A

Photographs of the 30-degree and 5-degree specimens are shown in Figure 4-10 (a) and (b) respectively. 


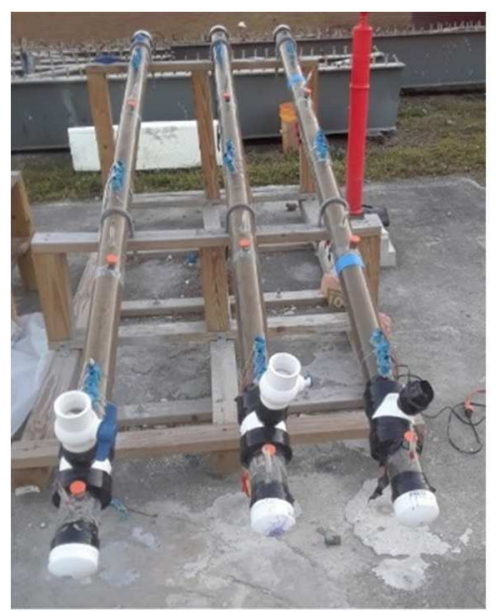

(a)

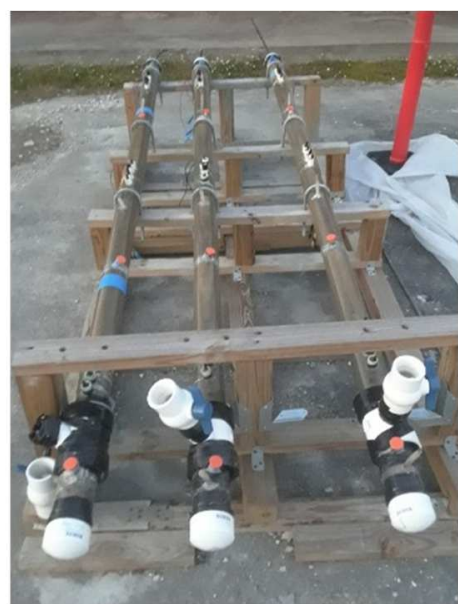

(b)

Figure 4-10: Specimens with (a) 30-degree strand profile and (b) 5-degree strand profile

\subsubsection{Construction}

\subsubsection{1. $\quad$ Strand Preparation}

Six typical 7-wire, low relaxation, uncoated strands with an ultimate strength of $270 \mathrm{ksi}$ were used in this experiment. External rust was cleaned off using a 2-inch circular coarse wire brush and dust removed using acetone prior to testing, as shown in Figure 4-11.

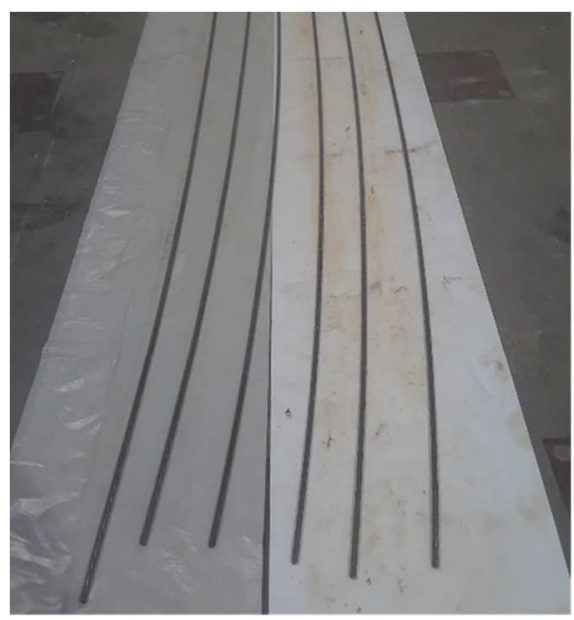

(a)

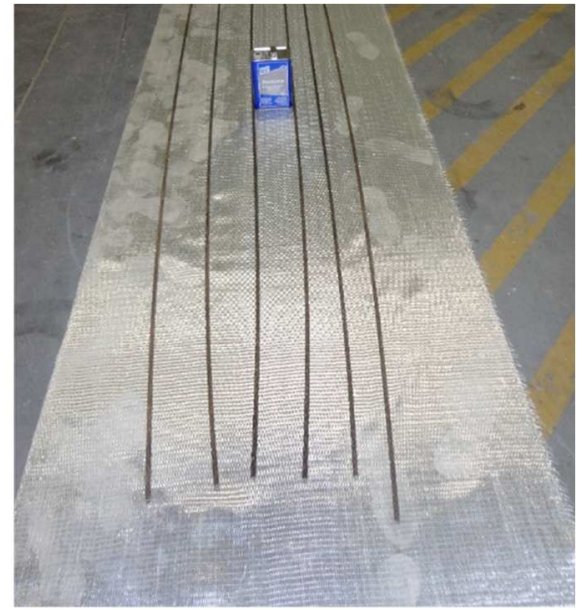

(b)

Figure 4-11: (a) Surface dust removal of strands before putting in plastic duct and (b) use of acetone to remove dust from the bar surface 
After cleaning, the strand was placed in the clear plastic PVC pipe, shown in Figure 4-11. A center-hole plastic disk was used at the ends of the clear plastic pipes to hold the strand at the centroid of the section.

\subsubsection{Grouting of Tendons}

Three different conditions were achieved using three different grout mixtures, shown in Table 4-2. Quikrete non-shrink precision grout was used as the base grout for all the grout mixtures. The good grout only contained the non-shrink grout and water with a water-to-cement ratio $(\mathrm{w} / \mathrm{cm})$ of 0.5 . Two different chloride-rich grout mixtures were used: one with voids and one without voids. The chloride content in both chloride-rich grout mixtures was 5-percent by weight of cement. Pieces of broken Styrofoam was used to create voids in one of the chloride-rich grouts.

Table 4-2: Mix designs for grout used in small-scale testing

\begin{tabular}{|l|c|c|c|}
\hline Component & Good Grout & $\begin{array}{c}\text { Chloride-Rich } \\
\text { (w/voids) }\end{array}$ & $\begin{array}{c}\text { Chloride-Rich } \\
\text { (w/o voids) }\end{array}$ \\
\hline $\begin{array}{l}\text { Quikrete Non-Shrink } \\
\text { Precision Grout }\end{array}$ & $50 \mathrm{lb}$. & $50 \mathrm{lb}$. & $50 \mathrm{lb}$. \\
\hline Water & $13.5 \mathrm{lb}$ & $13.5 \mathrm{lb}$ & $13.5 \mathrm{lb}$ \\
\hline $\begin{array}{l}\text { Table Salt (Plain, Iodine } \\
\text { Free) }\end{array}$ & $0 \mathrm{lb}$ & $3 \mathrm{lb}$. & $3 \mathrm{lb}$. \\
\hline w/cm Ratio & 0.5 & 0.5 & 0.5 \\
\hline Total Chloride Content & $\begin{array}{c}0 \% \\
\text { (by weight } \\
\text { cement) }\end{array}$ & $\begin{array}{c}5 \% \\
\text { (by weight } \\
\text { cement) }\end{array}$ & $\begin{array}{c}5 \% \\
\text { (by weight } \\
\text { cement) }\end{array}$ \\
\hline
\end{tabular}

Grout was mixed in a five-gallon bucket and placed into each of the specimens from the top, as shown in Figure 4-12. Grouting was done in three lifts with each lift being placed before the previous lift had hardened, which avoided any cold joints between the lifts. The lifts in the dissimilar grout specimens had different mix designs: Lift 1 and Lift 3 having 
good grout and Lift 2 having chloride-rich grout without voids. All lifts in the other specimens were constructed of grout with the same mix design.
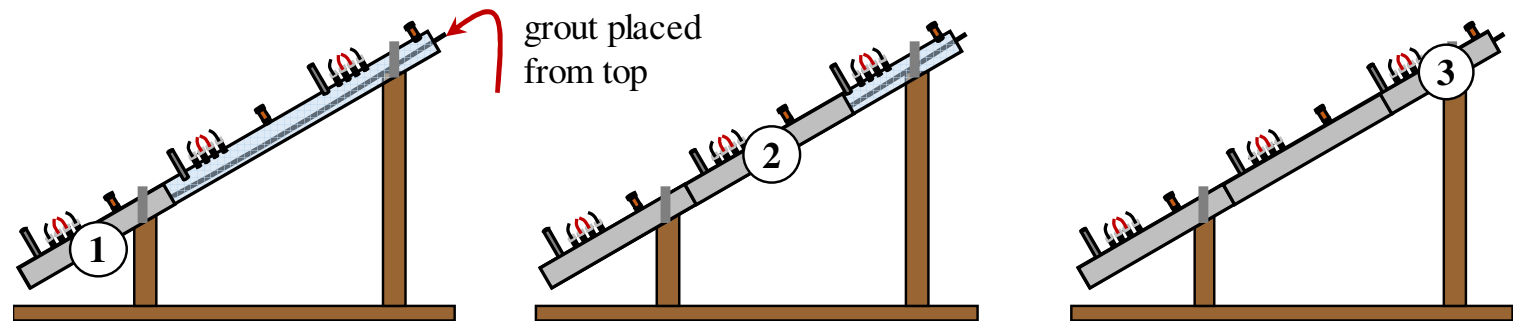

Figure 4-12: Grouting process for all specimens

The standard flow cone of grout test [56] was used to ensure the grout was flowable enough for proper consolidation. The compressive strength of the grout was measured for the three different mixtures using 3 -inch by 6 -inch cylinders at 7 and 28 days using standard test procedures [57]. The average strengths for the different grouts are shown in Table 4-3.

Table 4-3: Average compressive strength for grout

\begin{tabular}{|c|c|c|}
\hline \multirow{2}{*}{$\begin{array}{c}\text { Age } \\
\text { (days) }\end{array}$} & \multicolumn{2}{|c|}{ Average Compressive Strength } \\
\cline { 2 - 3 } & Good Grout & $\begin{array}{c}\text { Chloride-Rich } \\
\text { (w/voids) }\end{array}$ \\
\hline 7 & $937 \mathrm{psi}$ & $913 \mathrm{psi}$ \\
\hline 28 & $1737 \mathrm{psi}$ & $1253 \mathrm{psi}$ \\
\hline
\end{tabular}

\subsubsection{Test Protocol}

All the small-scale test specimens were cast on the same day with the resistivity sensors installed in the specimens prior to casting, as shown in Table 4-4. The relative humidity sensors were installed three months after the specimens were cast with the first readings being taken when the grout was 92 days old. 
Table 4-4: Dates of important events for small-scale test specimens

\begin{tabular}{|l|c|c|}
\hline Event & Date & $\begin{array}{c}\text { Age of Grout } \\
\text { (days) }\end{array}$ \\
\hline Casting of Specimens & $10 / 14 / 18$ & 0 \\
\hline Resistivity Sensors Installed & $10 / 14 / 18$ & 0 \\
\hline Relative Humidity Sensors Installed & $1 / 14 / 19$ & 92 \\
\hline $\begin{array}{l}\text { Cycle 1 of Accelerated Corrosion } \\
\text { (5V for 3 hours on all specimens) }\end{array}$ & $1 / 20 / 19$ & 97 \\
\hline $\begin{array}{l}\text { Cycle 2 of Accelerated Corrosion } \\
\text { (5V for 6 hours on all specimens) }\end{array}$ & $1 / 27 / 19$ & 104 \\
\hline $\begin{array}{l}\text { Cycle 3 of Accelerated Corrosion } \\
\text { (5V for 6 hours on all specimens) }\end{array}$ & $2 / 3 / 19$ & 111 \\
\hline
\end{tabular}

Three separate cycles of accelerated corrosion were applied to all six of the specimens. A 30-volt DC power supply was used to apply a potential difference of 5 volts for 3 hours for the first cycle when the specimens were 97 days old, as shown in Figure 4-13. A potential difference of 5 volts was applied for 6 hours for the second and third cycles when the specimens were 104 and 111 days, respectively.

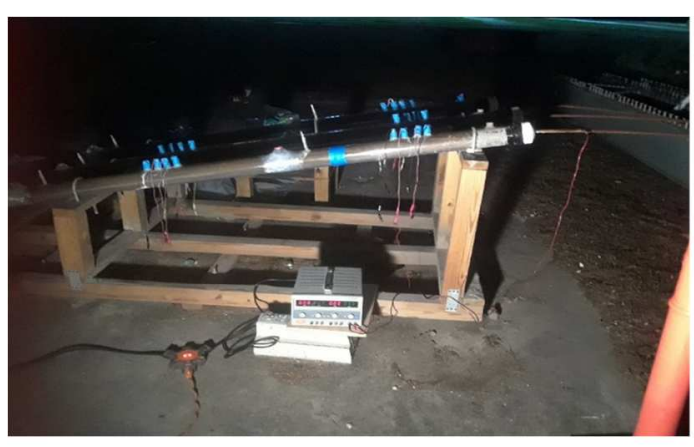

(a)

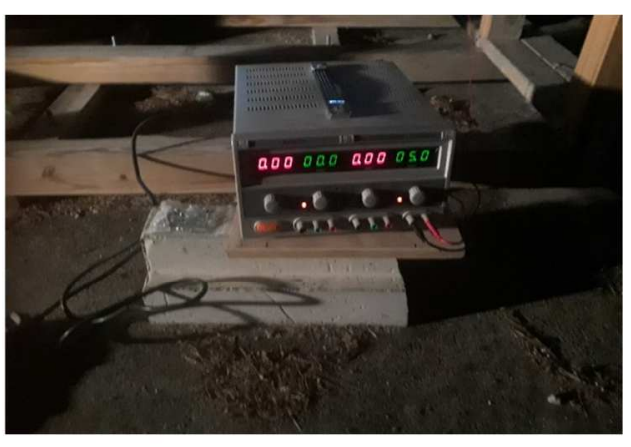

(b)

Figure 4-13: Constant potential difference created to induce strand corrosion 


\subsection{RESULTS AND OBSERVATIONS}

\subsubsection{Resistivity Measurements}

Theoretically, the resistance is measured and a nominal resistivity value can be calculated using Equation 4-1.

$$
\rho=2 \pi S R
$$

Equation 4-1

where,

$$
\begin{aligned}
& \rho=\text { resistivity }(\Omega-\mathrm{cm}) \\
& S=\text { electrode spacing }(\mathrm{cm}) \\
& R=\text { resistance value }(\Omega)
\end{aligned}
$$

The electrodes were isolated from the steel strand to avoid electrical contact; however, in geometries with a greater number of strands, current distribution effects may be significant. Smaller interelectrode spacing would require more intricate sensor design including electrode material, fabrication, and installation through the thick tendon wall. Nevertheless, the nominal calculated resistivity values are useful to compare regions of the grout deficiencies. The resistivity measurements from the specimens with good grout, chloride-rich grout with voids, and layered good grout and chloride-rich grout without voids are shown in Figure 4-14, Figure 4-15, and Figure 4-16, respectively. The resistivity values for the good grout specimens averaged 5,000 ohm-cm and above compared to less than $400 \mathrm{ohm}-\mathrm{cm}$ for the chloride-rich and layered grout specimens. 


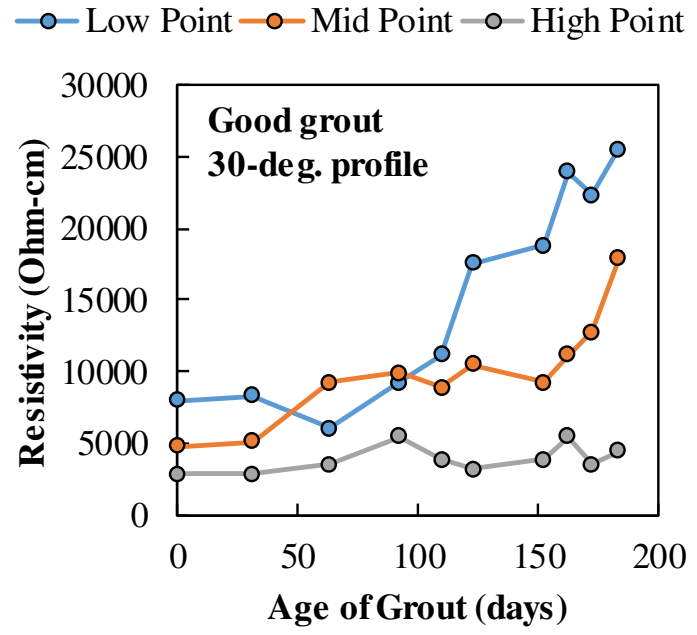

(a)

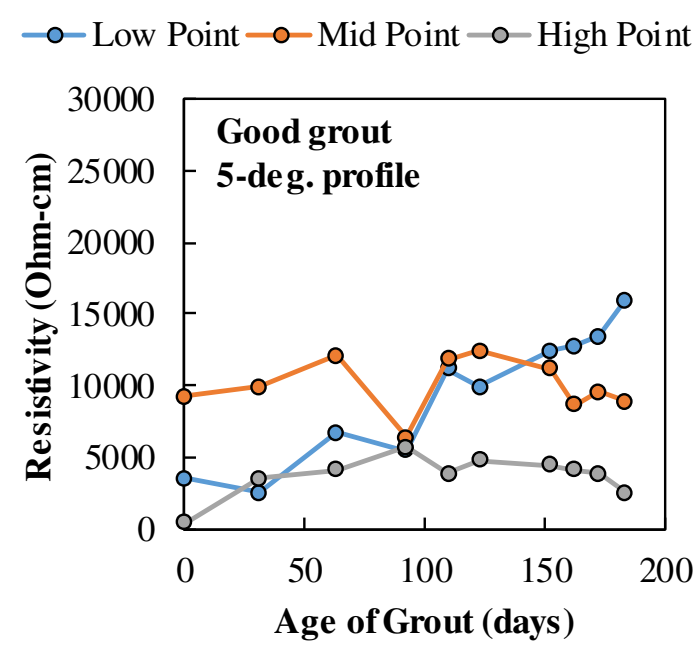

(b)

Figure 4-14: Good grout resistivity for (a) 30-degree strand profile and (b) 5-degree strand profile

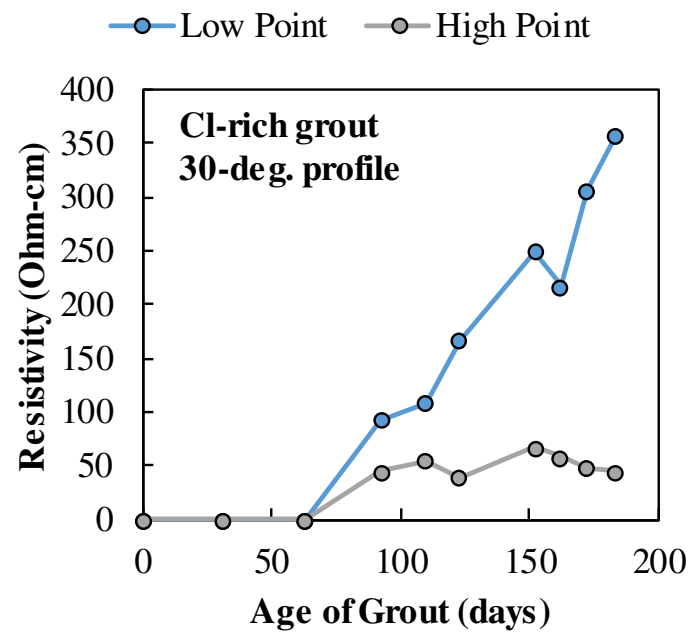

(a)

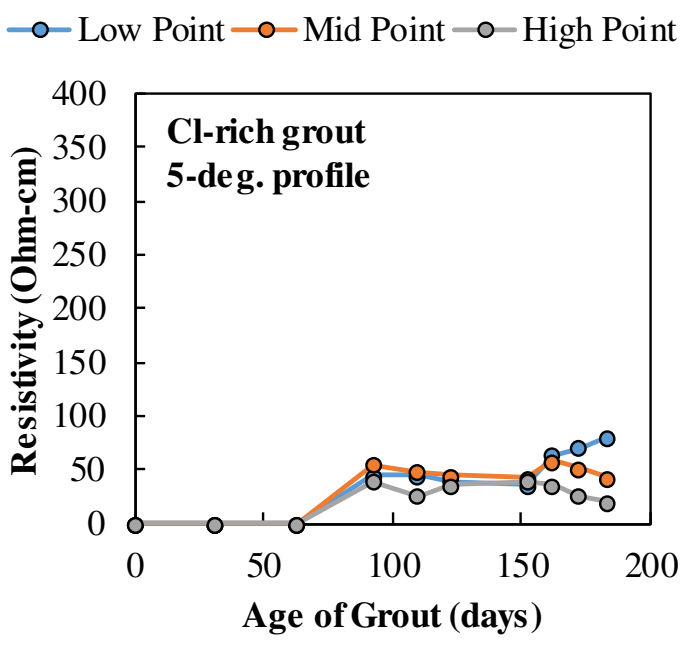

(b)

Figure 4-15: Chloride-rich grout resistivity for (a) 30-degree strand profile and (b) 5-degree strand profile 


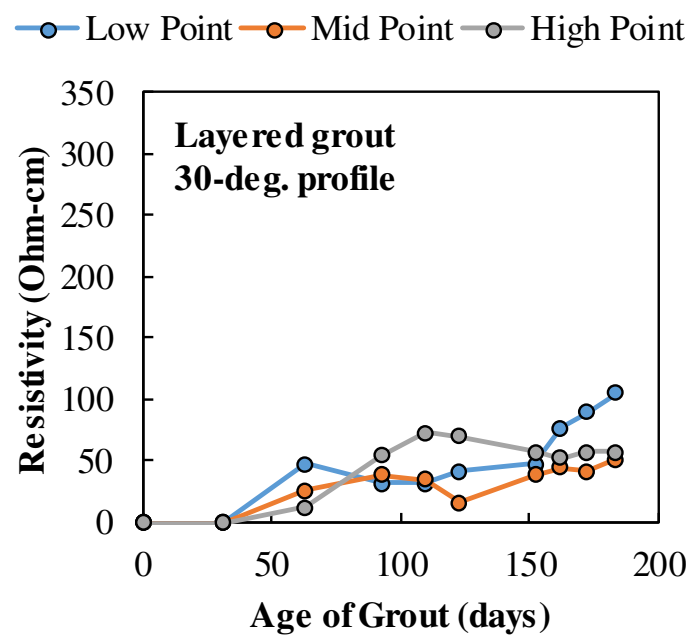

(a)

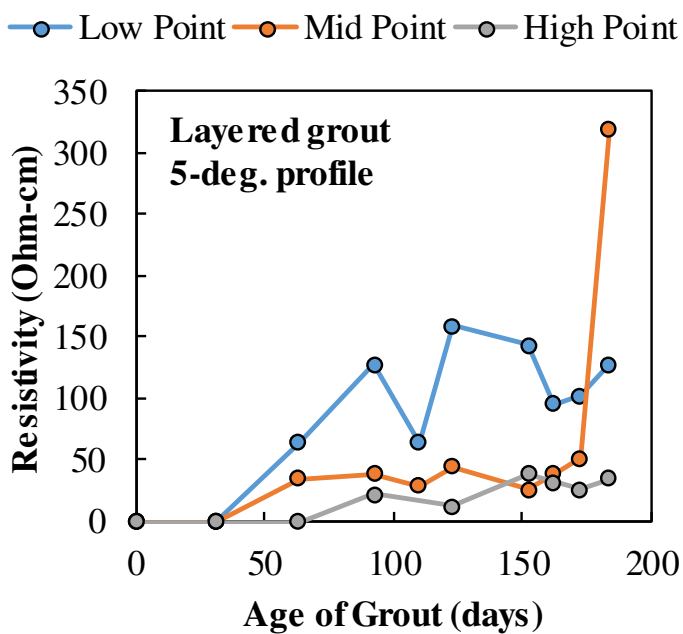

(b)

Figure 4-16: Layered grout resistivity for (a) 30-degree strand profile and (b) 5degree strand profile

\subsubsection{Relative Humidity Measurements}

Relative humidity (RH) was measured at three different locations in each of the six small-scale specimens:

- Low point: toward the bottom of the specimen (near one-third length from the end of the specimens),

- Mid-point: approximately two-thirds length from the bottom end of the specimens, and

- High point: almost at the top end of the specimens.

The external ambient $\mathrm{RH}$ and temperature near the storage location of the specimens was gathered (from [58]) to see if there was a correlation between the internal measured RH and external RH, shown in Figure 4-17. 


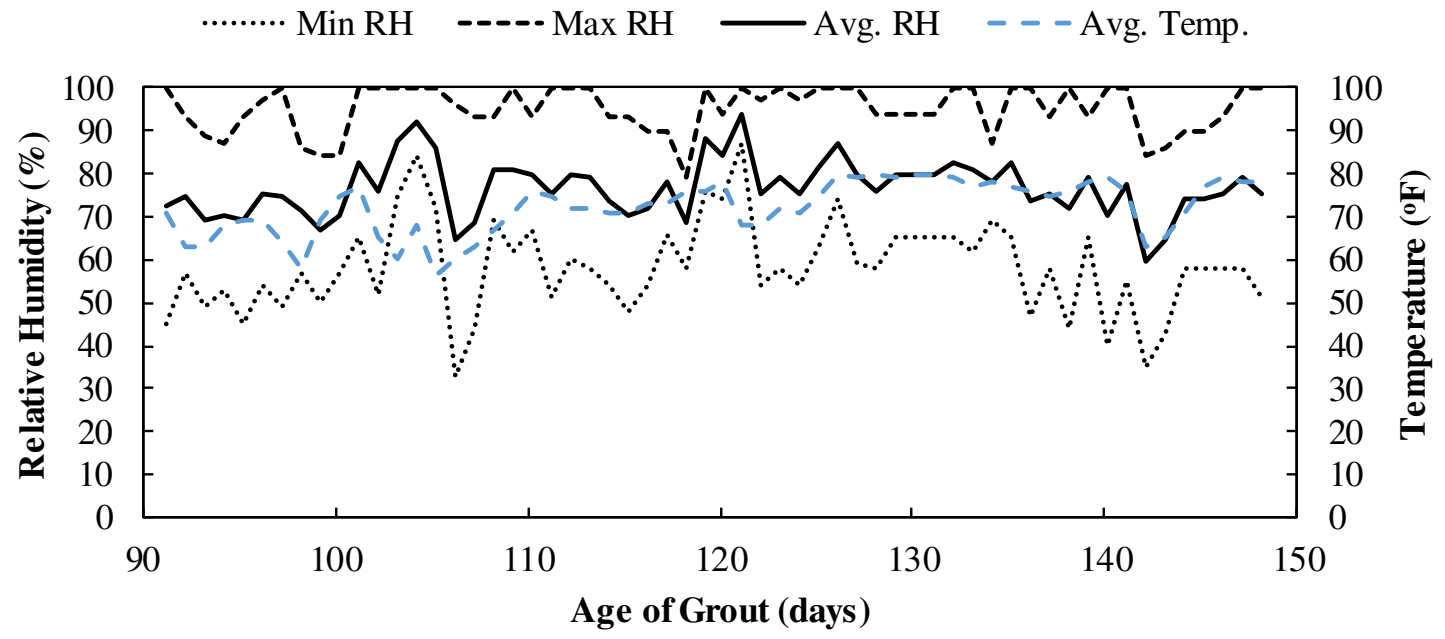

Figure 4-17: Minimum and maximum daily ambient humidity and average daily temperature during time of testing 


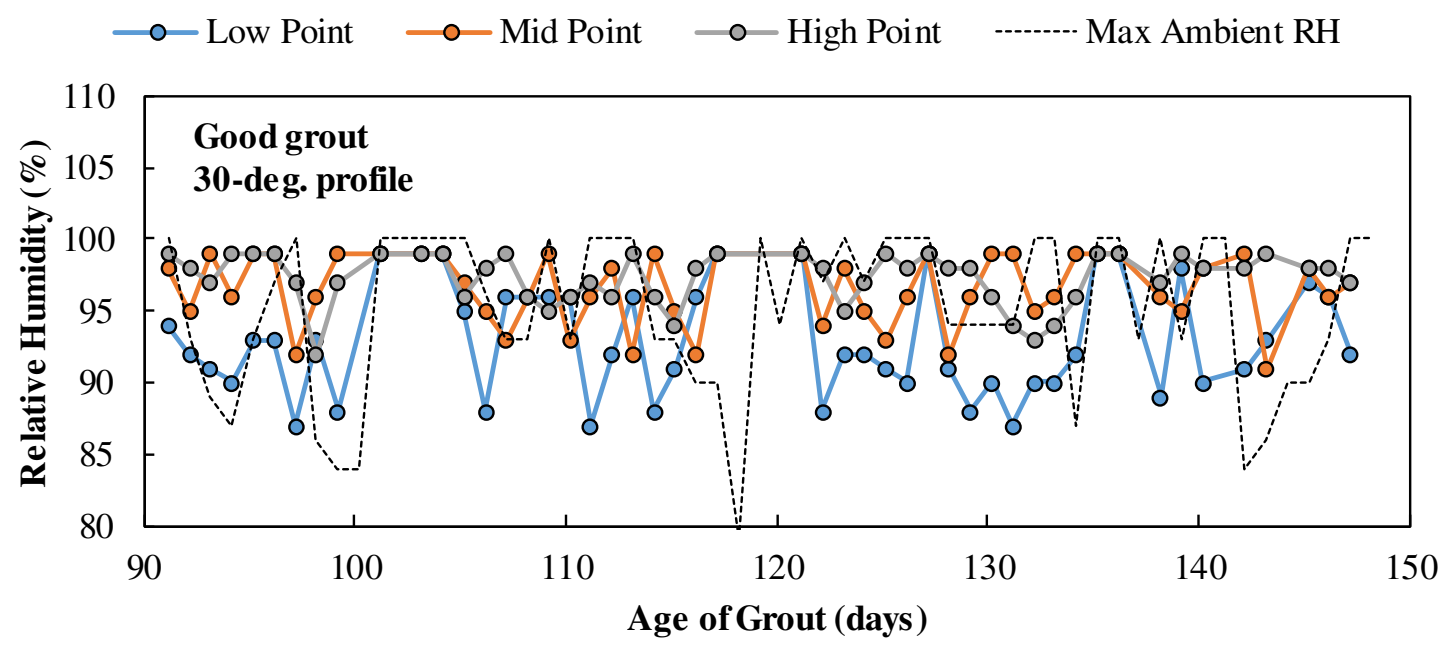

(a)

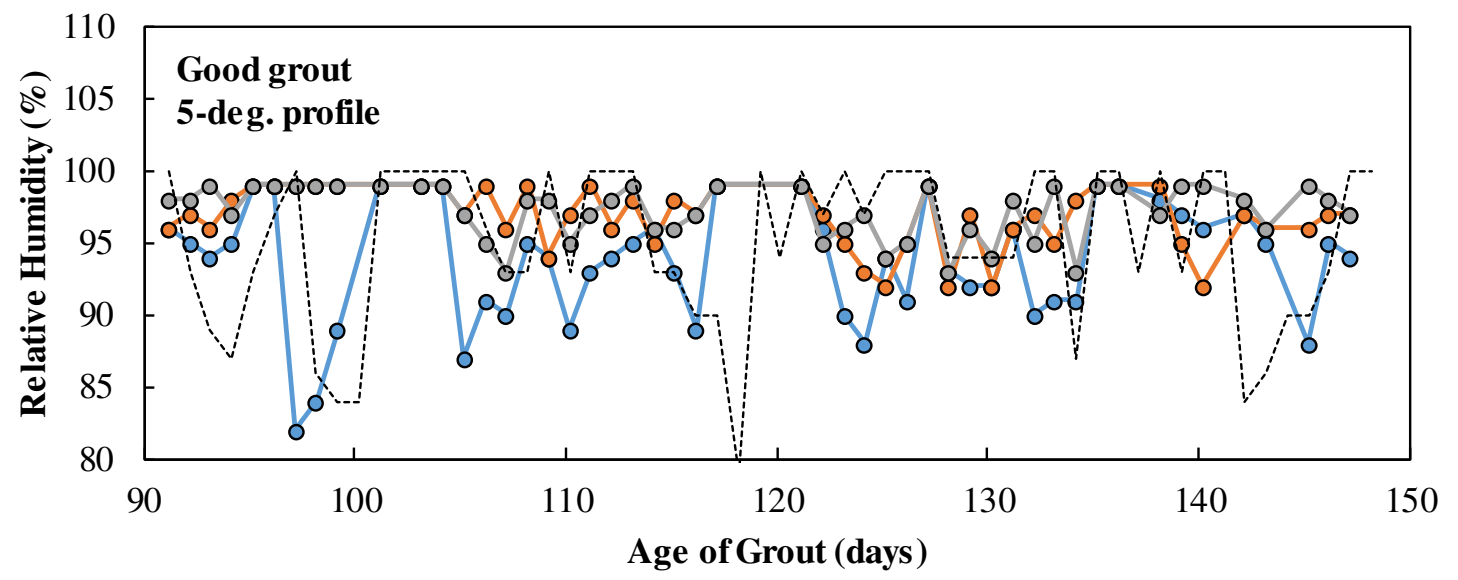

(b)

Figure 4-18: Relative humidity of good grout for (a) 30-degree strand profile and (b) 5-degree strand profile 


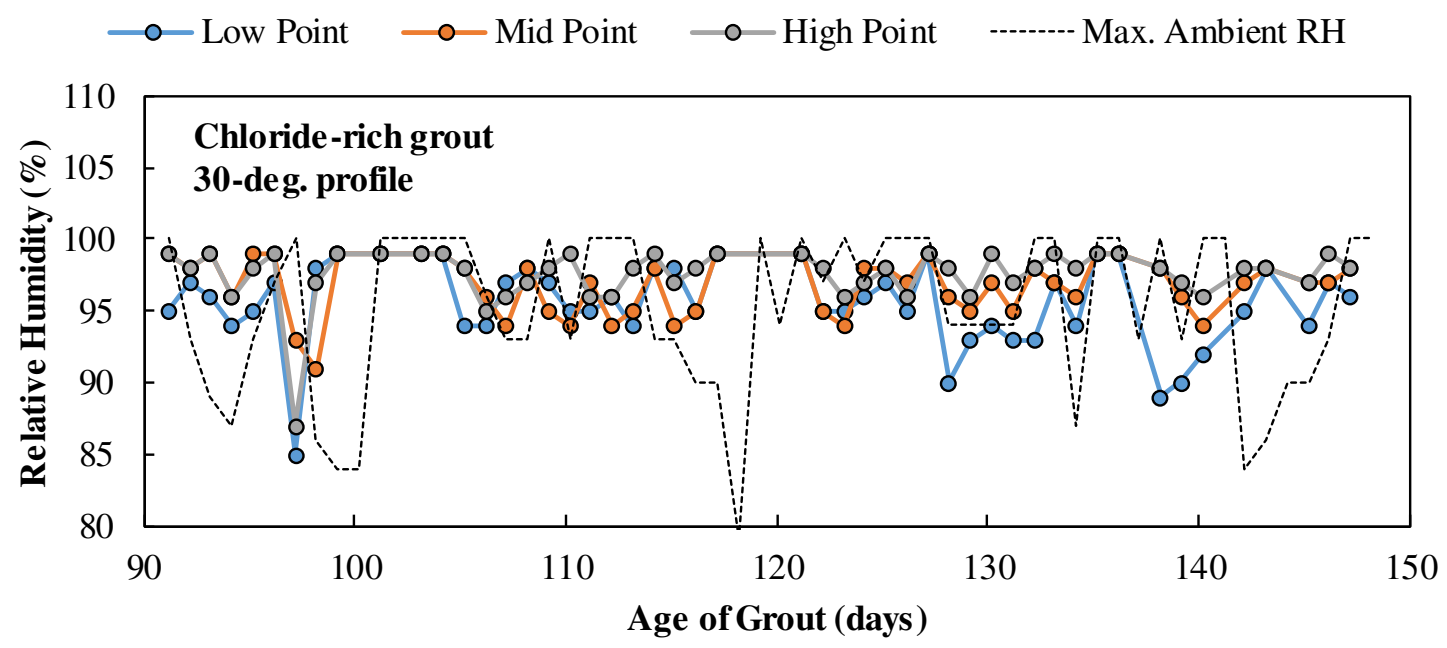

(a)

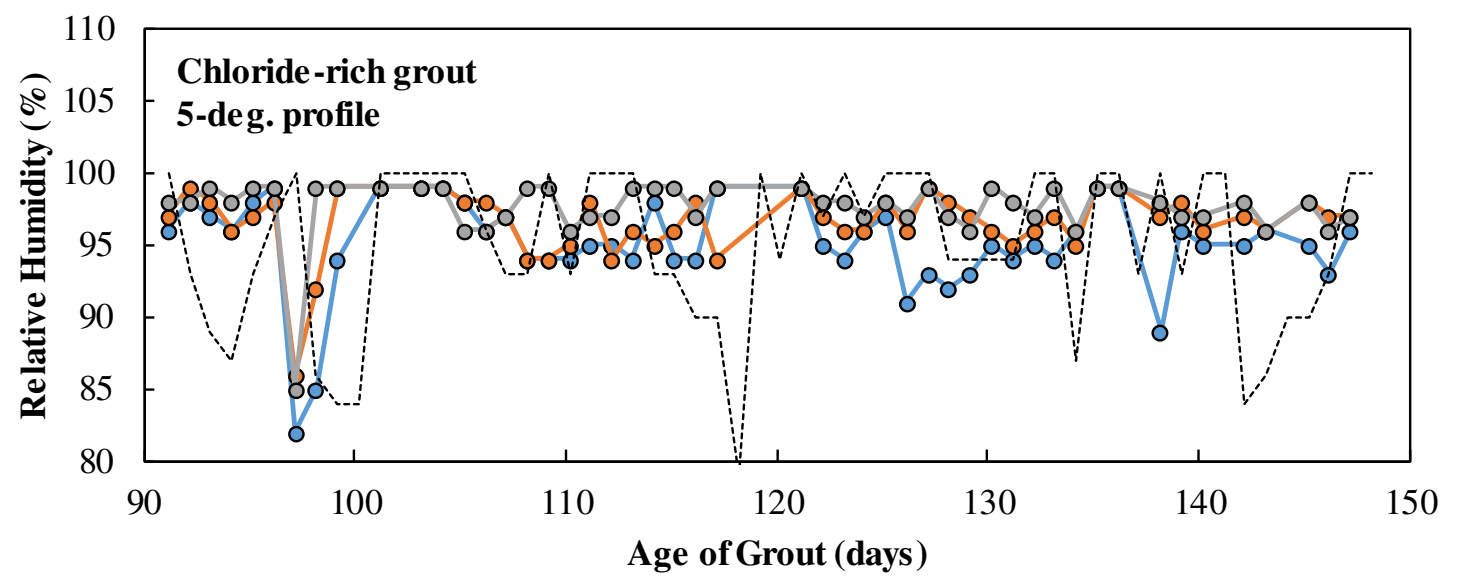

(b)

Figure 4-19: Relative humidity of chloride-rich grout for (a) 30-degree strand profile and (b) 5-degree strand profile 


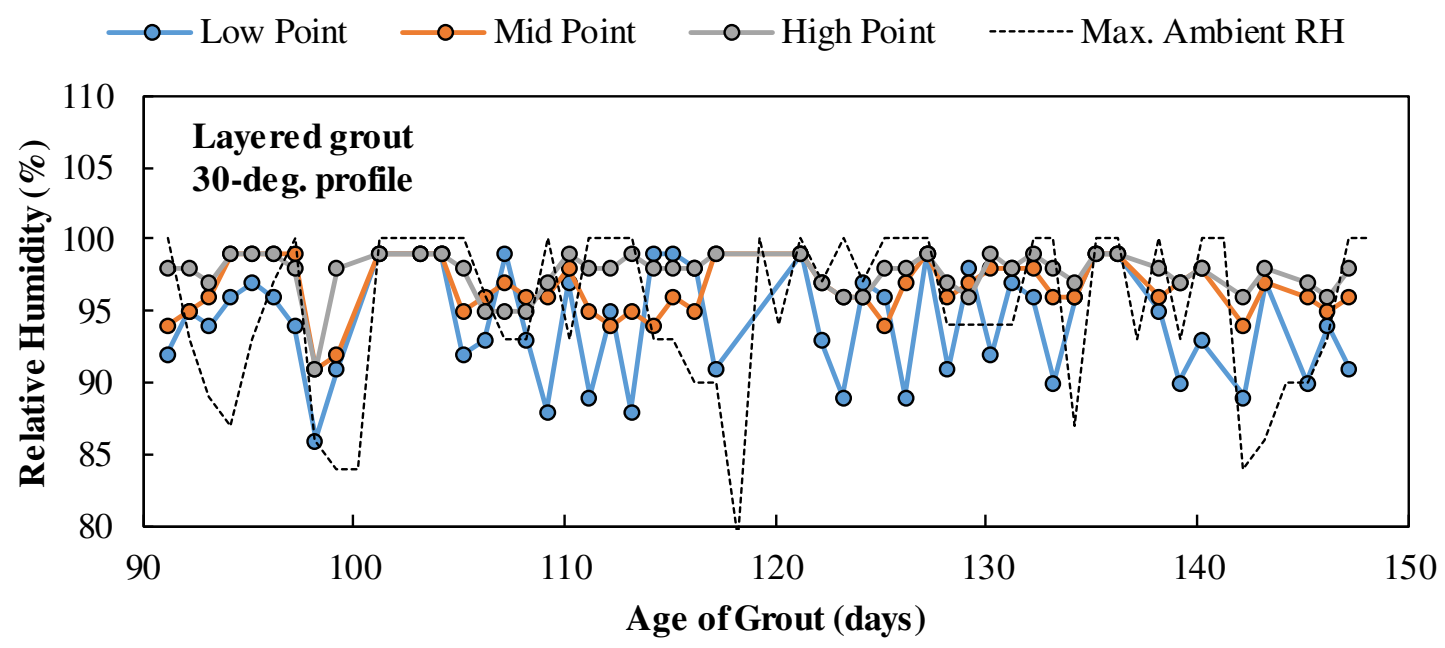

(a)

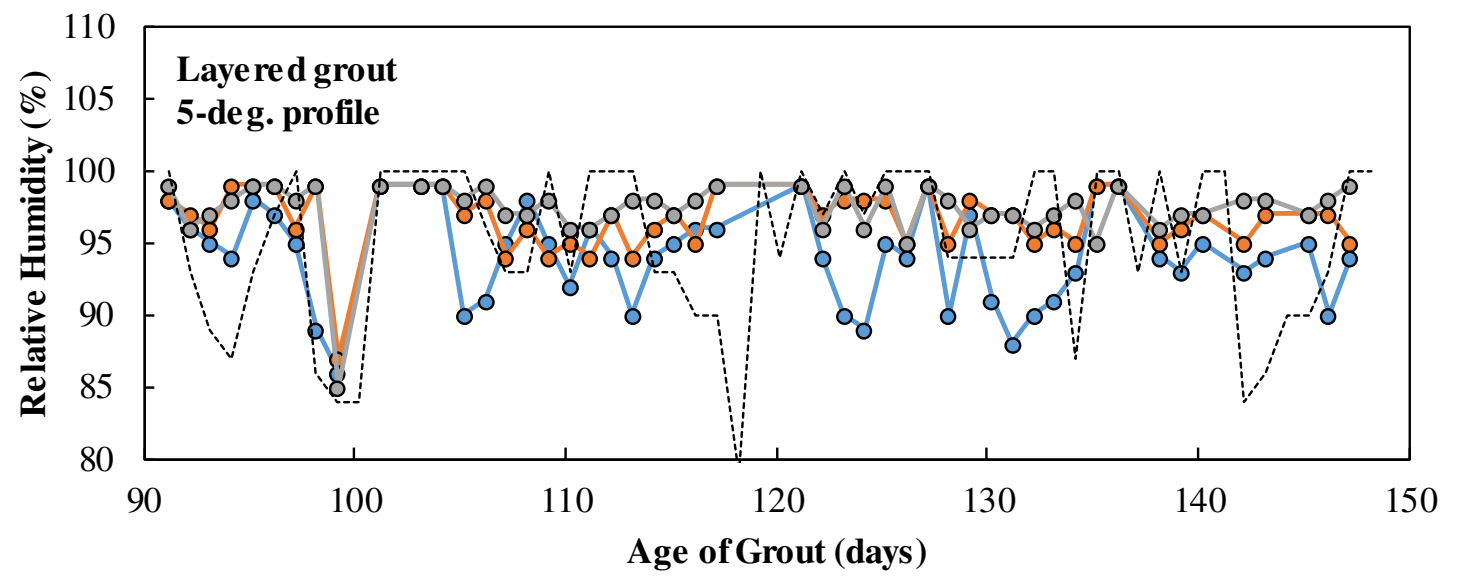

(b)

Figure 4-20: Relative humidity of layered grout for (a) 30-degree strand profile and (b) 5-degree strand profile

\subsection{RESONANT SENSOR DEVELOPMENT}

In addition to the experimental testing of the ducts with resistivity and relative humidity gauges, a preliminary feasibility investigation was conducted on resonant corrosion sensors. Resonant corrosion sensors appear to be one of the more promising possible local sensors. A resonant sensor is a passive wireless sensor made of resistorinductor-capacitor (RLC) circuits that exhibit unique resonance properties. These sensors have a sacrificial element component that affects the resonant frequency and phase dip of 
the system as it corrodes. There were no commercially available RLC sensors, so a preliminary feasibility investigation was conducted during this task.

In process of development of RLC circuit, instead of analyzing each passive element separately, combining all three elements together would form a series RLC circuit. The impedance elements of an RLC circuit is shown in Table 4-5 and Figure 4-21 given below:

Table 4-5: Impedance element of RLC Circuit

\begin{tabular}{|c|c|c|c|}
\hline Circuit Element & Resistance (R) & Reactance (X) & Impedance (Z) \\
\hline Resistor & $\mathrm{R}$ & 0 & $\begin{array}{c}\mathrm{ZR}=\mathrm{R} \\
=\mathrm{R}<0^{\circ}\end{array}$ \\
\hline Inductor & 0 & $\omega \mathrm{L}$ & $\begin{array}{c}\mathrm{ZL}=\mathrm{j} \omega \mathrm{L} \\
=\omega \mathrm{L}<+90^{\circ}\end{array}$ \\
\hline Capacitor & 0 & $-1 / \omega \mathrm{C}$ & $\begin{array}{c}\mathrm{ZC}=1 / \mathrm{j} \omega \mathrm{C} \\
=1 / \omega \mathrm{C}<-90^{\circ}\end{array}$ \\
\hline
\end{tabular}

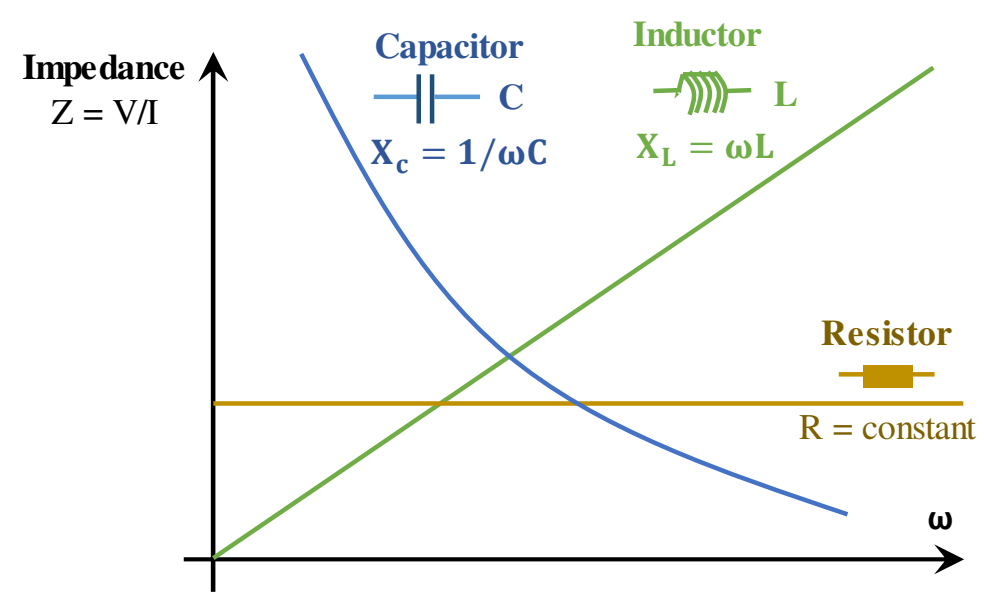

Figure 4-21: Graphical representation of RLC circuit impedance versus frequency [59]

\subsubsection{Numerical Effort}

The analysis mechanism of a series RLC circuit is the same as for the dual $\mathrm{Z}_{\mathrm{L}}$ and $\mathrm{Z}_{\mathrm{C}}$ circuit because the magnitude of reactance of the inductor and the magnitude of capacitance is used to find the overall circuit reactance. Series RLC circuit also acts as second-order circuits because of the energy storage of inductance (L) and capacitance (C) 
elements. So, preliminary efforts were made numerically to understand the behavior of a RLC sensor development and to transmit the information from within the embedded concrete condition. In doing so, simulation software Circuit Lab simulation software circuit lab has been used to replicate the behavior of the RLC circuit to accurately model the resonance frequency of the RLC circuit starting from the resistance R value of $10 \mathrm{~m} \Omega, 100$ $\mathrm{m} \Omega, 1 \Omega, 10 \Omega, 100 \Omega$ and $10 \mathrm{~K} \Omega$. The construction of the RLC circuit with the simulation software is shown in Figure 4-22. The value of capacitance (C) was kept $820 \mathrm{pF}$ and inductor (L) was kept $402 \mu \mathrm{H}$. Figure 4-23 and Figure 4-24 shows all the simulation results as the resistance value starts changing from $10 \Omega$ to $100 \Omega$ and at high resistance the magnitude of the resistance changes direction and phase angle of the resistance no longer remains zero.

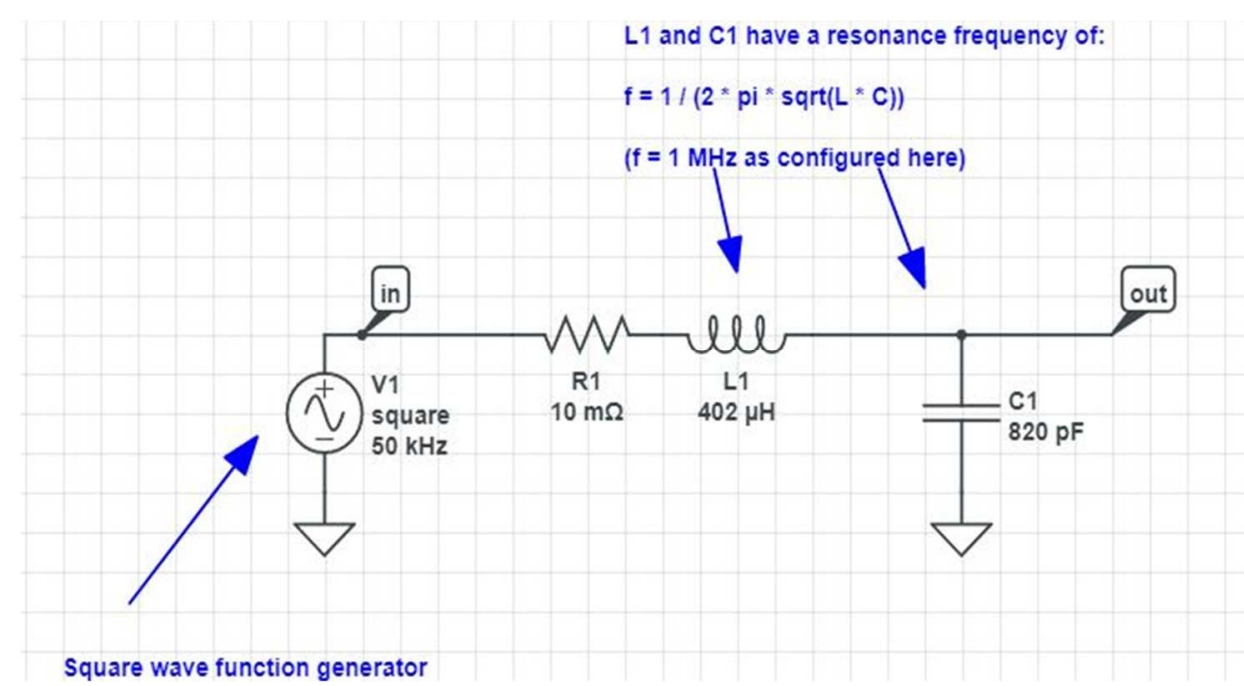

Figure 4-22: Construction of the series RLC circuit using CircuitLab software starting at $10 \mathrm{~m} \Omega$ resistance 


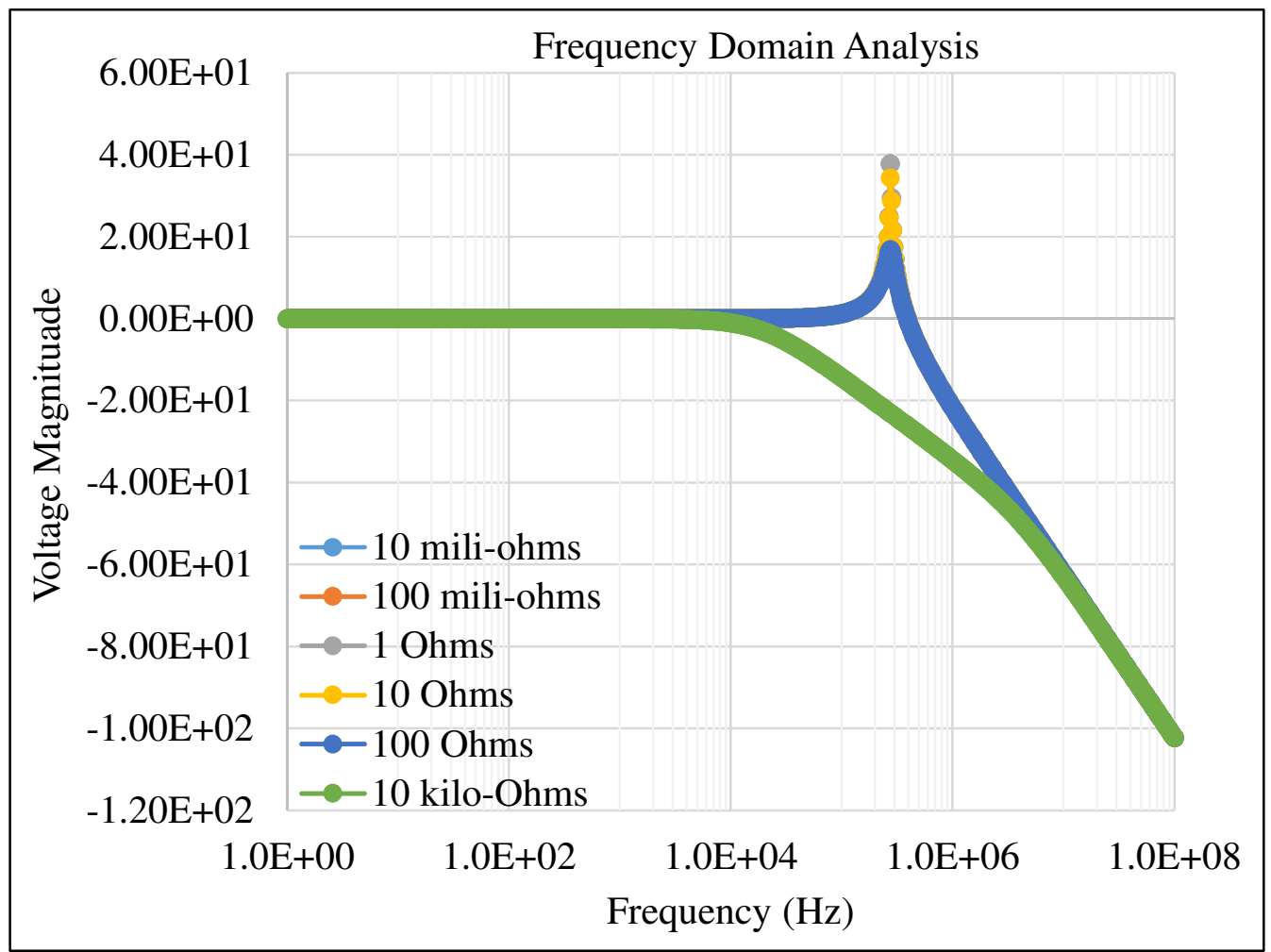

Figure 4-23: Magnitude of the series $R L C$ circuit at $10 \mathrm{~m} \Omega, 100 \mathrm{~m} \Omega, 1 \Omega, 10 \Omega, 100 \Omega$ and $10 \mathrm{k} \Omega$ resistance 


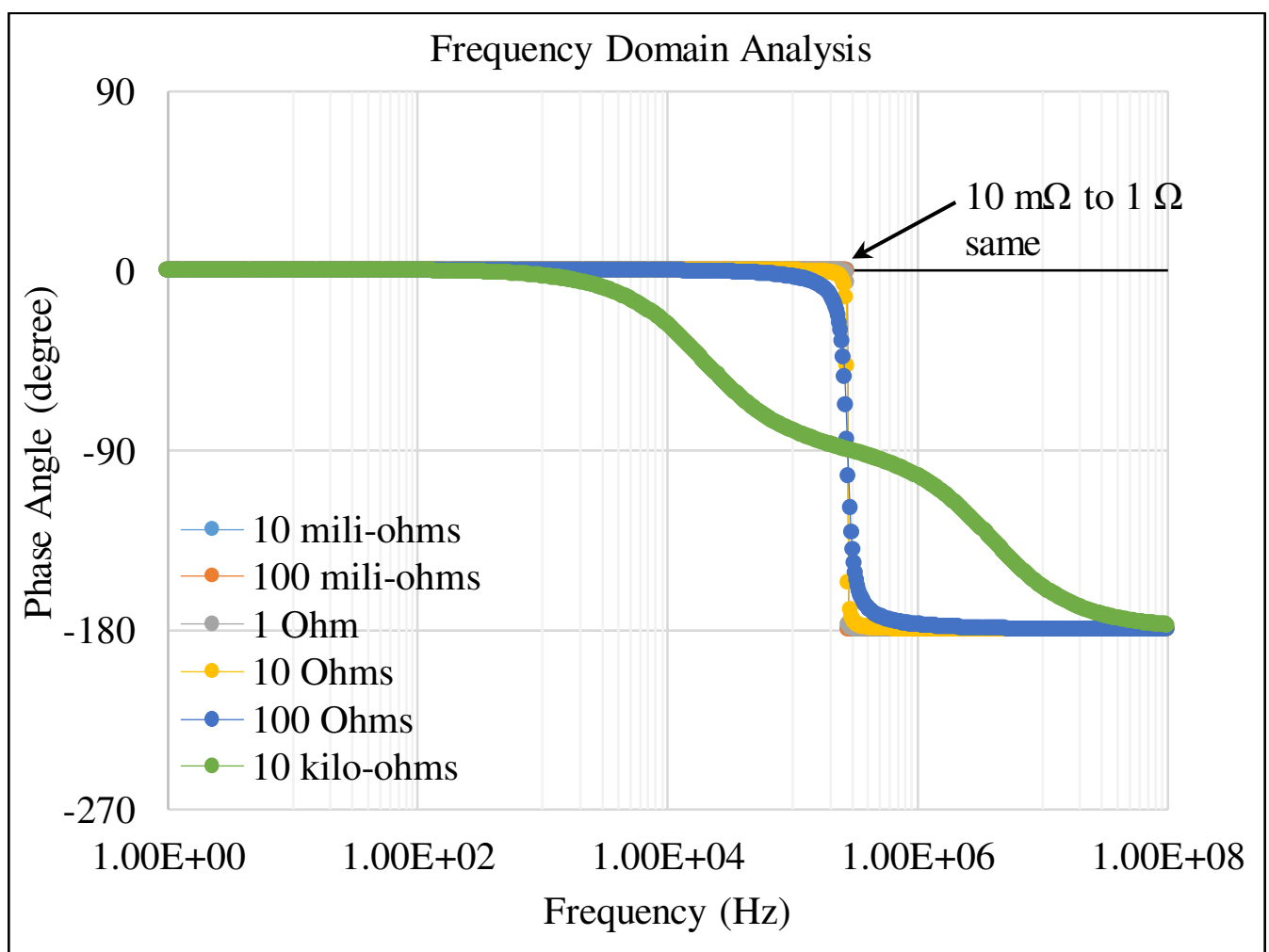

Figure 4-24: Phase angle of the series RLC circuit at $10 \mathrm{~m} \Omega, 100 \mathrm{~m} \Omega, 1 \Omega, 10 \Omega, 100 \Omega$ and $10 \mathrm{k} \Omega$ resistance

At the end of the numerical effort, the first experimental phase was attempted where the exposure condition under aggressive corrosive condition of each component of RLC circuit was tested with the help of an RLC meter (BK precision 875B). This experiment result would help to determine the durability of RLC circuit components and resonant frequency needed for external reader in order to determine the initiation of corrosion.

\subsubsection{Experimental Effort}

During laboratory experiment and before the construction of the RLC circuit, each individual component (capacitor, inductor and resistor) of the RLC circuit were analyzed under control environment (normal exposure with no accelerated corrosion) and aggressive corrosion exposure condition (5\% $\mathrm{NaCl}$ solution), as shown in Table 4-6. In $5 \% \mathrm{NaCl}$ solution, epoxy coating was used to protect the inductor and capacitor component of RLC 
circuit. A washer made of a Grade 1008-1010 shim steel with 0.0020-inch thickness, 1.75inch inside diameter, 2.75-inch outside diameter and $80 \mathrm{ksi}$ tensile strength was used as the resistor component. Only the resistor component was kept exposed to the corrosive environment to measure the changes in resistance over time due to corrosion as shown in Figure 4-25. The data received from this test helped to gauge the potential frequency range of the reader and the range of resonant frequency (before and after corrosion).

Table 4-6: Exposure test using RLC meter for different components of RLC circuit

\begin{tabular}{|c|c|c|c|c|}
\hline \multicolumn{2}{|c|}{ Circuit Element } & \multicolumn{2}{c|}{ Exposure Type } & \multirow{2}{*}{$\begin{array}{c}\text { Coating } \\
\text { condition }\end{array}$} \\
\cline { 3 - 4 } & $\begin{array}{c}\text { Control } \\
\text { (Normal Exposure })\end{array}$ & Saltwater & \\
\hline \hline Resistor & $\begin{array}{c}\text { (Grade 1008-1010 shim } \\
\text { steel washer) }\end{array}$ & $\mathrm{X}$ & $\mathrm{X}$ & Uncoated \\
\hline Inductor & $\begin{array}{c}\text { (Coilcraft inductor with a } \\
\text { capacity of } 402 \mu \mathrm{H})\end{array}$ & $\mathrm{X}$ & $\mathrm{X}$ & Epoxy coated \\
\cline { 3 - 4 } Capacitor & $\begin{array}{c}(820 \mathrm{pF} \text { ceramic } \\
\text { capacitor })\end{array}$ & $\mathrm{X}$ & $\mathrm{X}$ & Epoxy coated \\
\cline { 3 - 4 } & & \multicolumn{2}{|c|}{ Uncoated } \\
\hline
\end{tabular}

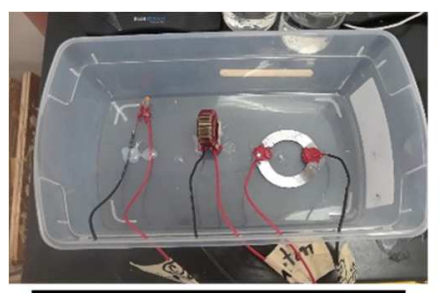

Control Specimen Resistor $=0.650 \Omega$ Capacitor $=0.882 \mathrm{nF}$ Inductor $=892 \mu \mathrm{H}$

(a)

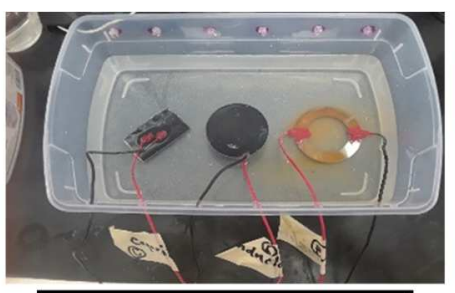

Day 01

Resistor $=0.560 \Omega$ Capacitor $=0.817 \mathrm{nF}$ Inductor $=921 \mu \mathrm{H}$

(b)

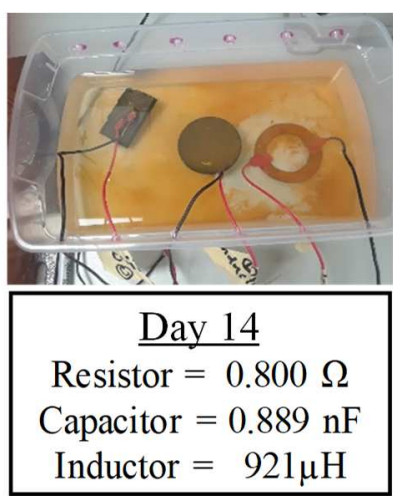

(c)

Figure 4-25: Exposure test using RLC meter for different components of the RLC circuit at (a) control environment, $(b)$ mild corrosive environment and $(c)$ severe corrosive environment 


\subsubsection{Prototype Concept Development}

In the development phase of RLC sensors, two prototypes were considered based on preliminary numerical and experimental results. Prototype I as shown in Figure 4-26 consists of a small loop of fixed resistor (made with Nichrome wire) which extents outside the housing of the sensor and is in direct contact with the concrete that is embedded in the plastic housing. Therefore, this Nichrome wire would be exposed to the same environmental condition as the real reinforcement does. In this simplified version of sensor, an inductive coil of wire housing inside the concrete is magnetically coupled to a second coil "reader", outside of the concrete. This reader coil would be used to interrogate and power the sensor housing inside the concrete. When the wire will be corroded, the second capacitor will be effectively removed from the circuit built, and a shift in resonant frequency will be recorded. However, in this prototype, the amount of corrosion that will cause the breakage of the wire is difficult to determine due to presence of "transition zone" between initial and final resonant state recorded by the reader.

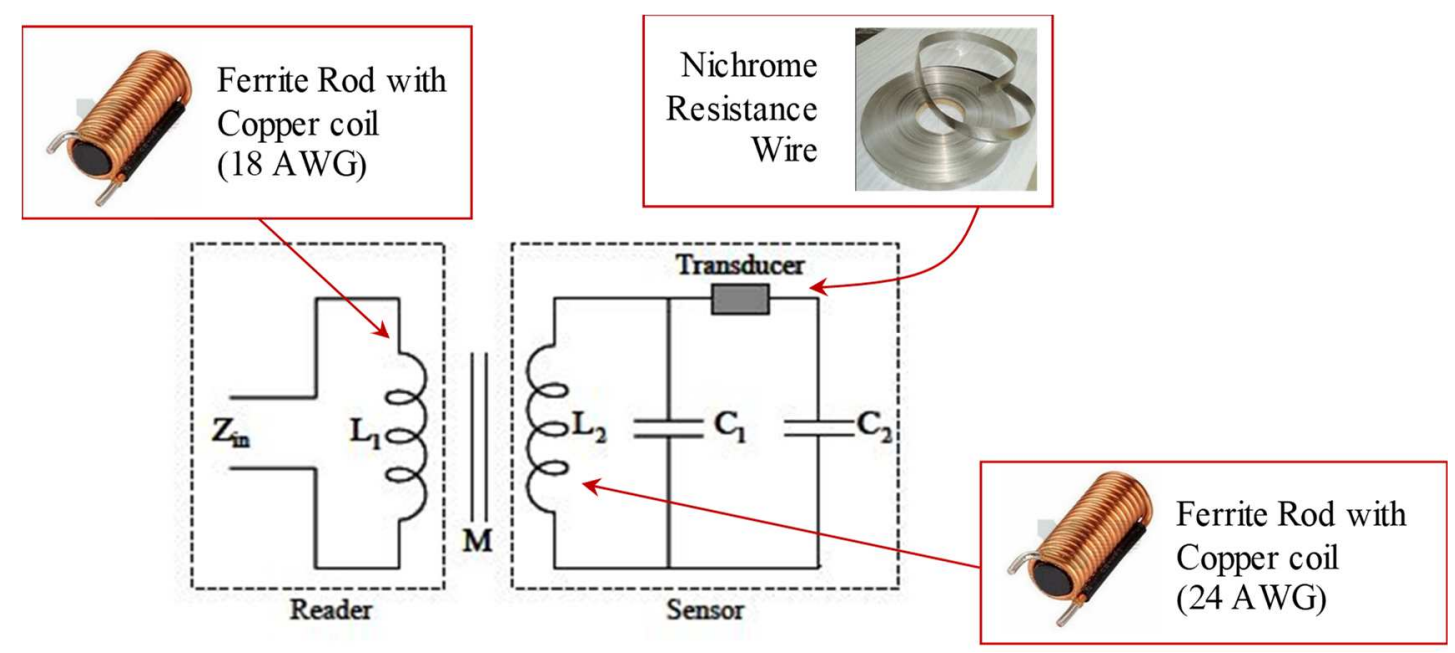

Figure 4-26: Development of RLC circuit (Prototype I) [60] 
To overcome the limitations of Prototype I, a second prototype concept was considered where the sensor resonance was kept to remain still even after the exposed wire has completely corroded but the reference circuit was protected from the corrosive environment. As shown in Figure 4-27, this prototype version is more desirable to distinguish between the intact wire and the broken wire within the conductive environment. In this design concept, the amount of corrosion happening over time would be different from the ratio of the extremely low resistance intact wire (reference circuit) and relatively high resistance of broken wire (exposed circuit). The ratio of the uncorroded sensor (when the exposed wire is intact) would be different from the corroded sensor (when the exposed wire is broken) and therefore this version of prototype will have the advantage to differentiate between corroded state and non-corroded state of the sensor when reasonable amount of corrosion occurred in the system. For the electrical components, same material would be used as described in Prototype I.

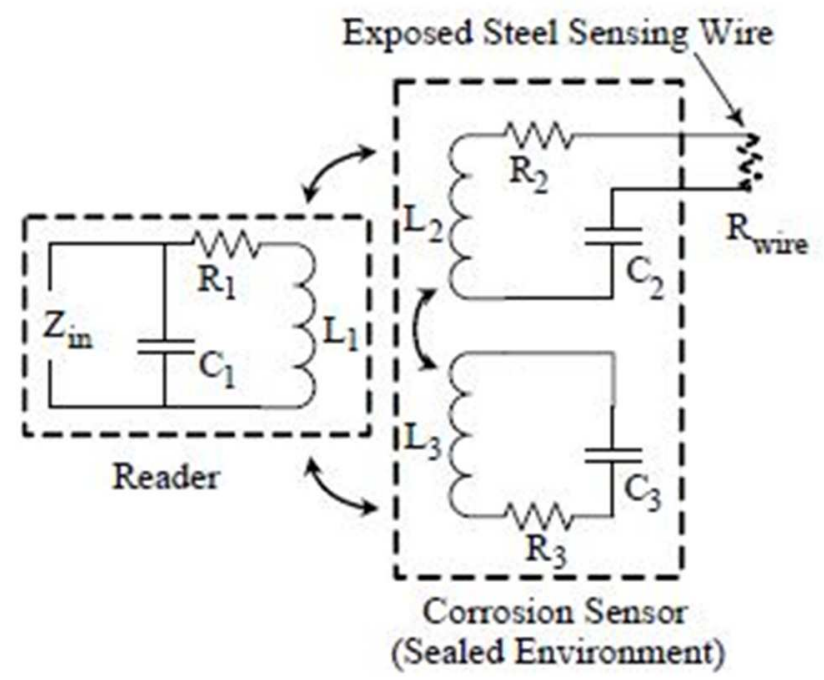

Figure 4-27: Development of RLC circuit (Prototype II) [60] 


\subsubsection{Limitations for Future Development}

After performing preliminary numerical and experimental results, further research was not being performed towards the RLC sensor development for the following reasons:

- Resonant sensors will be effective only to show the resonant frequency response after the corrosion has initiated in the sensing wire.

- A wide range $(10 \mu \mathrm{Hz}$ to $32 \mathrm{MHz})$ of impedance/Gain-phase analyzer is required to accurately produce flexible responses from the two prototypes. Currently, no such commercial Impedance analyzer is available for field exposure condition; only laboratory version are commercially available.

- In this research, for full-scale beam test, accelerated corrosive environment will be used and the prototypes are not designed to capture the response from accelerated corrosion.

- Under fully corroded environment, the sacrificial element will become an open circuit and will measure the resonant frequency of the reference circuit only. In full-scale beam application under accelerated corrosion environment, the frequency value of reference circuit might mislead and/or interfere between corroded and non-corroded state.

\subsection{CHAPTER SUMMARY}

Several conclusions can be made based on the small-scale testing:

- A clear difference was observed between the resistivity of the specimens with good grout compared to the specimens with chloride-rich grout with voids and layered-chloride rich grout without voids. 
- The resistivity of grout at high and low points of the tendon can be differentiated. Longer times for grout hydration allow for greater differentiation.

- There was not a significant difference in the measured RH between the specimens with good grout, chloride-rich grout with voids, and layered chloride-rich grout without voids.

- The internal RH should be an indicator of environments conducive for corrosion where moisture accumulation would allow greater concentration of ionic species. Furthermore, locations with bleed and segregation can be identified. Further work to eliminate the effects of external RH should be identified.

Detection of environments that may be conducive to corrosion initiation will not give direct information on actual corrosion rates and damage. Corrosion damage should affect the mechanical response, so, global strain sensing should provide a better indicator of corrosion propagation. In this process, the use of local sensors become ineffective or redundant where the replacement of strand becomes a necessity to ensure the safety of structures. Global sensing will provide a platform for overall structural safety of the structures by providing proactive engineering measures in a cost-effective way. 


\section{CHAPTER 5. EXPERIMENTAL CORROSION EVALUATION OF GLOBAL SENSORS}

\subsection{OVERVIEW}

This chapter discusses the experimental evaluation of the ability of strain sensors to detect changes to the structural behavior of a beam caused by localized corrosion damage. The following details are provided:

- Design and construction of prestressed beam element with an embedded monitoring system,

- Construction of defect to induce accelerated corrosion to the prestressing strands at specific location of the beams,

- Development of data acquisition system (DAQ) from the embedded monitoring system, and

- Results from monitoring including the changes in strain, prestress loss and changes in beam curvature with associated mass loss from applied controlled potential for a specific time period and location.

\subsection{BEAM DESIGN AND CONSTRUCTION}

After discussion with several precast plants, a pretensioned inverted-tee beam was selected with 2 layers of bottom strands as it provided the best option for controlled and systematic corrosion of the prestressing strands. The dimensions for the selected cross section and location and force of the prestressing strands is shown in Figure 5-1. Full drawings for the constructed beams are provided in the appendix. 


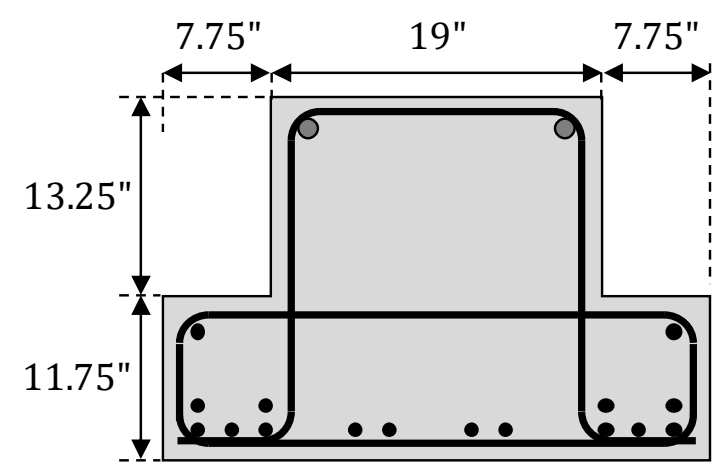

\begin{tabular}{|c|c|c|c|}
\hline Layer & Height & \# of Strands & Total Force \\
\hline 1 & $2.25 ”$ & 10 & 410 kips \\
\hline 2 & $4.50 "$ & 4 & 164 kips \\
\hline 3 & $10.0 "$ & 2 & 82 kips \\
\hline Total & $3.78 ”$ & 16 & 656 kips \\
\hline
\end{tabular}

(16) 0.6 "-diameter strands pulled to 41 kips each

Figure 5-1: Cross section dimensions and strand location and prestress force

The typical construction procedure is shown in Figure 5-2. The reinforcement cage was finished first by the precaster, Figure 5-2 (a). The defect and instrumentation were then installed, Figure 5-2 (b) and (c). The concrete was cast, Figure 5-2 (d), the morning after the defect and instrumentation were installed. The concrete used for casting was a $6.5 \mathrm{ksi}$ self-consolidating concrete (SCC) mix. No internal vibrators were needed for consolidation, but the concrete was still placed to avoid the sensors. Forms were removed and strands were torch cut one day after casting, Figure 5-2 (e) and (f). The beams were shipped to FIU and unloaded using a crane 7 days after casting, Figure 5-2 (g) and (h). Manual instrumentation readings were taken each day. 


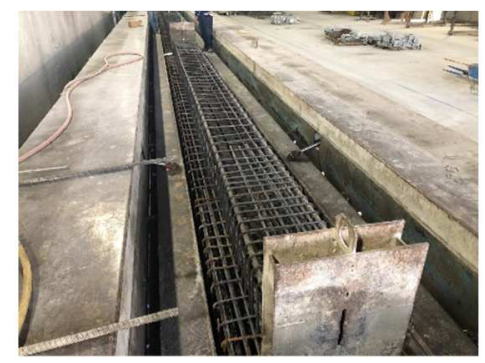

(a)

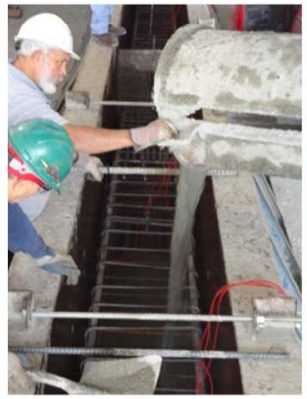

(d)

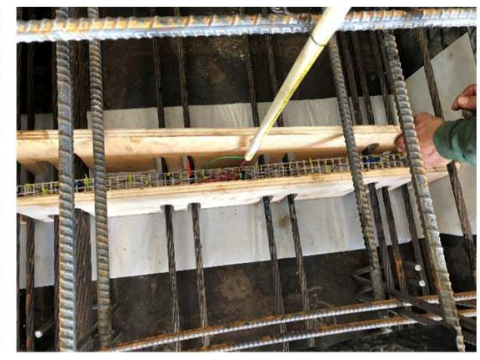

(b)

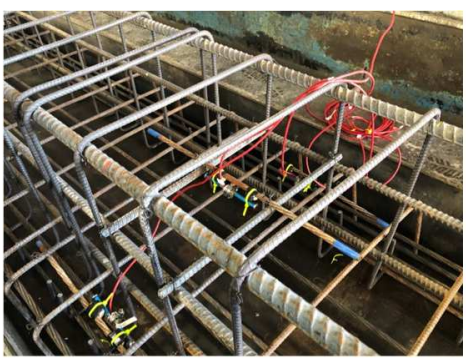

(c)

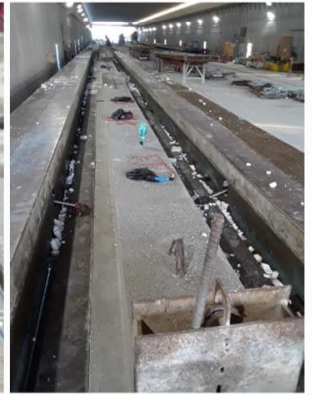

(e)

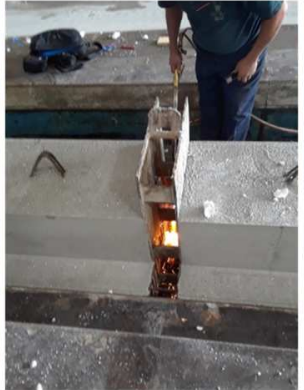

(f)

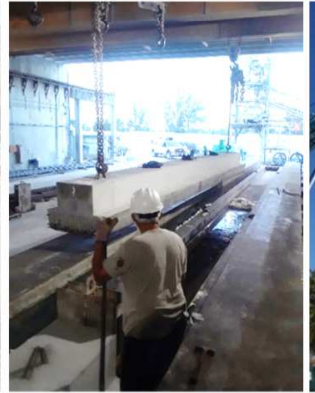

(g)

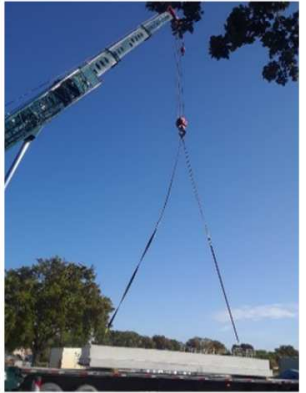

(h)

Figure 5-2: Typical construction procedure, including delivery to FIU

\subsection{DEFECT DESIGN AND CONSTRUCTION}

A defect was designed to accelerate corrosion in one location along the length of the beams. A mockup of the defect was first made to refine the design of the defect. The formwork for the defect, shown in Figure 5-3, was made of two slotted side forms made out of plywood to fit around the prestressing strand grid and additional strips of plywood to fill in the large spaces between the strands. Wood bottom and end forms were used and then expanding foam and caulk were used to make the formwork watertight. 


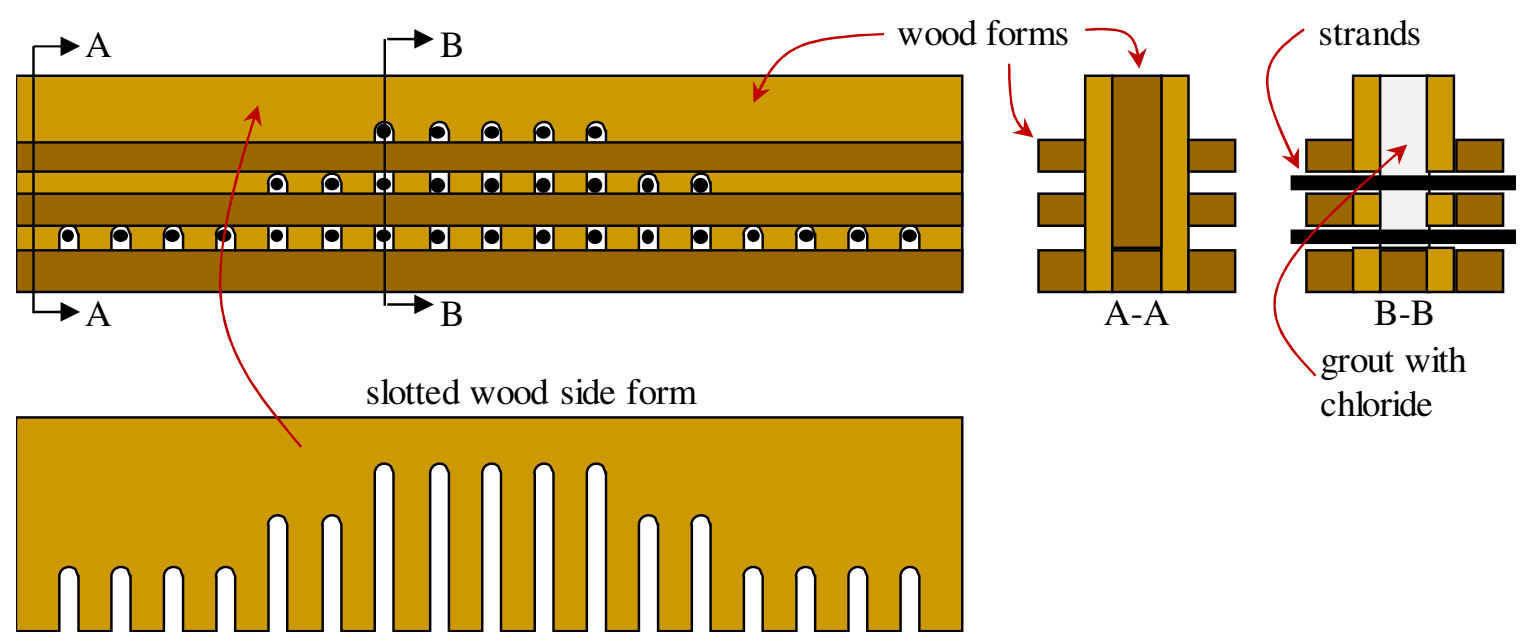

Figure 5-3: Schematic of formwork used for mockup defect

A mixed metal oxide (MMO) mesh strip was zip tied to a plastic grid spacer (made of white egg crate panels used as coverings for light panels) and then tied to the strands, as shown in Figure 5-4. The plastic grid spacer was used to ensure that the MMO mesh did not come in contact with the prestressing strands. Copper wire was connected to the mesh and the connection completed coated in epoxy to protect it from the corrosive grout. The protected copper wires were run through a conduit extending out the top to provide an additional level of protection. A cementitious grout with 5-percent salt content was then mixed and poured into the defect form

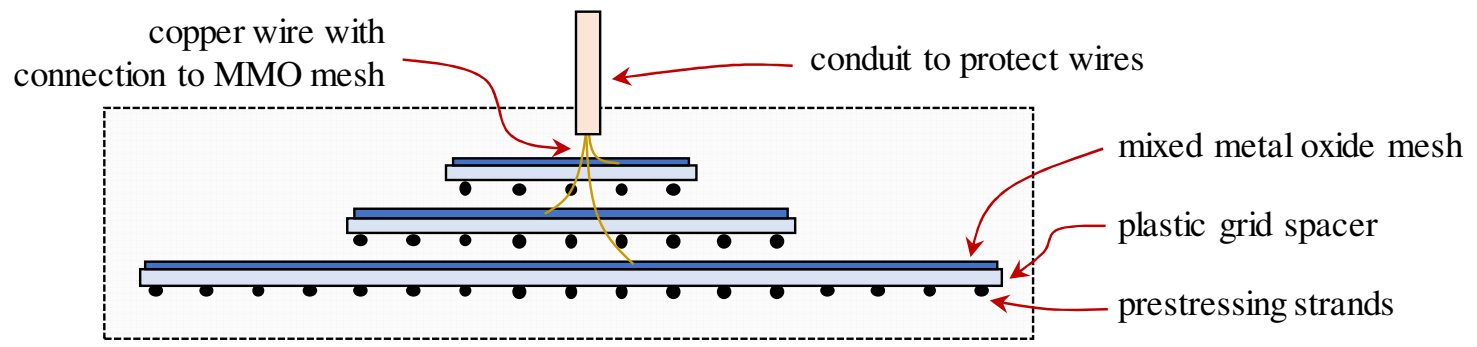

Figure 5-4: Schematic of mixed metal oxide mesh and other components in defect mockup

After the grout was allowed to harden, a constant voltage of 30-volt was applied to a single strand for 7 days. The voltage differential was measured during this time to 
determine the amount of corrosion that was occurring. The mockup of the defect after 4 days of applying the constant voltage to the strands is shown in Figure 5-5.

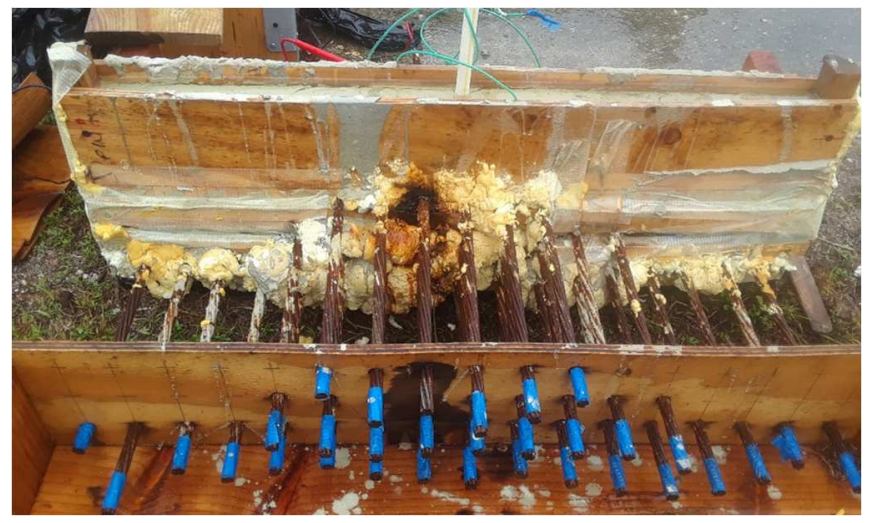

Figure 5-5: Corrosion damage of mockup after 4 days of applying voltage to one of top strands

The experience gained from the initial mockup construction was used to develop the detail for the defect in the full-scale beams. Similar formwork to the mockup, shown in Figure 5-3, and a similar configuration to the mockup, shown in Figure 5-4, were used in the full-scale beams. The steps for construction of the defect in the full-scale beams are shown in Figure 5-6. First, the shear and ledge reinforcement at the location of the defect was temporarily moved to give room for the construction of the defect, Figure 5-6 (a). Next, the wood slotted side forms were put into place, Figure 5-6 (b). The bottom soffit and side metal forms were used as the other sides of the form for defect casting. A plastic sheet was used to separate the grout from the metal forms. The MMO tied to the plastic grid spacer was then tied to the layers of strands, Figure 5-6 (c). The wires were run through a PVC pipe out the top of the beam and the other side form was put into place, Figure 5-6 (d). The form was sealed with foam and expanding foam and the grout with 5 percent salt 
content was cast. The final defect before casting of the concrete is shown in Figure 5-6 (e). The defect after casting of the beams is shown in Figure 5-6 (f).

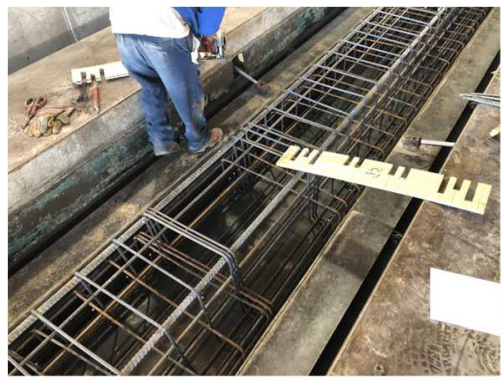

(a)

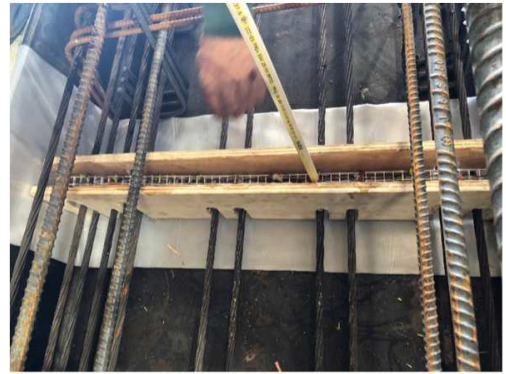

(d)

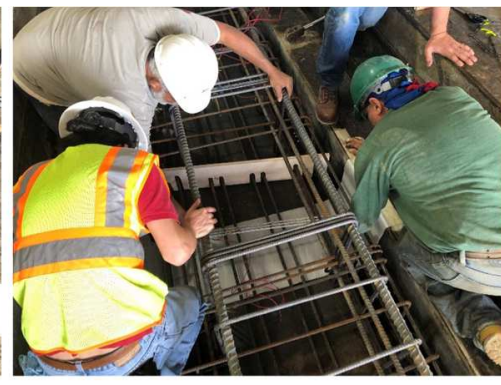

(b)

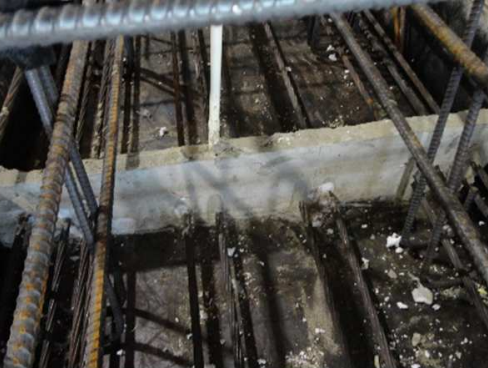

(e)

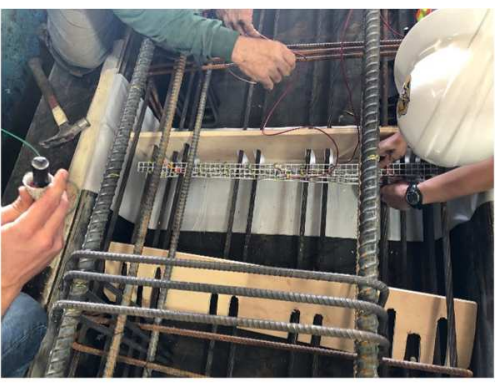

(c)

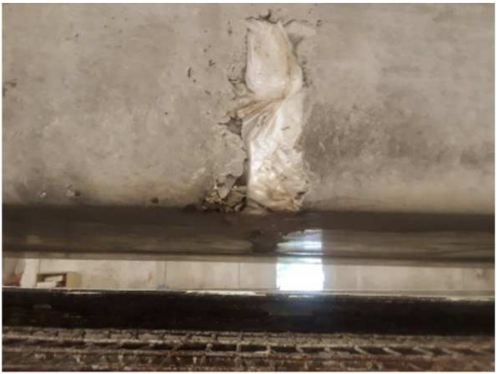

(f)

Figure 5-6: Procedure for creating defect in full-scale beams

The defect was placed at the mid-span of one beam and offset from the mid-span in the other beam.

\subsection{INSTRUMENTATION}

\subsubsection{Vibrating Wire Strain Gauges}

Vibrating wire strain gauges (VWSGs) are one type of strain measurement device that offer good long-term stability for monitoring, which is not true for typical resistance strain gauges. VWSGs consist of a steel wire tensioned between two end blocks, shown in Figure 5-7. An initial tensile stress is placed in the wire, and the wire is allowed to further tension or relax with the movement of the end blocks. An electromagnetic plucker is used to excite the wire and measure the resonant frequency. The change in frequency indicates 
the strain change between the end blocks, which will be the same as the average strain change in the concrete between the end blocks.

electromagnetic

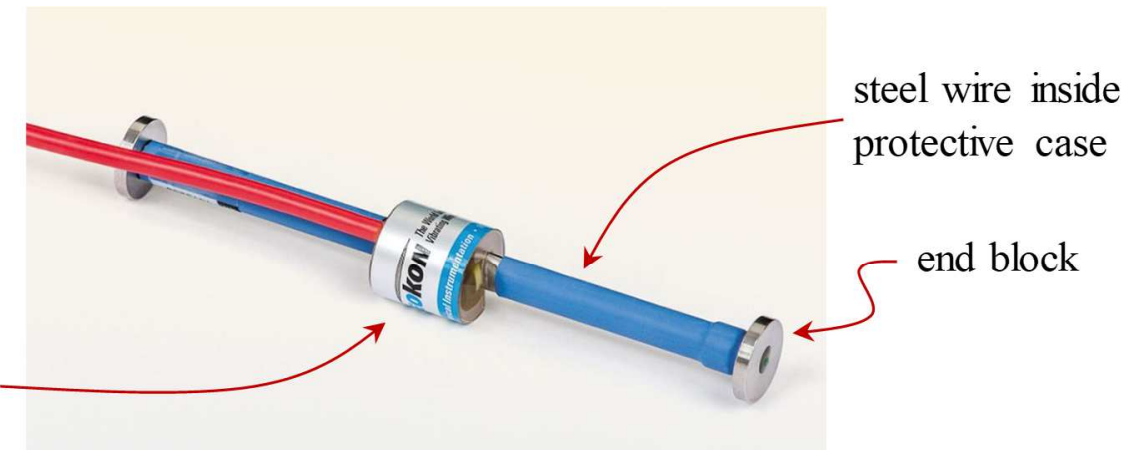

Figure 5-7: Concrete Embedment 4200 strain gauges (based on [61])

Geokon 4200 concrete embedment VWSGs were used to measure the strain in this project. The key parameters for these specific VWSGs are shown in Table 5.1.

Table 5.1: Geokon Model 4200 VWSGs Specification [61]

\begin{tabular}{|c|c|c|}
\hline Parameter & Value & Units \\
\hline \hline Standard range of strain & $1000-4000$ & $\mu \epsilon$ \\
\hline Resolution & 1.0 & $\mu \epsilon$ \\
\hline Temperature sensitivity & -20 to +80 & ${ }^{\circ} \mathrm{C}$ \\
\hline Thermistor resolution & \pm 0.5 & ${ }^{\circ} \mathrm{C}$ \\
\hline Active gauge dimension & $6.00 \times 0.75$ (length $\times$ dia.) & in \\
\hline
\end{tabular}

This VWSG model has the starting frequency of $450 \mathrm{~Hz}$ and end frequency of 1200

Hz. A gauge factor and batch factor (3.304 and 0.98, respectively, for the gauges used in this project) are used to calibrate the gauges. Temperature variations will affect the strain readings, because concrete and steel have different coefficients of thermal expansion. A thermistor is built into the VWSGs to measure temperature. The measured temperature was then used to take out the effects of temperature in the final reported strain measurements. 


\subsubsection{Installation of Vibrating Wire Strain Gauges}

There are several different ways that VWSGs can be installed in reinforced concrete members, see [61] for more details on all suggested installation methods. The method selected for this project was attachment to rebar. The VWSGs were attached to 2-foot pieces of prestressing strands prior to visiting the precast plant. The strands with the preattached VWSG was then tied to the rebar cage at the precast plant on the day the instrumentation was installed. A sample of the installed VWSG is shown in Figure 5-8.

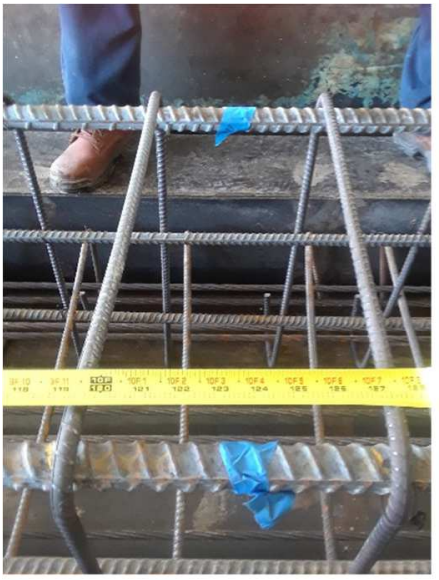

(a)

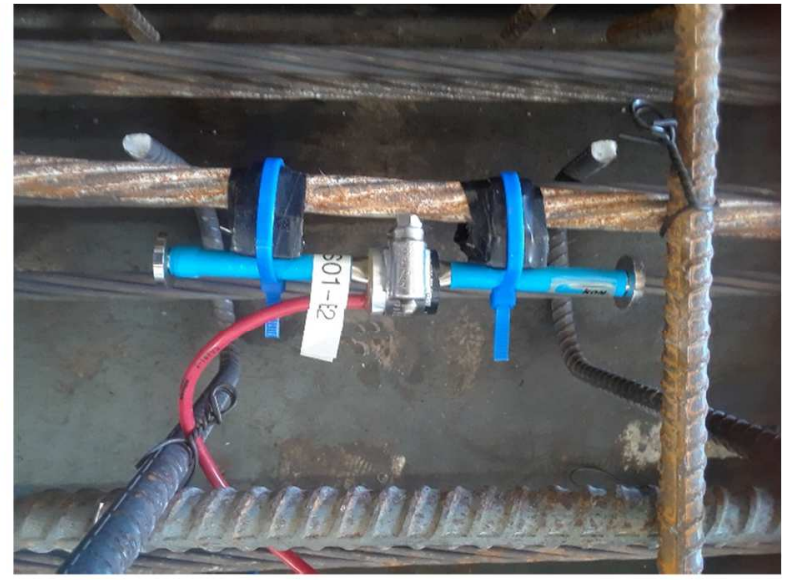

(b)

Figure 5-8: Installation of the vibrating wire gauges (VWSGs) (a) measuring the location, (b) fastening with rebar

\subsubsection{Location of Instrumentation}

The location of the VWSGs in the cross section for the constructed beams is shown in Figure 5-9 and along the length of the beam in Figure 5-10. Three VWSGs were used in three different locations along the length in beam FIU-1 with the offset defect. Four VWSGs were used in two different locations along the length in beam FIU-2 with the

defect located at midspan. The labeling system used for the VWSGs is also highlighted in Figure 5-9. 


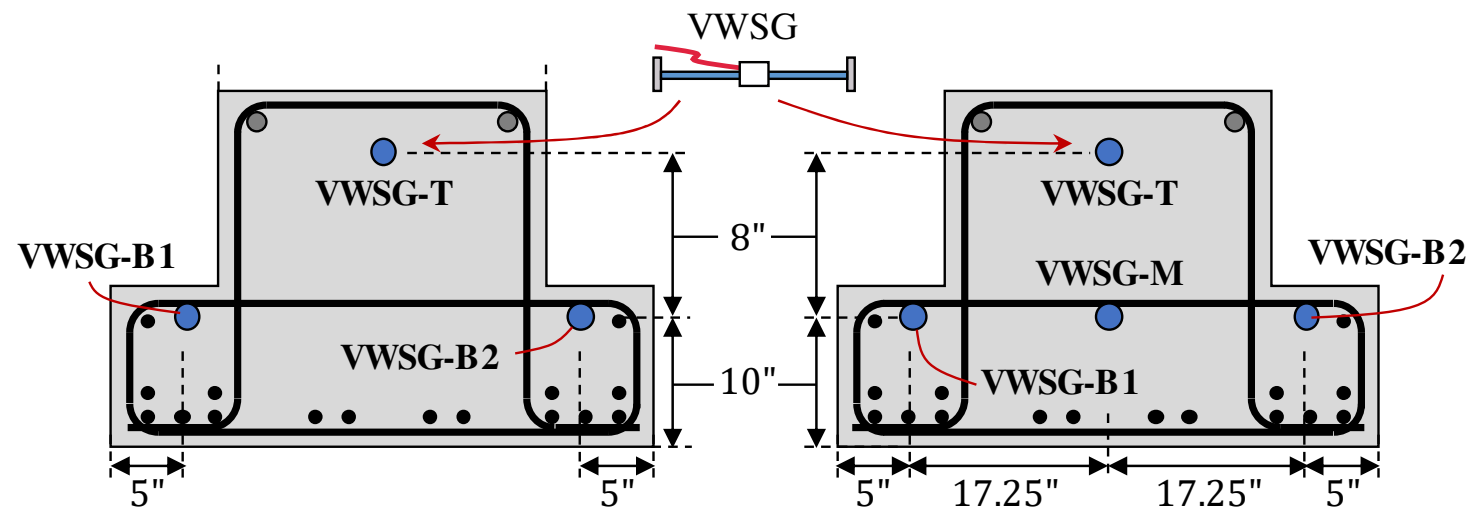

(a)

(b)

Figure 5-9: Location of VWSGs in cross section for (a) FIU-1 (offset defect) and (b) FIU-2 (mid-span defect)

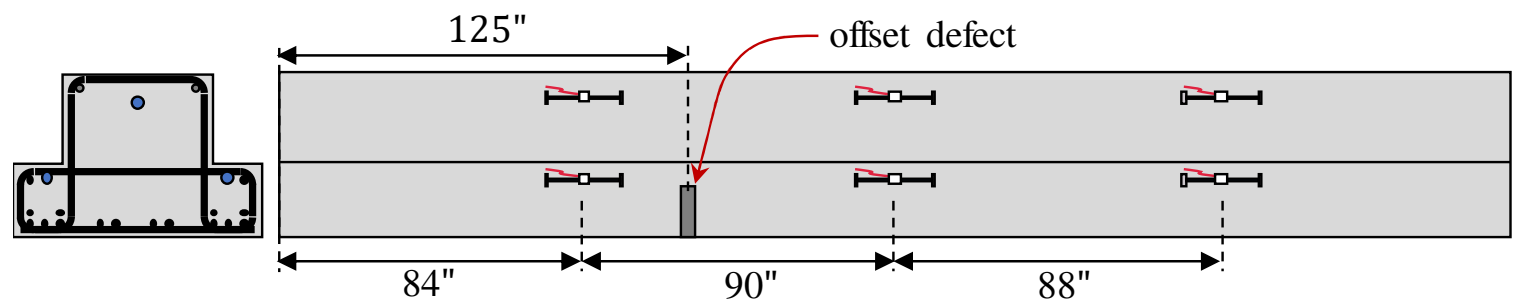

(a)

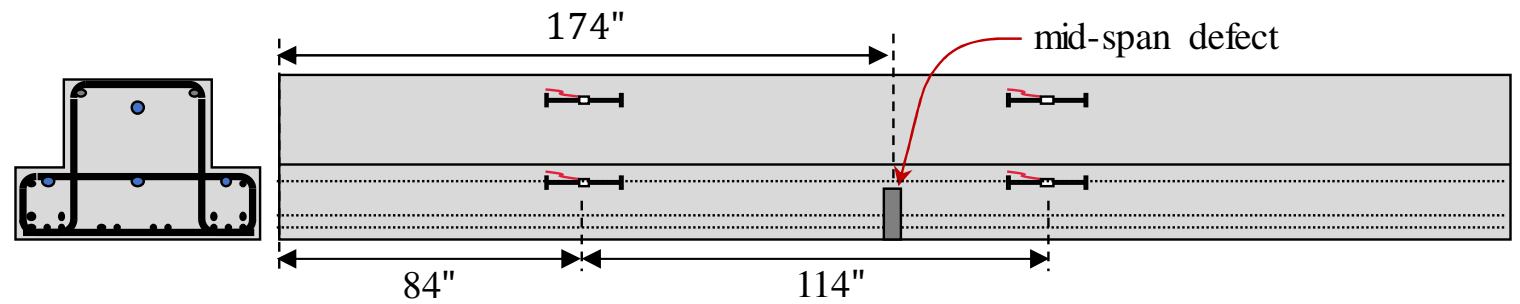

(b)

Figure 5-10: Location of VWSGs and defect along length of (a) FIU-1 (offset defect) and (b) FIU-2 (midspan defect)

Photographs of some of the installed VWSGs are shown in Figure 5-11. The wires from the VWSGs were all run to midspan of the beam and bundled together. The extra length of wire extending out of the beam was wrapped in plastic and placed outside the forms to protect it during casting of the beams. 


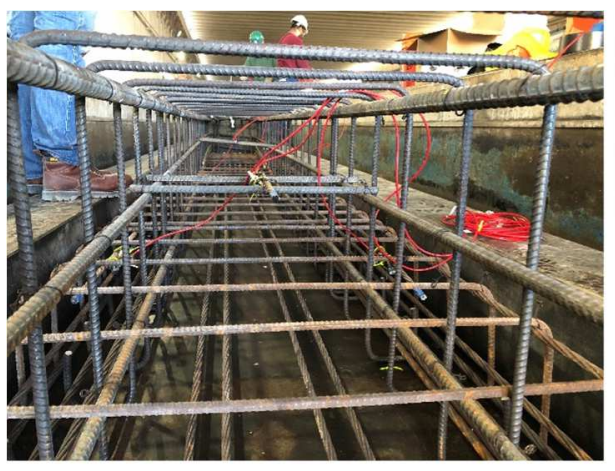

(a)

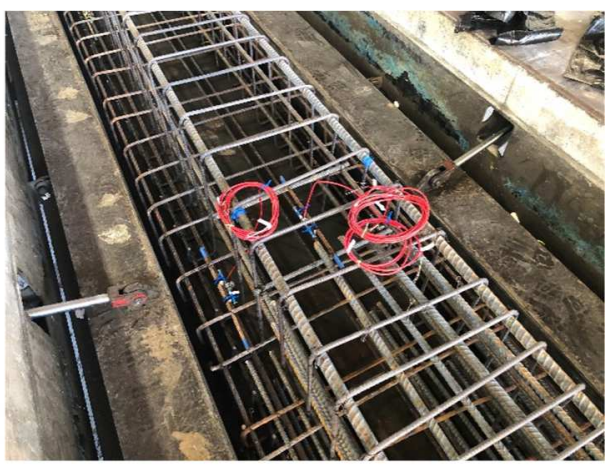

(b)

Figure 5-11: Installed VWSGs in full-scale beams

\subsubsection{Converting VWSG Data to Prestress Losses and Curvature}

The VWSGs give a longitudinal strain measurement in the beam at the location of

the gauge. These measured strains can be plotted along the depth of the cross section and a linear regression can be used to determine the strain profile across the depth of the section, as shown in Figure 5-12. The strain at the height of the prestressing strands can be found using this linear regression. The starting strain was measured in all the gauges before prestress transfer, so the change in strain caused by the prestress transfer, creep, shrinkage, and other applied loads can be determined using these measurements. 


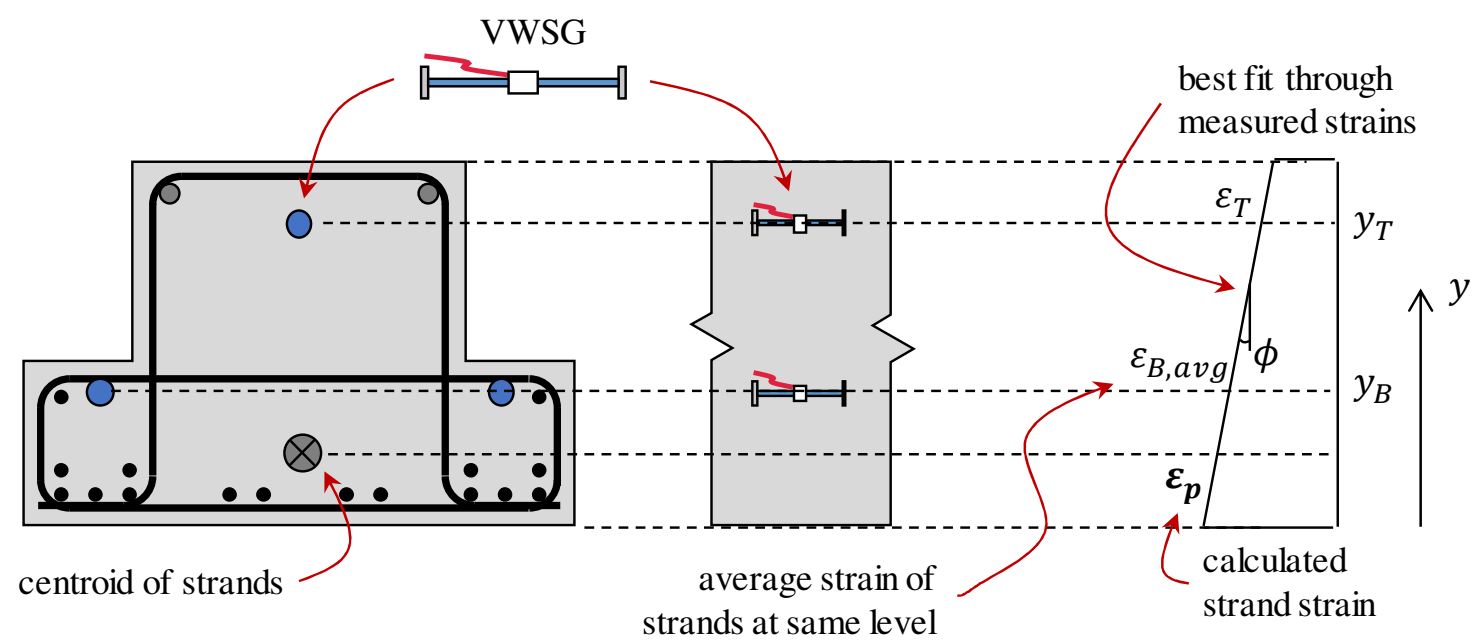

Figure 5-12: Method for determining strain in prestressing strands from VWSG strain measurements

A temperature correction was applied to determine the prestress loss in the strands, shown in Equation 5-1.

$$
\Delta f_{p, T-\text { corrected }}=\Delta \varepsilon_{p} \cdot E_{p}-\left(\alpha_{s}-\alpha_{c}\right)(-\Delta T) \cdot E_{p}
$$

where:

$$
\begin{aligned}
& \Delta \varepsilon_{\mathrm{p}} \quad=\text { strain change at centroid of prestressing strand measured by } \\
& \text { VWSGs } \\
& \mathrm{E}_{\mathrm{p}}=\text { modulus of elasticity of strands }(\mathrm{ksi}) \\
& \Delta \mathrm{T}=\text { temperature change respective to datum temperature }\left({ }^{\circ} \mathrm{C}\right) \\
& \alpha_{s}=\text { coefficient of thermal expansion of steel }\left(12.2 \mu \varepsilon /{ }^{\circ} \mathrm{C}\right) \\
& \alpha_{c}=\text { coefficient of thermal expansion of concrete }\left(10 \mu \varepsilon /{ }^{\circ} \mathrm{C}\right)
\end{aligned}
$$

This prestress loss was plotted versus time for all instrumented sections in the beams. 
The curvature $(\phi)$ across the depth of the section can also be determined for a plane with VWSGs at two or more locations across the depth of the section. The curvature is the slope of the strain profile across the depth of the section, as shown in Figure 5-12.

\subsection{DATA ACQUISITION SYSTEM}

Data can be collected from the VWSGs using either a handheld reader or a fully automated data acquisition system (DAQ). The initial readings were taken for the beams using a handheld reader. These results were compiled in a computer software for plotting and analysis. A DAQ was assembled within the first few weeks following beam construction. The DAQ was acquired from Campbell Scientific and consisted of three primary components:

CR6: This is a flexible DAQ that can be customized easily with the addition of separate modules. The separate modules are tied into the central DAQ through standard network cables.

CDM-VW305: This is a module that houses eight channels for dynamic VWSG reading at dynamic measurement rates of up to $333 \mathrm{~Hz}$. Thermistors are sampled at $1 \mathrm{~Hz}$ for each VWSG channel.

NL241: This is a wireless local network interface to provide connectivity between the CR6 and existing Wi-Fi networks.

The DAQ was housed in a tamper-resistant steel washdown enclosure to protect the equipment from vandalism, theft, and the weather. A schematic of the DAQ system in the enclosure is shown in Figure 5-13. 


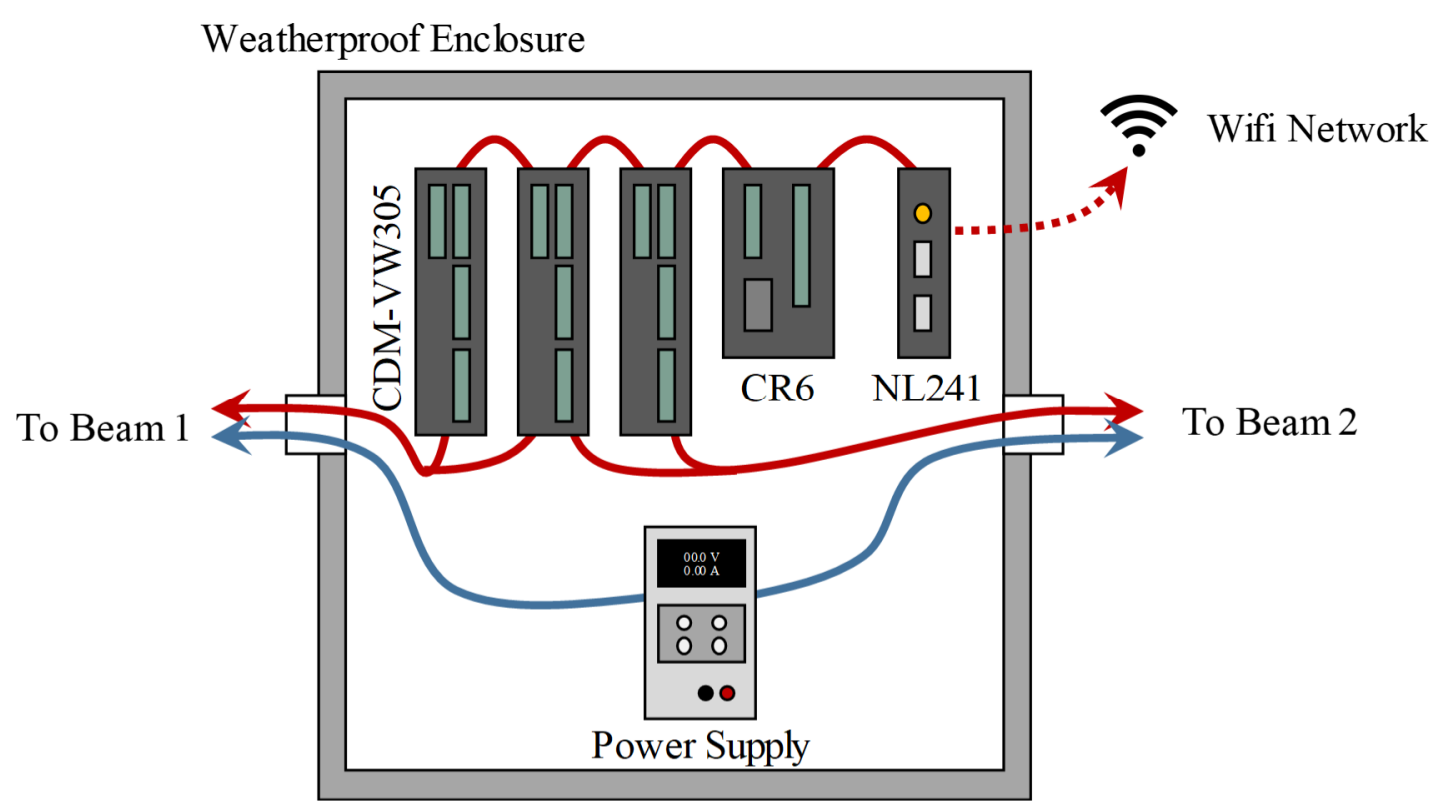

Figure 5-13: A typical DAQ system for collecting VWSGs data

A customized code was developed using Campbell Scientific software (CR-Basic).

A power supply was also placed inside the enclosure. This continuous adjustable DC power supply with a voltage output of 0-30 volts was used to provide constant voltage control between the strand (working electrode) and the mixed metal oxide (MMO) wire mesh (counter electrode). The temperature control system of this power supply has a built-in thermos sensor that effectively reduces noise and offers intelligent temperature control. Also, the power supply has multiple protection levels including current protection, thermal protection, and voltage overload protection and short-circuit protection.

\subsection{STABILIZATION OF LONG-TERM BEHAVIOR}

The beams were stored at FIU without inducing corrosion until there was reasonable stabilization of the long-term behavior (i.e. the majority of creep and shrinkage prestress losses occurred). The measured prestress losses are plotted versus time in the three measured sections of beam FIU-1 in Figure 5-14. The elastic shortening loss in the 
beam was an average of $15.9 \mathrm{ksi}$ in the three sections. The average long-term prestress losses were $18.0 \mathrm{ksi}$ in the three sections. The prestress losses began to level out around 40 days.

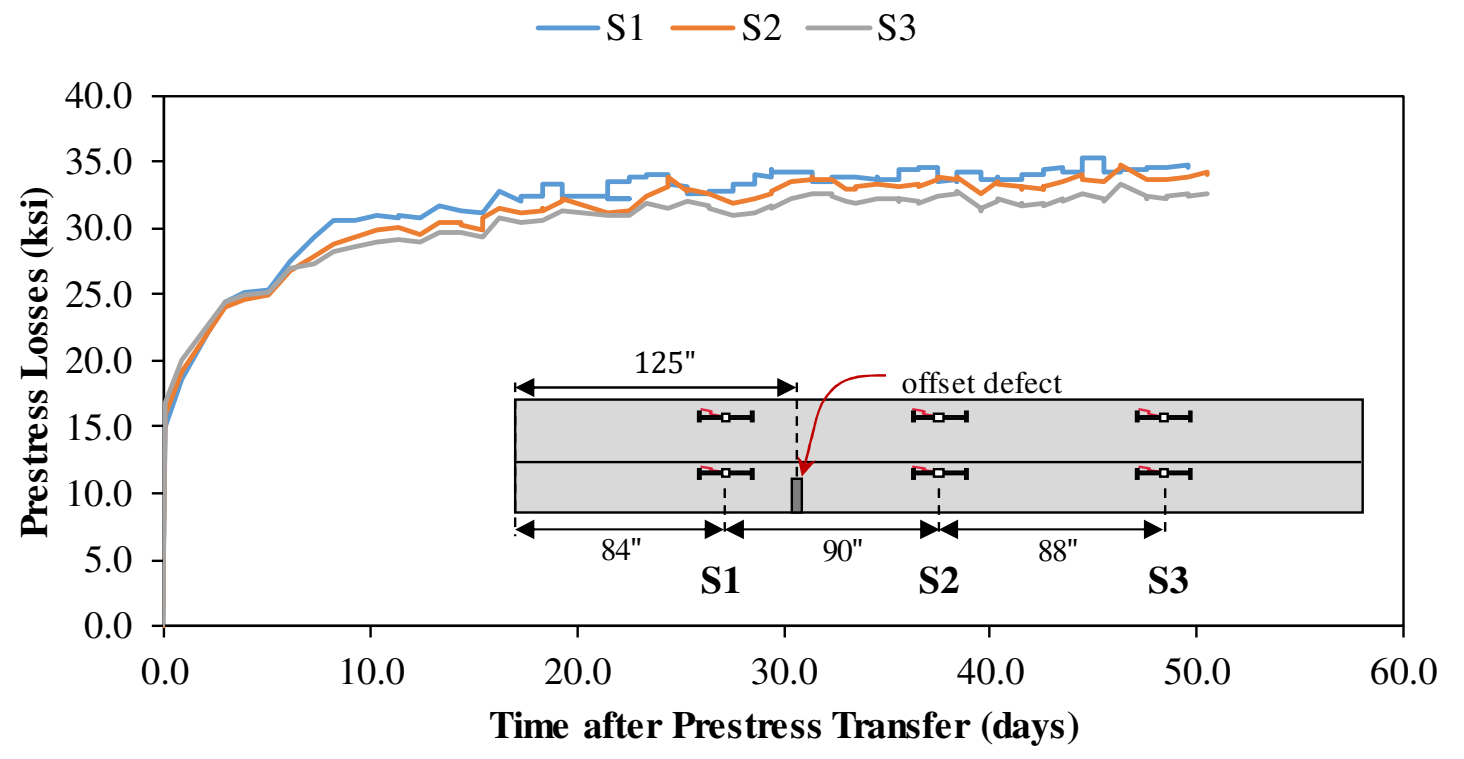

Figure 5-14: Prestress losses measured at three sections in FIU-1 (with mid-span defect)

The measured prestress losses are plotted versus time in the two measured sections of beam FIU-2 in Figure 5-15. The elastic shortening loss in the beam was an average of $14.0 \mathrm{ksi}$ in the two sections. The average long-term prestress losses were $18.8 \mathrm{ksi}$ in the two sections. The prestress losses began to level out around 40 days. There was a larger difference in measured prestress loss between the two sections in this beam. 


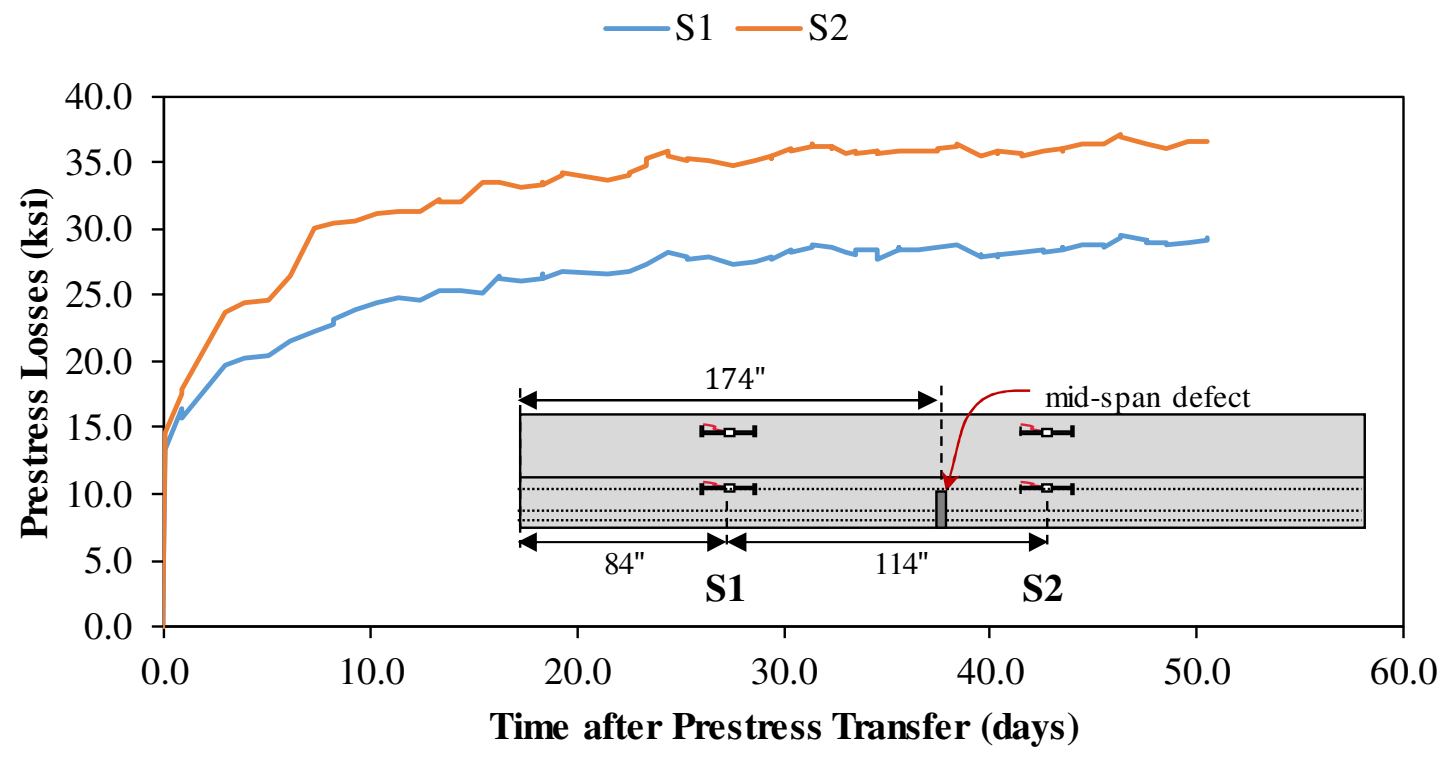

Figure 5-15: Prestress losses measured at two sections in FIU-2 (with offset defect)

The measured strains versus time in all the VWSGs in beam FIU-1 are shown in Figure 5-16. 
$-\mathrm{T}-\mathrm{B} 1-\mathrm{B} 2$

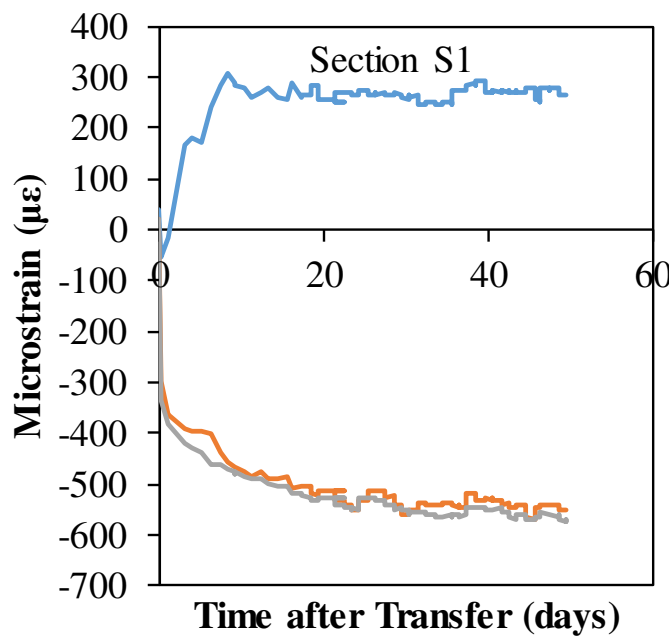

(a)

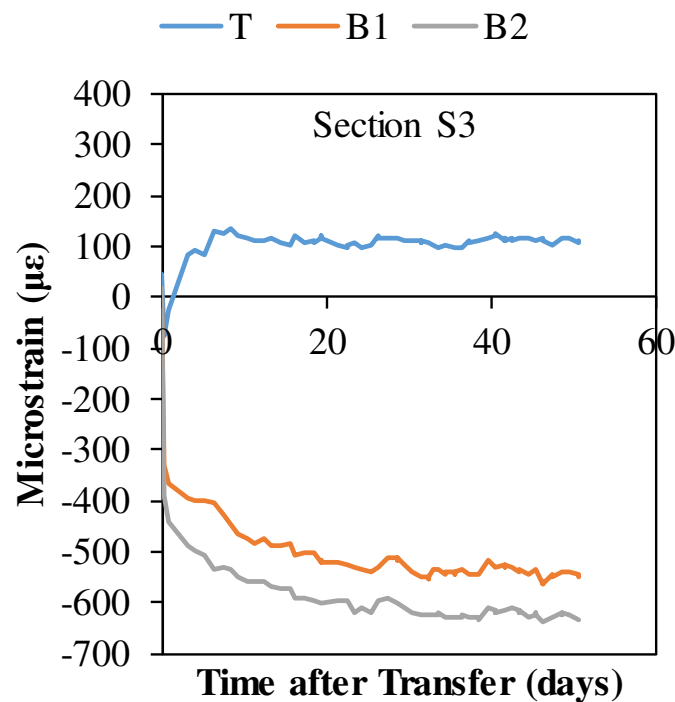

(c)
$-\mathrm{T}-\mathrm{B} 1-\mathrm{B} 2$

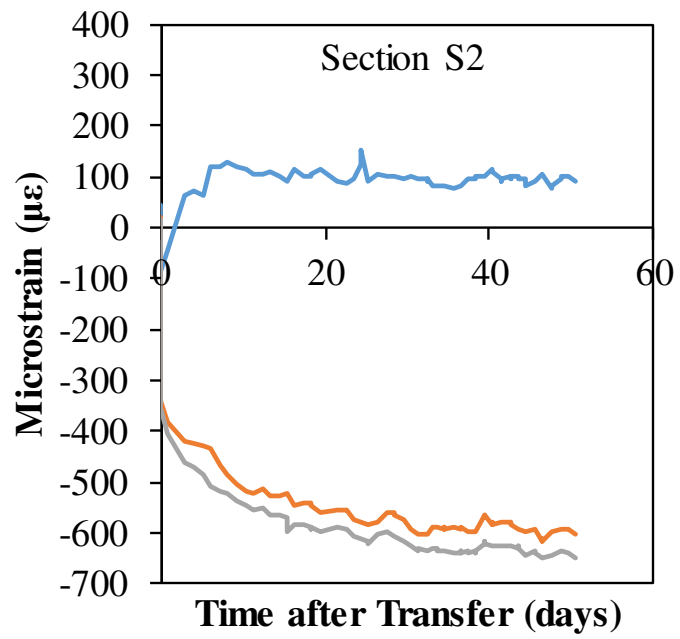

(b)

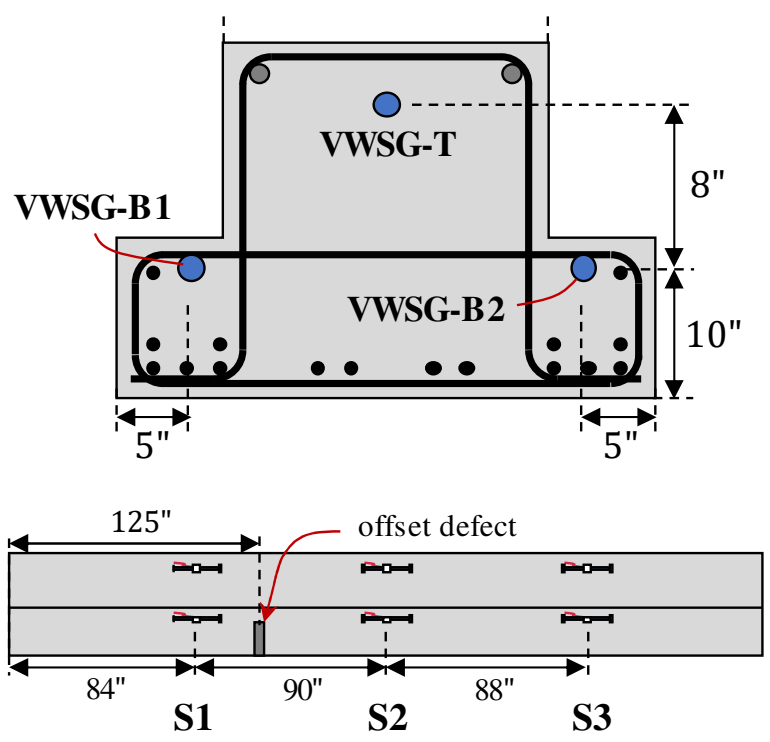

Figure 5-16: Strain readings in all VWSGs in FIU-1

The measured strains versus time in all the VWSGs in beam FIU-2 are shown in Figure 5-17. There was a noticeable difference between strains across the width of the section (comparing VWSG-B1 and VWSG-B2 with VWSG-M). 


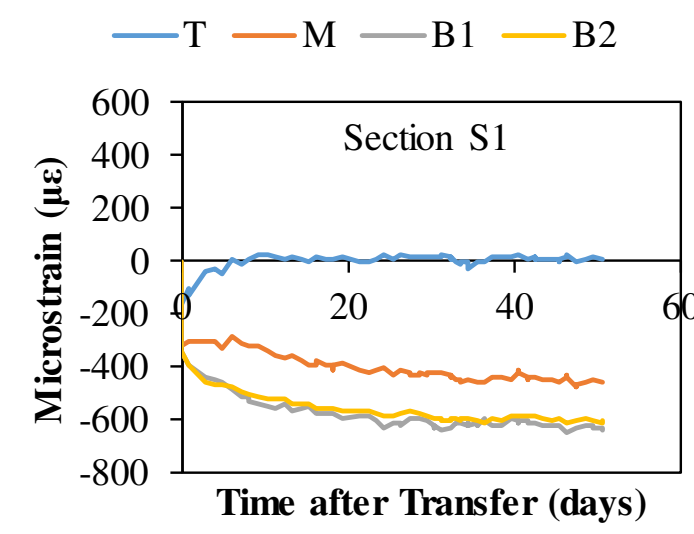

(a)

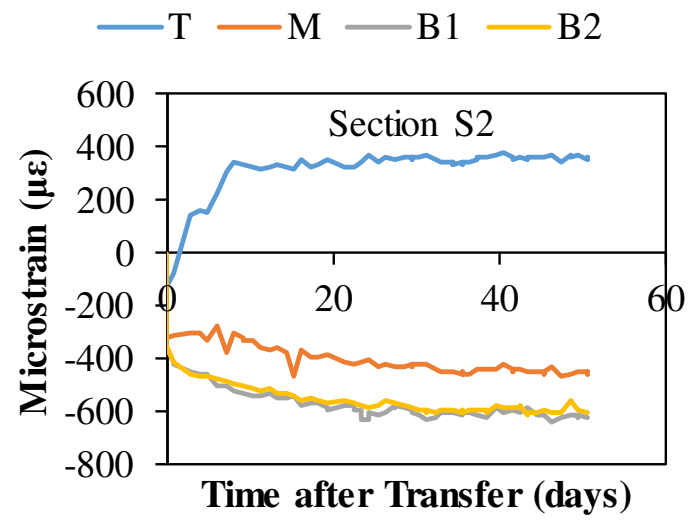

(b)
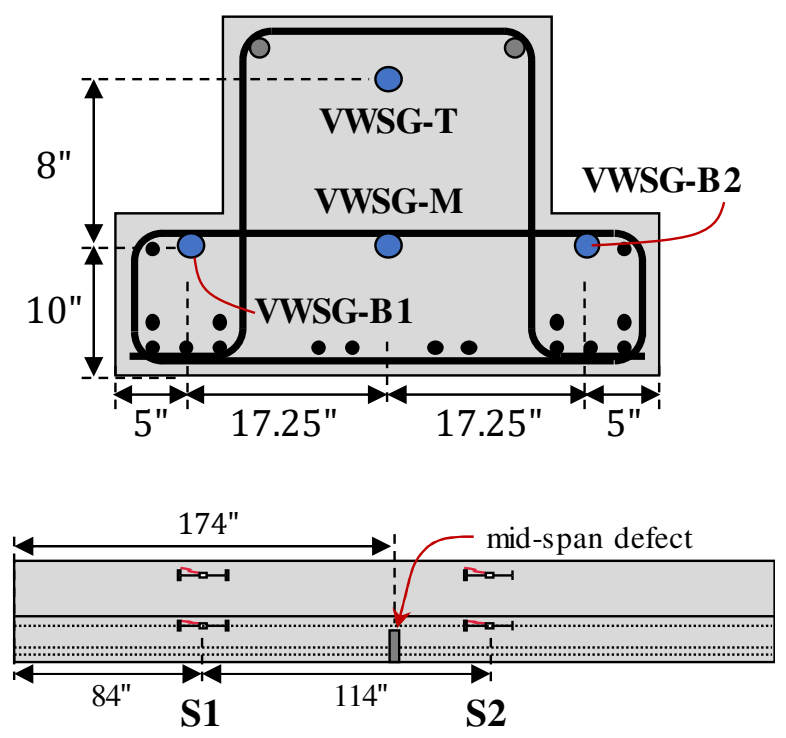

Figure 5-17: Strain readings in all VWSGs in FIU-2

The slopes in all the VWSG readings began to approach zero after approximately 50 days. This is when the cycles of active corrosion of the strands were started.

\subsection{CORROSION INITIATION OF STRANDS}

\subsubsection{Accelerated and Controlled Corrosion}

The galvanostatic method used to create accelerated corrosion in the prestressing strands in this study by applying a potential difference from a DC power supply to the prestressing strands. The positive terminal of the DC power supply was connected to the steel strand (anode). The negative terminal was connected to the counter electrode (cathode). The electrons are lost created by the forced potential difference through the 
electrolyte, which was a chloride-rich grout section cast before the precast concrete section.

The components for the defect in the inverted-tee beams are shown in Figure 5-18.

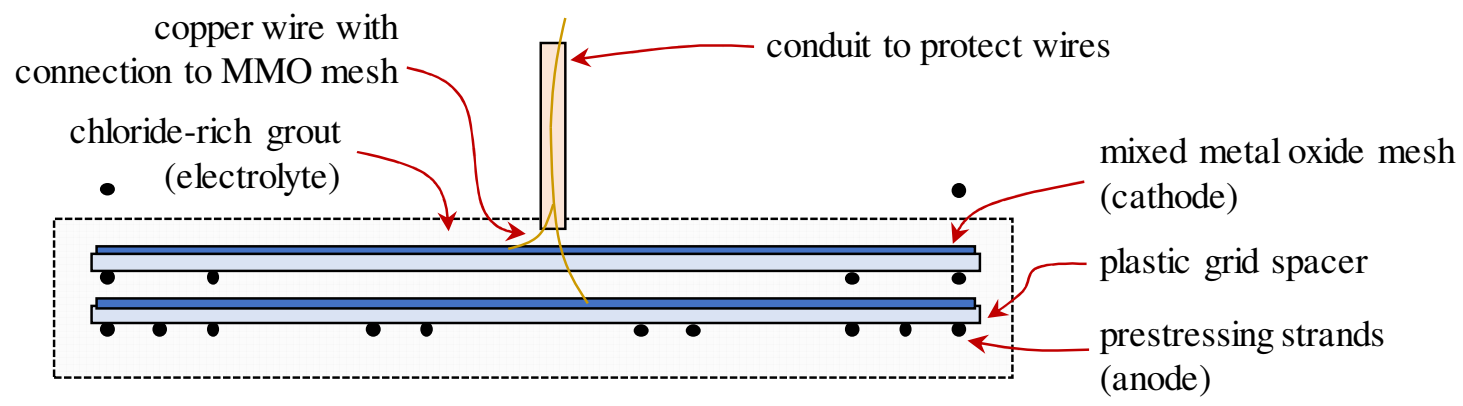

Figure 5-18: Schematic of mixed metal oxide mesh and other components for accelerated and controlled corrosion

One of the benefits of this kind of corrosion is that the degree of corrosion occurring in the strand can be determined theoretically using Faraday's law and the percentage of the amount of steel lost in corrosion can be calculated. Another benefit of the galvanostatic method is that a strand can completely corrode at a localized defect in only a few days to weeks, which is much faster than natural rates of corrosion. The strands were systematically subjected to the accelerated corrosion for 9 to 19 days.

\subsubsection{Selection of Strands to Corrode}

The strand labeling system used for both inverted-tee beams is shown in Figure 5-19. The vulnerability of the strands to corrosion damage (if placed in service in marine exposure environments) was determined based on the clear cover and the number of faces of exposure. The two corner strands (A1 and A10) were considered to have the highest possible exposure to chloride ions that can diffuse through the cover by direct splashing of water or airborne salts, so these were the first two strands corroded in the beams. Starting on the outside strands also allowed for a torsional effect on the system. A2 through A9, B1, $\mathrm{B} 10, \mathrm{C} 1$, and $\mathrm{C} 10$ were determined to have the next highest risk of corrosion. Strands A1 
and A10 were the first strands to be corroded in FIU-1, followed by strand A9. Strand A10 was corroded first in FIU-2 followed by strand A9.

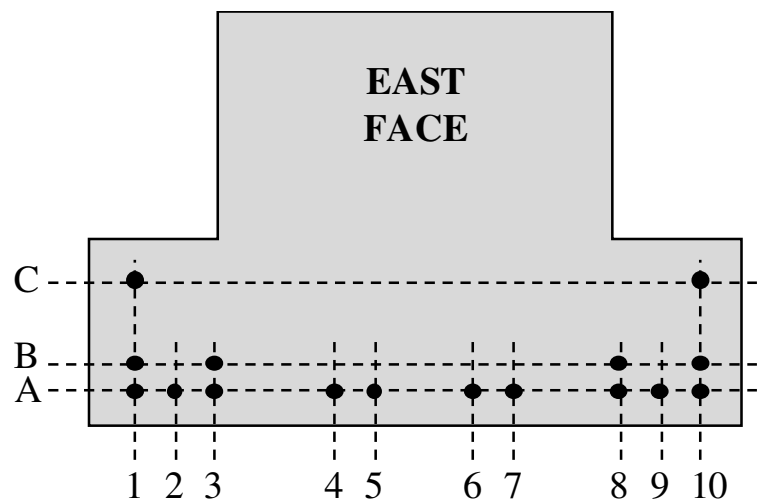

(a)

\begin{tabular}{|l|l|}
\hline $\begin{array}{l}\text { Risk of } \\
\text { Corrosion }\end{array}$ & Strands \\
\hline High & A1, A10 \\
\hline Medium & $\begin{array}{l}\text { A2 to A9, B1, B10, } \\
\text { C1, C10 }\end{array}$ \\
\hline Low & B3, B8 \\
\hline
\end{tabular}

(b)

Figure 5-19: (a) Strand labeling and (b) categorization of risk of corrosion initiation

\subsubsection{Timing for Accelerated Corrosion}

Both beams (FIU-1 and FIU-2) were cast on the same day (February 7, 2019) with prestress transfer occurring one day later (February 8, 2019), as shown in Table 5.2. The beams were moved to FIU one week after prestress transfer. Strain measurements were taken daily with a handheld reader until the data acquisition system was built and attached to the beams (April 9, 2019).

Table 5.2: Important events for both beams

\begin{tabular}{|l|c|c|}
\hline Event & Date & Days after Transfer \\
\hline Casting & $2 / 7 / 19$ & - \\
\hline Prestress transfer & $2 / 8 / 19$ & 0 \\
\hline Beams moved to FIU & $2 / 15 / 19$ & 7 \\
\hline DAQ attached to beams & $4 / 9 / 19$ & 60 \\
\hline
\end{tabular}

Accelerated corrosion cycles were started after the strain measurements began to stabilize. The timing for the corrosion cycles is shown in Table 5.3. Strand A1 in FIU-1 was the first strand to be corroded. No strands were corroded in FIU-2 to see if the long- 
term effects had stabilized. The voltage was removed from A1 in FIU-1 on April 29, 2019. Voltage was applied a few days later (May 5, 2019) to strand A10 in both beams (FIU-1 and FIU-2) and then removed on May 28, 2019. A longer period was allowed between accelerated corrosion for strand A10 and the next strand A9 to see if the behavior stabilized following the active corrosion period. Voltage was then applied to strand A9 on July 1, 2019 and removed on July 12, 2019.

Table 5.3: Timing for accelerated corrosion cycles

\begin{tabular}{|l|c|c|}
\hline Event & Date & Days after Transfer \\
\hline Voltage applied to A1 in FIU-1 & $4 / 10 / 19$ & 61 \\
\hline Voltage removed from A1 in FIU-1 & $4 / 29 / 19$ & 80 \\
\hline Voltage applied to A10 in FIU-1 and FIU-2 & $5 / 5 / 19$ & 86 \\
\hline Voltage removed from A10 in FIU-1 and FIU-2 & $5 / 28 / 19$ & 109 \\
\hline Voltage applied to A9 in FIU-1 and FIU-2 & $7 / 1 / 19$ & 143 \\
\hline Voltage removed from A9 in FIU-1 and FIU-2 & $7 / 12 / 19$ & 154 \\
\hline
\end{tabular}

\subsubsection{Mass Loss Measurement}

The mass loss was measured in both beams during the accelerated corrosion period of strand A9. The applied current was measured every 6 minutes using voltage probes on each beam with data gathered by a Vernier data acquisition system. For each time increment, $i$, the incremental mass loss, $\Delta m_{i}$, was found from the applied current, $I$, using

\section{Equation 5-2.}




$$
\Delta m_{i}=\frac{I_{i} \Delta t_{i} M_{F e}}{n F}
$$

Where:

$$
\begin{aligned}
& I_{i}=\text { measured current for increment i }(\text { Amps }=\mathrm{C} / \mathrm{s}) \\
& \Delta t_{i}=\text { time increment }\left(\mathrm{t}_{\mathrm{i}}-\mathrm{t}_{\mathrm{i}-1}\right) \\
& M_{\mathrm{Fe}}=\text { equivalent weight of iron }(55.85 \mathrm{~g} / \mathrm{mol}) \\
& n=\text { valency number of iron }(2) \\
& F=\text { Faraday constant }(96500 \mathrm{C} / \mathrm{mol})
\end{aligned}
$$

The cumulative mass loss at any time $t$ was determined by summing the incremental mass losses between initial time ( $\mathrm{t}_{\mathrm{i}}$ ) and the time of interest ( $\mathrm{t}$ ), as shown in Equation 5-3.

$$
\Delta m_{t}=\sum_{t_{i}}^{t} \Delta m_{i}
$$

The mass loss measured during accelerated corrosion of strand A-9 is shown in Figure 5-20. 


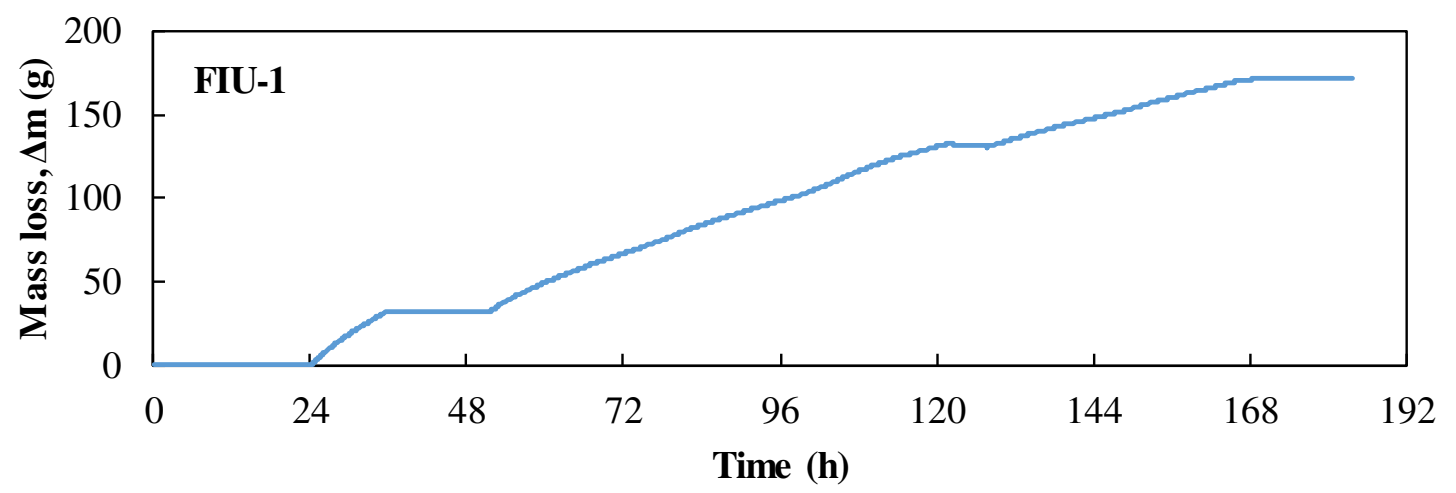

(a)

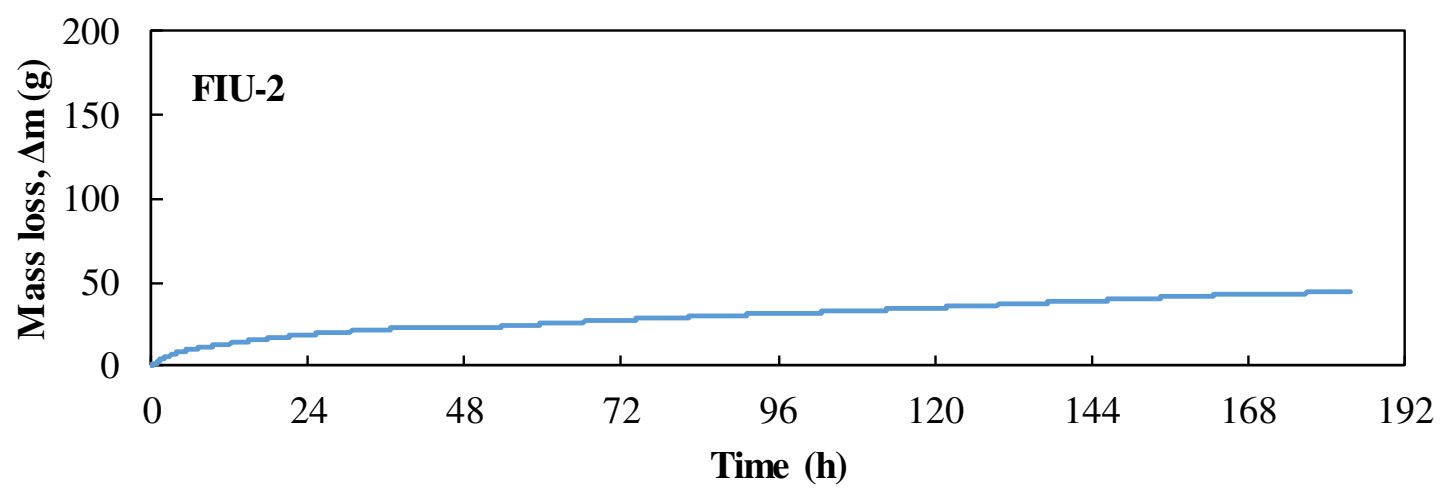

(b)

Figure 5-20: Mass loss versus time for strand A9 after start of accelerated corrosion in (a) FIU-1 and (b) FIU-2

The calculated mass loss would suggest that a large portion of the strand was corroded during this stage. Visual inspection was done during the corrosion of all strands. There was visible rust leaking from the defect at the location of the strand being corroded, as shown in Figure 5-21. 


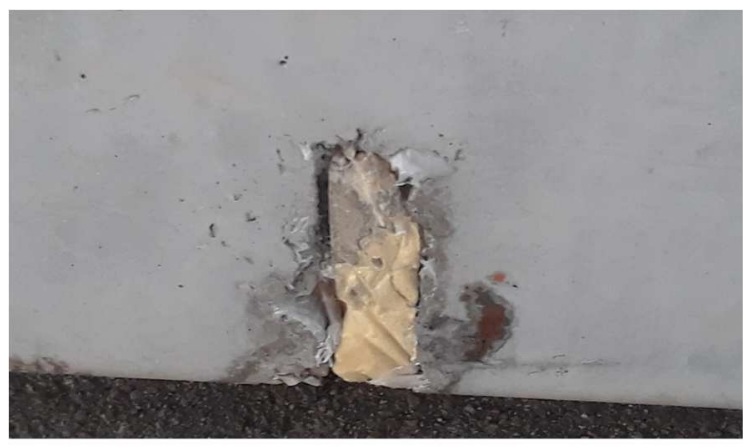

(a)

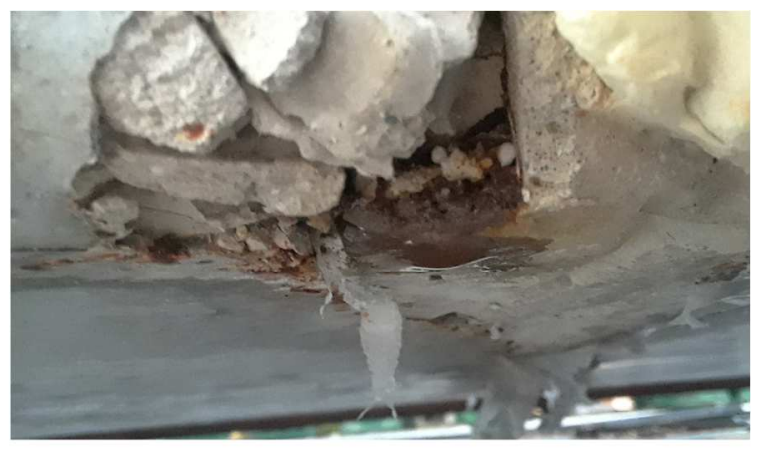

(b)

Figure 5-21: Visual corrosion product after accelerated corrosion of Al on FIU-1 on (a) side of beam and (b) bottom of beam

\subsection{EXPERIMENTAL RESULTS}

\subsubsection{Strain Measurement}

The strains measured by all the VWSGs are shown in Figure 5-22 for FIU-1 and Figure 5-23 for FIU-2. 


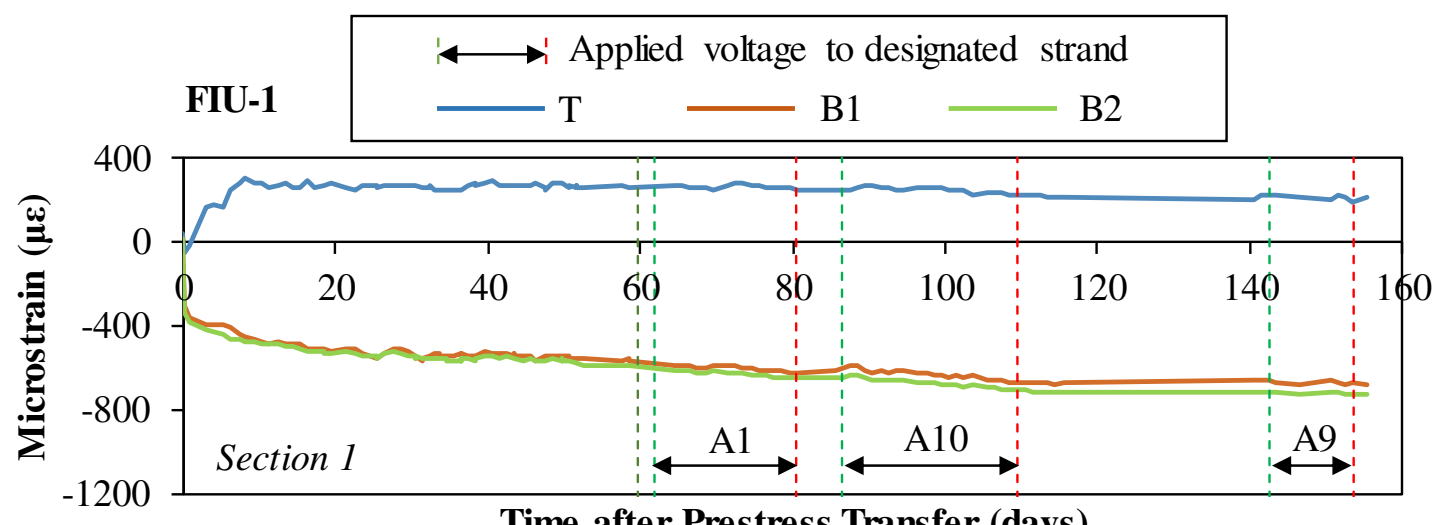

Time after Prestress Transfer (days)

(a)

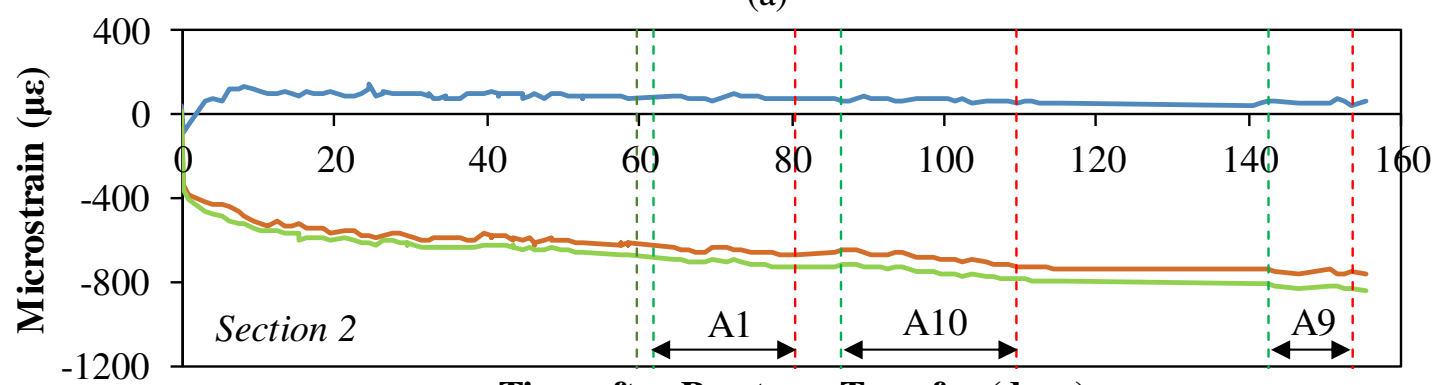

Time after Prestress Transfer (days)

(b)

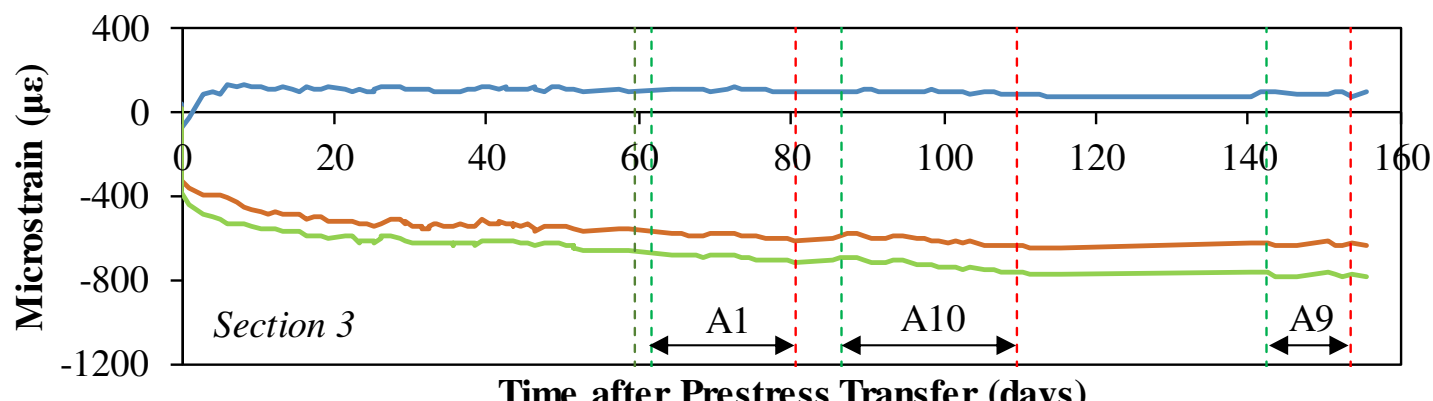

(c)

Figure 5-22: Strain measurements from VWSGs in FIU-1 for (a) Section 1, (b) Section 2, and (c) Section 3

The slopes of the strains for FIU-1 for the important time ranges from before are shown in Table 5.4. 
Table 5.4: Relevant slopes for strain readings loss for FIU-1 (all units $\mu \varepsilon / d a y$ )

\begin{tabular}{|l|c|c|c|c|c|c|c|c|c|}
\hline \multirow{2}{*}{ Time Period } & \multicolumn{3}{|c|}{ Section 1 } & \multicolumn{3}{c|}{ Section 2 } & \multicolumn{3}{c|}{ Section 3 } \\
\cline { 2 - 10 } & $\boldsymbol{T}$ & $\boldsymbol{B 1}$ & $\boldsymbol{B} 2$ & $\boldsymbol{T}$ & $\boldsymbol{B 1}$ & $\boldsymbol{B 2}$ & $\boldsymbol{T}$ & $\boldsymbol{B} 1$ & $\boldsymbol{B} 2$ \\
\hline $\begin{array}{l}\text { 7 days before } \\
\text { Al }\end{array}$ & 0.038 & -0.238 & -0.448 & -0.964 & -0.572 & -2.499 & -0.009 & 1.714 & -0.355 \\
\hline Corroding A1 & -0.249 & -2.208 & -2.415 & -0.188 & -2.084 & -2.227 & -0.046 & -1.818 & -2.345 \\
\hline $\begin{array}{l}\text { Between A1 } \\
\text { and A10 }\end{array}$ & -0.511 & 3.388 & 1.002 & -0.838 & 3.414 & 1.428 & -0.835 & 3.642 & 2.152 \\
\hline $\begin{array}{l}\text { Corroding } \\
\text { Al0 }\end{array}$ & -1.375 & -3.174 & -3.083 & -0.548 & -3.305 & -3.256 & -0.520 & -2.540 & -3.016 \\
\hline $\begin{array}{l}\text { Between A10 } \\
\text { and A9 }\end{array}$ & -0.202 & 0.578 & 0.042 & -0.031 & -0.408 & -0.552 & 0.230 & 0.767 & 0.133 \\
\hline \begin{tabular}{l} 
Corroding A9 \\
\hline
\end{tabular} & -2.096 & -0.521 & -0.643 & -1.102 & -0.701 & -1.219 & -0.976 & -0.228 & -0.373 \\
\hline
\end{tabular}

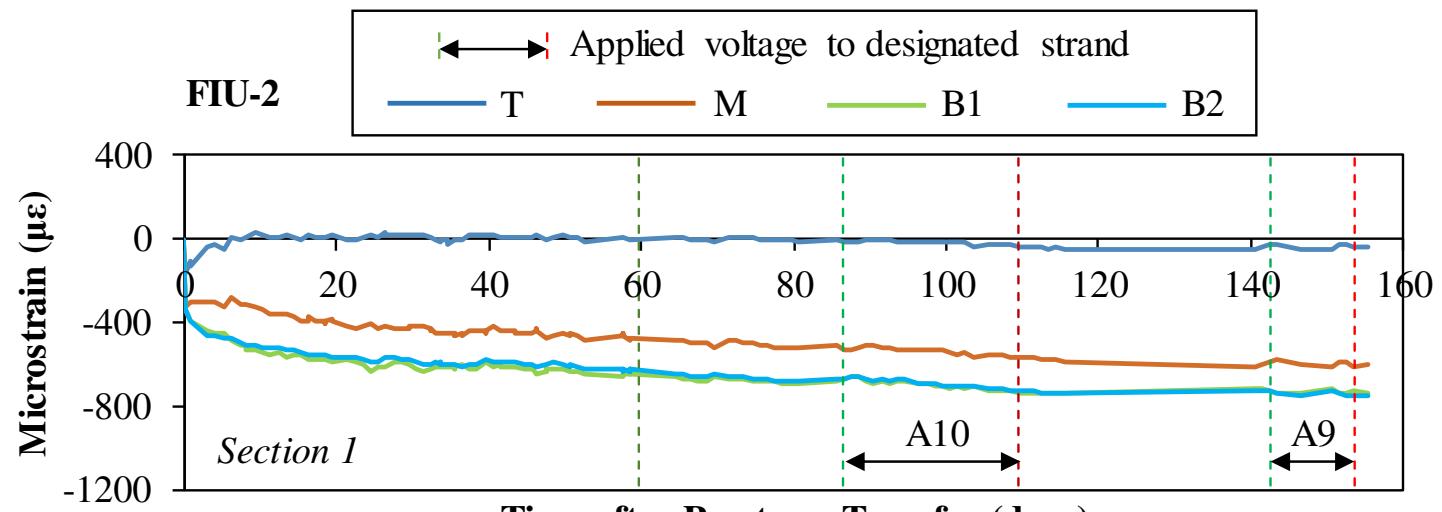

Time after Prestress Transfer (days)

(a)

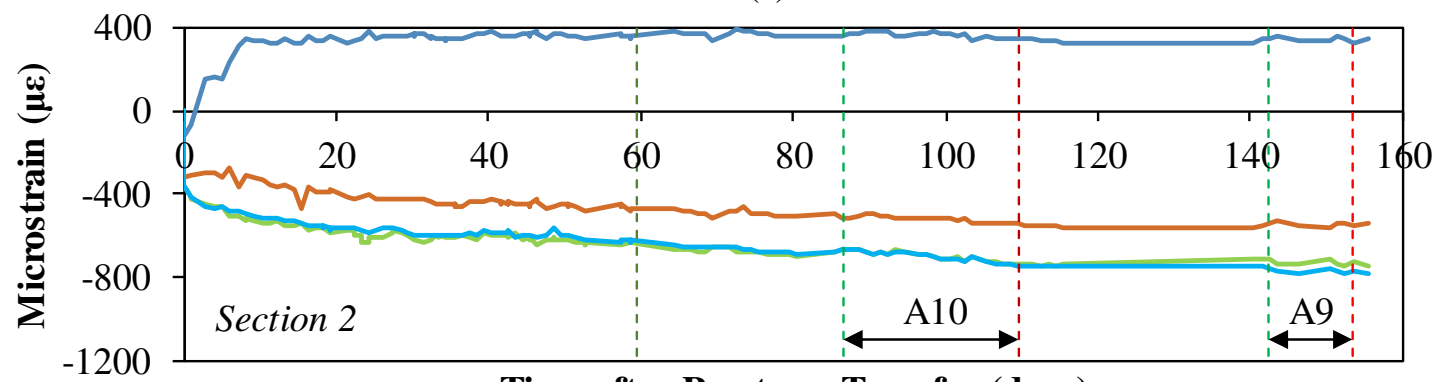

Time after Prestress Transfer (days)

(b)

Figure 5-23: Strain measurements from VWSGs in FIU-2 for (a) Section 1 and (b) Section 2

The slopes of the strains for FIU-2 for the important time ranges from before are shown in Table 5.5. 
Table 5.5: Relevant slopes for strain readings loss for FIU-2 (all units $\mu \varepsilon / d a y$ )

\begin{tabular}{|l|c|c|c|c|c|c|c|c|}
\hline \multirow{2}{*}{ Time Period } & \multicolumn{4}{|c}{ Section 1 } & \multicolumn{5}{c|}{ Section 2 } \\
\cline { 2 - 9 } & $\boldsymbol{T}$ & $\boldsymbol{M}$ & $\boldsymbol{B 1}$ & $\boldsymbol{B} 2$ & $\boldsymbol{T}$ & $\boldsymbol{M}$ & $\boldsymbol{B} 1$ & $\boldsymbol{B} 2$ \\
\hline 7 days before A1 & 1.624 & 1.038 & 0.689 & -0.261 & 0.901 & 0.739 & 0.554 & -0.463 \\
\hline Corroding A1 & -0.231 & -1.676 & -1.950 & -2.214 & 0.251 & -1.330 & -2.388 & -2.556 \\
\hline Between A1 and A10 & -0.856 & 0.076 & 2.998 & 1.827 & -0.214 & 0.112 & 3.514 & 1.899 \\
\hline Corroding A10 & -0.921 & -2.272 & -2.924 & -2.953 & -1.158 & -1.854 & -3.110 & -3.321 \\
\hline Between A10 and A9 & 0.080 & -0.837 & 0.606 & 0.161 & -0.133 & -0.088 & 0.800 & -0.158 \\
\hline Corroding A9 & -0.601 & -1.952 & -0.245 & -0.914 & -1.329 & -0.881 & 0.020 & -0.084 \\
\hline
\end{tabular}

\subsubsection{Prestress Loss Measurement}

The average prestress loss across all the sections in FIU-1 and FIU-2 are shown in Figure 5-24. The prestressed inverted-tee beams first experienced elastic shortening when the strand stress was transferred from the prestressing bed to the beams. The beams were then stored at the precast plant for a week before being shipped to FIU. The beam experienced additional deformation during storage from creep and shrinkage of the concrete. Testing did not begin on the beams until the long-term behavior began to level out. There is a noticeable change in the slope of the average prestress loss during the active corrosion periods for strands A1 and A10 in FIU-1 and during the active corrosion period for strand A10 in FIU-2. 


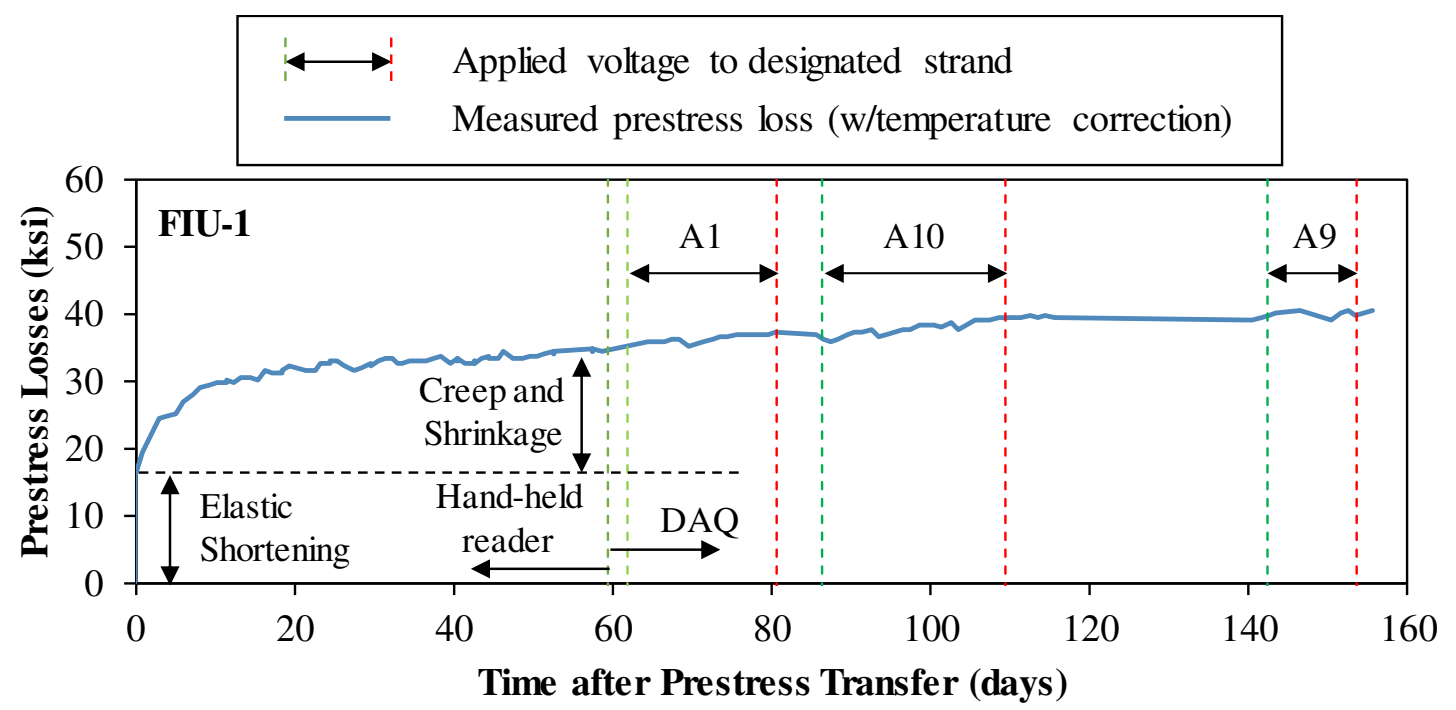

(a)

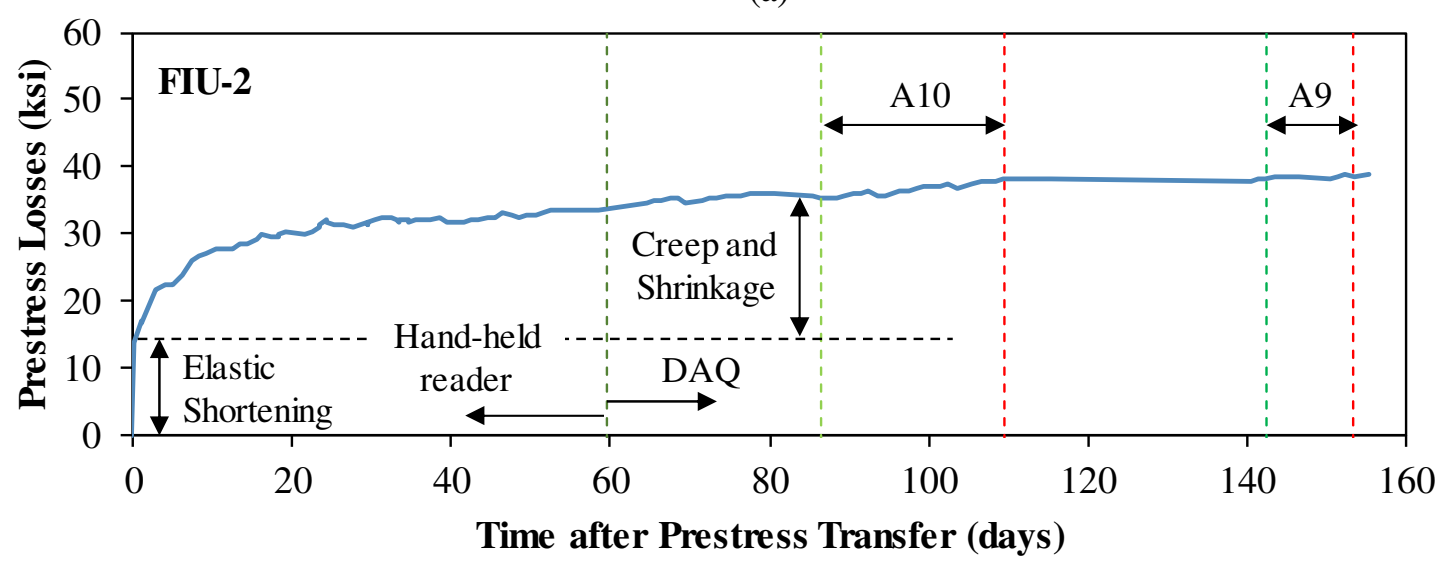

(b)

Figure 5-24: Average prestress loss versus time for (a) FIU-1 (with offset defect) and (b) FIU-2 (with midspan defect)

The strains were measured at three planes along the length for FIU-1 and two planes along the length in FIU-2, as shown in Figure 5-10. This allowed for the prestress loss to be determined at several different planes in both beams. The measured prestress losses at the three different section for FIU-1 are shown in Figure 5-25. The measured prestress losses at two different sections for FIU-2 are shown in Figure 5-26. 


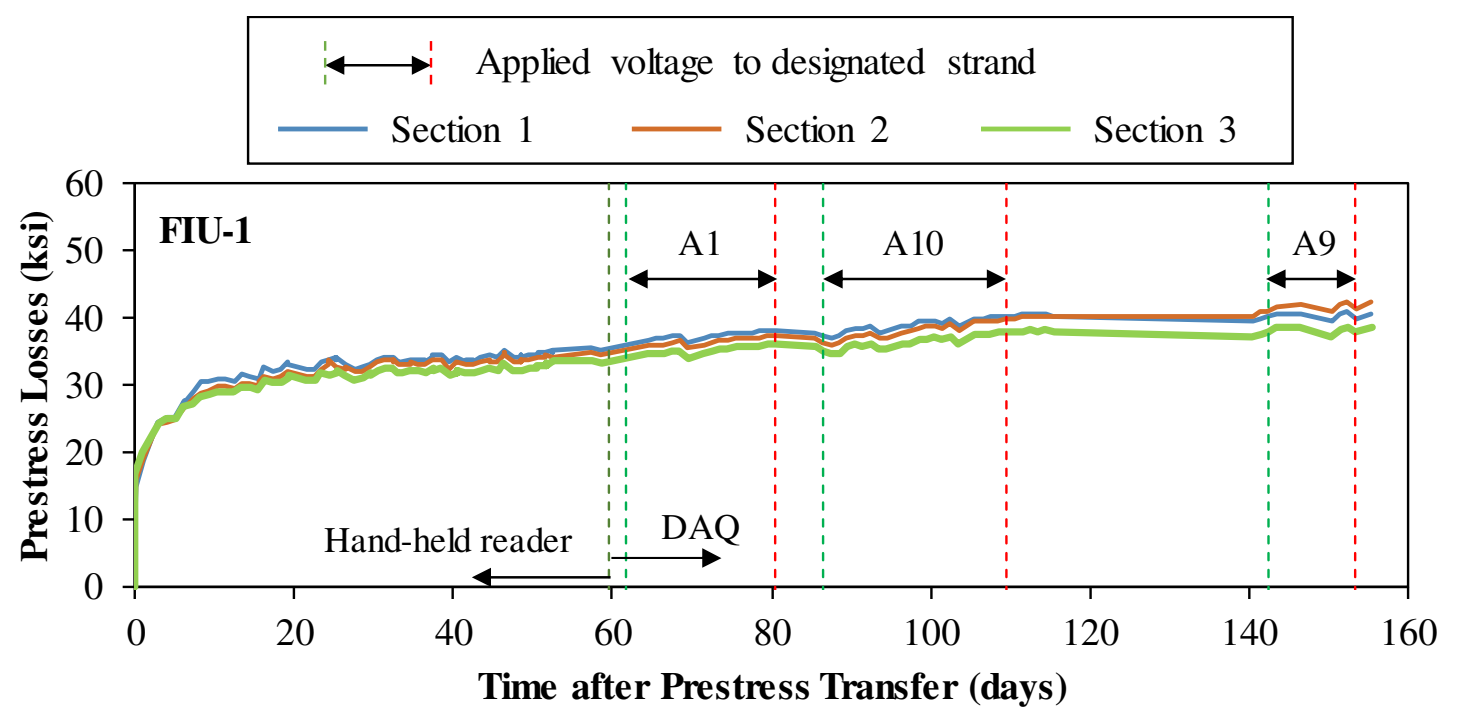

Figure 5-25: Prestress loss at different sections in FIU-1

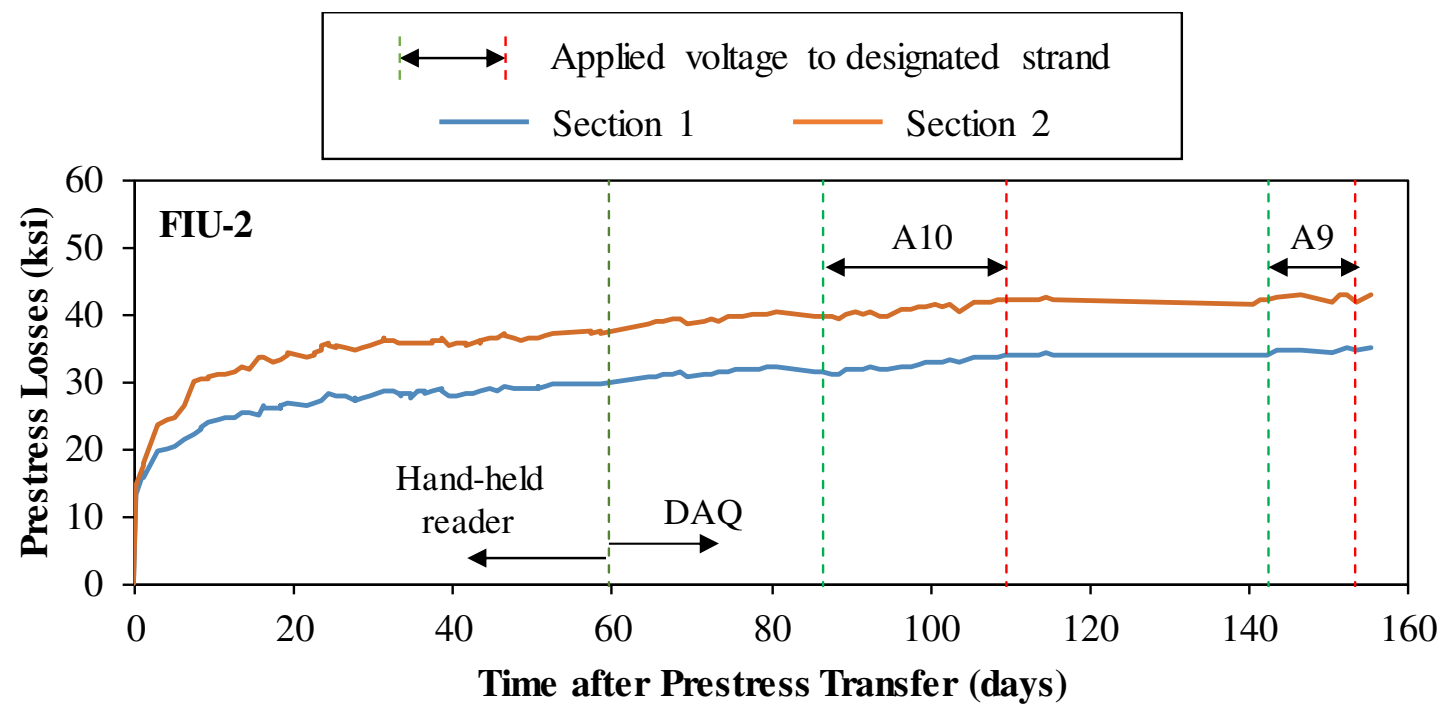

Figure 5-26: Prestress loss at different sections in FIU-2

The slope of the prestress loss and curvature measured at different sections was determined during the accelerated corrosion stages and time periods surrounding these stages. A linear regression and slope were found for measurements seven days before accelerated corrosion began and during periods where no voltage was applied and 
compared to the regression and slope during the accelerated corrosion period, as shown in Figure 5-27.

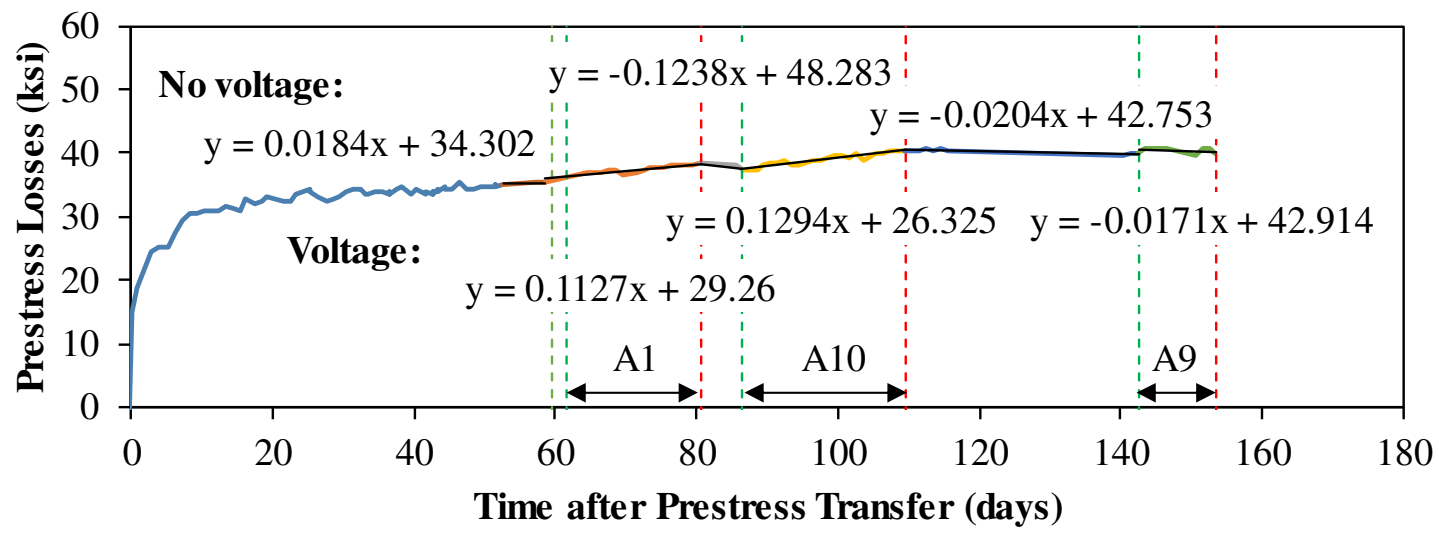

Figure 5-27: Measured prestress loss in FIU-1 at Section 1 with linear regressions for voltage applications on strands A1, A10, and A9

The slope for curvature and prestress loss at the three instrumented sections in FIU1 are shown in Table 5.6. There was a change in slope for prestress loss for FIU-1 during the first two periods of voltage application (accelerated corrosion of A1 and A10) compared to the surrounding times when there was no voltage application to the strands. The largest change in slope occurred in Section 1, which was the closest to the defect location. The slope of the prestress loss measured at Section 1 during accelerated corrosion of A1 was 5.1 times larger than the slope 7 days before the accelerated corrosion of A1 started. There was a negative slope during the time between A1 and A10 and then a noticeably larger positive slope again during the accelerated corrosion of A10. The slope between A10 and A9 being corroded was about zero and the slope remains unchanged while A9 is being corroded. 
Table 5.6: Relevant slopes for prestress loss for FIU-1

\begin{tabular}{|l|c|c|c|}
\hline \multirow{2}{*}{ Time Period } & \multicolumn{3}{|c|}{ Loss (ksi/day) } \\
\cline { 2 - 4 } & Section 1 & Section 2 & Section 3 \\
\hline 7 days before A1 & 0.018 & 0.057 & -0.035 \\
\hline Corroding A1 & 0.113 & 0.106 & 0.106 \\
\hline Between A1 and A10 & -0.124 & -0.143 & -0.167 \\
\hline Corroding A10 & 0.129 & 0.156 & 0.131 \\
\hline Between A10 and A9 & -0.020 & 0.024 & -0.018 \\
\hline Corroding A9 & -0.017 & 0.024 & -0.006 \\
\hline
\end{tabular}

The slope for prestress loss at two instrumented sections in FIU-2 are shown in

Table 5.7. There was a change in slope of the measured prestress loss in FIU-2 between the accelerated corrosion of A10 and 7 days prior to start of active corrosion. The slope leveled out following the accelerated corrosion of A10 and then slightly increased when accelerated corrosion of A9 started.

Table 5.7: Relevant slopes for prestress loss for FIU-2

\begin{tabular}{|l|c|c|}
\hline \multirow{2}{*}{ Time Period } & \multicolumn{2}{|c|}{ Loss (ksi/day) } \\
\cline { 2 - 3 } & Section 1 & Section 2 \\
\hline 7 days before A10 & -0.103 & -0.099 \\
\hline Corroding A10 & 0.119 & 0.115 \\
\hline Between A10 and A9 & 0.003 & -0.012 \\
\hline Corroding A9 & 0.013 & 0.003 \\
\hline
\end{tabular}

The slope during the period of accelerated corrosion for the first strand is similar in both beams $(0.108 \mathrm{ksi} /$ day for FIU-1 and $0.117 \mathrm{ksi} /$ day for FIU-2). Strands A1 and A10 were on opposite sides of the beam to each other, so the accelerated corrosion of A10 in FIU-1 still had a large effect on the slope of the measured prestress loss. However, strand 
A9 was immediately next to strand A10, which likely contributed to there being a less significant impact on the behavior in FIU-2 and no impact on behavior in FIU-1.

\subsubsection{Curvature Measurement}

The average curvature of the instrumented sections for FIU-1 and FIU-2 is shown in Figure 5-28.
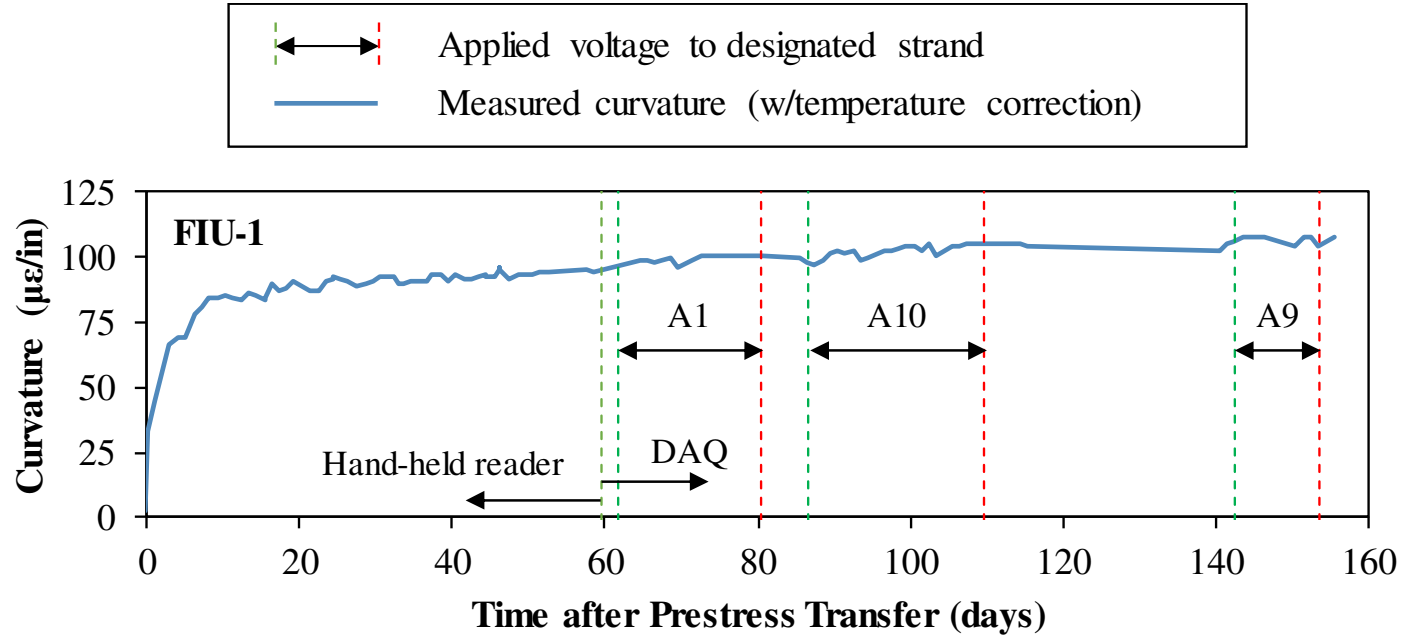

(a)

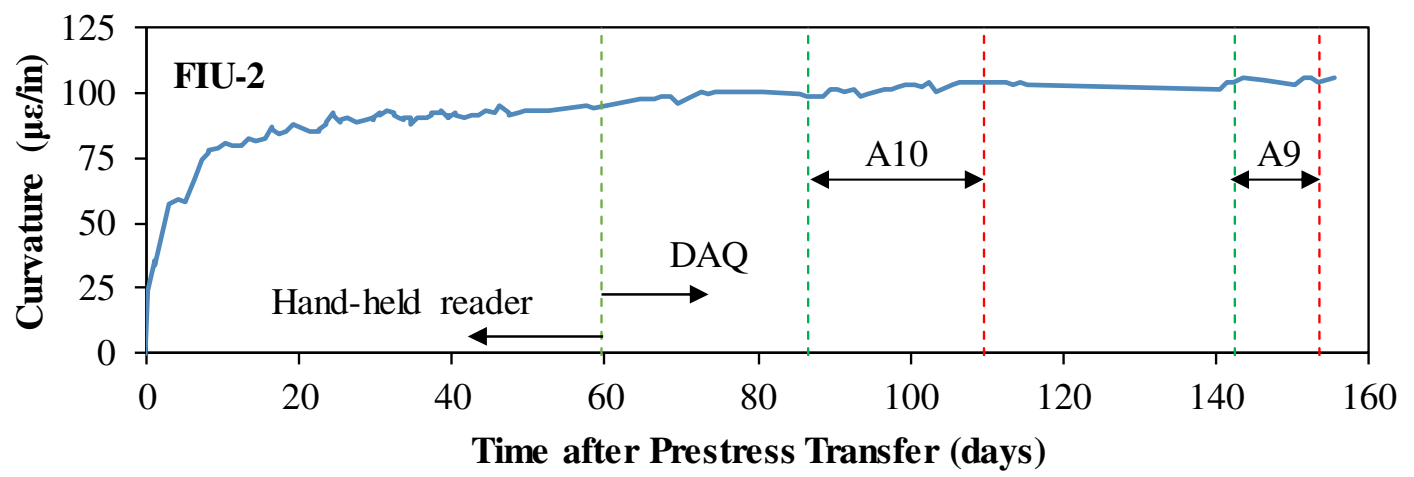

(b)

Figure 5-28: Average measured curvature for (a) FIU-1 and (b) FIU-2

The measured curvature at the three different section for FIU-1 are shown in Figure 5-29. The measured curvature at two different sections for FIU-2 are shown in Figure 5-30. 


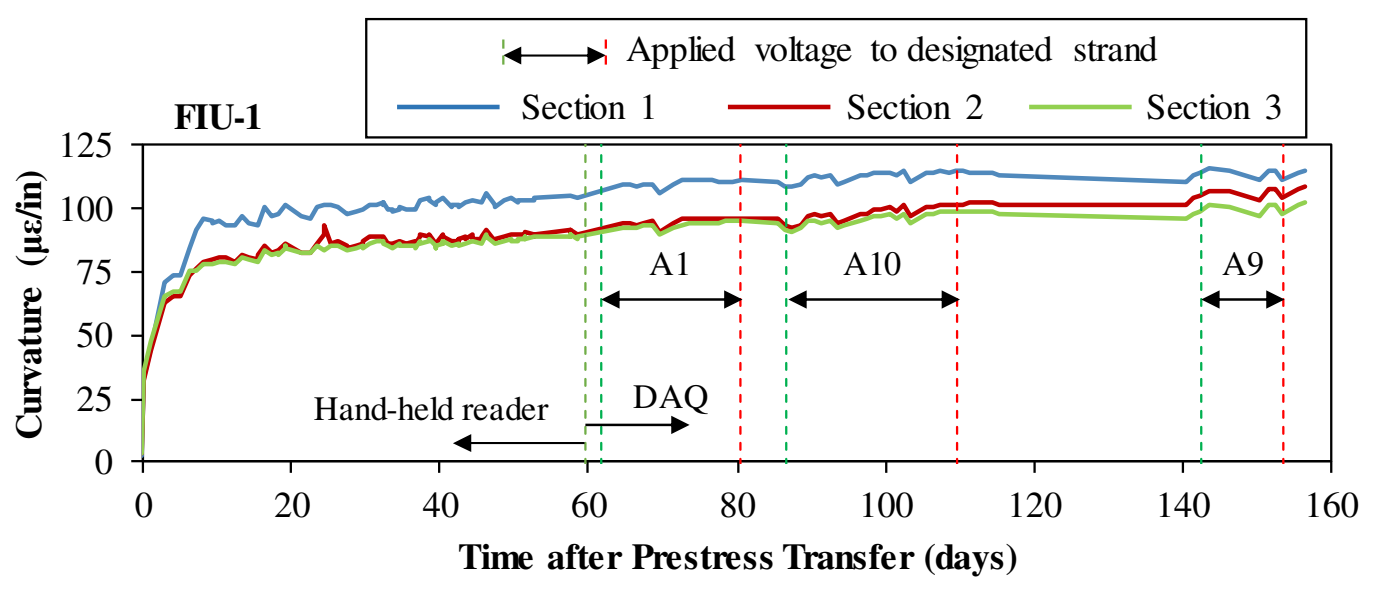

Figure 5-29: Curvature at different sections in FIU-1

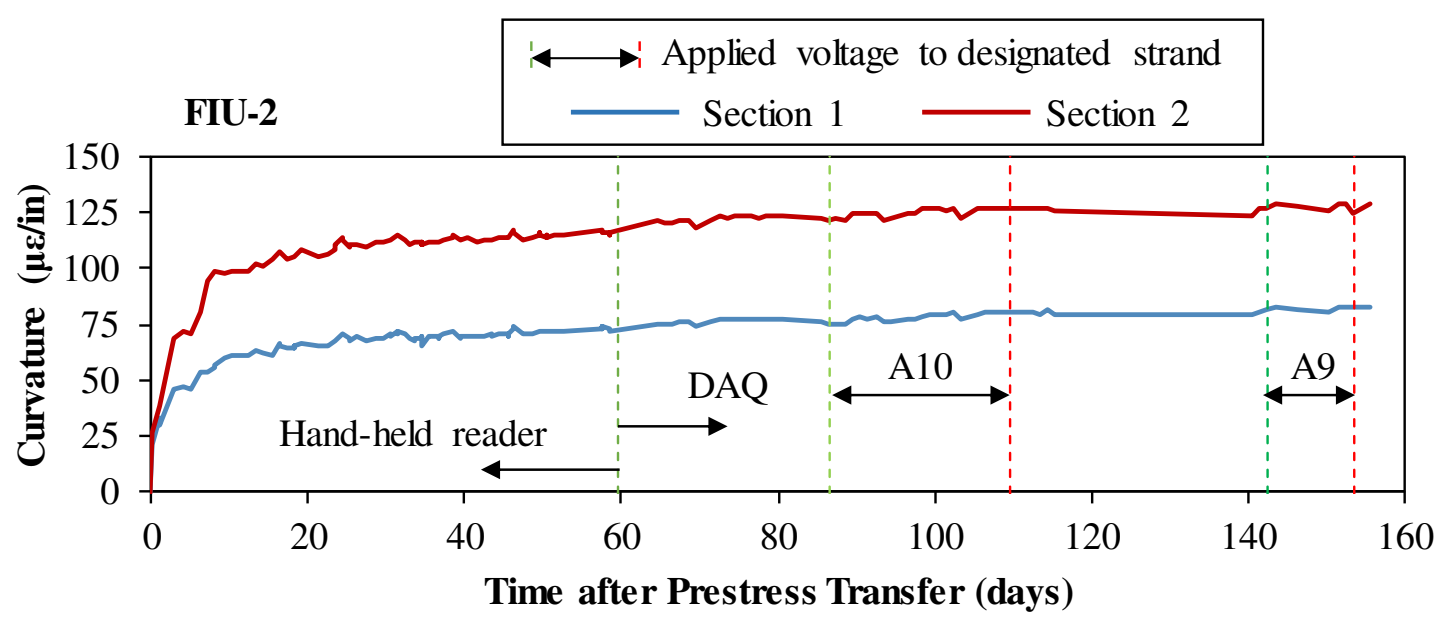

Figure 5-30: Curvature at different sections in FIU-2

The slope for curvature at the three instrumented sections in FIU-1 are shown in

Table 5.8. Similar to the slope of prestress loss, there is a change in slope for the measured curvature in FIU-1 between the accelerated corrosion periods for strands A1 and A10 and off periods. The slope between the time of accelerated corrosion for A10 and A9 is slightly different than the slope of the accelerated corrosion period for A9, but this is not as significant as the accelerated corrosion periods for the first two strands. 
Table 5.8: Relevant slopes for curvature for FIU-1

\begin{tabular}{|l|l|l|l|}
\hline \multirow{2}{*}{ Time Period } & \multicolumn{3}{|c|}{$\phi(\mu \varepsilon / \mathrm{in} /$ day $)$} \\
\cline { 2 - 4 } & Section 1 & Section 2 & Section 3 \\
\hline 7 days before A1 & 0.048 & 0.071 & -0.086 \\
\hline Corroding A1 & 0.175 & 0.197 & 0.211 \\
\hline Between A1 and A10 & -0.338 & -0.407 & -0.466 \\
\hline Corroding A10 & 0.219 & 0.342 & 0.282 \\
\hline Between A10 and A9 & -0.064 & 0.056 & -0.027 \\
\hline Corroding A9 & -0.030 & 0.099 & 0.018 \\
\hline
\end{tabular}

The slope for curvature at the two instrumented sections in FIU-1 are shown in Table 5.9. Similar to FIU-1, there is a noticeable change in slope of the curvature in both sections when the voltage was applied to strand A10. The slope was near zero when the voltage was removed from strand A10 and increased slightly when voltage was applied to A9.

Table 5.9: Relevant slopes for curvature for FIU-2

\begin{tabular}{|l|c|c|}
\hline \multirow{2}{*}{ Time Period } & \multicolumn{2}{|c|}{$\phi(\mu \varepsilon / \mathrm{in} / \mathrm{day})$} \\
\cline { 2 - 3 } & Section 1 & Section 2 \\
\hline 7 days before A10 & -0.311 & -0.257 \\
\hline Corroding A10 & 0.226 & 0.200 \\
\hline Between A10 and A9 & 0.013 & -0.040 \\
\hline Corroding A9 & 0.041 & 0.007 \\
\hline
\end{tabular}

There is a negative slope for the curvature in both beams during the period between accelerated corrosion of strands A1 in FIU-1 and A10 in both beams. Since the negative curvature was observed in both beams (FIU-1 which had already had one strand corroded 
and FIU-2 which had not had any strands corroded), the negative slope was not likely caused by the effects of accelerated corrosion.

\subsection{CHAPTER SUMMARY}

Galvanostatic accelerated corrosion was used to corrode three strands (A1, A10, and A9) in FIU-1 and two strands (A10 and A9) in FIU-2 while monitoring the strain across the section depth at multiple planes in each beam using VWSGs. Several conclusions can be made:

- There was a change in slope for the prestress loss and curvature versus time plots at all sections during accelerated corrosion of strands A1 and A10 for FIU-1 and A10 for FIU-2 (when compared to the surrounding periods when no voltage was being applied).

- There was little to no change in slope for the prestress loss during the accelerated corrosion of strand A9 in both beams. There was a small change in the slope of the curvature during the corrosion of strand A9, but less than during the corrosion of the other strands.

- The largest change in slope for the prestress loss and curvature in FIU-1 was observed in Section 1, the section closest to the defect.

The preliminary results suggest there is a noticeable change in the overall behavior of the member when corrosion of the prestressing strands first initiates and that this change in behavior can be measured using VWSGs. 


\section{CHAPTER 6. FIELD APPLICATION}

\subsection{OVERVIEW}

As described in Chapter 3, one of the objectives of this research was to develop a recommended sensor placement layout to give engineers guidance to when and where sensors should be used. The focus of this research was to develop this layout for posttensioned (PT) structures. Because the full-scale testing was on pretensioned beams, the applicability of the results from the testing on pretensioned beams to post-tensioned structures is first discussed. The recommended local corrosion sensors and strain sensors are then discussed. Finally, two different strategies for using local corrosion sensors and strain gauges to monitor and maintain PT structures are introduced followed by a recommended instrumentation schedule. This chapter can used by practicing engineers to design an effective instrumentation program for PT structures.

\subsection{APPLICABILITY TO POST-TENSIONED STRUCTURES}

Although this research was conducted on prestressed concrete beams with pretensioned strands, all the results would also be valid for PT structures or structures with both pre and post-tensioning. In pretensioned structures, the prestressing in the strands is applied prior to casting of the concrete and stress in the strand is transferred to the beam over a certain length. The strands are assumed to have a perfect bond with the surrounding concrete, so applied loads will impact the local strains and stresses in the prestressing strand along the length of the beam, as shown in Figure 6-1 (a). 

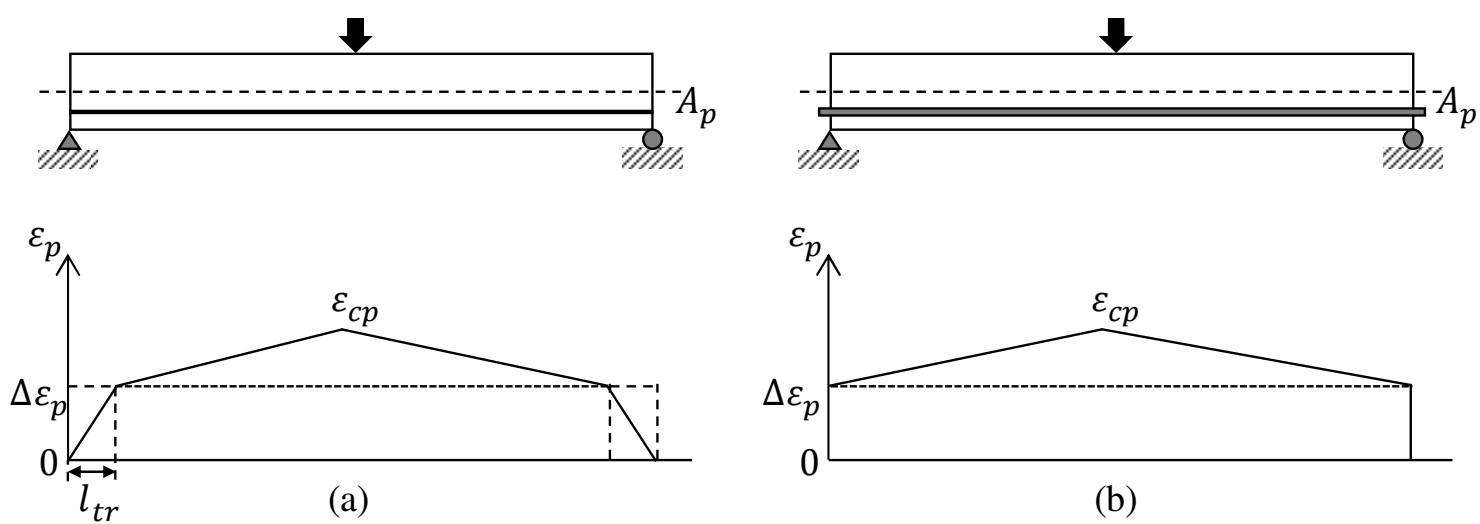

(b)

Figure 6-1: Strain response in prestressing strands for (a) pretensioned and $(b)$ bonded post-tensioned beams

In a PT structure, the prestressing strands are stressed after the concrete is placed and allowed to harden. The strands are anchored at the ends of the beams, so the locked in strain begins at the anchor points, as shown in Figure 6-1 (b). Grout is then placed in the beams, which locks in the strain differential along the length of the beam. The strands are then also assumed to have a perfect bond with the surrounding concrete after grouting, so applied loads will impact the local strains and stresses in the strands along the length of the beams, Figure 6-1 (b). Because the strands are bonded in PT, the response of the structure to localized corrosion damage would be the same as pretensioned structures. The results of this research conducted on pretensioned beams would also be applicable for PT structures.

The initial prestressing process is similar for bonded and unbonded PT structures. The primary difference between the two systems is that the strain in the prestressing strand will be equal along the length of the beam, as the only point of stress transfer between the strand and the beam is at the PT anchors. This means that when a load is applied, the average total strain in the beam will increase, as shown in Figure 6-2. It is assumed that localized damage would result in a decrease in the average strain and stress in the beam, but further research is needed to verify this concept. 

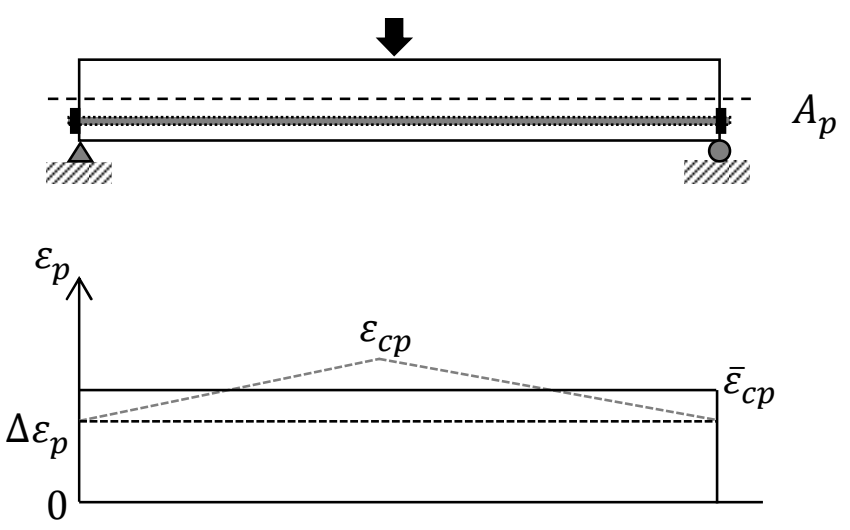

Figure 6-2: Strain response in prestressing strands for unbonded PT structures

\subsection{SENSOR AND GAUGE SELECTION}

\subsubsection{Local Corrosion Sensors}

Three local corrosion sensors were investigated. The relative humidity (RH) sensors likely have the most promise for post-tensioning applications. RH was higher at locations in the small-scale specimens where corrosion was more likely. Additional thought needs to be given to RH sensor type and installation; the RH sensors used in this experimental program required installation after grout placement and were influenced by the external RH conditions.

The four-point resistivity sensors were able to detect a clear difference between the grouted ducts with good grout compared to ducts with chloride-rich grout with voids and layered-chloride rich grout without voids. The small-scale tests were performed on 3-inch diameter pipes with only one 0.6 -inch diameter prestressing strand, so most of the current returned to the opposite electrode, as shown in Figure 6-3 (a). These sensors may not function as well for ducts with larger amounts of prestressing strands because the majority of the current may flow through the prestressing strands and not return to the opposite electrode, as shown in Figure 6-3 (b). 


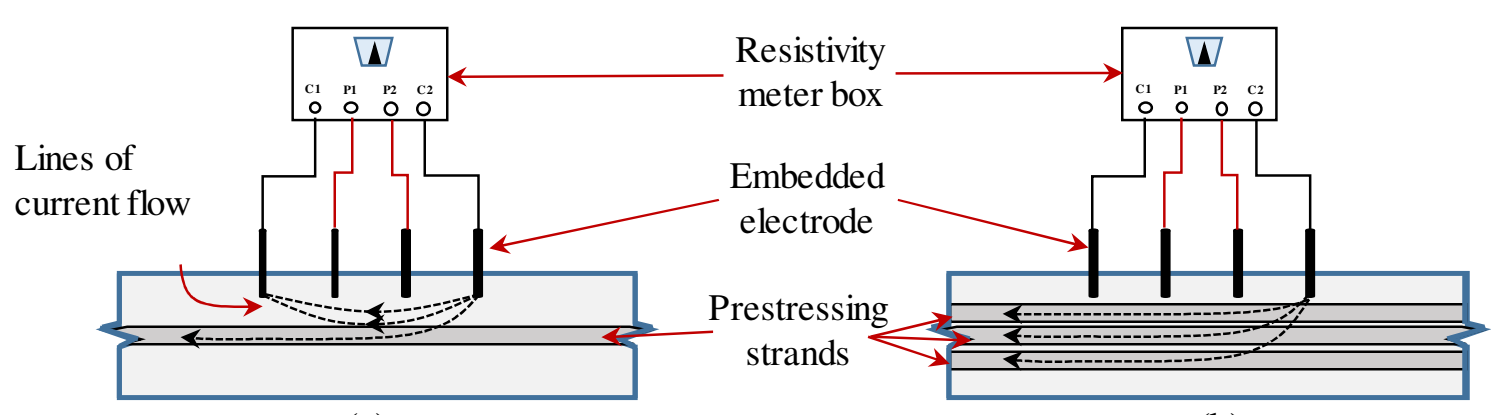

(a)

(b)

Figure 6-3: Schematic of current flow in four-point resistivity sensors with (a) smaller and (b) larger amounts of prestressing strands

The RLC sensor would have the capability to detect when the sacrificial element is corroded to a certain point and may have the ability to detect the rate of corrosion propagation. However, there are not any commercially available RLC sensors and further sensor development would be needed before it could be implemented in the field.

\subsubsection{Strain Sensors}

Vibrating wire strain gauges (VWSGs) are commercially available and have been shown by many researchers to be stable over long periods of time. The VWSGs used in this research were able to clearly detect the initiation of corrosion in the first prestressing strand in each beam. The local corrosion damage in the first strand resulted in a change in the behavior of the beam, which was detected by the VWSGs (through a change in slope of curvature versus time).

Other gauges capable of measuring strain may be used in place of the VWSGs. Radio frequency identification (RFID) based strain gages, described in Chapter 2, may be a wireless option for measuring strain, although the long-term durability of these gauges would need to be verified. Fiber-optic gauges may also be used in place of the VWSGs to get more strain measurements along the length of the beam. 


\subsection{OVERVIEW OF INSTRUMENTATION STRATEGIES}

Two possible strategies could be utilized to combine local sensors with strain sensors that measure the global response to create a robust system for providing proactive engineering measures in a cost-effective way:

1. Local sensors (e.g. RH sensors) could be used to identify possible problem areas in the beam early on, mediation could then be considered (e.g. inhibitor impregnation and drying), and strain gauges could be used to see if the mediation worked.

2. Strain gauges could be used to identify when corrosion damage to strands first begins to impact the global response of the beam and then local sensors (e.g. RH sensors) used to identify the regions where the corrosion damage most likely has occurred.

Both options could use similar sensor layouts.

\subsection{RECOMMENDED INSTRUMENTATION SCHEDULE}

VWSGs are recommended to be used for the strain monitoring of the global structural behavior. At least three gauges should be installed at three different levels in single-web members, as shown in Figure 6-4 (a). Having three gauges at three allows for the strain profile to be determined across the depth of the section and provides verification of the linear strain profile. At least four gauges installed at three different levels are recommended for multi-web sections, as shown in Figure 6-4 (b). Two gauges should be placed at mid-height of the outside webs. 


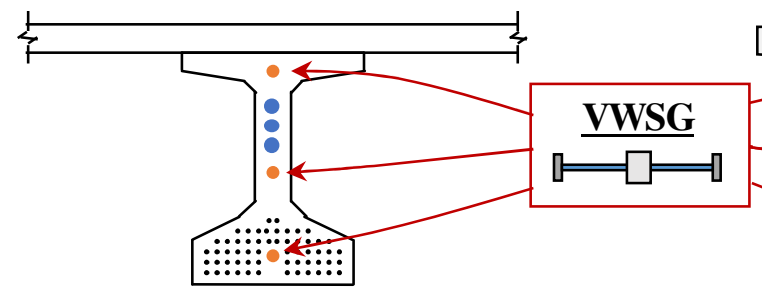

(a)

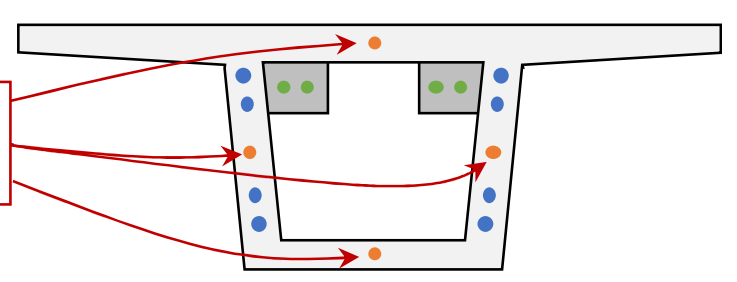

(b)

Figure 6-4: Recommended VWSG placement in (a) single web and (b) multi-web sections

The recommended instrumentation layout for VWSGs and RH sensors is shown in

Figure 6-5. VWSGs should at least be placed at the points of maximum positive and negative moment along the length of the beams (locations 2 and 4 in Figure 6-5). Additional VWSGs can also be placed at the PT anchor point at the end of the beams (locations 1 and 5 in Figure 6-5). Note location 3 may be a point of maximum moment or a PT anchor point depending on the design.

The RH sensors should be located near the PT anchor points (locations 1, 3, and 5 in Figure 6-5 depending on the design) and at the high points in the PT tendons (locations 2 and 4 in Figure 6-5). The RH sensor should be installed on the top side of the PT duct if possible. 


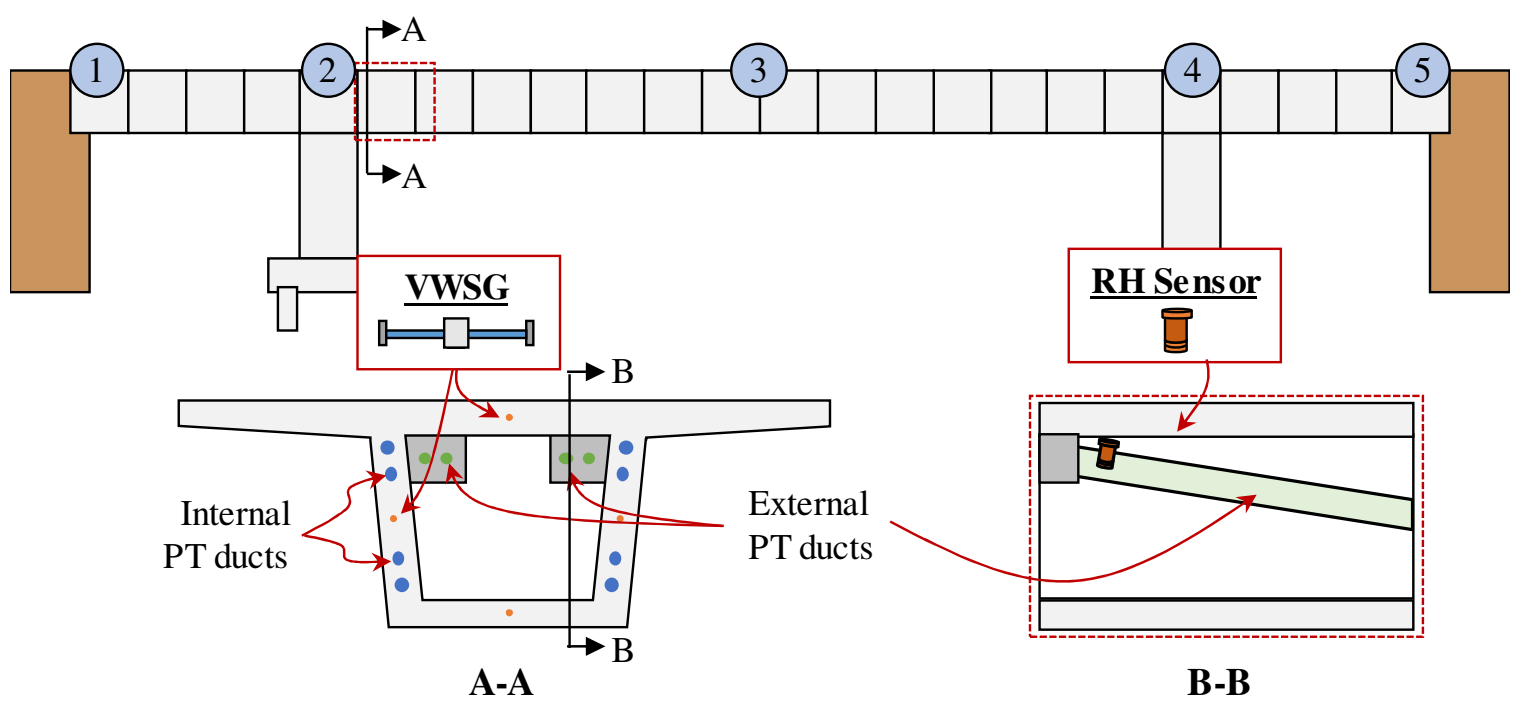

Figure 6-5: Schematic of recommended instrumentation schedule

\subsection{CHAPTER SUMMARY}

This chapter contained recommendations for:

- Type of local corrosion sensors and strain sensors,

- Strategies for creating a robust monitoring system for providing proactive engineering measures in a cost-effective way, and

- Locations for local corrosion sensors and strain sensors. 


\section{CHAPTER 7. CONCLUSION AND RECOMMENDATIONS}

\subsection{SUMMARY AND CONCLUSIONS}

This research study explored the feasibility of using embedded sensors to monitor the corrosion of prestressing strands in post-tensioned (PT) structures. Experimentally, three local corrosion sensors (resistivity sensors, relative humidity $[\mathrm{RH}]$ sensors, and resistor-inductor-capacity [RLC] sensors) were chosen for further investigation through small-scale experimental tests using laboratory-scale specimens and inclined grouted tendons with different grout conditions. In this research, local sensors (i.e. RH sensors and four-point resistivity sensors) placed at an interval of every three foot were able to detect corrosion conducive environment in PT ducts by measuring the electrical properties and moisture contents of the grout. Following are the key findings developed from the smallscale testing of the local corrosion sensors:

- $\quad \boldsymbol{R H}$ Sensors: The results of RH sensors were largely influenced by external relative humidity, exposure condition and rainfall condition. There was not a significant difference in the measured $\mathrm{RH}$ between the specimens with good grout, chloride-rich grout with voids, and layered chloride-rich grout without voids. However, the measured RH was consistently lower in the low point of the specimens compared to the high points for all the specimens. RH was higher at locations in the small-scale specimens where corrosion was more likely. RH sensors likely have the most promise for post-tensioning applications. Additional thought needs to be given to $\mathrm{RH}$ 
sensor type and installation; the RH sensors used in this experimental program required installation after grout placement.

- Resistivity Sensors: The four-point resistivity sensors were able to detect a clear difference between the grouted ducts with good grout compared to ducts with chloride-rich grout with voids and layered-chloride rich grout without voids. These sensors may not function as well for ducts with large amounts of prestressing strands because the majority of the current may flow through the prestressing strands and not return to the opposite electrode.

- $\quad \boldsymbol{R} L \boldsymbol{C}$ Sensors: The RLC sensor would have the capability to detect when the sacrificial element is corroded to a certain point and may have the ability to detect the rate of corrosion propagation. However, there are not any commercially available RLC sensors and further sensor development would be needed before it could be implemented in the field.

Detection of environments that may be conducive to corrosion initiation will not give direct information on actual corrosion rates and damage.

Two full-scale prestressed concrete inverted-tee (IT) beams were constructed and instrumented with vibrating wire strain gauges (VWSGs) located in multiple planes along the length to evaluate the effectiveness of global monitoring systems to detect localized corrosion damage. A defect was created at mid-span in one beam and at about a third of the beam length in the other beam; the defect was designed to allow for accelerated corrosion of the prestressing strands at the location of the defect. A voltage differential was 
systematically applied to strands in each beam to cause accelerated corrosion while the strain response of the beams was measured at different locations.

Some key findings from the developed full-scale testing of the prestressed concrete IT beams are:

- The largest change in slope for the prestress loss and curvature in FIU-1 was observed in Section 1, the section closest to the defect.

- $\quad$ The compressive strain in the beam cross section read by the bottom layer VWSGs typically increased during the strand corrosion periods. This increase in compressive strain would suggest that the changes in slopes for beam curvature and prestress loss were a result of the mass loss of the strand. Relaxation of the strand at the location of corrosion would have likely resulted in higher compression in sections adjacent to the corroded strand as the strand redevelops.

- Development of rust on the strand can possibly allow for some level of cracking of the cementitious materials surrounding the strand. If damage to that material becomes significant, changes in strain would be more greatly highlighted.

- The VWSGs were able to clearly detect the initiation of corrosion in the first prestressing strand in each beam. The local corrosion damage in the first strand resulted in a change in the behavior of the beam, which was detected by the VWSGs (through a change in slope of curvature versus 
time). Additional corrosion of a strand adjacent to an already corroded strand did not have as much an impact on the response of the beam.

\subsection{CONTRIBUTION TO THE FIELD}

PT bridges are difficult to inspect using only currently available inspection techniques. The early corrosion damage that has been observed in several PT bridges in Florida highlights the need for improved means to assess corrosion damage in PT bridges. Corrosion monitoring of PT bridges with embedded sensors (both local corrosion sensors and strain gauges to measure the global response) can be used to compliment common corrosion inspection methods and improve the maintenance of these structures. This research showed that:

1. Local sensors (e.g. RH sensors) can be used to determine that specific locations in a PT are more vulnerable to corrosion initiation and propagation and that localized corrosion damage will impact the overall behavior of a member (confirming Hypothesis \#1), and

2. A global instrumentation scheme using strain gauges (e.g. VWSGs) can be implemented to effectively monitor the corrosion propagation of PT structures (confirming Hypothesis \#2).

Instrumentation strategies and recommended sensor layouts were developed for PT structures to guide engineers responsible for their maintenance. This information can provide a satisfactory platform to engineers to repair and replace the critical component of prestressed concrete structures when needed. The in-situ monitoring of corrosion using a network of embedded sensors will last for several decades. This will enhance the safety 
measures of the structures, and remedial measures can be more efficiently applied to extend the service life in a cost-effective manner.

\subsection{RECOMMENDATIONS FOR FUTURE RESEARCH}

The following were identified as future research needs related to this topic. Additional research would be valuable:

1. To see if wireless versions of a similar strain gauge (e.g. surface acoustic wave sensors) could be used to detect corrosion occurring over longer periods of time,

2. To investigate means for installing gauges in existing structures and the effectiveness of these gauges,

3. To investigate how the system response to live loads would change as corrosion damage occurred,

4. To differentiate structural deterioration of PT system in bridges with the impact of corrosion damage and other external event (e.g. support settlement) and

5. To determine the effectiveness of strain-based global monitoring system on PT structures with unbonded tendons 


\section{LIST OF REFERENCES}

[1] K. LeBeau and S. Wadia-Fascetti, "Predictive and Diagonostic Load Rating Model of A Prestressed Concrete Bridge," Journal of Bridge Engineering, pp. 399-407, 2010.

[2] G. H. Koch, M. Brongers, N. G. Thompson, Y. P. Virmani and J. H. Payer, "Corrosion Costs and Preventive Strategies in the United States," Federal Highway Administration, McLean, 2002.

[3] Y. P. Virmani and G. . G. Clemena, "CORROSION PROTECTION CONCRETE BRIDGES," Federal Highway Administration, McLean, Virginia, September 1998.

[4] M. D. Beard, M. J. S. Lowe and P. Cawley, "Ultrasonic Guided Waves for Inspection of Grouted Tendons and Bolts," Journal of Materials in Civil Engineering, pp. 212-218, 2003.

[5] "www.nace.org," [Online]. Available: https://www.nace.org/CORROSION-FAILURES-Lowes-Motor-SpeedwayBridge-Collapse.aspx.

[6] "www.nace.org," [Online]. Available: https://www.nace.org/CORROSION-FAILURES-San-Francisco-BayBridge-Bolt-Failure.aspx.

[7] E. Stromquist, "Controltrends.org," 2014. [Online]. Available: http://controltrends.org/tag/structural-health-monitoring/.

[8] A. Cruz, W. Vélez and P. Thomson, "Optimal sensor placement for modal identification of structures using genetic algorithms-a case study: the olympic stadium in Cali, Colombia," Annals of Operations Research, vol. 181, p. 769-781, 2010.

[9] F. E. Udwadia, "Methodology for Optimum Sensor Locations for Parameter Identification in Dynamic Systems," Journal of Engineering Mechanics, vol. 120, no. 2, pp. 368-390, 1994.

[10] M. M. Ettouney and S. Alampalli, Infrastructure Health in Civil Engineering, Boca Raton, London, New York: CRC Press , 2011. 
[11] B. Glisic and D. Inaudi, "Distributed fiber-optic sensing and integrity monitoring," Transportation Research Record: Journal of the Transportation Research Board, vol. 2150, pp. 96-102, 2010.

[12] J. W. Nilsson and S. A. Riedel, ELECTRIC CIRCUITS, Addison-Wesley Publishing, 1996.

[16] F. Rajabipour, G. Sant and J. Weiss, "Development of Electrical Conductivity-Based Sensors for Health Monitoring of Concrete Materials," in TRB Annual Conference, Washington, DC, 2007.

B. J. Christensen, R. T. Coverdale, R. A. Olson, S. J. Ford, E. J. Garboczi, H. M. Jennings and T. O. Mason, "Impedance Spectroscopy of Hydrating Cement-based Materials: Measurement, Interpretation, and Application," Journal of the American Ceramic Society, vol. 77, no. 11, pp. 2789-2802, 1994.

[18] E. J. Garboczi, "Permeability, Diffusivity, and Microstructural Parameters: A Critical Review," Cement and Concrete Research, vol. 20, no. 4, pp. 591-601, 1990.

[19] D. M. Jayant, HEALTH MONITORING OF CIVIL ENGINEERING MATERIALS, West Lafayette: Master of Science in Civil Engineering Thesis, Purdue University , 2008.

[20] F. Rajabipour, INSITU ELECTRICAL SENSING AND MATERIAL HEALTH MONITORING IN CONCRETE STRUCTURES, West Lafayette, Indiana: PhD. Dissertation, Purdue University, 2006.

[21] F. Rajabipour, W. J. Weiss and D. Abraham, "Insitu Electrical Conductivity Measurements to Assess Moisture and Ionic Transport in Concrete," in 
Advances in Concrete through Science and Engineering; Proceedings of the International RILEM Symposium, Evanston, Illinois, 2004.

"VIRGINIA TECHNOLOGIES INC," [Online]. Available: http://corrosioninstrument.com/advances-in-corrosion-monitoring/.

[23] R. A. Reis and M. Gallaher, "Evaluation of the VTI ECI-1 Embedded Corrosion Instrument," California Department of Transportation , Sacramento, 2006.

[24] C. Xu, Z. Li and W. Jin, "A New Corrosion Sensor to Determine the Start and Development of Embedded Rebar Corrosion Process at Coastal Concrete," Sensors, vol. 13, no. 10, pp. 13258-13275, 2013.

[25] [Online]. Available: http://germann.org/products-by-application/corrosionrate/corrowatch.

[26] [Online]. Available: http://www.pcte.com.au/corrowatch-embeddablecorrosion-front-probes.

[27] [Online]. Available: http://www.analatom.com/products-LPR.html\#2ToW.

[28] D. Jones, Principles and prevention of corrosion, Prentice Hall, 1996.

[29] S. Feliu, J. Gonzalez and C. Andrad, "Electochemical methods for onsite determinations of corrosion rates of rebars," ASTM, 1996.

[30] J. Broomfield, J. Rodriguez, L. Ortega and A. Garcia, "Corrosion rate measurements in reinforced concrete structures by a linear polarization device," ACI Special Publication 151, pp. 163-181, 1994.

[31] J. Broomfield, Corrosion of steel in concrete : understanding, investigation and repair, New York: Taylor and Francis, 2007.

[32] R. Betti, D. Khazem, M. Carlos, R. Gostautas and Y. P. Virmani, "Corrosion Monitoring Research for City of New York Bridges," Office of Infrastructure Research and Development,Federal Highway Administration, McLean, Virginia, 2014.

[33] A. C. 222, "Protection of Metals in Concrete Against Corrosion," American Concrete Institute, 2010.

[34] D. Watters, A. Bahr, P. Jayaweera and D. Huestis, "SMART PEBBLESTM: Passive Embeddable Wireless Sensors for Chloride Ingress Monitoring in 
Bridge Decks," California Department of Transportation, Sacramento, 2003.

[35] R. Cain, B. Carkhuff, P. Pandolfini and F. Weiskopf, "Smart Aggregate Sensor Suite for Bridge Deck Measurements - Phase 1," Maryland State Highway Administration, Baltimore, 2003.

[36] S. Lyon and T. Gooderham, "Corrosion Monitoring Systems and Sensors to Track Material and Dyrability in Concrete Structures," Intertek, 2013.

[39] Geokon, Inc. , [Online]. Available:

http://www.geokon.com/content/manuals/4200-4202-42044210_Strain_Gages.pdf.

[40] E. DiBiagio, "A Case Study of Vibrating Wire Sensors Vibrated Continuously for 27 Years," in 6th International Symposium on Field Measurements in Geomechanics (FMGM), Oslo, 2003.

[41] B. D. Hedegaard, C. E. W. French and C. K. Shield, "Time-Dependent Monitoring and Modeling of I-35W St. Anthony Falls Bridge. II: FiniteElement Modeling," Journal of Bridge Engineering, vol. 22, no. 7, pp. 04017026: 1-15, 2017.

[42] Campbell Scientific, Inc. , [Online]. Available: https://www.campbellsci.com/falls-bridge.

[43] PHASE IV ENGINEERING INC. , [Online]. Available: http://www.phaseivengr.com/wireless-technologies/wireless-technologiesoverview/about-wireless-rfid-sensors/about-ultra-long-range-uhf-rfidsensors/about-uhf-rfid-strain-gauges/.

[44] Q. Ruan, W. Xu and G. Wang, "RFID and ZigBee-based Manufacturing Monitoring System," in IEEE International Conference on Electric Information and Control Engineering (ICEICE), Wuhan, 2011.

[45] C. Roberts, "Radio Frequency Identification (RFID)," Computers \& Security, pp. 18-26, 2006. 
[46] B. Cook, R. Vyas, S. Kim, T. Thai, T. Le, A. Traille, H. Aubert and M. Tentzeris, "RFID-Based Sensors for "Zero-Power" Autonomous Wireless Sensor Networks," IEEE Sensors Journal, pp. 2419-2431, 2014.

[47] C. Swedberg, "RFID Helps Contractors Measure Strain During Construction of Seattle Rail Tunnel," RFID Journal, 2015.

[48] H. Ceylan, L. Dong, S. Yang, Y. Jiao, S. Yavas, S. Kim, K. Gopalakrishnan and P. Taylor, "Development of a Wireless MEMS Multifunction Sensor System and Field Demonstration of Embedded Sensors for Monitoring Concrete Pavements: Volume I - Field Demonstration of Embedded Sensors for Monitoring Concrete Pavements," Iowa Highway Research Board and Iowa Department of Transportation, Ames, 2016.

[49] A. D. 6431-18, "Standard Guide for Using the Direct Current Resisitivty Method for Subsurface Site Characterization," ASTM Committee D18.01 on Surface and Subsurface Characterization, West Conshohocken, Pennsylvania, UnitedState, 2018.

[50] R. Benson, R. Glaccum and M. Noel, "Geophysical Techniques for Sensing Buried Wastes and Waste Migration," in National Water Well Association, Dublin, OH, 1988.

[51] W. J. McCarter and S. Garvin, "Dependence of Electrical Impedance of Cement-Based Materials on Their Moisture Condition," Journal of Physics D: Applied Physics, vol. 22, no. 11, pp. 1875-1880, 1989.

U. B. Halabe, J. Kavi and H. V. S. GangaRao, "Sensors for Monitoring Corrosion of Steel Embedded in Concrete," in NACE International, Pittsburgh, PA, 2015.

[53] R. Melchers, "Corrosion uncertainty modelling for steel structures," Journal of Constructional Steel Research, vol. 52, no. 1, pp. 3-19, October 1999.

[54] [Online]. Available:

http://www.animations.physics.unsw.edu.au/jw/AC.html.

[55] M. M. Andringa, D. P. Neikirk, N. P. Dickerson and S. L. Wood, "Unpowered wireless corrosion sensor for steel reinforced concrete," in SENSORS, 2005 IEEE, Irvine, 2005. 
[56] T. Liu and R. W. Weyers, "Modeling the Dynamic Corrosion Process in Chloride Contaminated Concrete Structures," Cement and Concrete Research, vol. 28, no. 3, pp. 365-379, 1998.

[57] K. Hornbostel, C. K. Larsen and M. R. Geiker, "Relationship between concrete resistivity and corrosion rate - A literature review," Cement and Concrete Composites, vol. 39, pp. 60-72, 2013.

[58] A. Ghorbanpoor and S. Madathanapalli, "Performance of Grouts for PostTensioned Bridge Structures," FHWA-RD-92-095, Springfield, VA, 1993.

[59] R. Powers, A. Sagüés and Y. Virmani, "Corrosion of Post-Tensioned Tendons in Florida Bridges," Florida Department of Transportation, Tallahassee, Florida, 2001.

[60] Ø. Vennesland and J. Havdahl, "Effect of humidity and chloride content on the corrosion of steel embedded in LWA concrete," Materials and Corrosion, vol. 60, no. 2, pp. 106-110, 2009.

[61] P. Y. Virmani and H. Ghasemi, "Literature Review of Chloride Threshold Values for Grouted Post-Tensioned Tendons," Federal Highway Administration, McLean, 2012.

[62] S.-K. Lee and J. Zielske, "An FHWA Special Study: Post-Tensioning Tendon Grout Chloride Thresholds," Federal Highway Administration, McLean, VA, 2014.

[63] American Society for Testing and Materials (ASTM), "Standard Test Method for Flow of Grout for Preplaced-Aggregate Concrete (Flow Cone Method) (C939/C939M-16a)," 2016.

[64] American Society for Testing and Materials (ASTM), "Standard Test Method for Compressive Strength of Grouts for Preplaced-Agregate Concrete in the Laboratory (C942-15)," 2015.

[65] The Weather Company, "Weather History for Miami International Airport Station," [Online]. Available:

https://www.wunderground.com/history/monthly/us/fl/miami/KMIA/date/2 019-3. [Accessed 27 May 2019].

[66] Geokon, "Model 4200 Series Vibrating Wire Strain Gauges Instruction Manual," 2018. 
[67] S. Lyon and T. Gooderham, "Corrosion Monitoring Systems and Sensors to Track Material and Durability in Concrete Structures," Intertek, 2013.

[68] "https://www.geokon.com/4200-Series," 04 December 2018. [Online]. Available: https://www.geokon.com/content/manuals/4200-4202-42044210_Strain_Gages.pdf. 
APPENDIX A - DRAWING OF INVERTED TEE (IT) BEAM 


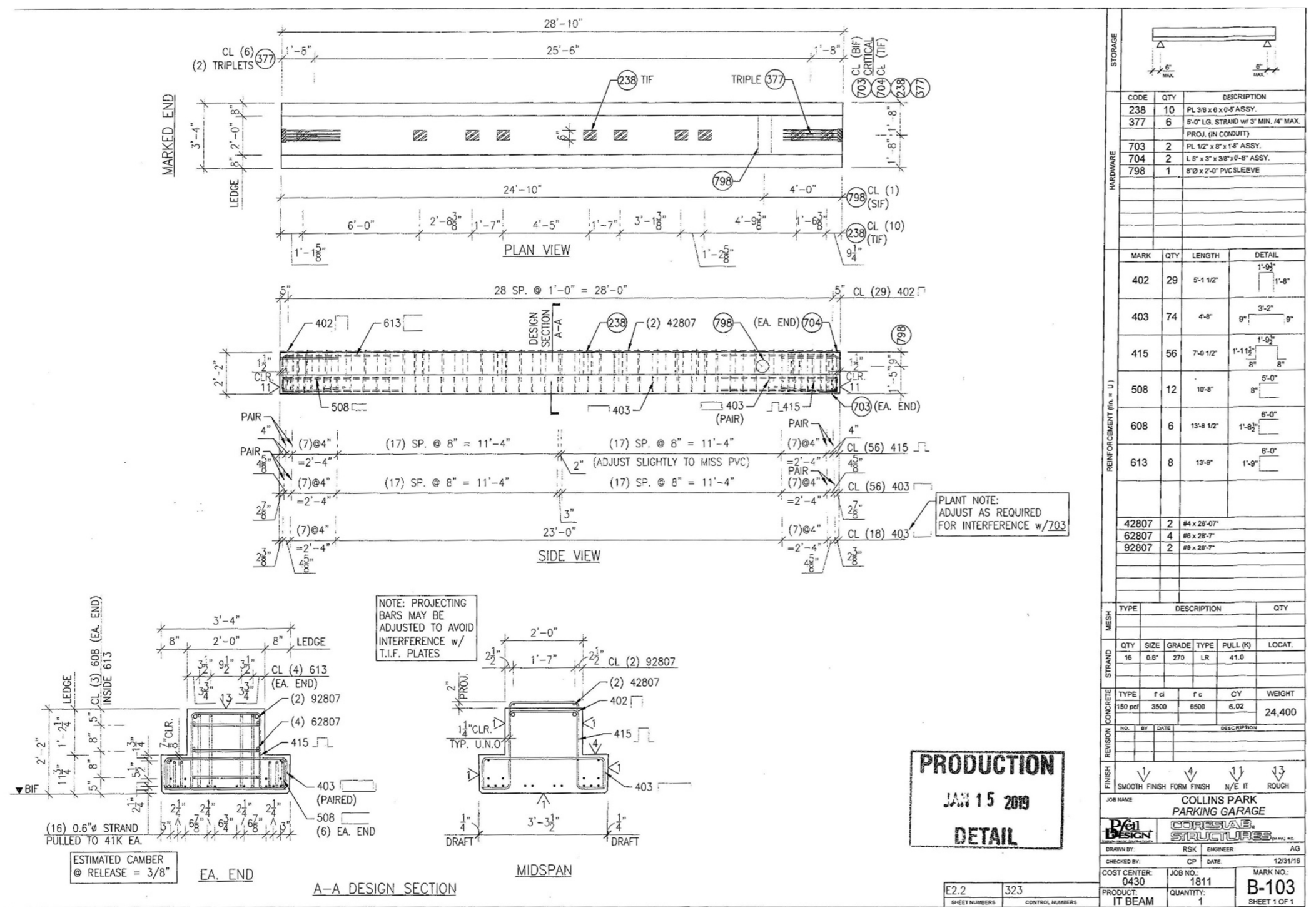


APPENDIX B - PROGRAMMING FOR DATA ACQUISITION SYSTEM (DAQ) 
'50Hz sampled data from one CDM-VW305 device (8 channels)

'Make sure the CPI address given here 'matches what is shown in DevConfig/DVWTool

'for the intended CDM-VW300 series device

Const CPI_ADDR $1=5$ 'VW305 CPI Address \#5

Const CPI_ADDR2 $=6$ 'VW305 CPI Address \#6

Const CPI_ADDR $3=7$ 'VW305 CPI Address \#7

Const CPI2_ADDR $=10$ 'CDM-A115 CPI addresss \#10

Public Freq1(8) 'variables for VW305 \#1

Public Diag1(8) As Long

Public StaticFreq1(8)

Public Therm1(8)

Public DynStdDev1(8)

Public Freq2(8) 'Variables for VW305 \#2

Public Diag2(8) As Long

Public StaticFreq2(8)

Public Therm2(8)

Public DynStdDev2(8)

Public Freq3(8) 'Variables for VW305 \#3

Public Diag3(8) As Long

Public StaticFreq3(8)

Public Therm3(8)

Public DynStdDev3(8)

'CDM-A116 variables

Public CDM2PTempC(4)

Alias CDM2PTempC $(1)=\mathrm{CDM} 2 \mathrm{PTempC} 1$

Alias CDM2PTempC $(2)=\mathrm{CDM} 2 \mathrm{PTempC} 2$

Alias CDM2PTempC(3)=CDM2PTempC3

Alias CDM2PTempC(4)=CDM2PTempC4

Public BattV

Units BattV=Volts

Units CDM2PTempC ()$=$ Deg $C$

Public VR1000(8)' number of measurement channels on the CDM-A116

Public Strain(8)

Units Strain=microstrain

Units VR1000=mV/V

Units GFAdj=unitless

Units BrZero $=\mathrm{mV} / \mathrm{V}$ 
Units CDM2PTempC1=DegC

Units CDM2PTempC2=DegC

Units CDM2PTempC3=DegC

Units CDM2PTempC4=DegC

Public Cindex

Public CAvg

Public CReps

Public LCount

Public GFAdj(8)

Public GFsRaw $(8)=\{2.0,2.0,2.0,2.0,2.0,2.0,2.0,2.0\}$

Public FCloaded

Public BrZero(8)

Public QBSSMode

Public CKnown(8)

Public Zmode

Public PS_1, PS_2, PS_3

'Rainflow Histogram Outputs - 2 dimensional arrays

Const MBINS1 = 10 'VW305 \#1

Const ABINS1 $=10$

Public RF1_1(MBINS1,ABINS1)

Public RF2_1(MBINS1,ABINS1)

Public RF3_1(MBINS1,ABINS1)

Public RF4_1(MBINS1,ABINS1)

Public RF5_1(MBINS1,ABINS1)

Public RF6_1(MBINS1,ABINS1)

Public RF7_1(MBINS1,ABINS1)

Public RF8_1(MBINS1,ABINS1) for VW305\#1

Dim Enable1(8) As Long $=\{1, \quad 1, \quad 1, \quad 1,1, \quad 1, \quad 1,1\} \quad$ 'Setting $0.002\}$

Dim Max_AMP1 $(8)=\quad\{0.002,0.002,0.002,0.002,0.002,0.002,0.002$,

Dim F_Low $1(8)=\quad\{300,300,300,300,300,300,300,300\}$

Dim F_High $1(8)=\quad\{6000,6000,6000,6000,6000,6000,6000,6000\}$

Dim OutForm1(8) As Long $=\left\{\begin{array}{llllllll}0, & 0, & 0, & 0, & 0, & 0, & 0, & 0\end{array}\right\}$

Dim Mult1 $(8)=\quad\{1.0,1.0,1.0,1.0,1.0,1.0,1.0,1.0\}$

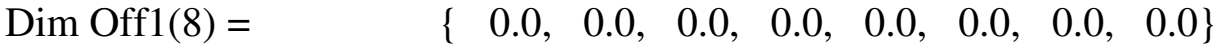

Dim SteinA1 $(8)=\quad\{1.4051 \mathrm{E}-3,1.4051 \mathrm{E}-3,1.4051 \mathrm{E}-3,1.4051 \mathrm{E}-3,1.4051 \mathrm{E}-$

3,1.4051E-3,1.4051E-3,1.4051E-3\} '1.4051E-3,2.369E-4,1.019E-7 Geokon 4000 coefficients

$\operatorname{Dim} \operatorname{SteinB} 1(8)=$

$\{2.369 \mathrm{E}-4,2.369 \mathrm{E}-4,2.369 \mathrm{E}-4,2.369 \mathrm{E}-4,2.369 \mathrm{E}-$ 4,2.369E-4,2.369E-4,2.369E-4\} 
Dim SteinC1 $(8)=$

$\{1.019 \mathrm{E}-7,1.019 \mathrm{E}-7,1.019 \mathrm{E}-7,1.019 \mathrm{E}-7,1.019 \mathrm{E}-$

7,1.019E-7,1.019E-7,1.019E-7\}

'Rainflow Histogram configuration

Dim RF_mean_bins1(8) As Long $=\{$ MBINS1, MBINS1, MBINS1, MBINS1, MBINS1, MBINS1, MBINS1, MBINS1\} 'Mean Bins

Dim RF_amp_bins1(8) As Long $=\{$ ABINS1, ABINS1, ABINS1, ABINS1, ABINS1, ABINS1, ABINS1, ABINS1\} 'Amplitude Bins

Dim RF_Lo_lim1 $(8)=\quad\{400.0,400.0,400.0,400.0,400.0,400.0,400.0$,

400.0\} 'Low Limit

Dim RF_Hi_lim1(8)

$\{4000.0,4000.0,4000.0,4000.0,4000.0,4000.0,4000.0,4000.0\}$ 'High Limit

Dim RF_Hyst $1(8)=\quad\{0.005,0.005,0.005,0.005,0.005,0.005,0.005$,

$0.005\}$ 'Hysteresis

'Output format consists of three digits $\mathrm{ABC}$, that can be either 1 or 0

$110\}$

Dim RF_OutForm1(8) As Long $=\{110,110,110,110,110,110,110$,

'RF Histogram Digit Code Histogram output result

'A $=0$

'A $=1$

Reset histogram after each output.

'B $=0$

Do not reset histogram.

'B $=1$

Divide bins by total count.

'C $=0$

Output total in each bin.

' $\mathrm{C}=1$

Open form. Include outside range values in end bins.

Closed form. Exclude values outside range.

CDM_VW300Config(1,CPI_ADDR1,0,Enable1(),Max_AMP1(),F_Low1(),F_Hi

gh1 ()$, \quad$ ' VW305 \#1 configuration

OutForm1(),Mult1(),Off1(), SteinA1(),SteinB1(),SteinC1(),

RF_mean_bins1(),RF_amp_bins1(),RF_Lo_lim1(), _

RF_Hi_lim1(),RF_Hyst1(),RF_OutForm1())

1********************************************************************

$* * * * * * * * * * * * * * * * * * * * * * * * *$

'second CDM-VW305 configuration

'Rainflow : Mean Bins and Amplitude Bins dimensions

Const MBINS2 $=10$

Const ABINS2 $=10$

'Rainflow Histogram Outputs - 2 dimensional arrays

Public RF1_2(MBINS2,ABINS2)

Public RF2_2(MBINS2,ABINS2)

Public RF3_2(MBINS2,ABINS2)

Public RF4_2(MBINS2,ABINS2)

Public RF5_2(MBINS2,ABINS2)

Public RF6_2(MBINS2,ABINS2)

Public RF7_2(MBINS2,ABINS2)

Public RF8_2(MBINS2,ABINS2) 

$0.002\}$

Dim Enable2(8) As Long $=\quad\{1, \quad 1, \quad 1, \quad 1, \quad 1, \quad 1, \quad 1, \quad 1\}$ Dim Max_AMP2 $(8)=\quad\{0.002,0.002,0.002,0.002,0.002,0.002,0.002$,

Dim F_Low2 $(8)=$ $\{300,300,300,300,300,300,300,300\}$

Dim F_High2 $(8)=$ $\{6000,6000,6000,6000,6000,6000,6000,6000\}$ Dim OutForm2(8) As Long $\left.=\quad \begin{array}{llllllll}0, & 0, & 0, & 0, & 0, & 0, & 0, & 0\end{array}\right\}$ Dim Mult2(8) $\quad \quad \quad\{1.0,1.0,1.0,1.0,1.0,1.0,1.0,1.0\}$

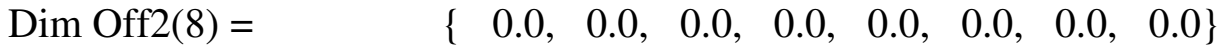
Dim SteinA2 $(8)=\{1.4051 \mathrm{E}-3,1.4051 \mathrm{E}-3,1.4051 \mathrm{E}-3,1.4051 \mathrm{E}-3,1.4051 \mathrm{E}-$ $3,1.4051 \mathrm{E}-3,1.4051 \mathrm{E}-3,1.4051 \mathrm{E}-3\} \quad$ '1.4051E-3,2.369E-4,1.019E-7 Geokon 4000 coefficients

Dim SteinB2(8) = $\{2.369 \mathrm{E}-4,2.369 \mathrm{E}-4,2.369 \mathrm{E}-4,2.369 \mathrm{E}-4,2.369 \mathrm{E}-$ 4,2.369E-4,2.369E-4,2.369E-4\}

Dim SteinC2 $(8)=$ $\{1.019 \mathrm{E}-7,1.019 \mathrm{E}-7,1.019 \mathrm{E}-7,1.019 \mathrm{E}-7,1.019 \mathrm{E}-$ 7,1.019E-7,1.019E-7,1.019E-7\}

'Rainflow Histogram configuration

Dim RF_mean_bins2(8) As Long $=\{$ MBINS2, MBINS2, MBINS2, MBINS2, MBINS2, MBINS2, MBINS2, MBINS2\} 'Mean Bins

Dim RF_amp_bins2(8) As Long $=\{$ ABINS2, ABINS2, ABINS2, ABINS2, ABINS2, ABINS2, ABINS2, ABINS2\} 'Amplitude Bins

Dim RF_Lo_lim $2(8)=\quad\{400.0,400.0,400.0,400.0,400.0,400.0,400.0$, 400.0\} 'Low Limit

Dim RF_Hi_lim2(8) $\{4000.0,4000.0,4000.0,4000.0,4000.0,4000.0,4000.0,4000.0\}$ 'High Limit

Dim RF_Hyst2 $(8)=\quad\{0.005,0.005,0.005,0.005,0.005,0.005,0.005$, $0.005\}$ 'Hysteresis

'Output format consists of three digits $\mathrm{ABC}$, that can be either 1 or 0

Dim RF_OutForm2(8) As Long $=\{110,110,110,110,110,110,110$,

'RF Histogram Digit Code Histogram output result

$\begin{array}{ll}\text { 'A }=0 & \text { Reset histogram after each output. } \\ \text { 'A }=1 & \text { Do not reset histogram. } \\ \text { 'B }=0 & \text { Divide bins by total count. } \\ \text { 'B }=1 & \text { Output total in each bin. } \\ \text { 'C }=0 & \text { Open form. Include outside range values in end bins. } \\ \text { 'C }=1 & \text { Closed form. Exclude values outside range. } \\ \text { CDM_VW300Config(1,CPI_ADDR2,0,Enable2(),Max_AMP2(),F_Low2(),F_Hi } & \\ \text { 'VW305 \#2 Configuration } & \\ \text { OutForm2(),Mult2(),Off2(), SteinA2(),SteinB2(),SteinC2(), _ } \\ \text { RF_mean_bins2(),RF_amp_bins2(),RF_Lo_lim2(), } \\ \text { RF_Hi_lim2(),RF_Hyst2(),RF_OutForm2()) } \\ \text { '****************************************************************** }\end{array}$ ;****************************

'3rd CDM-VW305 configuration 
'Rainflow : Mean Bins and Amplitude Bins dimensions

Const MBINS3 $=10$

Const ABINS3 $=10$

'Rainflow Histogram Outputs - 2 dimensional arrays

Public RF1_3(MBINS3,ABINS3)

Public RF2_3(MBINS3,ABINS3)

Public RF3_3(MBINS3,ABINS3)

Public RF4_3(MBINS3,ABINS3)

Public RF5_3(MBINS3,ABINS3)

Public RF6_3(MBINS3,ABINS3)

Public RF7_3(MBINS3,ABINS3)

Public RF8_3(MBINS3,ABINS3)

Dim Enable3(8) As Long $=\quad\{1,1, \quad 1, \quad 1, \quad 1, \quad 1, \quad 1,1\}$ $0.002\}$

Dim Max_AMP3(8) $=\{0.002,0.002,0.002,0.002,0.002,0.002,0.002$,

Dim F_Low3(8) $=\quad\{300,300,300,300,300,300,300,300\}$

Dim F_High3(8) $=\quad\{6000,6000,6000,6000,6000,6000,6000,6000\}$

Dim OutForm3(8) As Long $=\quad\left\{\begin{array}{llllllll}0, & 0, & 0, & 0, & 0, & 0, & 0, & 0\end{array}\right\}$

$\operatorname{Dim}$ Mult3 $(8)=\quad\{1.0,1.0,1.0,1.0,1.0,1.0,1.0,1.0\}$

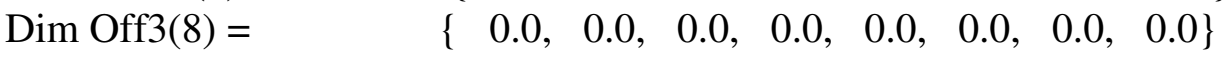

Dim SteinA3(8) $=\{1.4051 \mathrm{E}-3,1.4051 \mathrm{E}-3,1.4051 \mathrm{E}-3,1.4051 \mathrm{E}-3,1.4051 \mathrm{E}-$

3,1.4051E-3,1.4051E-3,1.4051E-3\} '1.4051E-3,2.369E-4,1.019E-7 Geokon 4000 coefficients

$\operatorname{Dim} \operatorname{SteinB} 3(8)=$

$\{2.369 \mathrm{E}-4,2.369 \mathrm{E}-4,2.369 \mathrm{E}-4,2.369 \mathrm{E}-4,2.369 \mathrm{E}-$

4,2.369E-4,2.369E-4,2.369E-4\}

Dim SteinC3(8) =

$\{1.019 \mathrm{E}-7,1.019 \mathrm{E}-7,1.019 \mathrm{E}-7,1.019 \mathrm{E}-7,1.019 \mathrm{E}-$

7,1.019E-7,1.019E-7,1.019E-7

'Rainflow Histogram configuration

Dim RF_mean_bins3(8) As Long $=\{$ MBINS3, MBINS3, MBINS3, MBINS3, MBINS3, MBINS3, MBINS3, MBINS3\} 'Mean Bins

Dim RF_amp_bins3(8) As Long $=\{$ ABINS3, ABINS3, ABINS3, ABINS3, ABINS3, ABINS3, ABINS3, ABINS3\} 'Amplitude Bins

Dim RF_Lo_lim3(8) $=\quad\{400.0,400.0,400.0,400.0,400.0,400.0,400.0$, 400.0 \} 'Low Limit

Dim RF_Hi_lim3(8)

$\{4000.0,4000.0,4000.0,4000.0,4000.0,4000.0,4000.0,4000.0\}$ 'High Limit

Dim RF_Hyst3 $(8)=\quad\{0.005,0.005,0.005,0.005,0.005,0.005,0.005$,

$0.005\}$ 'Hysteresis

'Output format consists of three digits $\mathrm{ABC}$, that can be either 1 or 0

$110\}$

Dim RF_OutForm3(8) As Long $=\{110,110,110,110,110,110,110$,

'RF Histogram Digit Code Histogram output result

$\begin{array}{ll}\text { 'A }=0 & \text { Reset histogram after each output. } \\ \text { 'A }=1 & \text { Do not reset histogram. }\end{array}$ 


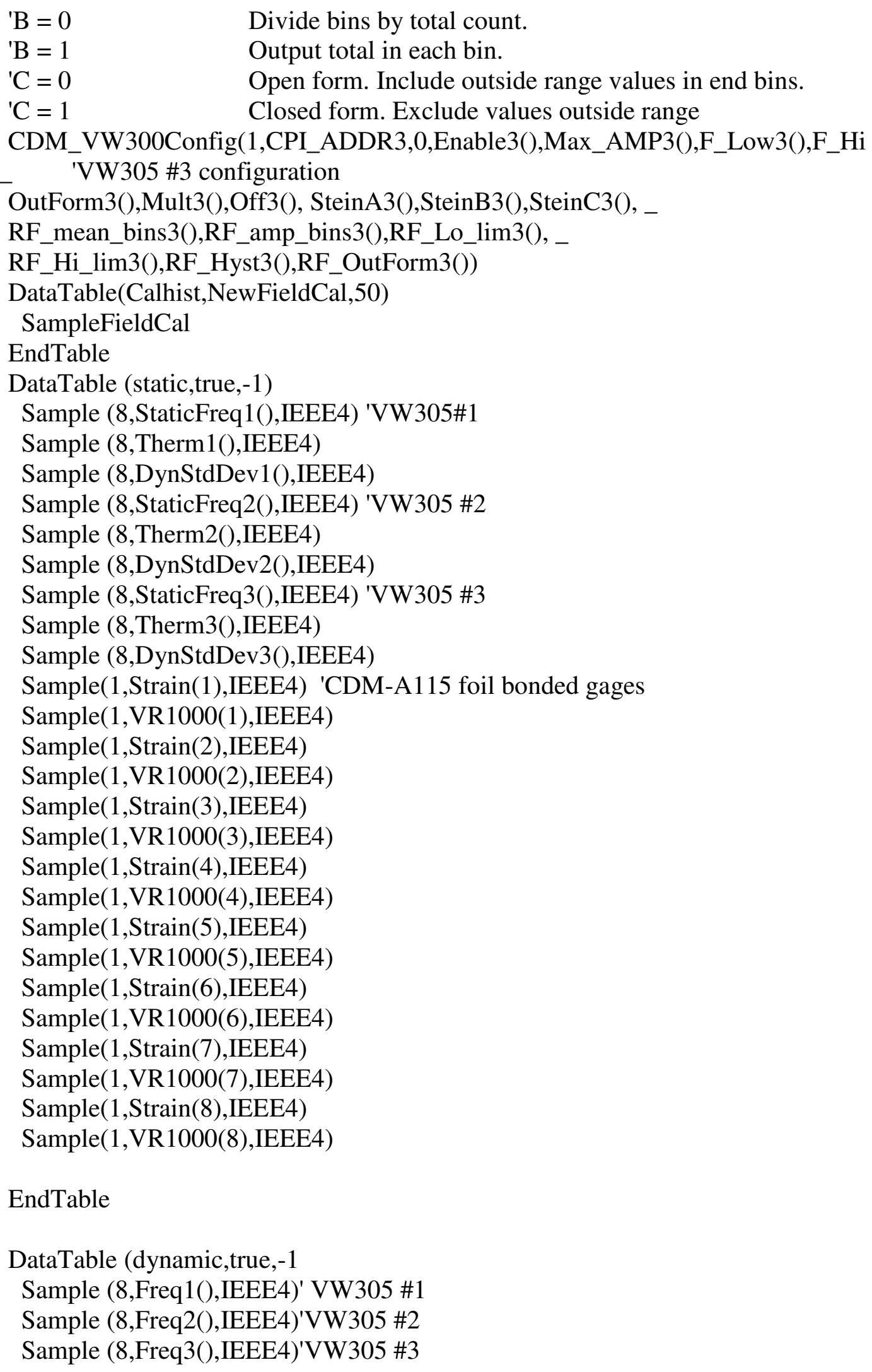

EndTable

DataTable (dynamic,true,-1

Sample (8,Freq1(),IEEE4)' VW305 \#1 Sample (8,Freq2(),IEEE4)'VW305 \#2

Sample (8,Freq3(),IEEE4)'VW305 \#3 
Sample(1,Strain(1),IEEE4) 'CDM-A116 foil bonded gages

Sample(1,VR1000(1),IEEE4)

Sample(1,Strain(2),IEEE4)

Sample(1,VR1000(2),IEEE4)

Sample(1,Strain(3),IEEE4)

Sample(1,VR1000(3),IEEE4)

Sample(1,Strain(4),IEEE4)

Sample(1,VR1000(4),IEEE4)

Sample(1,Strain(5),IEEE4)

Sample(1,VR1000(5),IEEE4)

Sample(1,Strain(6),IEEE4)

Sample(1,VR1000(6),IEEE4)

Sample(1,Strain(7),IEEE4)

Sample(1,VR1000(7),IEEE4)

Sample(1,Strain(8),IEEE4)

Sample(1,VR1000(8),IEEE4)

EndTable

DataTable (PowerSup_1min,true,-1)

DataInterval (0,1,Min,3)

Sample (1,PS_1,FP2)

Average (1,PS_1,FP2,False)

StdDev (1,PS_1,FP2,False)

Sample (1,PS_2,FP2)

Average (1,PS_2,FP2,False)

StdDev (1,PS_2,FP2,False)

Sample (1,PS_3,FP2)

Average (1,PS_3,FP2,False)

StdDev (1,PS_3,FP2,False)

EndTable

BeginProg

'Initialize calibration variables for

'Quarter Bridge Strain, 3-wire $350 \mathrm{ohm}$ with 4WFBS350 TIM measurement 'Vr1000()' on CDM-A116 with CPI address 2

Cindex $=1:$ CAvg $=1:$ CReps $=8$

For LCount $=1$ To 8

GFAdj $($ LCount $)=$ GFsRaw $($ LCount $)$

Next

'Load the most recent calibration values from the CalHist table

FCloaded=LoadFieldCal(True)

'Main Scan

'50 Hz/20msec scan rate 
$\operatorname{Scan}(20, \mathrm{msec}, 500,0)$

CDM_VW300Dynamic(CPI_ADDR1,Freq1(),Diag1()) 'CDM\#1

CDM_VW300Dynamic(CPI_ADDR2,Freq2(),Diag2()) 'CDM\#2

CDM_VW300Dynamic(CPI_ADDR3,Freq3(),Diag3()) 'CDM\#3

CallTable dynamic

\section{'CDM Address 10}

CDM_PanelTemp(CDM_A116,CPI2_ADDR,CDM2PTempC(),4,1,15000)

'Quarter Bridge Strain, 3-wire 350 ohm with 4WFBS350 TIM measurement 'Vr1000()' on CDM-A116 with CPI address 2

CDM_BrFull(CDM_A116,CPI2_ADDR,VR1000(),8,mV200,1,1,2,5000,False,False,500, $15000,1,0)$

'Calculated strain result 'Strain()' for

'Quarter Bridge Strain, 3-wire 350 ohm with 4WFBS350 TIM measurement 'Vr1000()' on CDM-A116 with CPI address 2

StrainCalc(Strain(),8,VR1000(),BrZero(),-1,GFAdj(),0)

'Quarter bridge strain shunt calibration for

'Quarter Bridge Strain, 3-wire $350 \mathrm{ohm}$ with 4WFBS350 TIM measurement 'Vr1000()' on CDM-A116 with CPI address 2

FieldCalStrain(13,Strain(),1,GFAdj(),0,QBSSMode,CKnown(),Cindex,CAvg,GFsRaw(), $0)$

'Zeroing calibration for

'Quarter Bridge Strain, 3-wire 350 ohm with 4WFBS350 TIM measurement 'Vr1000()' on CDM-A116 with CPI address 2

FieldCalStrain(10,VR1000(),CReps,0,BrZero(),Zmode,0,Cindex,CAvg,0,Strain())

'Call Data Tables and Store Data

If TimeIntoInterval $(0,2, \mathrm{Min})$ Then VW305 \#1

CDM_VW300Static(CPI_ADDR1,StaticFreq1(),Therm1(),DynStdDev1())' VW305 \#2

CDM_VW300Static(CPI_ADDR2,StaticFreq2(),Therm2(),DynStdDev2())'

VW305 \#3

CDM_VW300Static(CPI_ADDR3,StaticFreq3(),Therm3(),DynStdDev3())'

CallTable static

EndIf

CallTable CalHist

NextScan

SlowSequence

$\operatorname{Scan}(5, \sec , 10,0)$

Battery (BattV) 
VoltDiff (PS_1,1,mV5000,U1,True ,0,60,0.01,0.01)

VoltDiff (PS_2,1,mV5000,U3,True ,0,60,0.01,0.01)

VoltDiff (PS_3,1,mV5000,U5,True ,0,60,0.01,0.01)

CallTable PowerSup_1min

EndProg 
VITA

\section{DEWAN HOSSAIN}

\section{EDUCATION}

2005-2009 B.Sc., Civil Engineering

Bangladesh University of Engineering \& Technology (BUET),

Dhaka, Bangladesh

2011-2013 M.Sc. Civil Engineering

Louisiana Tech University

Louisiana, U.S.A.

2016-2019 Doctoral Candidate

Department of Civil and Environmental Engineering

Florida International University (FIU),

Miami, Florida, U.S.A.

2018-2019 Teaching Assistant

Department of Civil and Environmental Engineering

Florida International University (FIU),

Miami, Florida, U.S.A.

\section{PUBLICATIONS AND PRESENTATIONS}

Hossain, D., Lau, K., and Garber, D. (April, 2017) "An Approach to Detect Steel Corrosion in Concrete Using Global Strain Measurement," NACE 2017 Conference, New Orleans, Louisiana.

Hossain, D., Lau, K., and Garber, D. (April, 2017) "Quantification of Time-Dependent Effect of Corrosion of Steel on Unbonded Post Approach to Determine Time-Dependent Prestress Losses from Corrosion in Post-Tensioned -tensioned Concrete BeamA Numerical Approach." Paper presented at the NACE 2017 Conference, New Orleans, Louisiana.

Hossain, D., Lau, K., and Garber, D. (April, 2019) "Approach to Determine TimeDependent Prestress Losses from Corrosion in Post-Tensioned Tendons with Deficient Grout." Paper presented at the American Society of Civil Engineers - Structural Congress, Orlando, Florida. 